\author{
Universidade de São Paulo \\ Faculdade de Filosofia, Letras e Ciências Humanas \\ Departamento de Sociologia \\ Programa de Pós-Graduação em Sociologia
}

\title{
Estratégias nacionais de catch-up aeronáutico
}

\author{
Demétrio Gaspari Cirne de Toledo
}

Tese apresentada ao Programa de PósGraduação em Sociologia do Departamento de Sociologia da Faculdade de Filosofia, Letras e Ciências Humanas da Universidade de São Paulo para obtenção do título de Doutor em Sociologia.

Orientador: Professor Dr. Glauco A. T. Arbix

\section{São Paulo}

2013 


\section{Índice}

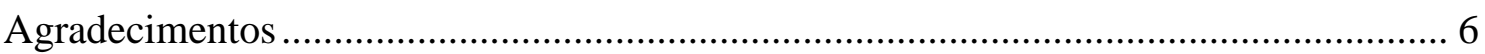

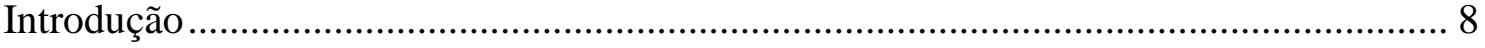

Capítulo 1: Catch-up, conhecimento e desenvolvimento ............................................. 12

Estratégias de catch-up e capacidade absortiva das nações ........................................ 12

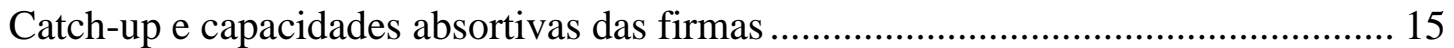

Catch-up, capacidades absortivas e estratégias nacionais de desenvolvimento .......... 16

Catch-up, capacidades absortivas e distância da fronteira tecnológica ...................... 23

Um modelo das estratégias de catch-up............................................................... 27

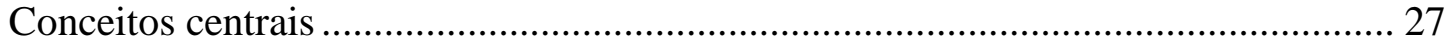

Modelo analítico dos fatores condicionantes do sucesso das estratégias de catch-up

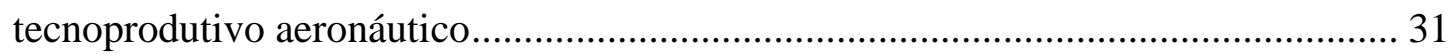

Os casos estudados critérios de seleção de países e generalização dos achados ........ 32

Capítulo 2: O setor aeronáutico mundial: história e atualidade.................................... 35

Surgimento e consolidação do avião e do setor aeronáutico ....................................... 35

Estrutura do setor aeronáutico contemporâneo......................................................... 39

Duas tentativas - malogradas - de catch-up do setor aeronáutico: Argentina e Indonésia

Capítulo 3: Momentos iniciais da estratégia de catch-up do setor aeronáutico do Brasil

Instituições, políticas públicas e capacidade absortiva: a formação do sistema tecnoprodutivo do setor aeronáutico brasileiro ...................................................... 53

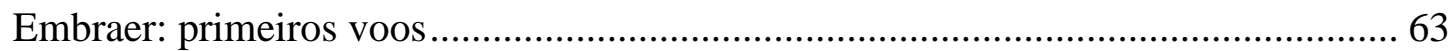

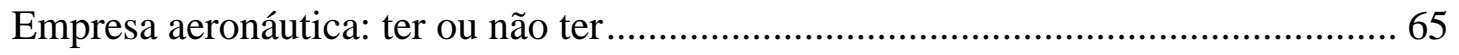

Trajetórias tecnoprodutivas e aprendizagem no sistema tecnoprodutivo aeronáutico

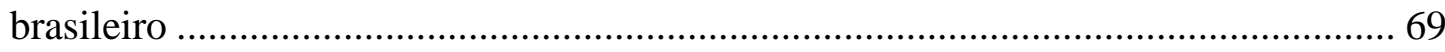

Outro modo de aprendizado pela prática: a produção sob licença............................. 86

Capítulo 4: A competição hoje: a Embraer e o segmento de jatos regionais .................. 94

Uma nova estratégia tecnoprodutiva e comercial: as famílias de jatos regionais da

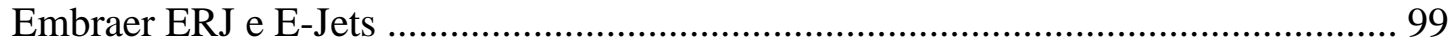

Capítulo 5: O perigo vem do leste: Japão, catch-up tecnoprodutivo aeronáutico ......... 110 
Estratégias de aprendizagem tecnoprodutiva e catch-up no setor aeronáutico japonês: um fracasso, uma reorientação e uma nova tentativa

Uma nova estratégia: aprendizagem tecnoprodutiva por meio da participação como fornecedores em cadeias globais de valor.

O MRJ e a cartada final - por ora - do catch-up aeronáutico japonês

Capítulo 6: Um negócio da China? Meu mercado por sua tecnologia: off-sets como estratégia de aprendizagem tecnoprodutiva

Economia, ciência, tecnologia e inovação na China

O setor aeronáutico chinês: instituições, políticas e empresas

A atual estratégia chinesa de catch-up aeronáutico

Tentando levantar voo novamente: a estratégia atual de catch-up do setor tecnoprodutivo aeronáutico chinês

COMAC ARJ21 e COMAC C919.

Apostas arriscadas: diversificar riscos ou dispersas recursos?

Capítulo 7: Rússia e a (difícil) volta por cima do setor aeronáutico civil

Rússia: idas e vindas do setor aeronáutico e o catch-up contemporâneo 164

O setor aeronáutico russo hoje: estrutura e empresas

Duas apostas russas: Sukhoi Superjet 100 e Irkut MS-21

Perspectivas do catch-up russo: vencer no mundo ou vencer na Ásia, perder no mundo ou perder na Ásia

Capítulo 8: Análise comparativa da configuração das estratégias de catch-up de Brasil, Argentina, Indonésia, Japão, Rússia e China..... 176

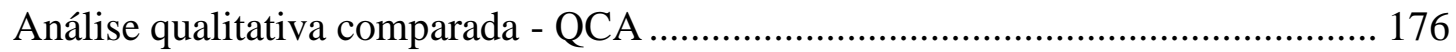

Dados histórico-qualitativos

Operacionalização do modelo analítico de estratégias de catch-up no setor aeronáutico e análise comparativa sistemática entre casos.

Resultados da análise de Análise Qualitativa Comparada - QCA

Discussão: condições de ocorrência de sucesso das estratégias de catch-up ontem e hoje

Conclusão

Bibliografia 


\section{Resumo}

Esta tese compara as estratégias de catch-up aeronáutico de Brasil, Argentina, Indonésia, Japão, China e Rússia ao longo da segunda metade do século XX e começos dos anos 2000. Mais especificamente, examina os modos como esses países tentaram desenvolver empresas capazes de projetar, produzir e comercializar aviões civis para o mercado interno e externo. Partindo das noções de sistema tecnoprodutivo, distância da fronteira tecnológica e catch-up industrial, foi desenvolvido um modelo analítico dos fatores que explicam o sucesso ou o fracasso de cada um dos casos estudados. À reconstrução histórica segui-se a comparação formal dos casos por meio de um modelo de análise qualitativa comparada (QCA) composto por três dimensões: estratégia de aprendizagem tecnoprodutiva; fatores institucionais; fator empresarial. Os resultados da reconstrução histórica e do modelo de análise qualitativa comparada indicam que a estratégia de aprendizagem tecnoprodutiva e os fatores institucionais são aspectos altamente relevantes da explicação do sucesso ou fracasso das estratégias de catch-up aeronáutico. No entanto, apenas os sistemas tecnoprodutivos aeronáuticos que lograram desenvolver o fator empresarial, ou seja, formar uma empresa comercialmente orientada responsável pelo desenvolvimento, produção e comercialização de aviões, obtiveram pleno sucesso em suas tentativas de catch-up. A tese pretende, além de formalizar um modelo das estratégias de catch-up, contribuir para a reflexão mais ampla sobre as possibilidades de desenvolvimento industrial disponíveis aos países que atualmente se encontram a grande distância da fronteira tecnoprodutiva contemporânea. 


\begin{abstract}
This thesis compares aeronautical catch-up strategies in Brazil, Argentina, Indonesia, Japan, China and Russia during the second half of the $20^{\text {th }}$ century and the beginning of the 2000s. In particular, it examines the ways in which these countries have tried to develop companies capable of designing, producing and selling civilian aircraft for domestic and foreign markets. Building on the notions of technoproductive system, distance to the technological frontier and industrial catch-up, we develop an analytical model of the factors that explain the success or failure of each of the cases examined. The historical reconstruction of the cases is followed by a formal comparison of cases by means of a model of qualitative comparative analysis (QCA) composed of three dimensions: technoproductive learning strategy; institutional factors; firm factor. The results of the historical reconstruction and of the comparative qualitative analysis indicate that technoproductive learning strategy and institutional factors are highly relevant aspects in explaining the success or failure of each aeronautical catch-up strategy. However, it is only the technoproductive aeronautical systems that succeed in developing the firm factor, ie, in forming a commercially oriented firm responsible for the development, production and commercialization of civil aircraft, that achieve full success in their attempts to catch-up. In addition to formalizing a model of catch-up strategies, this thesis contributes to a broader discussion on the possibilities of industrial development available to countries which are currently at a significant distance from the contemporary technoproductive frontier.
\end{abstract}




\section{Agradecimentos}

Esta tese não teria sido possível sem o apoio de várias instituições e pessoas. $\mathrm{O}$ Programa de Pós-Graduação em Sociologia do Departamento de Sociologia da Faculdade de Filosofia, Letras e Ciências Humanas da Universidade de São Paulo, instituição na qual realizei meus estudos de doutorado; o Observatório da Inovação e Competitividade do Instituto de Estudos Avançados da Universidade de São Paulo, no qual venho pesquisando os temas desta tese; e o Departamento de Ciência Política do Massachusetts Institute of Technology, onde realizei estágio doutoral, ofereceram ambientes acadêmicos desafiadores que muito contribuíram para o andamento desta tese.

O Conselho Nacional de Desenvolvimento Científico e Tecnológico (CNPq) concedeu a bolsa que garantiu minha dedicação exclusiva às atividades de pesquisa que resultaram neste doutorado. Sem o apoio financeiro dessa instituição, esta pesquisa não teria sido possível.

As pessoas diferem das instituições num aspecto fundamental: elas ficam tristes se são esquecidas nos Agradecimentos das teses. Por isso, faço um esforço sincero, ainda que frustrante, pois necessariamente fadado a deixar alguém de fora, para lembrar todas as pessoas que me ajudaram ao longo do doutorado.

Devo ao professor Ben Ross Schneider, do Departamento de Ciência Política do Massachusetts Institute of Technology, a oportunidade de passar o semestre de outono de 2010 no Instituto. O professor Ben Schneider provou-se amigo dedicado do Brasil e dos brasileiros nesse pequeno gesto de generosidade ao me receber como aluno de doutorado em sua prestigiosa instituição. A ele, e ao Instituto, serei sempre grato e devedor.

O professor Mario Sergio Salerno, do Departamento de Engenharia de Produção da Escola Politécnica da Universidade de São Paulo, desempenhou, primeiro informal, depois formalmente, um valioso papel de coorientador desta tese. Seus conhecimentos sobre dinâmicas tecnológicas e empresariais foram muito valiosos para este sociólogo.

O professor Glauco Arbix, meu orientador, foi, incontáveis vezes, muito além das atribuições que seu papel de orientador exigiam. Mestre cuidadoso e dedicado, sempre 
pronto a incentivar seus alunos a irem mais longe do que às vezes supúnhamos capazes, Glauco dirigiu esta tese com grande sensibilidade e carinho. Os erros que resistiram às suas correções são de minha inteira responsabilidade. A ele, meus mais sinceros agradecimentos.

Família e amigos, como sempre, e pelos melhores motivos, merecem os maiores agradecimentos. Afinal, são eles que zelam por nossa sanidade lembrando-nos discretamente que a vida é muito, mas muito mais mesmo, que uma tese de doutorado. A família: minha mãe Angela, meu pai Elói, meus irmãos Marcelo, Joaquim, Daniel e Felipe, tios, tias, primos e primas, sempre ofereceram momentos de alegria que afastaram minhas preocupações da tese, da pesquisa, do doutorado. A eles sou enormemente grato. $\mathrm{O}$ mesmo vale para meus mais queridos amigos: reconheço o privilégio de suas amizades.

Agradecimentos especiais ficam para Muryatan Santana Barbosa, amigo de longa data com quem, por uma feliz coincidência, dividi casa em Cambridge, quando ele fazia seu doutorado-sanduíche em Harvard; Itaquê Santana Barbosa, que discutiu ponto a ponto esta tese, seus resultados e desdobramentos, além de ter me guiado na modelagem e aplicação da metodologia; Tiago dos Santos Mesquita, Joaquim Elói Cirne de Toledo, Jr. e Zil Miranda, que leram, corrigiram e comentaram capítulos desta tese; e Alexandre Oliveira, testemunha das idas e vindas da tese. A eles meu muitíssimo obrigado.

Flavia Lima, que acompanhou mais de perto que ninguém esta tese, foi sempre a grande, generosa e amorosa companheira que ela é nos outros quadrantes da vida. A ela, e à sua paciência de conviver já se vão quase quatro anos com um doutorando por vezes monotemático em suas preocupações com a tese, meus mais amorosos agradecimentos. Sem você, fazer esta tese não teria sido tão bom.

São Paulo, 13 de maio de 2013, num fim de tarde de outono. 


\section{Introdução}

O Brasil realizou o mais bem-sucedido processo de catch-up aeronáutico dos últimos 50 anos. O resultado não se resume à dimensão tecnológica. É preciso, tendo dominado a tecnologia, aplicá-la à produção em série de produtos aeronáuticos e comercializá-los com sucesso em mercados altamente competitivos dominados por empresas de países dotados de base tecnológica e industrial bastante avançadas. Afinal, quais são as condições que aumentam as chances de sucesso de uma estratégia de catch-up aeronáutico? Elas dependem, em suma, de uma combinação de aprendizagem tecnológica, existência de instituições de apoio aos esforços de desenvolvimento tecnológico e dinamismo empresarial da empresa responsável pela produção e comercialização dos aviões. Ausentes uma ou mais dessas condições, o processo de catch-up quase certamente ficará aquém de seus objetivos maiores: dominar a tecnologia de desenvolvimento e produção de aviões e constituir uma empresa capaz de auferir lucros com a comercialização de aviões em mercados altamente competitivos.

Esta tese examina os modos como alguns países, mobilizando recursos públicos e privados por meio de suas instituições e empresas, executam estratégias de catch-up tecnoprodutivo em relação a países mais avançados. Mais especificamente, trata das diferentes estratégias de catch-up tecnoprodutivo no setor aeronáutico civil, identificando as condições mais ou menos conducentes ao sucesso ou ao fracasso do processo de catch-up. Examino as tentativas de catch-up tecnoprodutivo aeronáutico de Brasil, Argentina, Indonésia, Japão, China e Rússia para tentar identificar as condições que aumentam as chances de sucesso - e de fracasso - na redução da distância da fronteira tecnoprodutiva do setor aeronáutico mundial, marcada por um conjunto restrito de países que dominam os conhecimentos necessários para projetar, desenvolver e produzir aviões civis.

Por meio da reconstrução dos casos de catch-up tecnoprodutivo aeronáutico daqueles países, foi desenvolvido um modelo de estratégias de catch-up que procura identificar as condições mais relevantes para o seu sucesso ou fracasso. Nenhum caso, evidentemente, é idêntico. Sua análise comparada, no entanto, permite identificar condições recorrentes

e condições específicas dos casos. O modelo analítico das estratégias de catch-up tecnoprodutivo aeronáutico é composto por três dimensões: o processo de aprendizagem 
tecnoprodutiva, o arranjo institucional e a competitividade da empresa encarregada de produzir e comercializar os produtos finais da estratégia de catch-up. A tese tem o objetivo de contribuir, por meio da análise comparada sistemática de tentativas de catch-up tecnoprodutivo aeronáutico, para a compreensão dos modos como países conseguem, por meio da coordenação de ações de atores públicos e privados, reduzir a distância que os separa da fronteira tecnoprodutiva contemporânea em determinado setor.

As estratégias de catch-up são frequentemente interpretadas como catch-up em relação à fronteira tecnológica estrito senso. O modelo de catch-up desenvolvido nessa tese critica a utilização, como ponto de referência único do catch-up, da noção restrita de fronteira tecnológica, propondo a noção ampliada de fronteira tecnoprodutiva, que acrescenta à noção de fronteira tecnológica as dimensões institucionais e empresariais. A noção ampliada de catch-up tecnoprodutivo, em comparação com a noção restrita de catch-up tecnológico, desloca o peso explicativo dos termos ciência e tecnologia para os termos produção, inovação, empresa e mercado. A noção ampliada de catch-up tecnoprodutivo tem o seguinte corolário: a mais avançada tecnologia não resulta necessariamente no mais competitivo produto.

A tese está estruturada em sete capítulos, além desta breve Introdução e de Considerações Finais. No primeiro capítulo, faço um balanço da literatura sobre catchup industrial e tecnológico. A discussão concentra-se em articular os elementos teóricos relevantes para a construção do modelo analítico de catch-up tecnoprodutivo e em apresentá-lo ao leitor, terminando com uma discussão metodológica e a justificação dos critérios de escolha de casos em estudo.

O capítulo 2 faz um apanhado histórico do setor aeronáutico mundial e uma caracterização de seu estágio corrente, de modo a dar o contexto em que se desenvolveram e se desenvolvem as estratégias de catch-up tecnoprodutivo aeronáutico. Também neste capítulo são examinadas as tentativas de catch-up de Argentina e Indonésia e discutem-se as razões do fracasso de uma e outra.

Nos capítulos 3 a 6 as estratégias de catch-up tecnoprodutivo aeronáutico de Brasil, Japão, China e Rússia são reconstruídas em maiores detalhes, com especial atenção para as dimensões que compõem o modelo analítico que será empregado para comparação dos casos. No capítulo 3, analiso o catch-up tecnoprodutivo aeronáutico brasileiro, caso 
paradigmático em função de seu sucesso. Com efeito, estudiosos e gestores públicos olham para o catch-up aeronáutico brasileiro com grande interesse por conta não apenas da raridade de casos de sucesso de catch-up aeronáutico como também em busca de elementos para explicar e aprimorar estratégias presentes e futuras de catch-up tecnoprodutivo aeronáutico.

No capítulo 4, examino as duas tentativas de catch-up tecnoprodutivo aeronáutico do Japão: a primeira, nas décadas de 1950 e 1960, que resultou em fracasso, e a atual, cujas chances de sucesso são altas, ainda que não certas. A segunda tentativa de catch-up japonesa tem a peculiaridade de partir do desenvolvimento da cadeia produtiva aeronáutica para só então procurar desenvolver os conhecimentos de desenvolvimento, produção e comercialização de aviões civis.

No capítulo 5, trato dos esforços de aprendizagem tecnoprodutiva da China e de sua atual estratégia de catch-up aeronáutico. Argumento que, não obstante o acelerado desenvolvimento tecnológico e industrial chinês nas últimas duas décadas, o sucesso do catch-up tecnoprodutivo aeronáutico não está garantido, uma veza que as condições de sustentação de uma economia baseada em setores de alta intensidade de conhecimento parecem ainda não existir na China.

No capítulo 6, discuto a atual estratégia de catch-up tecnoprodutivo aeronáutico da Rússia, caso interessante de país que procura retomar a dianteira tecnológica em um setor que já chegou a dominar na era soviética. A Rússia dispõe de um acúmulo considerável de conhecimentos e instituições do setor aeronáutico, mas esses conhecimentos são em grande parte obsoletos em relação às novas gerações de aviões civis. O sucesso do catch-up russo dependerá da capacidade de aproveitar os conhecimentos anteriores e aplicá-los na atualidade.

O capítulo 7, por sua vez, faz uma análise comparativa das estratégias de catch-up tecnoprodutivo de Brasil, Argentina, Indonésia, Japão, China e Rússia. Discuto o modelo analítico de catch-up tecnoprodutivo e sua operacionalização por meio de uma técnica formal chamada qualitative comparative analysis, ou QCA. Nesse capítulo, apresento os resultados do modelo e explico as razões de sucesso e fracasso das diferentes tentativas de catch-up aeronáutico. 
Nas Considerações Finais, retomo a discussão sobre a relevância de estudos sobre estratégias de catch-up tecnoprodutivo para o Brasil e outros países emergentes. Generalizo, na medida do possível, o modelo analítico e seus resultados, discutindo os elementos sem os quais uma estratégia de catch-up tecnoprodutivo tem grandes chances de fracassar. 


\section{Capítulo 1: Catch-up, conhecimento e desenvolvimento}

Neste capítulo, são discutidas as mais importantes contribuições ao debate sobre processos de catch-up de nações, empresas e setores, utilizadas para a construção do modelo analítico de catch-up tecnoprodutivo com o qual serão examinados em capítulos posteriores as estratégias de catch-up aeronáutico de Brasil, Argentina, Indonésia, Japão, China e Rússia, além de justificar a seleção de casos a serem estudados.

\section{Estratégias de catch-up e capacidade absortiva das nações}

A ideia de que o Estado possa acelerar o desenvolvimento de indústrias ou setores tidos como estratégicos não é de hoje: em seu Sistema Nacional de Economia Política, de 1841, Friedrich List apresenta o que talvez seja a primeira defesa explícita da importância de apoiar o desenvolvimento de setores estratégicos nascentes com sua noção de proteção de indústrias infantes. Não vou, no entanto, fazer uma genealogia da ideia de catch-up; vou direto à discussão contemporânea na forma em que ela aparece nos trabalhos de Abramovitz (1986), Cohen e Levinthal (1990) e Mathews (2002, 2006 e 2009).

Moses Abramovitz estabeleceu os termos da discussão contemporânea sobre catch-up em Catching Up, Forging Ahead, and Falling Behind (1986). Seu argumento retoma a discussão sobre convergência dos níveis de renda entre países, mas oferece algumas novas ideias, em especial uma incipiente noção de distância da fronteira tecnológica e um modelo formal em que os retornos do processo de catch-up variam de acordo com o estágio de desenvolvimento dos países, ideias que se tornaram centrais no debate contemporâneo sobre catch-up.

A hipótese de convergência da riqueza das nações para um nível de equilíbrio encantou muitas gerações de economistas políticos, tendo servido tanto para justificar políticas de desenvolvimento econômico - o que fazer para acelerar a convergência - como para criticá-las - a convergência seria um processo automático que dispensa ajuda. $\mathrm{O}$ prestígio da hipótese variou muito; em especial, o crescimento econômico dos países do Atlântico Norte no pós-guerra fez com que muitos tomassem um processo específico 
localizado no tempo e no espaço por uma tendência geral do capitalismo. Segundo a interpretação que os defensores da hipótese de convergência dos níveis de renda das nações davam do processo histórico, a desigualdade entre as nações nada tinha de estrutural, sendo apenas uma fase de um processo cujo fim era o desaparecimento - no longo prazo - das diferenças substantivas entre os níveis de renda entre as nações.

Abramovitz (1986) retoma a ideia de catch-up um tanto desconfiado de sua aplicabilidade a todo e qualquer caso. Abramovitz parte da hipótese de convergência dos níveis de produtividade dos países, para mostrar que, apesar da hipótese mais geral de convergência entre os níveis de produtividade se sustentar quando se analisa a trajetória histórica de um grupo de países que lograram se industrializar entre 1970 e 1979 (em sua maioria países do Atlântico Norte) "the rate of convergence, however, varied from period to period and showed marked strength only during the first quartercentury following World War II' (Abramovitz 1986: 385).

Não obstante a tendência à convergência condicional identificada por Abramovitz, o fato é que a posição relativa dos países mudou e muito ao longo desse período, e isso devido em grande parte à vantagem inicial dos primeiros líderes e das estratégias dos países retardatários que lograram se desenvolver rapidamente, diminuindo a distância em relação aos níveis de produtividade dos países líderes e consequentemente aproximando-se dos seus níveis de renda. Para explicar a convergência dos níveis de produtividade entre países que partiram de posições relativas muito díspares, Abramovitz formula a hipótese de catch-up: "the hypothesis asserts that being backward in level of productivity carries a potential for rapid advance. Stated more definitely the proposition is that in comparisons across countries the growth rates of productivity in any long period tend to be inversely related to the initial levels of productivity". (Abramovitz 1986: 386). Por quê? Segundo Abramovitz, isso se deve ao nível de tecnologia de um país. Abramovitz resume seu argumento nos seguintes termos: "Those who are behind, however, have the potential to make a larger leap. New capital can embody the frontier of knowledge, but the capital it replaces was technologically superannuated. So - the larger the technological and, therefore, the productivity gap between leader and follower, the stronger the follower's potential for growth in productivity; and, other things being equal, the faster one expects the follower's growth rate to be. Followers tend to catch up faster if they are initially more backward" (Abramovitz 1986: 386-387) Nessas condições, o processo de catch-up é 
autolimitado, uma vez que "as a follower catches up, the possibility of making large leaps by replacing superannuated with best-practice technology becomes smaller and smaller. A follower's potential for growth weakens as its productivity level converges towards that of the leader" (Abramovitz 1986: 387).

Não basta, porém, a um país ser atrasado para ter taxas elevadas de crescimento de produtividade e consequentemente realizar o catch-up. $\mathrm{O}$ potencial de redução da distância em relação ao líder tem a ver com as capacidades sociais (social capabilities) de cada país, definidas como as instituições políticas e econômicas e o estoque de conhecimento incorporado à força de trabalho que contribuem para o processo de catchup, conforme resume Abramovitz: "a country's potential for rapid growth is strong not when it is backward without qualification, but rather when it is technologically backward but socially advanced" (Abramovitz 1986: 388); "the combination of technological gap and social capability defines a country's potentiality for productivity advance by way of catch-up". (Abramovitz 1986: 389-390).

As capacidades sociais desempenham papel fundamental nos processos de catch-up, pois elas definem o potencial de absorção de tecnologias disponíveis em dado período. Se não for possuidor das capacidades sociais necessárias para absorção de tecnologias mais avançadas em substituição de tecnologias obsoletas, um país "atrasado", isto é, distante da fronteira tecnológica, não será capaz de acelerar seus níveis de produtividade e convergir para os níveis de tecnológicos dos países líderes. Abramoviz conclui que "countries that are technologically backward have a potentiality for generating growth more rapid than that of more advanced countries, provided their social capabilities are sufficiently developed to permit successful exploitation of technologies already employed by the technological leaders. (...) The process of catching up tends to be selflimiting, but the strength of the tendency may be weakened or overcome, at least for limited periods, by advantages connected with the convergence of production patterns as followers advance towards leaders or by an endogenous enlargement of social capabilities". (Abramovitz 1986: 390).

Para ser bem sucedido, um país depende da adoção de estratégias que tirem proveito das oportunidades existentes em dado momento; e é preciso compreender as vantagens de que dispõem os países mais avançados para manter suas posições relativas, em especial seus "high levels of general and technical education, the broad bases of their science, 
and the well-established connections of their science, technology, and industry" (Abramovitz 1986: 405), e tentar replicá-las em alguma medida. Se países emergentes quiserem reduzir a distância dos países líderes, terão que adotar estratégias condizentes com um processo de catch-up por meio da redução da distância em relação à fronteira tecnológica. E é isso que alguns países vêm tentando fazer em setores estratégicos de suas economias, como veremos no caso específico do setor aeronáutico.

\section{Catch-up e capacidades absortivas das firmas}

Se por um lado o argumento de Abramovitz (1986) sobre catch-up toma como unidade analítica a nação em perspectiva histórica, Cohen e Levinthal (1990) desenvolvem um modelo de catch-up da firma individual e dos fatores que explicam sua capacidade inovativa. A relação entre esses autores, contudo, é muito mais de complementaridade do que de divergência. Abramovitz (1986) formula uma teoria para o conjunto de firmas e instituições de um grupo de países que se mostra consistente quando testada contra as evidências históricas disponíveis: de fato, ainda que em ritmos diferentes - em função das capacidades sociais de cada país -, a análise de Abramovitz mostra que um conjunto (restrito, é bem verdade) de países conseguiu diminuir a distância da fronteira tecnológica; mostra também que não obstante a tendência mais geral de convergência dos níveis de produtividade, e consequentemente dos níveis de renda, entre os países, as posições relativas mudam, com alguns países inicialmente líderes sendo ultrapassados por países que partiram de situações de atraso em relação à fronteira do conhecimento. Cohen e Levinthal (1990) apresentam um argumento em muitos pontos análogo ao de Abramovitz, mas referido à firma.

Em "Absorptive capacity: a new perspective on learning and innovation" (1990), Cohen e Levinthal partem da ideia de que a capacidade de uma firma "recognize the value of new, external information, assimilate it, and apply it to commercial ends is critical to its innovative capabilities" (Cohen e Levinthal 1990: 128); a isso os autores dão o nome de capacidade absortiva da firma. A capacidade absortiva é função dos níveis prévios de conhecimento da firma. Cohen e Levinthal argumentam que "the development of absorptive capacity, and, in turn, innovative performance are historyor path-dependent and argue how lack of investment in an area of expertise early on 
may foreclose the future development of a technical capability in that area" (Cohen e Levinthal 1990: 128). A capacidade absortiva de uma firma, ou setor ou país é função de sua habilidade de recorrer a fontes externas de conhecimentos.

Depois da publicação de "Absorptive capacity: a new perspective on learning and innovation", raros foram os trabalhos que não fizeram referência direta ao conceito de capacidade absortiva, e não foram poucos os que o aplicaram à análise de setores e de países. Entre esses últimos, Mathews (em especial 2002, 2006 e 2008) desenvolveu uma abordagem que analisa a relação entre capacidades absortivas e processos de catch-up de países, acrescentando uma noção de ação estratégica dos Estados e das firmas em sua busca pelo desenvolvimento econômico; ação estratégica no sentido de atribuir ao aproveitamento mais ou menos pensado e planejado de oportunidades e condições favoráveis para o catch-up papel central na redução da distância à fronteira tecnológica e, consequentemente, no aumento dos níveis de produtividade, competitividade, inovação e indiretamente da riqueza de um país. Em outras palavras, Mathews troca o fatalismo das teorias do subdesenvolvimento e o esperancismo passivo das teorias de convergência por uma noção forte de estratégia, que confere ao Estado e às empresas de um país a condição de protagonistas na luta pelo desenvolvimento econômico.

\section{Catch-up, capacidades absortivas e estratégias nacionais de desenvolvimento}

Até o momento, foram examinados, com base nas ideias de Abramovitz (1986) e Cohen e Levinthal (1990), elementos que permitem pensar o catch-up como ação estratégia com vistas à redução da distância da fronteira tecnológica e as capacidades absortivas como fator determinante do sucesso de uma estratégia baseada no catch-up. John Mathews (2002, 2006 e 2008) reintroduziu a nação no debate, tomando a noção de estratégia empresarial e desenvolvendo um modelo de catch-up em países emergentes.

Estudioso de estratégias empresariais, em especial de empresas asiáticas, o australiano John A. Mathews adaptou sua análise das estratégias de catch-up de empresas entrantes tardias (latecomers) da região Ásia-Pacífico (Mathews 2002) a uma teoria das estratégias de catch-up de países (Mathews 2006), para finalmente analisar as estratégias de catch-up de Brasil, Índia e China (Mathews 2008). 
Em "Competitive Advantages of the Latecomer Firm: A Resource-Based Account of Industrial Catch-Up Strategies", Mathews (2002) formula uma "strategic theory of the overcoming of competitive disadvantages through linkage, resource leverage, and learning" (Mathews 2002: 467). Mathews está interessado na "successful creation of sophisticated and competitive firms within industrializing countries" (Mathews 2002: 467) e na contribuição que a literatura sobre estratégia empresarial pode dar para compreender o fenômeno do surgimento de players globais em setores intensivos em tecnologia em países emergentes. Mathews toma os casos bem sucedidos de catch-up de empresas dos setores de TI e semicondutores da região da Ásia-Pacífico para mostrar as limitações das teorias que apontam como vantagens competitivas o pioneirismo dos primeiros entrantes em um setor ou mercado, as barreiras de entrada e a sustentabilidade das vantagens competitivas, mas deixam de lado a análise dos casos de empresas que criaram ou adquiriram vantagens competitivas que antes não possuíam. Segundo Mathews, "the arrival of the latecomer firms, in such high technology sectors as semiconductors, in practice, shows that competitive advantages which appeared to be sustainable can be undermined; that barriers to entry can be overcome; that advantages of imitation and fast followership can balance advantages due to innovation" (Mathews 2002: 468).

Mathews desenvolve uma definição das empresas entrantes tardias para explorar o modo como essas empresas superam suas desvantagens competitivas recorrendo às poucas vantagens disponíveis a elas: estabelecimento de laços com empresas avançadas mediante arranjos contratuais ou de licenciamento e alavancagem de recursos estratégicos, em especial tecnologias, conhecimentos de gestão e acesso a canais de mercado por meio de laços com empresas avançadas. A estratégia vencedora tende a ser aquela em que a empresa "latecomer has to craft its strategy so as to complement the strategic initiatives of incumbents" (Mathews 2002: 468). Por sucessivas interações, as empresas entrantes tardias se veem envolvidas em um processo de aprendizagem no qual passam a dominar as tecnologias básicas e avançadas do setor, os conhecimentos de gestão específicos ao setor e os canais de acesso a fornecedores e clientes, ao mesmo tempo em que reduzem a distância em relação às empresas mais avançadas, aproximando-se da fronteira tecnológica. Ao fim desse processo, muitas empresas bem sucedidas saem de uma posição de atraso tecnológico e produtivo para assumir a condição de players globais em seus setores. 
Mathews estabelece uma relação entre empresas entrantes tardias e países entrantes tardios referindo-se aos trabalhos de Alexander Gershenkron sobre países de industrialização tardia e identifica as vantagens comuns às duas situações: "latecomer firms, like latecomer nations, are able to exploit their late arrival to tap into advanced technologies, rather than having to replicate the entire previous technological trajectory. They can accelerate their uptake and learning efforts utilizing various forms of collaborative processes and state agencies to assist with the process, bypassing some of the organizational inertia that holds back their more established competitors" (Mathews 2002: 470).

Para Mathews, a empresa entrante tardia entra tardiamente não por opção, mas por necessidade histórica: ela parte de uma condição inicial de escassez de recursos, sobretudo barreiras de acesso a tecnologias e mercados. Seu objetivo principal é realizar o processo de catch-up partindo de algumas poucas vantagens competitivas iniciais, como baixos custos de mão de obra, utilizando-as para alavancar sua competitividade. É por meio do reconhecimento de suas "deficiencies that the LCF [latecomer firm] secures its first “competitive advantage." It formulates a strategy commensurate with its deficiencies and limitations. It harbors no illusions as to its own capabilities, and looks instead to the wider world for sources of technology, knowledge and market access" (Mathews 2002: 472). As escolhas estratégicas da empresa entrante tardia, por sua vez, giram em torno dos seguintes passos: em primeiro lugar, o estabelecimento de laços que geram oportunidades para a empresa entrante tardia; em segundo, a alavancagem de recursos (tecnologia, conhecimento, acesso a mercados) como forma de aproveitar os laços estabelecidos; e por último, a aprendizagem como resultado das repetidas experiências de estabelecimento de laços e alavancagem de recursos, que permitem a aquisição de capacidades dinâmicas (dynamic capabilities), resumidas na fórmula - linkage, leverage and learning.

O estabelecimento de laços com cadeias globais de valor é fator central de qualquer estratégia de catch-up em setores operando próximos à fronteira tecnológica, pois é por meio de repetidas interações da empresa entrante tardia com as líderes do setor que aquelas alavancam recursos tecnológicos e canais de mercado e aprendem a competir com as empresas líderes: "it is therefore the multiplying linkages between firms, in the globally interconnected economy, that provides the latecomer firm with its first potential advantage. If it can fashion a strategy of linkage that complements the strategies of 
incumbents, by meeting their needs and offering valued services, then it opens the door to further advance and industrial upgrading" (Mathews 2002: 476). A empresa entrante tardia precisa desenvolver uma estratégia complementar à estratégia das empresas líderes, de modo a aproveitar as externalidades positivas geradas nas interações. $\mathrm{O}$ estabelecimento de laços com as empresas líderes permite à empresa entrante tardia criar as primeiras possibilidades de alavancagem de recursos tecnológicos e de acesso a mercados para empreender os passos seguintes do processo de catch-up.

Se a empresa entrante tardia não tem os recursos tecnológicos ou acesso a mercados necessários para crescer e se desenvolver tecnologicamente, ela pode recorrer à alavancagem de recursos externos identificando as complementaridades com outras empresas e com instituições de desenvolvimento e inovação tecnológica e industrial. Nesse sentido, o conceito de alavancagem de recursos é diferente dos conceitos de transferência e difusão tecnológicas: estas últimas são associadas às estratégias das empresas líderes de países avançados, ao passo que o conceito de alavancagem de recursos atribui a iniciativa à estratégia das empresas entrantes tardias de países emergentes. O sujeito da ação estratégica muda: empresas de países emergentes deixam de ser receptoras passivas de tecnologias transferidas ou difundidas a partir de empresas tecnologicamente mais avançadas, passando a empreender ações estratégicas com fins à alteração estrutural das relações econômicas e tecnológicas.

O terceiro componente de uma estratégia de catch-up é a aprendizagem. Para Mathews, estabelecimento de laços e alavancagem de recursos não são fatores suficientes para desencadear e sustentar o catch-up. É nesse ponto que o conceito de capacidade absortiva de Cohen e Levinthal (1990) volta à cena em companhia do conceito de capacidades combinativas (Kogut e Zander 1992) e recursos institucionais.

A noção de capacidade absortiva no contexto de uma estratégia de catch-up refere-se à capacidade de uma empresa ou país absorver os recursos alavancados (tecnologias de produtos e processos, conhecimento codificado e tácito). Se a empresa não for capaz de absorver os recursos alavancados externamente, o processo de aprendizagem iterativo de estabelecimento de laços e alavancagem de recursos não tem sequência, o que impede a redução da distância da fronteira tecnológica da empresa entrante tardia em relação às empresas líderes. 
O processo de aprendizagem de uma empresa entrante tardia engajada em uma estratégia de catch-up envolve também o que Kogut e Zander (1992) denominaram capacidade combinativa: a capacidade de uma empresa gerar novas aplicações a partir de conhecimentos e tecnologias previamente existentes. Nas palavras de Kogut e Zander, capacidade combinativa é a "intersection of the capability of the firm to exploit its knowledge and the unexplored potential of the technology" (Kogut e Zander 1992: 391 apud Mathews 2002); para Mathews, "the LCF (...) is concerned most assuredly to develop its capacities through 'learning', i.e. through the absorption of resources leveraged externally and their internalization into manufacturing and product development capabilities. In such a venture, the LCF is not concerned to generate "new knowledge" but to adapt existing technologies as fast as possible for its own catch-up endeavors. These technologies are unlikely to be presented to the LCF in a discrete "chunk"; rather, they will have to be assembled from a variety of existing sources" (Mathews 2002: 479).

Por fim, as empresas entrantes tardias de países emergentes contam com a mobilização de recursos institucionais que apoiam, guiam, aceleram e investem nos processos de aprendizagem dessas empresas: "public agencies and various forms of interorganizational superstructures create the conditions in which the processes of learning and leverage can be applied, over and over again, each time at higher levels of technological and organizational capability" (Mathews 2002: 479-480). É o que Mathews denomina alavancagem de recursos institucionais.

Mathews também faz uma distinção importante entre os tipos de recursos a serem alavancados pelas empresas entrantes tardias de países emergentes em suas estratégias de catch-up e aqueles alavancados por empresas líderes de países avançados. Em termos de tipos de recursos, o que é bom para as empresas próximas à fronteira tecnológica não é necessariamente bom para as empresas em processo catch-up, pois o objetivo das empresas entrantes tardias é desenhar uma estratégia para reduzir a distância da fronteira tecnológica partindo de uma situação caracterizada pela escassez dos recursos necessários para tanto (o que leva a empresa entrante tardia a se envolver no processo iterativo de estabelecimento de laços, alavancagem de recursos e aprendizagem), ao passo que o objetivo das empresas líderes é sustentar suas fontes de competitividade. Aquela precisa avançar sem possuir de saída os recursos necessários; essa quer manter sua liderança. 
Para a empresa líder que domina a fronteira tecnológica, os recursos mais importantes para sua estratégia de manter a liderança mostram-se, entre outros aspectos: valiosos e raros; inimitáveis (melhor, são de difícil imitação pelos competidores); e intransferíveis (por não serem facilmente vendidos ou comprados em mercados, estando fortemente conectados aos direitos proprietários de uma empresa). Esses tipos de recursos garantem a vantagem competitiva de empresas líderes.

Este não é o caso das empresas entrantes tardias, pois do ponto de vista delas, esses tipos de recursos dificultam sua estratégia de catch-up. Essas vantagens competitivas desestimulam empresas entrantes tardias a arriscarem seu domínio dos mercados e das tecnologias. As empresas entrantes tardias simplesmente não conseguem alavancar recursos dos tipos mobilizados pelas empresas líderes. Elas precisam recorrer, portanto, a outros tipos de recursos - recursos por assim dizer alavancáveis a partir de sua posição de entrantes tardias.

Mathews define os recursos alavancáveis por empresas entrantes tardias como: menos raros; mais imitáveis; mais transferíveis (Mathews 2002). As empresas entrantes tardias precisam alavancar recursos com essas características se quiserem superar as barreiras colocadas pelas empresas líderes e reduzir aceleradamente sua distância da fronteira tecnológica.

Não é possível, no entanto, executar uma estratégia de catch-up sem que a empresa entrante tardia tenha algumas vantagens iniciais. Só a partir delas é possível estabelecer laços, alavancar recursos e criar as condições para um processo de aprendizagem contínuo. Essas vantagens iniciais são bastante variadas: custos baixos, acesso a mercados em rápido crescimento, participação em cadeias de fornecedores de uma empresa líder. Sem alguma vantagem inicial, a empresa entrante tardia não consegue reduzir sua distância da fronteira tecnológica e aumentar suas vantagens competitivas e inovativas. O objetivo final de uma empresa entrante tardia deve ser passar da imitação à inovação.

Mathews aplicou esse quadro analítico e conceitual a empresas, setores e países. Em "Catch-up Strategies and the Latecomer Effect in Industrial Development" (2006), Mathews passa do catch-up como estratégia empresarial para o catch-up como estratégia de desenvolvimento de países. Mathews discute a relação entre estratégias de catch-up e desenvolvimento industrial, retomando as ideias de Mathews (2002) e 
aplicando os conceitos de estabelecimento de laços, alavancagem de recursos e aprendizagem à análise de casos de catch-up de países. Mathews acrescenta ao quadro analítico e conceitual anterior a noção de aprendizagem institucional para descrever o processo iterativo de construção de instituições de suporte ao desenvolvimento industrial.

Sua contribuição mais importante nesse artigo - pelo menos no que diz respeito a nosso problema de pesquisa, o exame comparado das estratégias de catch-up nos setores aeronáutico de Brasil, Argentina, Indonésia, Japão, China e Rússia - é o conceito de sistema nacional de aprendizagem econômica, conjunto de instituições voltadas a orientar e dar apoio às estratégias de catch-up de um país. Essas instituições são abandonadas ou substituídas à medida que o país e suas empresas deixam de ser imitadores e seguidores e passam a ser eles mesmos líderes: "the institutions developed in the process of achieving catch-up may then need to be discarded as the country approaches the leaders; imitation will give way to innovation and, for this, new institutions will be needed. To reach such a state, and leave the institutions of followership behind, is the goal of all latecomers and all catch-up strategies" (Mathews 2006: 329).

Em "China, India and Brazil: Tiger Technologies, dragon multinationals and the building of national systems of economic learning" (2008), Mathews volta sua atenção ao exame das estratégias de catch-up de empresas do Brasil, Índia e China para pensar em que medida as experiências desses três países "in developing national systems of economic learning may be said to replicate the strategies that worked so successfully in East Asia" (Mathews 2008: 6). Mathews considera Brasil, Índia e China como os legítimos sucessores dos tigres asiáticos e cunha, como termo para entender a questão, o conceito de sistema nacional de aprendizagem econômica, definido por Mathews como "national-level routines for the capture and dissemination of the knowledge needed to become a player in advanced industries and to build what we called national systems of economic learning" (Mathews 2009: 24).

A atenção ao papel das instituições de desenvolvimento econômico não deixa de lado a seguinte ideia que devemos reter ao longo desta tese, a saber, que "the central category in the development lexicon, and the most important tool in the developmental toolbox, has to be the firm. The firm is the means of entry into the global economy" (Mathews 
2008: 15), para dizer logo em seguida e sem disfarçar o sarcasmo que "most of the development literature is written as if firms did not exist" (Mathews 2008: 15). Compreender as interações das estratégias nacionais com as estratégias das empresas é, portanto, fundamental.

\section{Catch-up, capacidades absortivas e distância da fronteira tecnológica}

Diferenciar as fases do processo de catch-up é o último ponto que precisa ser abordado para desenvolver um modelo analítico das razões de sucesso e fracasso das estratégias de catch-up. A noção de fronteira tecnológica recebeu alguns de seus mais importantes tratamentos nos trabalhos de Criscuolo e Narula (2002), Narula (2003), Rogers (2004), Acemoglu, Aghion e Zilibotti (2006), Esteves e Porcille (2010). Em especial, Narula (2003) e Criscuolo e Narula (2002) desenvolveram um quadro conceitual relacionando catch-up, capacidades absortivas e distância à fronteira tecnológica em termos de estágios desta última e adequação das diferentes formas de capacidade absortiva a cada estágio do catch-up.

Em 'Understanding Absorptive Capacities in an 'Innovation Systems' Context: Consequences for Economic and Employment Growth" (2003) Rajneesh Narula discute o conceito de capacidade absortiva e as implicações para a discussão sobre crescimento econômico, em especial o modo como a "nature of absorptive capacity changes with stages of economic development, and the importance of the different aspects of absorptive capability at different stages" (Narula 2003: i). Trabalhando com a noção de distância da fronteira tecnológica, Narula oferece uma explicação sobre os retornos decrescentes de políticas e instituições voltadas ao catch-up por meio do aumento da capacidade absortiva de um setor ou país ao longo de sua trajetória de desenvolvimento, argumentando que as estratégias de catch-up precisam incorporar a seu arsenal a ideia de que os instrumentos de aumento da capacidade absortiva e de realização do catch-up variam de acordo com a distância da fronteira tecnológica. A recomendação é importante não apenas para os que querem compreender e explicar os processos de crescimento e desenvolvimento econômico, mas também, e sobretudo, para a formulação de políticas e a construção de instituições de suporte a uma estratégia de catch-up. 
O argumento de Narula (2003), em seus pontos essenciais, é o seguinte: para haver crescimento econômico uma unidade econômica (seja ela um país ou uma empresa) precisa ter ganhos de produtividade. Estes dependem em larga medida da aquisição, desenvolvimento, difusão e utilização eficiente de conhecimento gerado por meio da inovação. Em países em desenvolvimento (ou emergentes), uma parte muito importante dos ganhos de produtividade é fruto da capacidade de países e empresas de "absorb, internalize and utilize the knowledge potentially made available to them" (Narula 2003: 1) e assim realizarem o catch-up com os países mais avançados. A capacidade de absorver, internalizar e usar conhecimento, por sua vez, é função do estágio de desenvolvimento de um país ou empresa: essa função é dependente do estágio (stage dependent), não-linear e não-monotônica (Narula 2003: 2).

Narula faz uma distinção muito importante entre capacidade absortiva e capacidade de absorver: esta sempre aumenta, ao passo que aquela "is a function of the amount of knowledge that remains to be assimilated. To illustrate the difference take a world of finite knowledge. When all available knowledge has been absorbed, absorptive capacity is zero, but the capability to absorb remains high" (Narula 2003: 6). A capacidade de absorver está relacionada ao acúmulo prévio de conhecimento e aos processos de aprendizagem em que um país ou uma empresa se envolveu anteriormente. Ela é, portanto, uma característica da unidade econômica (país ou empresa). A capacidade absortiva, por sua vez, é função da distância de uma unidade econômica (país ou empresa) da fronteira tecnológica: quanto maior a distância da fronteira tecnológica, maior a capacidade absortiva, uma vez que há mais conhecimento disponível para ser absorvido. E quanto menor a distância de um país ou uma empresa da fronteira tecnológica, menor sua capacidade absortiva, dado que na vizinhança da fronteira há menos conhecimento disponível para ser absorvido.

Narula examina a relação entre capacidades absortivas de empresas e países partindo da seguinte ideia: "national absorptive capacity is not simply an aggregation of the absorptive capacity of a nation's industries. There are numerous additional, combinatory and multiplier effects which - although negligible at the firm-level - take on considerable significance at the national level. As with firms, so with nations: absorptive capacity includes not only the ability of creating new knowledge through investment in knowledge, but also the ability to search and select the most appropriate technology to be assimilated from existing ones available to other economic actors. (...) 
If the institutions and organizations are absent or underdeveloped, economic actors within the system will be unable to absorb and efficiently internalize knowledge" (Narula 2003: 7). Narula distingue dois tipos de atores econômicos: empresas (públicas e privadas) envolvidas em atividades de inovação; e não-empresas, responsáveis pela oferta de "knowledge infrastructure which supplements and supports firm-specific innovation. We define "knowledge infrastructure" (...) as being "generic, multi-user and indivisible" and consisting of public research institutes, universities, organizations for standards, intellectual property protection, etc., the infrastructure that enables and promotes science and technology development" (Narula 2003: 7). Um país ou empresa só consegue por em prática uma estratégia de catch-up se possuir um patamar mínimo de capacidade absortiva, função do estoque de conhecimento disponível, sem o qual o país ou a empresa não consegue absorver, internalizar e usar o conhecimento disponível externamente de modo eficiente.

Criscuolo e Narula (2002) identificam quatro estágios de desenvolvimento e capacidade de absorção de conhecimento: pré-catch-up; catch-up; o pré-compartilhamento da fronteira tecnológica; e compartilhamento da fronteira tecnológica. O potencial de retorno das capacidades absortivas varia de acordo com o estágio em que um país ou empresa se encontra. Segundo Narula (2003), a função que descreve a relação entre estágio de desenvolvimento e capacidade absortiva comporta-se da seguinte maneira: "once the country has reached the threshold level of knowledge base, absorptive capacity rapidly increases. It reaches a maximum when the country achieves an intermediate level of development and foreign technology is more technologically congruent. As the country approaches the frontier, absorptive capacity declines both because the knowledge available to be assimilated is smaller and the complexity involved in its exploitation is higher. Note that regardless of whether we use a fixed or moving frontier, absorptive capacity will tend to zero as the country approaches the frontier (...). However, the capability to absorb reaches a maximum at the frontier, and may be said to be monotonically related to knowledge accumulation (...). In other words, at the frontier, it is theoretically possible to absorb more knowledge, since the capability to absorb can only increase with knowledge accumulation, but absorptive capacity is an inverse function of the available unlearned knowledge" (Narula 2003: 2627). 
No estágio de pré-catch-up, o processo de acumulação de conhecimento ocorre de forma lenta até o ponto em que se atinge o patamar mínimo de conhecimento sem o qual países e empresas não são capazes de por em prática uma estratégia de catch-up. Uma vez atingido o patamar mínimo, o processo de catch-up tem início efetivamente. Nesse estágio, a infraestrutura de conhecimento é de um tipo genérico, não especializado; o P\&D formal é mínimo; e o conhecimento é acumulado pelo aprendizado pela prática (learning by doing). Grande parte do processo de absorção de conhecimento pode se dar simplesmente pela compra de máquinas e equipamentos mais avançados. O Estado concentra seus esforços em oferecer a infraestrutura básica de conhecimento e fazer com que os fluxos tecnológicos tenham impactos positivos no processo de acumulação de conhecimento e no crescimento econômico; para isso, constrói as instituições que darão suporte aos estágios seguintes do processo de catch-up.

O estágio de catch-up tem início quando o patamar mínimo de capacidades absortivas já existe. Esse estágio é “characterized by high rates of accumulation and absorption of foreign knowledge, which in itself leads to further development of absorptive capacities" (Narula 2003: 34) em um processo iterativo e cumulativo. Nesse estágio a acumulação tecnológica aumenta rapidamente, e é nele que se atinge o pico da capacidade absortiva. Adicionalmente, nesse estágio é fundamental que os países tenham "the capacity not just to absorb and imitate technological development created by others, but also the ability to generate inventions of their own" (Narula 2003: 34).

O estágio de compartilhamento da pré-fronteira do conhecimento é a vizinhança da convergência à fronteira tecnológica. Nesse estágio o processo de acumulação de conhecimento começa a desacelerar: "The assimilation of external knowledge becomes harder, both because of the increasing complexity and the quantity of knowledge, and the difficulties of acquiring this knowledge" (Narula 2003: 37).

Por último, no estágio de compartilhamento da fronteira tecnológica, "when a country approaches the frontier, it must be able not only to absorb and imitate technological developments but also to generate innovations of its own. Under these circumstances, strategies adopted at the catching-up stage have decreasing returns" (Narula 2003: 38).

São essas as ideias que, combinadas e adaptadas em diferentes proporções, fornecerão os elementos para o desenvolvimento de um modelo de estratégias de catch-up a partir de casos do setor aeronáutico civil. 


\section{Um modelo das estratégias de catch-up}

Em sua definição mais sintética, catch-up tecnoprodutivo é o processo de redução acelerada da distância que separa determinados atores (país, empresa, setor etc.) da fronteira tecnológica de certo artefato tecnológico (produto, tecnologia, processo etc.). Nas páginas a seguir, desenvolvo o modelo teórico de catch-up tecnoprodutivo que será empregado na análise das estratégias de catch-up tecnoprodutivo aeronáutico no Brasil Argentina, Indonésia, Japão, China e Rússia, casos discutidos nos capítulos 3 a 6. No capítulo 7, o modelo é aplicado àqueles casos de tentativas de catch-up tecnoprodutivo. No restante deste capítulo, formalizarei o modelo de catch-up tecnoprodutivo e justificarei a escolha dos casos deste estudo.

\section{Conceitos centrais}

O problema de pesquisa tratado nesta tese, estratégias nacionais de catch-up de sistemas tecnoprodutivos aeronáuticos, organiza-se em um espaço teórico formado pelos conceitos de fronteira tecnológica, catch-up tecnoprodutivo e sistema tecnoprodutivo. Esses conceitos e as relações existentes entre eles compõem o modelo analítico usado para responder à seguinte pergunta: por que algumas estratégias de catch-up de sistemas tecnoprodutivos aeronáuticos dão certo, enquanto outras dão errado? A hipótese é que apenas sistemas tecnoprodutivos que dispõem de estratégias de aprendizagem, instituições de produção e difusão de conhecimento e empresas dinâmicas logram obter sucesso no catch-up aeronáutico.

O conceito de fronteira tecnológica tem sido empregado por diversos autores para compreender as relações entre tecnologia e desenvolvimento econômico e social (cf. Criscuolo e Narula 2002, Narula 2003, Rogers 2004, Acemoglu, Aghion e Zilibotti 2006, Esteves e Porcille 2010). Ainda que referido a correntes teóricas e modelos analíticos muito diferentes entre si, o conceito de fronteira tecnológica utilizado por esses e outros autores tem assumido formas bastante estáveis e convergentes, sendo possível falar até mesmo em um relativo consenso sobre o significado do termo. Por fronteira tecnológica entendo o limite máximo do estoque de conhecimentos e habilidades aplicáveis à reprodução ampliada de capital em determinada empresa, setor 
ou país. A fronteira tecnológica é o ponto ótimo, ou mais eficiente, de emprego de conhecimentos e habilidades na produção de produtos ou processos. $\mathrm{Na}$ fronteira tecnológica, os retornos são maximizados em relação aos fatores produtivos disponíveis.

A fronteira tecnológica é histórica, social, cultural e economicamente determinada: histórica, porque dependente das trajetórias, aprendizagens e acúmulos anteriores; social, porque influenciada pelas formas de distribuição de poder, riqueza e conhecimento; cultural, porque imersa nas disposições e modos de ser das pessoas; e economicamente, porque produzida segundo os potenciais e limitações de um determinado modo de produção.

Do ponto de vista de sua dinâmica, a fronteira tecnológica alterna períodos de grande estabilidade com fases de mudanças profundas. Os períodos de estabilidade são caracterizados por inovações incrementais, enquanto as fases de mudanças caracterizam-se por inovações disruptivas ou radicais.

Da noção de fronteira tecnológica e das implicações de sua definição nos termos acima, derivamos a noção de catch-up em relação à fronteira tecnológica. Catch-up refere-se à dimensão estratégica ou agencial das pessoas e instituições em relação à fronteira tecnológica: é a ação social que visa transformar as condições de reprodução ampliada do capital em determinada empresa, setor ou país por meio do acúmulo acelerado de conhecimentos e habilidades aplicáveis à produção de bens econômicos. Em função de seu componente estratégico e agencial, a noção de catch-up distingue-se e se contrapõe à noção de acúmulo vegetativo ou constante de conhecimentos e habilidades aplicáveis economicamente: naquela, a aceleração do processo de acúmulo de conhecimentos e habilidades tem o potencial de alterar as posições relativas de empresas, setores ou países por meio do aumento de sua competitividade decorrente da redução da distância da fronteira tecnológica ou pelo menos sustentar a posição; nesta, a não alteração da velocidade basal de acúmulo de conhecimentos e habilidades pode, na melhor das hipóteses, manter inalteradas as posições relativas de empresas, setores ou países, e no caso de aceleração por parte de outras empresas, setores ou países, redundar na perda de posições relativas em decorrência de sua menor competitividade, função do aumento de sua distância em relação à fronteira tecnológica. 
O conceito de sistema tecnoprodutivo descreve o conjunto de instituições que aprendem, desenvolvem e acumulam conhecimento e aplicam esse conhecimento à produção de artefatos tecnológicos. Instituições são organizações formais, que atuam ofertando ou demandando componentes humanos ou materiais na forma de ciência, tecnologia, pessoal qualificado, capacidades produtivas e de comercialização em um determinado setor econômico. Um sistema tecnoprodutivo, portanto, é o conjunto de instituições que proveem direta e indiretamente os recursos e incentivos em uma determinada área do conhecimento científico, tecnológico, produtivo e comercial. Os sistemas tecnoprodutivos aeronáuticos, para ficarmos nos limites do tema desta pesquisa, são compostos por empresas, instituições de formação de pessoal especializado, institutos de pesquisa e desenvolvimento, laboratórios e agências regulatórias que interagem para projetar, desenvolver, produzir e comercializar aviões e componentes aeronáuticos.

O conceito de sistema tecnoprodutivo distingue-se da noção de sistema nacional e setorial de inovação em pontos importantes, não obstante os muitos pontos em comum entre uma ideia e outra. $\mathrm{O}$ conceito de sistema tecnoprodutivo enfatiza as relações entre conhecimento, produção e comercialização de um artefato tecnológico e a dimensão sistêmica e de complementaridade entre as instituições que o formam. Sem descurar dos aspectos científicos e tecnológicos do problema, a noção de sistema tecnoprodutivo procura enfatizar os processos de aprendizagem cumulativa iterativa entre projeto e produção, bem como a viabilidade comercial do artefato tecnológico. O foco recai menos na proficiência tecnológica estrito senso e mais no modo como o conjunto de organizações que compõem determinado sistema tecnoprodutivo viabilizam projeto, produção e comercialização de um artefato tecnológico.

Ainda que à primeira vista o conceito de sistema tecnoprodutivo pareça acrescentar pouco em relação aos conceitos de sistema nacional ou setorial de inovação, a distinção ganha sentido por oferecer um contraponto ao fetichismo tecnológico e novidadeiro que muitas vezes acompanha a ideia de sistema nacional ou setorial de inovação. O conceito de sistema tecnoprodutivo enfatiza a importância dos conhecimentos que permitem a transição da fase de projeto para a fase de produção e desta para a fase de comercialização; realça o fato de que a proficiência tecnológica de bancada ou de laboratório precisa ser complementada por proficiência produtiva e de comercialização; atribui igual valor aos conhecimentos científicos, tecnológicos, produtivos, comerciais e 
institucionais, ou antes, não define a priori a importância relativa de diferentes formas de conhecimento, insistindo na variedade de fatores determinantes da competitividade; e destaca um fato recorrente - mais comum do que se costuma pensar, aliás - das trajetórias de desenvolvimento tecnoprodutivo: artefatos tecnológicos avançadíssimos do ponto de vista tecnológico, isto é, indubitavelmente na fronteira tecnológica, podem dar em retumbantes fracassos tecnoprodutivos ou levar a lugar algum se a produção e comercialização desses artefatos tecnológicos não se realizarem no mercado.

A partir desse arcabouço conceitual, esta tese examina o processo de redução da distância da fronteira tecnológica por meio de estratégias de catch-up de sistemas tecnoprodutivos aeronáuticos nacionais no segmento de aviação civil, mais especificamente, no nicho de jatos regionais - em que Brasil e Canadá enfrentarão muito em breve a concorrência de Japão, China e Rússia -, passando ao largo do segmento militar. A distinção entre aviação civil e militar é não só possível como também necessária em função das muitas e significativas diferenças entre um e outro. A começar pelo fato de que, em se tratando de aviação militar, preocupações com otimização de custos em relação às tecnologias empregadas, produção em escala e comercialização são secundárias se comparadas com aviões civis. Governos podem aceitar altos custos de produção de aviões militares se isso garantir uma vantagem efetiva em relação aos equipamentos militares de outros países. A escala de produção de aviões militares, que podem girar entre as poucas dezenas e algumas centenas, é muito menor do que a escala de produção de aviões civis, que para compensarem os custos de entrada em produção devem garantir encomendas nas casas de uma ou duas centenas. Os parâmetros técnicos de aviões militares também são muito mais exigentes do que aquelas para aviões civis, condição garantida em parte pela utilização de componentes de altíssima qualidade (e portanto mais caros) e pela montagem semiartesanal de aviões militares. Como se não bastasse, a aviação militar ainda esbarra em restrições geopolíticas: para quem vender, com quais componentes e com que grau de transferência tecnológica são aspectos determinados menos por considerações produtivas e comerciais (como otimização de custos, facilidade de reposição de peças e de serviços de manutenção) e mais por cálculos estratégicos e militares.

O foco em jatos regionais decorre diretamente dos aspectos tecnoprodutivos e de mercado que determinam as estratégias atuais de catch-up aeronáutico. Projetar e produzir jatos regionais permite às empresas entrantes aprender e acumular 
conhecimentos críticos para as OEMs (original equipment manufacturers, empresas que projetam, produzem e comercializam aviões), em especial aqueles relativos a projeto e integração de sistemas, que definem as principais atividades desempenhadas por OEMs. Ao mesmo tempo, a estratégia centrada em jatos regionais se esquiva da competição com as duas maiores e mais avançadas OEMs do mundo, que desempenham atualmente papel de líderes de desenvolvimento tecnológico, Airbus e Boeing, que além de sua competitividade no segmento comercial também se beneficiam de sua atuação no segmento militar, significativamente maior do que nos casos da Embraer e da Bombardier. Por último, a opção por jatos regionais atende à necessidade de prover infraestrutura de transporte a mercados de países emergentes que ainda não dispõem da escala nem dos níveis de renda que justificariam o emprego de aviões maiores.

\section{Modelo analítico dos fatores condicionantes do sucesso das estratégias de catch-up tecnoprodutivo aeronáutico}

Esta tese examina o problema das estratégias de catch-up de sistemas tecnoprodutivos aeronáuticos tomando como parâmetro do sucesso ou fracasso do catch-up o grau em que um sistema tecnoprodutivo aeronáutico se aproximou da fronteira tecnológica de projeto, produção e comercialização de aviões. Ela investiga os esforços que vários países despendem para constituírem empresas OEM, interessando-se pelas estratégias de constituição de cadeias de fornecedoras aeronáuticas apenas na medida em que elas fazem parte da estratégia de formação de uma OEM.

Serão examinadas as estratégias de catch-up de seis países: Brasil, Argentina e Indonésia, estratégias já plenamente executadas, e Japão, China e Rússia, com estratégias em curso e já bastante avançadas, com seus jatos regionais próximos do ponto de receber certificação e entrar em produção seriada. O propósito do modelo analítico é identificar, por meio da comparação de estratégias de catch-up tecnoprodutivo aeronáuticas já encerradas com aquelas atualmente em curso, os pontos fortes e fracos, acertos e erros de cada estratégia de modo a oferecer prognósticos sobre as chances de sucesso de cada uma das estratégias ora em curso.

As dimensões do modelo analítico sobre condições de fracasso ou sucesso de estratégias nacionais de catch-up tecnoprodutivo aeronáutico são a base da análise qualitativa 
comparada que empreenderei. O modelo explicativo é composto por três dimensões e seis variáveis-condição que serão identificadas em cada um dos casos de estratégias de catch-up tecnoprodutivo aeronáutico analisados nesta pesquisa: dimensões de estratégia de aprendizagem tecnoprodutiva: 1) aprendizagem tecnoprodutiva por produção sob licença; 2) aprendizagem tecnoprodutiva por internacionalização endógena (atração de empresas estrangeiras para produzirem no país); 3) aprendizagem tecnoprodutiva por internacionalização exógena (inserção de empresas nacionais em cadeias globais de valor); dimensões institucionais: 4) instituições de formação de recursos humanos (técnicos, tecnológicos e científicos) especializados no setor aeronáutico; 5) instituições de pesquisa e desenvolvimento dedicadas ao setor aeronáutico; e dimensão empresarial: 6) OEM comercialmente orientada.

Para a modelagem formal do problema, será utilizada a metodologia de análise comparativa qualitativa (qualitative comparative analysis, ou QCA), apresentada em detalhes no capítulo 7.

Para além de sua aplicação à análise de estratégias de catch-up tecnoprodutivo aeronáutico, o modelo é generalizável para um conjunto mais amplo de estratégias de desenvolvimento tecnoprodutivo em setores intensivos em conhecimento. Nesse sentido, o modelo analítico em particular e esta tese como um todo formulam uma teoria sobre os modos de aceleração da aprendizagem tecnoprodutiva: sobre formas de realizar catch-ups tecnoprodutivos.

\section{Os casos estudados critérios de seleção de países e generalização dos achados}

Nesta tese analiso seis países e sete casos de estratégias de catch-up tecnoprodutivo aeronáutico: Brasil, Argentina, Indonésia, Japão (duas tentativas de catch-up), China e Rússia. Trata-se, portanto, de um desenho de pesquisa baseado na comparação de múltiplos estudos de casos (Yin 2003). Desses, quatro países são tomados como casos encerrados, isto é, tentativas de catch-up já executadas e cujos resultados conhecemos: Brasil, uma tentativa bem-sucedida de catch-up tecnoprodutivo aeronáutico, e Argentina, Indonésia e a primeira tentativa de catch-up tecnoprodutivo aeronáutico do Japão (décadas de 1950 e 1960). Esses últimos casos são contrastados com o catch-up 
empreendido pelo Brasil. A comparação desses quatro casos permitirá compreender os fatores que contribuem para o sucesso ou fracasso de uma tentativa de catch-up tecnoprodutivo aeronáutico. Este é o momento em que são examinadas as condições que influem no resultado de estratégias de catch-up tecnoprodutivo aeronáutico.

Os casos encerrados de Brasil, Argentina e Indonésia são comparados aos casos de Japão (segunda tentativa de catch-up tecnoprodutivo aeronáutico, nos anos 2000), China e Rússia, ainda em execução, mas já nas fases finais das respectivas estratégias de catch-up, para estabelecer quais das atuais tentativas de catch-up tecnoprodutivo aeronáutico têm maiores chances de serem bem-sucedidas.

Nunca é demais esclarecer que a seleção desses casos é presidida não por uma lógica amostral probabilística, mas por aquilo que Yin (2003) chamou de lógica de replicação: "each case must be carefully selected so that it either (a) predicts similar results (a literal replication) or (b) predicts contrasting results but for predictable reasons (a theoretical replication)" (Yin 2003: 47). Portanto, os casos foram selecionados por sua relevância teórica. Do mesmo modo, a generalização dos achados desses múltiplos estudos de casos é uma generalização analítica, isto é, de fundo teórico, e não uma generalização estatística, de fundo probabilístico. Não se trata, assim, de determinar a frequência relativa de determinados fatores, mas de demonstrar, por meio do aparato teórico adequado ao problema, como determinadas configurações de fatores aumentam ou diminuem as chances de sucesso das tentativas de catch-p tecnoprodutivo aeronáutico (Yin 2003).

A relevância dos casos foi estabelecida pelo exame da literatura especializada sobre política de desenvolvimento tecnoprodutivo aeronáutico, em especial Narula 2003, Criscuolo e Narula 2002, McGuire 2011, Goldstein 2005 e 2005, Nolan e Zhang 2002 e 2003, Vertesey e Szirmay 2010, Niosi e Zhegu 2008, Niosi e Zhegu 2010, Bédier et al 2008, Kanatsu 2006, Kimura e 2006 Kuo 2009, entre outras referências. Com base nessa literatura é possível argumentar que, salvo engano, os casos examinados nesta tese representam a quase totalidade de casos de catch-up tecnoprodutivo aeronáutico no pósSegunda Grande Guerra.

Razões adicionais, estas menos de ordem metodológica e mais de fundo político, orientaram a seleção dos casos estudados comparativamente. Em primeiro lugar, trata-se de competidores diretos do Brasil no segmento aeronáutico, e mais especificamente de 
jatos regionais: China, Rússia e Japão. É preciso antecipar os movimentos estratégicos desses competidores de modo a subsidiar o sistema tecnoprodutivo aeronáutico brasileiro com análises sobre seus potenciais competidores.

Em segundo lugar, dois desses países podem ser considerados competidores diretos do Brasil em sentido mais amplo por suas condições de potências emergentes: China e Rússia, consistindo de três dos quatro países denominados BRIC. A exceção fica por conta da Índia, que não está no momento implementando uma estratégia de catch-up tecnoprodutivo aeronáutico com vistas à constituição de uma OEM indiana, concentrando-se no momento no aproveitamente de suas capacidades de serviços de engenharia e manutenção decorrentes sobretudo do baixo custo da mão de obra qualificada indiana. Aumentar o conhecimento sobre as estratégias de desenvolvimento industrial de China e Rússia é de grande importância para que o Brasil possa fazer frente aos desafios colocados pela emergência dessas outras potências.

Por último, mas nem por isso menos importante, uma teoria historicamente informada sobre as razões para o sucesso e fracasso de estratégias de catch-up tecnoprodutivo aeronáutico presta-se, guardados os devidos cuidados, à generalização para uma teoria de alcance médio sobre os modos de acelerar o desenvolvimento tecnoprodutivo de diferentes setores. Nesse sentido, esta tese esboça uma tentativa inicial de compreender e sistematizar as formas de aprendizagem tecnoprodutiva que levam a estratégias de catch-up bem-sucedidas com potencial de replicação a outros setores econômicos. Esse é um conhecimento da maior relevância para a fase de desenvolvimento econômico e social pela qual o Brasil passa neste momento, podendo qualificar as decisões e escolhas que o país terá que tomar num futuro muito próximo. 


\section{Capítulo 2: O setor aeronáutico mundial: história e atualidade}

Nascido no começo do século XX, disperso em centenas de pequenas empresas na América do Norte e na Europa disputando a corrida tecnoprodutiva para definição da arquitetura do avião e do modelo de negócios da indústria, o setor aeronáutico passou por dois momentos de inflexão ao longo daquele século: ao final da II Guerra Mundial, momento em que tomou forma a grande empresa verticalizada com pesquisa e desenvolvimento internos, com as norte-americanas Boeing e McDonnell Douglas como casos paradigmáticos dessa fase do setor aeronáutico; e na década de 1980, quando a grande empresa verticalizada e com pesquisa e desenvolvimento interno deu lugar às grandes integradoras de sistemas, coordenadoras de cadeias globais de fornecedores com os quais compartilham riscos financeiros e de inovação.

Niosi (2009) e Niosi e Zhengu (2010) dividem a história do setor aeronáutico em quatro grandes períodos: crescimento inicial (1900-1935), consolidação (1935-1955), oligopólio estável (1955-1980) e o período das formações das cadeias globais de valor e emergência de novos entrantes na indústria (1980 até a atualidade).

Neste capítulo discuto as principais características e fases do setor aeronáutico mundial nos séculos XX e XXI, detendo-me um pouco mais na discussão das mudanças estruturais pelas quais o setor passou nas décadas de 1980 e 1990 e nas condições de entrada em cena de desafiantes de países emergentes.

\section{Surgimento e consolidação do avião e do setor aeronáutico}

A fase romântica do setor aeronáutico não durou muito, naturalmente: a princípio uma corrida tecnológica cheia de pioneiros, inventores e aventureiros, o setor logo se viu às voltas com a necessidade de produzir e vender seus aviões para clientes ainda incertos e reticentes. Tenhamos em mente que fazer um objeto mais pesado que o ar voar, sem cair muito frequentemente, foi apenas a parte mais fácil dos primórdios do setor aeronáutico. Impor o avião como meio tecnológica e economicamente viável foi o verdadeiro desafio das duas primeiras décadas do século XX. Só no momento de sua prova de fogo, na I Guerra Mundial, quando as inúmeras vantagens do avião deixaram de ser uma 
possibilidade, que a tecnologia se afirmou. Quando uma tecnologia disputa a preeminência de sua solução para se impor como arquitetura tecnoprodutiva dominante, considerações de ordem técnica e prática são apenas parte do problema: sua viabilidade econômica e comercial, o ambiente regulatório e o maior ou menor apoio governamental são tão importantes quanto as virtudes do artefato tecnológico estrito senso e determinam-se mutuamente em sua trajetória evolutiva.

No período de invenção e desenvolvimento inicial do avião em começos do século XX, alguns dos traços que mais tarde definiriam os elementos básicos de sua arquitetura tecnoprodutiva foram pensados e testados. O nascente setor aeronáutico caracterizava-se pelo grande número de empresas semiartesanais trabalhando de forma autônoma e produzindo por encomendas quase exclusivamente privadas. Pesquisa e desenvolvimento eram em geral levadas a cabo por alguns poucos mecânicos e engenheiros, no mais das vezes sem qualificação técnica formal. $\mathrm{O}$ aprendizado pela prática era regra geral. O setor não possuía as instituições e arranjos de mercado que propiciariam a disseminação do conhecimento produzido nas empresas individuais, dificuldade aumentada pela própria estrutura da cadeia produtiva, com poucos fornecedores e sem grandes clientes que pudessem dar escala e incentivar a padronização de soluções produtivas. Essas empresas estavam quase todas localizadas nos EUA, Canadá, Grã-Bretanha, França e Alemanha. São dessa época empresas como as norte-americanas Gallaudet Engineering Company, fundada em 1908 e que daria origem à General Dynamics em 1952, à Boeing e à Loughead (mais tarde Lockheed), ambas criadas em 1916, às britânicas Rolls-Royce, fundada em 1906, produzindo seu primeiro motor para aviões em 1914, e Avro, criada em 1910, e à bávaro-germânica Fokker, fundada em 1912.

O emprego de aviões na I Guerra Mundial ofereceu um vislumbre do que seriam as principais características do setor aeronáutico nos 90 anos seguintes: o aumento constante da intensidade tecnológica dos produtos e processos e as economias de escala possibilitadas tanto por encomendas estatais para fins principalmente de defesa quanto pelo surgimento das primeiras empresas de aviação civil para transporte de passageiros e cargas. A arquitetura do avião também sofreu significativas alterações nessa época. $\mathrm{O}$ avião triplano com motor traseiro deu lugar ao biplano com motor dianteiro. Empresas como as britânicas De Havilland, fundada em 1920, e Pratt \& Whitney, criada em 1925, 
e sua subsidiária canadense Pratt \& Whitney Canada, criada em 1928, marcariam os desenvolvimentos subsequentes do setor aeronáutico.

Provado em suas qualidades militares, o avião como empreendimento tecnoprodutivo depois fez sua transição para a esfera civil. As primeiras companhias de transporte aéreo de passageiros e de cargas surgiram após a I Guerra Mundial. As décadas de 1920 e 1930 viram o crescimento da aviação civil e avanços importantes da arquitetura tecnoprodutiva do avião e do setor aeronáutico. Surgem aviões maiores com corpo metálico e monoplano, múltiplos motores e autonomia de voo significativamente estendida. Os primeiros voos transcontinentais e transoceânicos datam desse período.

Quanto à estrutura do setor aeronáutico, o impulso dado pela nascente indústria de aviação civil permitiu às empresas produtoras de aviões fazerem seus primeiros experimentos de padronização de projeto e componentes, o que levou à especialização e divisão do trabalho produtivo no setor aeronáutico entre fabricantes de equipamentos originais (OEMs) - empresas responsáveis pelo projeto do avião e integração de sistemas - e fornecedores de partes, com destaque para as empresas produtoras de motores: Pratt \& Whitney e Rolls-Royce concentram suas linhas de produção de componentes aeronáuticos na fabricação de motores até hoje. O setor, portanto, passou por um processo de especialização e divisão do trabalho que levou à desverticalização da produção e ao estabelecimento de uma cadeia produtiva incipiente. Do ponto de vista das técnicas de manufatura, as empresas do setor aeronáutico foram forçadas a transitar da construção semiartesanal de aviões de madeira, tecido e tirantes de aço para a produção industrial em série de componentes em metais leves. As barreiras de entrada no setor, tanto tecnológicas quanto de capital, aumentaram exponencialmente durante esse período. Os conhecimentos produtivos e o capital físico e financeiro necessários para produzir componentes e aviões inteiros tornaram-se progressivamente mais elevados, dificultando a entrada de novas empresas no setor.

O entreguerras também assistiu à consolidação das empresas de aviação civil, em especial das linhas aéreas de transporte de passageiros. Foi apenas na década de 1930 que o transporte de passageiros se tornou viável economicamente: a reduzida capacidade de carga e autonomia de voo dos aviões, somada à competição de outros meios de transporte - trens para viagens transcontinentais e navios para viagens transoceânicas, ambos meios de transporte largamente presentes na América do Norte e 
na Europa - eram muito mais competitivos do que o transporte por aviões, numa época em que viagens de longa distância e travessias transatlânticas eram feitos de heroísmo e orgulho nacional.

Esses desenvolvimentos da tecnologia do avião e da estrutura produtiva do setor aeronáutico fizeram com que, às vésperas da II Guerra Mundial, o avião enquanto empreendimento tecnoprodutivo tivesse vingado: de curiosidade da era industrial para máquina bélica a meio de transporte de passageiros e cargas. Em pouco mais de três décadas o avião demonstrou sua viabilidade tecnológica, produtiva e econômica. A II Guerra Mundial deu ao setor aeronáutico o impulso que faltava, criando as condições para produção em larga escala de aviões e componentes altamente padronizados. Seu emprego em larga escala durante a guerra exigiu uma especialização ainda maior da divisão do trabalho: a cadeia produtiva do setor aeronáutico se adensou e diversificou.

As tecnologias de projeto e manufatura de aviões e seus componentes avançaram muito durante a II Guerra Mundial. A mais importante inovação tecnológica do setor nessa época foi o motor de propulsão a jato. Desenvolvido a partir de fins da década de 1930 e ao longo de toda a II Guerra Mundial, os aviões a jato só seriam empregados nos últimos anos da guerra e mesmo assim em pequena escala, uma vez que a baixa maturidade da tecnologia e os altos custos associados a ela impediam sua ampla adoção. A principal aplicação do motor a jato durante a II Guerra Mundial foi como sistema de propulsão de mísseis de cruzeiro e balístico.

A invenção do motor de propulsão a jato definiu a arquitetura tecnoprodutiva do avião e do setor aeronáutico como o conhecemos hoje. O avião monoplano de propulsão a jato ou turboélice com fuselagem metálica se impôs como paradigma de arquitetura do avião. A especialização e divisão do trabalho entre empresas manufatoras de equipamentos originais (OEMs), dedicadas basicamente a projeto do avião e integração de sistemas, e fornecedoras de partes e componentes, assim como a existência de dois grandes clientes do setor aeronáutico, o Estado, por meio de compras de material de defesa, e as empresas de aviação civil, são características ainda presentes no setor aeronáutico contemporâneo. É o período que Niosi (2009) e Niosi e Zhengu (2010) denominam de oligopólio estável (1955-1980). 
No entanto, não obstante a maior estabilidade tecnoprodutiva do setor aeronáutico, o fato é que o setor passou por alterações de grande importância nas últimas duas ou três décadas. Com efeito, as alterações econômicas, geopolíticas e tecnológicas desse período modificaram sobremaneira a estrutura do setor aeronáutico contemporâneo e os desafios tecnoprodutivos a serem enfrentados. Na seção seguinte abordo as principais alterações do setor aeronáutico nesses trinta anos, em especial a entrada em cena de novos atores tecnoprodutivos de países emergentes, e preparo a discussão de suas implicações sobre as estratégias de catch-up de Brasil, Argentina, Indonésia, Japão, China e Rússia.

\section{Estrutura do setor aeronáutico contemporâneo}

Altamente dependente do Estado tanto em seu componente civil como no militar, não surpreende que o setor aeronáutico tenha sido e seja intimamente vinculado à geopolítica. Essa relação alcançou seu zênite durante a Guerra Fria, quando o apoio estatal ao setor, na forma de compras de defesa, atingiu seus níveis mais elevados, proporcionando às empresas do setor aeronáutico vultosos aportes de capital econômico e tecnológico. Grande parte das empresas hoje líderes de seus ramos consolidaram sua posição de liderança tecnológica e de mercado fornecendo produtos aeronáuticos de aplicação militar, civil e espacial, como são os casos da Boeing, da General Dynamics, da Lockheed Martin, da EADS, Northrop Grumman, BAE Systems e Raytheon - e, por que não, da Embraer.

O fim da Guerra Fria na virada dos anos 1980 para os 1990 e o novo contexto de regulação do comércio internacional, sob a égide da Organização Mundial do Comércio e da revisão e atualização dos acordos de comércio internacional vigentes desde fins da década de 1940, alteraram profundamente o padrão de relação do Estado com o setor. Os orçamentos militares, levados ao limite pela corrida tecnocientífica e armamentista, foram drasticamente reduzidos. O novo ambiente regulatório do comércio internacional na década de 1990, por sua vez, limitou severamente os instrumentos de desenvolvimento industrial de que podem lançar mãos os Estados contemporâneos. Esses eventos geopolíticos são coetâneos ao aprofundamento do processo de globalização nas décadas de 1990 e 2000 e à emergência de países em pleno processo 
de desenvolvimento e redução das diferenças de níveis de renda e conhecimento em relação aos países avançados. O setor aeronáutico mundial teve que se adaptar a essa nova realidade.

Ao período denominado por Niosi (2009) e Niosi e Zhengu (2010) de oligopólio estável (1955 a 1980) seguiu-se um período de duplo duopólio em que as duas maiores OEMs que se constituíram no período anterior (Boeing e Airbus) passaram a dividir seu domínio com outras duas empresas, Bombardier e Embraer, com as duas primeiras concentrando-se em aviões grandes (mais de 150 assentos) e as duas últimas em aviões executivos e regionais (90-120 assentos). A passagem de uma situação de oligopólio para uma de quase-oligopólio só foi possível devido às alterações profundas pelas quais o setor aeronáutico passou da década de 1980 até o presente.

O setor aeronáutico tem características que o distinguem de outros setores industriais, conferindo-lhe dinâmica e desafios próprios. O setor é intensivo em conhecimento e capital e incorre em retornos crescentes e economias de escala em função do longo processo de desenvolvimento de produto (em geral de 5 a 10 anos) e do seu dilatado ciclo de vida (três décadas em média). A entrada no setor é dificultada pelas barreiras tecnológicas, pelos elevados custos de $\mathrm{P} \& \mathrm{D}$ e pelo rigoroso ambiente regulatório e de certificação dos aviões. O setor tem uma estrutura quase-oligopolista organizada em três níveis: umas poucas OEMs no topo da cadeia de produção, um número um pouco maior de fornecedores de primeiro nível de componentes e subsistemas, que interagem em estreita associação com as OEMs no desenvolvimento de tecnologias e produtos, e muitos fornecedores de segundo e terceiro níveis que interagem com os fornecedores de primeiro nível. Caracteriza-se também pelo forte apoio governamental, devido em grande parte aos elevados riscos de inovação e custos de P\&D do setor e ao longo e dispendioso processo de aprendizagem tecnológica e de gestão. O setor também experimenta acentuadas flutuações de demanda, associadas aos períodos de expansão e retração da economia mundial, ao preço do petróleo e à competição imperfeita entre produtos não homogêneos (cf. Niosi e Zhengu 2010, MacGuire 2011, Bédier et al 2008).

Essas características do setor aeronáutico explicam não apenas as suas transformações nos últimos trinta anos como também determinam, pela dependência de trajetória, as perspectivas tecnológicas e comerciais para as próximas décadas. Tratando-se de 
examinar as estratégias de catch-up do setor aeronáutico de Brasil, Japão, China e Rússia, é necessário ter em conta os cenários que dão base a essas mesmas estratégias, uma vez que o processo de catch-up envolve avançar no conhecimento e nas competências dos líderes do setor e tentar se antecipar aos avanços tecnológicos e comerciais que definirão o mercado aeronáutico no médio e longo prazo.

A fase de 1980 até o presente - período em que toma forma o duplo duopólio - é marcada por uma série de mudanças em relação ao período anterior, de oligopólio estável (1955-1980). As mudanças começaram na década de 1980, quando grandes OEMs norte-americanas e europeias alteraram seus modelos de negócios. O setor passou por um processo de desverticalização, isto é, as OEMs concentraram-se em suas áreas de especialização, a saber, projeto de aviões e integração de sistemas, transferindo para os fornecedores as atividades de desenvolvimento de componentes e subsistemas.

Em decorrência disso - e em função de características específicas do setor como altos custos de $P \& D$ e inovação, ambiente regulatório e de certificação rigorosos - a desverticalização das OEMs se fez acompanhar de uma maior e mais complexa integração com as empresas fornecedoras. As OEMs passaram a liderar e coordenar cadeias produtivas altamente integradas em que os riscos de pesquisa e desenvolvimento de produtos passaram a ser compartilhados. As empresas norteamericanas foram as primeiras a fazerem a transição de um modelo altamente verticalizado para um modelo baseado no outsourcing. Os riscos e custos eram compartilhados entre OEMs e fornecedores, isso já na década de 1980. Na década de 1990, empresas europeias e Embraer enveredaram pelo mesmo caminho.

As dificuldades de desverticalizar o setor fizeram com que a estrutura patrimonial do setor aeronáutico passasse por um processo de concentração. Trata-se de uma indústria altamente intensiva em tecnologia. Qualidade, confiabilidade e durabilidade são exaustivamente postas a prova e submetidas a rigorosos processos de certificação. Ao mesmo tempo, a relação entre OEMs e fornecedores estreitou-se ainda mais, envolvendo as fases de projeto, especificações de produção e financiamento de inovações (Niosi e Zhengu 2010).

As OEMs lideram e coordenam cadeias de fornecedores com quem compartilham os riscos e custos de desenvolvimento de novos produtos. Esse novo arranjo levou a outra mudança, essa de consequências ainda mais profundas no que diz respeito ao cenário 
global da produção de aviões: a relocalização geográfica para países de industrialização tardia cuja principal vantagem competitiva são os baixos custos, em especial os custos de mão de obra. A produção até então se concentrava nos EUA, Canadá, Europa, Japão, Rússia e Brasil. O setor aeronáutico se internacionalizou e se desconcentrou geograficamente. Isso permite que vários países disputem o fornecimento de produtos e serviços para as principais OEMs e fornecedores de primeiro nível.

A internacionalização promoveu trocas de conhecimento, tecnologia e capital entre países com cadeias avançadas e países que faziam suas primeiras incursões na produção de aviões. Essas trocas de tecnologia tomaram diversas formas: outsourcing de produtos e serviços de países com longa tradição para os países entrantes; acordos de offset com transferência tecnológica e suporte técnico das grandes OEMs e fornecedores de primeiro nível para fornecedores de segundo e terceiro níveis e empresas de serviços aeronáuticos; investimentos de multinacionais na produção, montagem e prestação de serviços em países entrantes; compartilhamento de custos e riscos de desenvolvimento de produtos e inovações; e alianças estratégicas entre empresas. O setor estruturou-se em cadeias globais de valor (Niosi e Zhengu 2010).

As mudanças do modelo de negócios e da estrutura da cadeia produtiva criaram as condições para que países com pouca ou nenhuma tradição (e mesmo alguns com bastante tradição, como Japão) tivessem seu quinhão. Não foram poucos os países que tentaram produzir aviões militares ou comerciais: África do Sul, Argentina, Austrália, Áustria, Bélgica, Coréia do Sul, Dinamarca, Egito, Espanha, Finlândia, Holanda, Hungria, Índia, Indonésia, México, Paquistão, Polônia, Romênia, Suécia, Suíça, Tchecoslováquia, Turquia e Ucrânia. Muitos viram na internacionalização e relocalização geográfica do setor aeronáutico a oportunidade de diminuir a distância da fronteira tecnológica e desenvolver a produção nacional, integrando as cadeias globais de valor na condição de fornecedores ou até criando uma campeã nacional que pudesse alavancar a cadeia de fornecedores locais.

A distância entre querer ter um setor aeronáutico e efetivamente tê-lo não ficou, contudo, menor nesses tempos de internacionalização e relocalização geográfica do setor aeronáutico e de criação de cadeias globais de valor. O setor continua altamente concentrado em poucas - e enormes - empresas em um punhado de países, e as barreiras de entrada são tão ou mais altas do que em períodos anteriores. 
Na última década, no entanto, surgiu um novo fator que alterou os cenários do setor aeronáutico global: a perspectiva de forte expansão do mercado de aviação comercial na Ásia - particularmente na China -, no Oriente Médio e na América Latina. Tudo indica que a aviação comercial nessas regiões será fortemente baseada em jatos regionais na faixa de 100-120 assentos, o que tem levado empresas estabelecidas (a norte-americana Boeing, o consórcio europeu Airbus, a canadense Bombardier e a brasileira Embraer) e entrantes (a chinesa COMAC, a russa Sukhoi e a japonesa Mitsubishi) a investirem no desenvolvimento de jatos regionais para atender a demanda das próximas décadas. Japão, China e Rússia veem no setor aeronáutico uma oportunidade estratégica de inserção em cadeias globais de valor com alta intensidade tecnológica e de capital e grande potencial de gerar spillovers de conhecimento que poderiam permitir aos países realizar um catch-up nos próprios setores aeronáuticos nacionais e quiçá em outros setores de suas economias, reduzindo assim a distância da fronteira tecnológica dos setores envolvidos.

O setor aeronáutico global nos últimos trinta anos e nos próximos vinte, portanto, passou e continuará a passar por dois processos de relocalização geográfica, ambos em direção aos países emergentes e em especial à Ásia: mudança na localização dos produtores e mudança na localização dos mercados.

Há dois modelos de reorganização logística da aviação comercial e, consequentemente, dois tipos de aviões que operarão nelas: o primeiro, em que a Airbus baseia sua estratégia de médio e longo prazo, é um modelo de logística centrado em hubs globais servidos por aviões de grande porte (daí sua aposta no Airbus A-380) conectados por aviões regionais de pequeno porte (de 90-100 assentos); o segundo modelo logístico, no qual apostam Boeing, Bombardier, Embraer, COMAC, Sukhoi e Mitsubishi, prevê uma rede de voos diretos entre cidades servidas por aviões regionais de médio porte (100120 assentos). O mercado de jatos regionais crescerá fortemente nas próximas décadas. Segundo projeções da Boeing (Boeing 2011), dois terços da demanda por aviões serão por aviões pequenos e médios, basicamente jatos regionais; Bombardier (CSeries) e Embraer (ERJs) já têm produtos nessa faixa, assim como Boeing (737) e Airbus (A320) também atuam nessa categoria; China, Rússia e Japão estão tentando entrar nesse segmento. A competição no setor aeronáutico, portanto, vai se acirrar fortemente já no curto prazo, tendência que deve se manter e se aprofundar nas próximas duas décadas. 
Antes de examinar as estratégias de catch-up no setor aeronáutico de Brasil, Japão, China e Rússia, discutirei brevemente os casos de Argentina e Indonésia naquilo que eles têm de exemplar em seus fracassos em realizar o catch-up.

\section{Duas tentativas - malogradas - de catch-up do setor aeronáutico: Argentina e Indonésia}

A produção de aviões na Argentina teve início em 1927, com a Fabrica Militar de Aviones (FMA). Primeiro, ela produziu sob licença modelos das fabricantes inglesas Avro e Bristol, da alemã Focke-Wulf e da francesa Dewoitine e, em seguida, passou a projetar e fabricar seu primeiro avião, o biplano AE C-1 Triplaza, em 1931. Produziu motores localmente, também sob licença de empresas como a francesa LorraineDietrich, a norte-americana Wright e a alemã Siemens (Niosi 2009; Vértesy e Szirmai 2010).

Durante e após a II Guerra Mundial, a Argentina adotou a estratégia de atrair engenheiros aeronáuticos estrangeiros, em especial alemães, para liderar o desenvolvimento de projetos de aviões nacionais. À época, a FMA foi reorganizada, passando a se chamar Instituto Aerotécnico e exercendo funções de pesquisa e desenvolvimento, projeto, fabricação e manutenção de aviões.

Apesar do acúmulo de conhecimento de projeto e fabricação de aviões antes da II Guerra Mundial, o setor aeronáutico argentino nunca decolou. A principal razão foi o caráter exclusivamente militar que sempre perpassou e orientou o projeto de desenvolvimento. Considerações de segurança nacional e de domínio tecnológico integral de projeto, bem como produção de aviões e componentes aeronáuticos excluíram preocupações referentes à viabilidade econômica e comercial. O setor aeronáutico argentino era altamente dependente de encomendas governamentais, incapazes de gerar economias de escala que viabilizassem a produção e desenvolvimento de aviões pela Argentina no médio e longo prazo. Além disso, no ambiente político e econômico da Argentina dos anos 1940 até começo dos 1980, o setor mostrou-se extremamente vulnerável à combinação de instabilidade política e institucional, com os altos e baixos da economia argentina e mundial; mais de um projeto parou pela metade, e a falta de visão estratégica fez com que arroubos de 
desenvolvimento tecnológico e produtivo local como o Pulqui II terminassem quase sempre com o encerramento do projeto em fase adiantada e com a substituição do desenvolvimento e produção autóctones pela compra de aviões estrangeiros, como os caças F-86 Sabre dos Estados Unidos, adquiridos no lugar Pulqui II (cf. Vertesy e Szirmai 2010).

A segunda razão do insucesso do setor aeronáutico argentino deveu-se à ausência de um sistema de inovação composto por empresas, universidades e institutos de pesquisa capazes de complementar os esforços uns dos outros de modo a criar sinergias que levassem a um ambiente de pesquisa, inovação e comercialização favoráveis ao seu desenvolvimento no médio e longo prazo.

Vertesy e Szirmai (2010) resumem assim as principais deficiências do sistema de inovação do setor aeronáutico argentino: a falta de empresas privadas capazes de introduzir considerações de ordem comercial, reduzindo assim seu caráter militar e criando incentivos de mercado para inovação e aumento da competitividade; subinvestimento; sua base tecnológica deficiente e incapaz de acompanhar os desenvolvimentos tecnológicos sem se distanciar demasiadamente da fronteira tecnológica aeronáutica; e a falta de mão de obra especializada.

O setor aeronáutico argentino jamais conseguiu comercializar seus produtos, fossem eles bons ou ruins. Sem os incentivos para inovar e comercializar, o setor perdeu participação no mercado nacional de aviões e jamais atingiu a escala de produção capaz de gerar retorno sobre as vultosas somas de capital investidas no seu desenvolvimento. Por volta de 1950, malgrado seu rápido desenvolvimento inicial antes da II Guerra Mundial, o setor estava em crise, e já na década seguinte seu domínio tecnológico em projeto e produção de aviões estava completamente defasado em relação à fronteira tecnológica (Vertesy e Szirmai 2010). Segundo Vertesy e Szirmai 2010, “A radical transition would have been required, but instead attempts were made to sustain the industry without major institutional changes. The industry and innovation system were still emerging and lacked important actors, including private firms, education and training institutes, but most importantly, a development strategy combining industrial, science and technology and education policies. It follows that both the size (lack of technology and financial inputs) and the innovative performance (very few new designs created) of the system decreased" (p. 53). 
As tentativas posteriores de dar novo impulso à produção esbarraram nos mesmos problemas: baixa capacidade tecnológica, distanciamento crescente da fronteira tecnológica do setor e insucesso na comercialização de seus produtos. A incapacidade de alterar radicalmente essa situação impediu que fosse feita a transição da fase de indústria infante em processo de aprendizagem e aquisição dos conhecimentos necessários para produzir e projetar aviões e componentes por conta própria para uma situação em que fosse capaz de sustentar índices de inovação, domínio tecnológico e competitividade comercial próximos àqueles de empresas líderes. Nesse ponto, nem a tentativa interrompida no meio do projeto por falta de investimentos argentinos de desenvolvimento conjunto de um avião regional entre FMA e Embraer, o EMB/CBA123 Vector, nem a privatização da empresa argentina em 1995, comprada pela norteamericana Lockheed Martin, foram suficientes para impedir que o setor regredisse de vez.

Em 2009, o governo de Cristina Kirchner nacionalizou a FMA, trocando seu nome para Fabrica Argentina de Aviones (FAdeA) e devolvendo o controle aos militares por meio do Ministério da Defesa. Além disso, a Argentina também se viu presa a uma estrutura altamente verticalizada, em um momento em que a produção aeronáutica mundial fazia uma transição muito rápida em direção a desverticalização das empresas líderes e outsourcing para empresas e países com custos de produção mais baixos. O país perdeu a chance. Não havia como, a essa altura, modernizar o setor aeronáutico argentino e aproximá-lo dos níveis de competitividade, inovação e domínio tecnológico dos outros países.

O setor aeronáutico da Argentina esteve diversas vezes bastante próximo da fronteira tecnoprodutiva, mas nunca conseguiu sustentar essa posição. A Argentina não logrou viabilizar-se produtiva, econômica e comercialmente: não acumulou conhecimentos e tecnologias de projeto e produção de aviões; não garantiu recursos, públicos ou privados, para seu desenvolvimento contínuo; e não atingiu escala de produção e experiência em comercialização de aviões que dessem ao setor aeronáutico argentino fôlego para se manter nas proximidades da fronteira tecnoprodutiva do setor.

Já a tentativa de desenvolver um setor aeronáutico na Indonésia é, comparada à história do setor na Argentina, bastante recente. Começou em 1976, por iniciativa do engenheiro aeronáutico Bacharuddin Jusuf Habibie. Figura interessantíssima, espécie de empresário 
schumpeteriano em uma economia predominantemente estatal, B. J. Habibie fez seu doutorado em engenharia aeronáutica na Alemanha. Lá trabalhou por mais de dez anos na empresa aeronáutica Messerschmitt-Boelkow-Blohm (MBB), hoje parte da EADS, voltando para a Indonésia em princípios dos anos 1970 com a missão expressa de liderar a criação de uma empresa aeronáutica indonésia, a Industri Pesawat Terbang Nusantara (IPTN), depois renomeada Indonesian Aerospace (Vertesy e Szirmai 2010).

Antes da fundação da IPTN, o governo da Indonésia já vinha criando uma série de instituições dedicadas a apoiar o desenvolvimento do setor aeronáutico indonésio, como a Preparatory Agency for Aviation Industry (LAPIP), de 1960, o National Council for Aeronautics and Space (DEPANRI), de 1962, e o National Aeronautics and Space Institute (LAPAN), de 1963. Um programa de bolsas para estudos de engenharia aeronáutica na Europa e nos EUA foi criado em 1958 para formar engenheiros para o setor; a Indonésia, no entanto, nunca chegou a desenvolver uma instituição especializada em formar engenheiros aeronáuticos em número e qualidade suficientes uma das principais deficiências dos setores aeronáuticos indonésio e argentino, em claro contraste com o caso brasileiro, que contou desde cedo com o ITA. Após a fundação da IPTN, em 1976, foram criados também o Center for Science and Technology Development (PUSPIPTEK) e a Agency for Assessment and Application of Technology (BPPT), instituições destinadas a suprir a falta de uma base de ciência e tecnologia na nascente indústria indonésia.

Quando B. J. Habibie deu início, a convite do presidente Suharto, ao desenvolvimento do moderno setor aeronáutico indonésio - assumindo primeiro a função de assessor de Suharto para assuntos de tecnologia, em 1974, e depois de Ministro da Tecnologia e Pesquisa, em 1978, além de diretor da Agency for Strategic Industries (BPIS) -, ele formulou uma estratégia de desenvolvimento em quatro fases: aquisição de tecnologia básica por transferência tecnológica pela produção sob licença de aviões de OEMs estrangeiras; integração da tecnologia adquirida aos processos de projeto e produção de aviões nacionais; desenvolvimento avançado das tecnologias previamente dominadas e incorporação em produtos do setor aeronáutico nacional; e construção de um setor de pesquisa e desenvolvimento de grande escala responsável pelo desenvolvimento não apenas de tecnologias para o setor aeronáutico como também de tecnologias genéricas de aplicação em outros setores (Vertesy e Szirmai 2010). B.J. Habibie formulou uma estratégia de catch-up que deveria idealmente gerar spillovers de conhecimentos e 
tecnologias para o desenvolvimento de outros setores industriais intensivos em tecnologia.

Ao contrário da Argentina, à Indonésia não faltou visão estratégica de longo prazo para o setor, clareza da necessidade de produzir aviões e componentes viáveis comercialmente e consciência da necessidade de reduzir a distância do setor aeronáutico indonésio da fronteira tecnológica do setor no resto do mundo. A Indonésia contava com uma estratégia de catch-up, um líder com visão e conhecimento capaz de executar essa estratégia e grandes volumes de capital, naquele momento abundante em decorrência da exploração de suas vastas reservas de petróleo e gás. Diga-se de passagem, aliás, que estratégias similares de catch-up tecnológico financiadas pelas rendas do petróleo e gás foram formuladas e implementadas em outros setores da economia indonésia, como construção naval, telecomunicações, energia nuclear e indústria automotiva (Vertesy e Szirmai 2010). No entanto, pelo menos no que diz respeito ao setor aeronáutico, o resultado final ficou muito aquém do que desejado.

O mais importante contrato de transferência de tecnologia do nascente setor aeronáutico indonésio foi o estabelecido com a espanhola Construcciones Aeronauticas S. A., primeiro para produção do C-212 Aviocar (turboélice de 19 lugares) sob contrato de licenciamento, em 1975, e depois para o desenvolvimento e produção conjunta do CN235 (biturboélice de 38-44 lugares), no ano de 1979. Este passo consistiu na passagem da primeira para a segunda fase da estratégia formulada por B. J. Habibie; as dificuldades começaram a surgir justamente nesse período de transição entre as duas primeiras fases da estratégia.

O acordo entre a IPTN e a CASA criou uma empresa conjunta com participações de 50/50 e previa a transferência de tecnologia e desenvolvimento conjunto do avião e de seus subsistemas. A parceria com a CASA foi muito importante para a IPTN e o setor aeronáutico indonésio de modo geral, uma vez que permitiu a qualificação das empresas em projetos aeronáuticos avançados. No entanto, foi justamente a forma em que se deu a divisão do trabalho entre as empresas que levou ao fracasso do projeto e da tentativa de desenvolver o setor aeronáutico indonésio dotando-o de uma OEM competitiva internacionalmente e tecnologicamente avançada.

O processo de certificação de aviões é um dos pontos críticos dos projetos aeronáuticos. Além das rigorosas exigências técnicas para garantir a qualidade, confiabilidade e 
segurança dos aviões e de seus subsistemas, a certificação também é afetada por relações de comércio exterior, acordos bilaterais e questões geopolíticas de modo geral. Uma vez que os produtos, para receberem certificação para operar em um país, precisam passar pelas respectivas agências nacionais de certificação, o fracasso na aprovação por uma agência nacional ou a inexistência de acordos bilaterais regulando o processo de certificação entre dois países pode por a perder décadas de trabalho dedicado ao desenvolvimento de um projeto. Esse fator foi determinante para o insucesso do CN-235 e mostra claramente a importância do arranjo institucional e da falta que uma instituição faz - nesse caso, a falta de uma agência nacional de certificação de aviação civil independente.

Quando submetido ao processo de certificação na agência norte-americana de aviação civil, apenas o CN-235 fabricado pela espanhola CASA foi aprovado, uma vez que Estados Unidos e Indonésia não possuíam tratados bilaterais que garantissem a validade dos processos de certificação indonésios. A agência norte-americana, a Federal Aviation Authority (FAA), alegava que a sua contraparte indonésia não era independente. Para contornar a situação, a IPTN submeteu seu CN-235 ao processo de certificação da agência britânica de aviação civil (British Aviation Authority), no que teve sucesso. Contudo, o estrago já estava feito. Potenciais clientes passaram a desconfiar do CN-235 da IPTN, dando preferência ao CN-235 de fabricação espanhola. O modelo da IPTN nunca alcançou grande sucesso comercial. CASA e IPTN terminaram por vender seus aparelhos a mercados muito distintos, com a espanhola concentrando suas vendas na Europa e a IPTN na Ásia e Oriente Médio.

O pouco sucesso comercial do $\mathrm{CN}-235$ não significa que o projeto de desenvolvimento conjunto não tenha sido, do ponto de vista da estratégia em quatro fases pensada por B. J. Habibie, um relativo sucesso tecnológico e industrial. O setor aeronáutico indonésio havia se mostrado capaz de projetar, construir e certificar um avião que, se não foi um sucesso de vendas, mostrou-se comercialmente viável. A transferência de tecnologia, o aprendizado pela prática e a experiência em certificação e comercialização deram a J. B. Habibie segurança para avançar à terceira fase de seu plano: desenvolvimento avançado das tecnologias previamente dominadas e incorporação em produtos do setor aeronáutico nacional. Em 1989, na feira aérea de Paris, B. J. Habibie anunciou o lançamento do N-250, turboélice regional de 50 lugares que incorporaria várias inovações do setor aeronáutico, como a tecnologia fly-by-wire. 
A recepção ao projeto não poderia ter sido melhor. A IPTN estabeleceu acordos de cooperação tecnológica com fornecedores norte-americanos e europeus. Mais importante ainda, fez planos de criar uma fábrica para montagem dos N-250 nos Estados Unidos, com investidores indonésios e norte-americanos, estando diretamente sob o ambiente de regulação e certificação dos EUA e podendo, portanto, submeter-se à certificação pela FAA. A British Aerospace manifestou interesse em produzir o N-250 sob licença no Reino Unido.

Contudo, do ponto de vista comercial, o N-250 foi um fracasso completo. Enfrentando problemas com o orçamento do projeto, apenas dois protótipos chegaram a ser construídos, nenhum tendo voado mais de 850 horas, metade do necessário para a certificação. Após a crise financeira asiática de 1997-1998 o projeto do N-250 foi encerrado (Vertesy e Szirmai 2010).

Vertesy e Szirmai (2010) avaliam assim os motivos do fracasso da estratégia indonésia de desenvolvimento do setor aeronáutico: "The unsuccessful commercial launch of the $\mathrm{N}-250$, an apparently technologically innovative plane, points in the direction of systemic failures in the Indonesian aerospace innovation system. First of all, the idea of 'going it alone' was in sharp contrast with the strategy of other foreign producers as well as airlines' expectations (...) Still, IPTN took the risk of going against the trend (...) The reason such an endeavor could go ahead was due to the very nature of the innovation system. It was not a system aiming at greater market success by commercial and technological interactions, but more a rather expensive public experiment to prove Habibie's theory that technological capabilities can be acquired through 'learning-bydoing’. (Vertesy e Szirmai, 2010: p. 74-75).

Em linha com a avaliação de Vertesy e Szirmai (2010), Niosi (2009), comparando os casos de catch-up da Argentina e da Indonésia, destaca os seguintes pontos: "Indonesia, like Argentina, had obtained production technology, but not $R \& D$ capabilities (...) required to innovate in the many different components of the aircraft, including materials, engines, avionics, communication equipment and the like. (...) Successful catching up requires more than simply importing engineers or scientists, and the transfer of machinery and equipment. It requires domestic institutions able to provide a continuous flow of human capital, research and development funds, and technology. Neither Argentina nor Indonesia provided such regular flow of resources to their 
fledging aircraft industries. (...) Converting design into production was not easy. Neither country sought to import production technology and to build a research infrastructure (i.e. wind tunnels) to conduct aviation $R \& D$. The national system of innovation, in sum, was in both cases absent or, at best, embryonic". (p. 22-23).

Esses são alguns dos elementos que explicam por que estratégias de catch-up aeronáutico fracassam: ausência de inteligência comercial e de mercado; arranjo institucional desprovido de instituições de formação de recursos humanos, pesquisa e desenvolvimento e certificação, instituições sem as quais não se logra a sustentabilidade a médio e longo prazo do setor; e empresas que persigam o lucro - sejam elas privadas ou públicas - e incorporem no mais alto grau preocupações com inovação e competitividade em nível internacional.

Nem tudo, no entanto, foram fracassos nas tentativas de catch-up do setor aeronáutico nesses dois países. A Argentina logrou, ainda que por breves períodos, reduzir a distância de seu setor aeronáutico da fronteira tecnológica; a ausência de um componente comercial na estratégia argentina foi o principal fator responsável pelas sucessivas interrupções e consequente aumento da distância da fronteira tecnológica do setor argentino. A Indonésia viveu dias de glória aeronáutica ainda mais recentemente do que a Argentina. Foi uma desafiante que por momentos afigurou-se bastante promissora. A dificuldade de transitar de um estágio de associação e transferência subordinada de tecnologia para uma situação de autonomia tecnológica e produtiva cobrou, no entanto, um preço alto, interrompendo duas décadas de esforços nacionais para o desenvolvimento econômico, tecnológico e industrial do país. Sucessos, no entanto, insustentáveis no longo prazo pelas razões que discutimos: deficiências institucionais, escassez de mão de obra especializada e incapacidade de viabilizar comercialmente suas respectivas empresas aeronáuticas nacionais, fatores responsáveis, ao fim e ao cabo, pelo fracasso dessas estratégias de catch-up. Os mesmos fatores, aliás, mas com sinal invertido, que explicam o sucesso da estratégia de catch-up do Brasil. 


\section{Capítulo 3: Momentos iniciais da estratégia de catch-up do setor aeronáutico do Brasil}

Neste capítulo, reconstruirei a estratégia de catch-up do setor aeronáutico do Brasil, com especial atenção ao papel do Estado e das políticas públicas voltadas para o aumento da capacidade absortiva do sistema tecnoprodutivo aeronáutico. A análise do caso brasileiro permitirá traçar um quadro de referência das estratégias de catch-up de modo a aumentar a compreensão sobre as políticas de desenvolvimento tecnológico e inovação no setor aeronáutico e comparar a experiência brasileira com as estratégias atuais de catch-up aeronáutico de Rússia, Japão e China.

O Brasil é o mais bem-sucedido caso de catch-up no setor aeronáutico nos últimos 50 anos; mais bem-sucedido e longevo, aliás, e nisto reside uma das dificuldades e limitações das estratégias de catch-up: a fronteira tecnológico-competitiva avança constantemente. Uma estratégia bem-sucedida de catch-up é, por definição, aquela que não perde eficácia ao longo do tempo. Por isso, a sustentabilidade da estratégia é um dos pontos fundamentais na avaliação dos resultados das diferentes estratégias de catch -up. Nesse como em outros pontos, o Brasil obteve sucesso, ao contrário de muitos outros países.

Se separarmos as tentativas de desenvolvimento de setores aeronáuticos nacionais em três grupos segundo seus resultados: 1) fracasso, 2) em andamento, portanto por ora indefinido, e 3) sucesso, na primeira categoria estariam, entre outros, Argentina, Indonésia e a primeira tentativa do Japão (décadas de 1950-1970); na segunda, China, Rússia e a atual tentativa do Japão; e na terceira, sozinho, o Brasil. O Brasil foi o único país a conseguir superar as barreiras de entrada econômicas e tecnoprodutivas do setor aeronáutico mundial, integrando hoje um duplo duopólio formado por Boeing-Airbus e Bombardier-Embraer. O mais recente capítulo dessa história, a entrada agressiva e pioneira da Embraer no mercado de jatos regionais, se deu em um momento de profunda reestruturação patrimonial do setor, com várias fusões e aquisições e muitas falências de tradicionais empresas norte-americanas e europeias (por exemplo, a compra da McDonnell Douglas pela Boeing e a falência da Fokker, ambas em 1996), o que só aumenta o mérito da Embraer e do setor aeronáutico brasileiro - e do sistema setorial de inovação que lhe dá suporte - como um todo. 
O sucesso da estratégia de catch-up do setor aeronáutico brasileiro e de sua empresa líder, a Embraer, deve-se a fatores bastante diversos: tecnológicos, políticos, institucionais, econômicos e empresariais. E é justamente a complementaridade desse sistema tecnoprodutivo que explica o sucesso do setor aeronáutico brasileiro $e$ da empresa líder Embraer. A Embraer é apenas um dos componentes, ainda que o mais importante, do sistema tecnoprodutivo aeronáutico brasileiro; a explicação do sucesso da estratégia como um todo e da empresa líder em particular não se resume, contudo, à Embraer.

\section{Instituições, políticas públicas e capacidade absortiva: a formação do sistema tecnoprodutivo do setor aeronáutico brasileiro}

A história do setor aeronáutico brasileiro pode ser dividida em dois momentos: antes da criação do complexo tecnológico-industrial de São José dos Campos e depois, a partir de 1946, ano de criação do Comando-Geral de Tecnologia Aeroespacial (CTA) rebatizado em 2009 como Departamento de Ciência e Tecnologia Aeroespacial (DCTA). Ponto de inflexão, não começo de tudo, uma vez que antes de 1945 várias empresas em diferentes estados vinham projetando e produzindo aviões no Brasil, como

a Companhia Nacional de Navegação Aérea (CNNA), a Fábrica do Galeão e a Companhia Aeronáutica Paulista (CPA), além da Sociedade Construtora Neiva, fundada em 1949 e incorporada pela Embraer na década de 1980. Segundo Miranda (2007), "nessas primeiras experiências de fabricação de aviões no Brasil foi grande a participação do Estado, viabilizando treinamento de engenheiros brasileiros no exterior, adquirindo licenças para produção local e mantendo um centro de pesquisas tecnológicas (IPT), o que ajudou a criar mão de obra especializada para o setor. Tais ações políticas visavam claramente a obter o domínio da tecnologia aeronáutica. Todavia, não foram suficientes para que as empresas se mantivessem ativas por longo tempo" (p. 37; grifos meus).

Apenas no início da década de 1940 o Estado brasileiro passou a dedicar maior atenção ao setor aeronáutico. Em 20 de janeiro de 1941, o governo de Getúlio Vargas cria o Ministério da Aeronáutica (MAER). O texto do decreto justifica a criação do ministério nos seguintes termos: "Considerando o desenvolvimento alcançado pela aviação 
nacional e a necessidade de ampliar as suas atividades e coordená-las técnica e economicamente; considerando que a sua eficiência e aparelhamento são decisivos para o progresso e segurança nacionais; considerando, finalmente, que sob uma orientação única esses objetivos podem ser atingidos de modo mais rápido e com menor dispêndio", decretava-se o seguinte: "Art. $1^{\circ}$ - Fica criada uma Secretaria de Estado com a denominação de Ministério da Aeronáutica; Art. $2^{\circ}$ - Ao Ministério da Aeronáutica compete o estudo e despacho de todos os assuntos relativos à atividade da aviação nacional, dirigindo-a técnica e administrativamente; Art. $4^{\circ}$ - Ficarão pertencendo ao novo Ministério, constituído inicialmente com os elementos existentes nas aeronáuticas do Exército e da Marinha e no Departamento de Aeronáutica Civil, os estabelecimentos, instituições e repartições públicas que se proponham à realização de estudos, serviços ou trabalhos especificados no art. $2^{\circ}(. .$.$) ; Art. 5^{\circ}$ - As instituições, repartições, órgãos e serviços referentes à atividade da aviação nacional, atualmente subordinados aos Ministérios da Guerra, da Marinha e da Viação e Obras Públicas, passam, a contar da publicação do presente decreto-lei, à jurisdição do Ministério da Aeronáutica" (grifos meus).

A criação do Ministério da Aeronáutica marca uma nova fase do setor aeronáutico brasileiro e atesta um compromisso político e institucional que se prolongaria por toda a metade do século XX: o status estratégico que o Estado passou a atribuir ao setor aeronáutico. A criação do MAER pretendia enfrentar um problema muito conhecido dos estudos institucionalistas: as dificuldades de coordenação entre diferentes instituições e burocracias. O MAER tinha como missão primeira centralizar e coordenar todas as instituições do setor aeronáutico e orientar os esforços de desenvolvimento do setor aeronáutico brasileiro, tendo assumido a coordenação de atividades e instituições até então dispersas pelos ministérios da Guerra, da Marinha e da Viação e Obras Públicas, pelo Departamento de Aeronáutica Civil e pelas aviações militares das armas do Exército e Marinha.

O passo crítico no processo de constituição de um sistema tecnoprodutivo aeronáutico brasileiro foi dado em 1946 com a criação do Centro Técnico de Aeronáutica, a cargo da Comissão de Organização do Centro Técnico de Aeronáutica (COCTA), dirigida pelo então Coronel-Aviador (Engenheiro) Casimiro Montenegro Filho, demiurgo

\footnotetext{
${ }^{1}$ Decreto-Lei N ${ }^{\mathrm{o}} 2.961$, de 20 de janeiro de 1941.
} 
daqueles primeiros tempos do sistema tecnoprodutivo aeronáutico nacional. Um ano antes o Coronel-Aviador Casimiro Montenegro Filho havia iniciado contatos com o professor Richard Habert Smith, do Departamento de Engenharia Aeronáutica do Massachusetts Institute of Technology (MIT), outra figura decisiva daqueles momentos definidores, sondando-o sobre sua disposição de contribuir com a criação das instituições do sistema tecnoprodutivo aeronáutico brasileiro (Smith 1945).

Vale a pena enfrentar uma questão da maior relevância teórica e política para o problema mais geral desta tese, que diz respeito à intencionalidade - ou não - dos atores envolvidos no processo de construção do sistema tecnoprodutivo aeronáutico brasileiro. Questão, aliás, para lá de complicada: é possível atribuir aos atores sociais - indivíduos e instituições - envolvidos no processo de construção do sistema tecnoprodutivo aeronáutico brasileiro intenção, ou será que o resultado final foi fruto de uma feliz conjunção de circunstâncias e acasos? É possível falar em agência - ação social orientada à transformação das estruturas sociais -, ou devemos nos ater a explicações que dão ênfase à reprodução de dinâmicas autônomas e altamente estáveis, ou pouco imutáveis ao longo do tempo, de indivíduos, burocracias e instituições? Estamos, enfim, diante de atores sociais reproduzindo um roteiro mais ou menos conhecido do qual são herdeiros por força das circunstâncias históricas e independentemente de suas vontades, ou estaríamos, pelo contrário, diante de agentes sociais que, malgrado herdarem um roteiro - instituições, burocracias, regras, arranjos de força, estrutura produtiva, nível científico e tecnológico do país -, escolhem reescrevê-lo a seu modo, retomando aqui e ali as palavras e gestos, maneirismos e temas inescapáveis dos quais não se pode sem mais abrir mão - afinal, não se faz nada do zero -, mas sempre que possível acrescentando novas ideias, personagens, tramas, palavras e até mesmo frases inteiras a um roteiro que, ao fim desse processo, acaba sendo muito diferente?

Não fosse o ponto de partida desta tese o exame comparado de estratégias de catch-up tecnoprodutivo de diferentes países, seria possível ignorar a questão da intencionalidade dos atores sociais que lideram o processo de catch-up; o resultado final, o sucesso do processo de catch-up de um determinado setor tecnoprodutivo, bastaria para justificar o interesse pelo tema, sem que para isso fosse preciso recorrer à ideia de estratégia de catch-up, isto é, ação concertada em que desde o início há um objetivo sendo perseguido: constituir um sistema tecnoprodutivo e realizar o catch-up. A ideia de estratégia, portanto, a princípio complica a questão, exigindo a apresentação de indícios 
muito convincentes de que o que se passou no caso da construção do sistema tecnoprodutivo aeronáutico brasileiro não se deu por acaso, por uma feliz e rara conjunção de fatores, mas foi um objetivo perseguido desde o início.

Em 26 de setembro de 1945, o professor Robert H. Smith apresentou no auditório do Ministério da Educação no Rio de Janeiro, a convite do Instituto Brasileiro de Aeronáutica, conferência intitulada "Brasil, futura potência aérea". Robert H. Smith teve papel central nos primeiros momentos do processo de construção do sistema tecnoprodutivo aeronáutico brasileiro: além de contribuir com ideias sobre o CTA e suas instituições associadas, foi o primeiro reitor do ITA, cargo no qual pode aplicar e transmitir grande parte do conhecimento e experiência adquiridos no Departamento de Engenharia Aeronáutica do MIT, do qual foi chefe.

A conferência do professor Robert H. Smith começou por situar a tentativa brasileira de construir um setor tecnoprodutivo aeronáutico no contexto do imediato pós-guerra, em especial as implicações da derrota de Alemanha, Itália e Japão, potências industriais e aeronáuticas antes da Segunda Guerra cuja estrutura produtiva não só foi inteiramente arrasada como também, por imposição das potências vencedoras, foram obrigadas a suspender qualquer desenvolvimento de tecnologias de aplicação militar direta ou indireta (tecnologias duais), entre as quais, evidentemente, a aeronáutica. Essa circunstância daria ao Brasil a oportunidade de desenvolver seu sistema tecnoprodutivo aeronáutico em um mercado mundial que havia sido extirpado de três tradicionais e fortes competidores. Mas se a saída de cena de fortes competidores - saída não por falta de competitividade ou obsolescência tecnológica, mas por manu militaris -, era conveniente para as pretensões do Brasil de desenvolver sua própria indústria aeronáutica, ainda restavam no páreo outros fortíssimos competidores: Estados Unidos, Inglaterra, França, Holanda e Canadá.

É nesse ponto que a argumentação de Smith esboça o que mais tarde Abramovitz (1986) apontaria como um dos mecanismos que favorecem o catch-up tecnológico: o fato de o país retardatário poder tirar proveito dos avanços estabelecidos pelos países pioneiros. Depois de afirmar que os vinte anos seguintes seriam de valor estratégico para o setor aeronáutico brasileiro, Smith argumenta que vantagens do atraso e catch-up tecnológico se combinavam para favorecer o projeto brasileiro, naquele momento ainda em sua primeira infância: "Para outros países, como a França e os EUA, por exemplo, essa será 
apenas a terceira fase de seu desenvolvimento aéreo. Em compensação, os países que tiveram seu desenvolvimento aéreo na primeira e na segunda fase levam as seguintes desvantagens em relação aos que se desenvolverem na terceira fase (como poderia, e efetivamente veio a ser, o caso do Brasil): a) os laboratórios não são de construção muito recente, não correspondendo, portanto, às necessidades da terceira fase que ora se inicia; b) grande parte do equipamento mais dispendioso, principalmente os túneis aerodinâmicos, tornar-se-á, provavelmente, obsoleto; c) as indústrias aeronáuticas, por maior que sejam, estão dispersas, por razões estratégicas, tornando muito elevado o custo dessa produção pós-guerra" (Smith 1945). As ideias do professor Smith lembram a argumentação de Abramovitz (1986) sobre a possibilidade de um país retardatário "queimar etapas" de desenvolvimento tecnoprodutivo, uma vez que essas picadas já tenham sido abertas pelos países que primeiro desenvolveram aquelas tecnologias.

Das desvantagens que incidem sobre os países tecnoprodutivamente mais avançados derivam-se vantagens inerentes ao próprio país tecnoprodutivamente retardatário, que para Smith são as seguintes: "Há, assim, vantagens e bem importantes para uma nova potência aérea, como o Brasil, que se candidata ao maior desenvolvimento aéreo somente no início da terceira fase: a) todos os laboratórios nacionais de aeronáutica podem ser construídos e concentrados num único grande centro de pesquisas e treinamento; b) sua indústria aeronáutica pode ter a liberdade de escolher o local mais apropriado para suas instalações; c) suas linhas aéreas podem ser equipadas com tipos nacionais de aviões modernos, logo que for possível produzir seus próprios modelos, projetados de acordo com suas necessidades" (Smith 1945, grifos meus).

Isso tudo, no entanto, não basta, acrescenta Smith. É preciso desenvolver internamente e no mais alto grau a autonomia e independência científica e tecnológica que dará base ao desenvolvimento avançado do sistema tecnoprodutivo aeronáutico nacional: "Como nenhum país poderá possuir indústria e comércio equivalentes aos de outras mais adiantadas, enquanto for subordinado à engenharia e às outras profissões correlatas dessas nações, o Brasil só poderá tornar-se independente das outras nações competidoras no comércio aéreo pela criação de escolas superiores nos campos da engenharia aeronáutica, aerologia, comércio aéreo e fabricação de aviões, e pela instalação, para essas especialidades, de laboratórios próprios de alto padrão científico" (Smith 1945). 
A esses primeiros indícios da intencionalidade dos atores envolvidos na construção do sistema tecnoprodutivo aeronáutico brasileiro, que ademais corroboram a caracterização do processo de desenvolvimento tecnoprodutivo aeronáutico como estratégia de catchup, acrescento outros, que dizem respeito à construção das instituições do sistema tecnoprodutivo aeronáutico brasileiro. O Coronel-Aviador Casimiro Montenegro Filho é o grande protagonista desses primeiros vinte anos do setor aeronáutico brasileiro, tendo cabido a ele dirigir a Comissão de Organização do Centro Técnico de Aeronáutica (COCTA), grupo que desenharia a primeira fase da estratégia de construção do sistema tecnoprodutivo aeronáutico brasileiro. Os estudos do COCTA elegeram a cidade de São José dos Campos, no estado de São Paulo, como a localização mais propícia - do ponto de vista econômico, climatológico e topográfico, quesitos importantes para a produção e teste de aeronaves - para sede do parque científico, tecnológico e industrial aeronáutico brasileiro em gestação.

O Centro Técnico da Aeronáutica foi a instituição encarregada de dirigir os esforços para a construção do sistema tecnoprodutivo aeronáutico brasileiro, coordenando as outras instituições que viriam a ser criadas para dar suporte ao sistema. O próprio CTA, no entanto, só estaria formalmente organizado em $1^{\circ}$ de janeiro de 1954 , em instalações projetadas por Oscar Niemeyer a convite do próprio Casimiro Montenegro Filho, que dirigiria o centro de 1954 a 1961 e de 1964 a 1965. O Decreto 34.701 de 26 de novembro de 1953, do presidente Getúlio Vargas, em face do adiantado das obras do CTA, que se achavam "em estado de desenvolvimento que permite sua plena utilização; e considerando estar, consequentemente concluída a missão atribuída à Comissão de Organização do Centro Técnico de Aeronáutica",2, assim definia as atribuições do Centro Técnico de Aeronáutica: “Art. 20 - O Centro Técnico de Aeronáutica, instituição cientifica e técnica de pesquisa e de ensino superior, tem por finalidade: ministrar o ensino de grau universitário correspondente às atividades de interesse para a aviação nacional e, em particular, para a Força Aérea Brasileira; promover, estimular, conduzir e executar a investigação e a aplicação científica e técnica, visando o progresso da aviação brasileira; cooperar com a indústria do país, para orientá-la em seu aparelhamento e aperfeiçoamento, visando atender às necessidades da Aeronáutica; colaborar com as organizações científicas, técnicas e de ensino do país e de outras

\footnotetext{
${ }^{2}$ Decreto No 34.701, de 26 de novembro de 1953.
} 


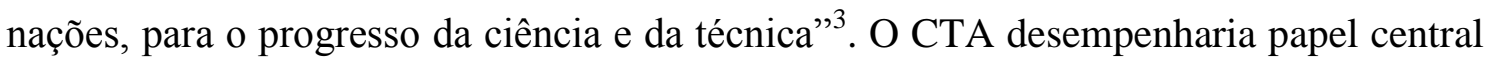
na coordenação dos esforços despendidos para a constituição do setor tecnoprodutivo aeronáutico brasileiro, servindo como ponto de referência para todos os demais atores envolvidos.

Do CTA surgiram duas instituições fundamentais para o desenvolvimento do setor aeronáutico brasileiro: o Instituto Tecnológico de Aeronáutica, cuja primeira turma formou-se em 1950, e o Instituto de Pesquisa e Desenvolvimento (IPD), de 1954, aquele dedicado à formação de engenheiros aeronáuticos em nível de graduação e pósgraduação, este ao desenvolvimento de projetos aeronáuticos com tecnologia nacional. Nacional talvez não seja a palavra mais precisa se levarmos em conta o papel central de especialistas estrangeiros nesses primeiros anos em que se deu o estabelecimento do setor aeronáutico brasileiro, como no caso já aludido do professor norte-americano Richard H. Smith, ex-chefe do Departamento de Engenharia Aeronáutica do MIT, envolvido na estruturação do CTA e primeiro reitor do ITA (1946-1951); do engenheiro alemão Henrich Focke, que coordenou o desenvolvimento do primeiro projeto de avião do CTA; e do engenheiro aeronáutico francês Max Holste, que integraria a equipe de desenvolvimento do Bandeirante, primeiro grande sucesso comercial da Embraer (cf. Miranda 2007).

O Instituto Técnico da Aeronáutica (ITA) de São José dos Campos assumiu o curso de engenharia aeronáutica da Escola Técnica do Exército, no Rio de Janeiro, dando início a sua primeira turma em 1946 (graduada em 1950). Seu decreto de criação (Decreto $N^{\circ}$ 27.695, de 16 de janeiro de 1950, sob a presidência de Eurico Gaspar Dutra), estabelecia que "Art. $1^{\circ}$ - Os atuais Curso de Preparação e Curso de Formação de Engenheiros de Aeronáutica ficam transformados, respectivamente, em Cursos Fundamental e Curso Profissional do Instituto Tecnológico de Aeronáutica; Art. $2^{\circ}$ - O Instituto Tecnológico de Aeronáutica (ITA), que faz parte do Centro Técnico de Aeronáutica, destina-se ao preparo e formação de engenheiros de aeronáutica; (...) Art. $4^{\circ}$ - O curso profissional do ITA se destina à formação de engenheiros de aeronáutica, nas especialidades de interesse para a aviação brasileira em geral e à Força Aérea Brasileira em particular" ${ }^{\prime 4}$. O ITA desde cedo se provou uma instituição de excelência, contando em seus quadros docentes com professores brasileiros e estrangeiros do mais elevado nível.

\footnotetext{
${ }^{3}$ Idem, grifos meus.

${ }^{4}$ Decreto No 27.695, de 16 de janeiro de 1950, grifos meus.
} 
Um dos componentes centrais de qualquer sistema tecnoprodutivo bem sucedido, a formação de pessoal altamente qualificado para desempenhar as atividades científicas e tecnológicas necessários para o desenvolvimento pleno do sistema, já estava, portanto, em pleno e satisfatório funcionamento em inícios da década de 1950.

Um sistema tecnoprodutivo não é, no entanto, constituído apenas por seu componente de formação de pessoal; é necessário que haja também instituições responsáveis por pesquisa e desenvolvimento tecnológico, e nisso, mais uma vez, o sistema tecnoprodutivo brasileiro acertou ao criar, em 1954, o Instituto de Pesquisa e Desenvolvimento (IPD), segundo instituto criado no CTA. O IPD era composto pelos Departamentos de Aeronaves (PAR), de Motores (PMO) e de Eletrônica (PEA). Dedicava-se a "ensaiar e homologar novos tipos de aeronaves produzidas no país bem como aeronaves modificadas ou alteradas $\mathrm{e}$ fornecer os certificados de tais homologações" e "ensaiar e homologar equipamentos, componentes e materiais de interesse dos órgãos da aeronáutica, por solicitação de outros órgãos do governo ou da indústria" (Centro Histórico Embraer).

No mesmo ano de criação do IPD foi fundada no Rio de Janeiro a Sociedade Construtora Aeronáutica Brasileira Neiva, transferida dois anos depois para Botucatu. A Neiva foi responsável pelo desenvolvimento de importantes projetos aeronáuticos, entre os quais o famoso avião Paulistinha, desenvolvido a partir do Paulistinha CAP-4, da Companhia Aeronáutica Paulista, e produzido até 1967. A essa altura, o CTA começava a consolidar sua posição de centro do sistema tecnoprodutivo aeronáutico brasileiro, levando a Sociedade Construtora Aeronáutica Neiva a abrir escritório em São José dos Campos, de modo a aproximar-se dos centros de formação, pesquisa e desenvolvimento aeronáutico. Em São José dos Campos foi projetado o monomotor de treinamento Universal, aproveitando a proximidade com engenheiros, técnicos e laboratórios do CTA. Nas décadas de 1960 e 1970, a Neiva passaria a colaborar cada vez mais estreitamente com o CTA e a Embraer, até ser incorporada por esta última em 1980, assumindo a fabricação de alguns aviões e componentes, caso do avião agrícola EMB200 Ipanema e dos componentes da linha Piper na década de 1990.

A importância das políticas de formação de engenheiros brasileiros em nível de pósgraduação por meio do envio de estudantes a instituições de excelência no exterior, sobretudo em universidades americanas e francesas, foi outro fator altamente relevante 
para o desenvolvimento do sistema tecnoprodutivo aeronáutico brasileiro (Miranda 2007: 38-39). O processo de qualificação de pessoal funcionou, portanto, em dupla mão: atração de engenheiros e professores do mais alto nível técnico, muitos deles profissionais experimentados na indústria com larga experiência em projetos aeronáuticos, ou professores e pesquisadores de instituições de ensino e de pesquisa de excelência mundial; e envio de brasileiros para completar sua formação em nível de pós-graduação nas melhores universidades do mundo. Esses jovens estudantes assumiriam posições de destaque no nascente sistema de formação, pesquisa, desenvolvimento, produção e inovação do setor aeronáutico brasileiro, tão logo regressassem ao Brasil.

A estratégia de qualificação de pessoal em mão dupla - atração de professores, pesquisadores e profissionais de ponta e envio de estudantes brasileiros para prosseguirem seus estudos em nível de pós-graduação no exterior - mostrou-se acertada; pode-se inclusive atribuir a essa estratégia os méritos pelos importantes avanços do sistema de formação, pesquisa, desenvolvimento, produção e inovação do setor aeronáutico brasileiro em particular e do sistema de ciência e tecnologia brasileiro em geral. Essa estratégia nasceu em primeiro lugar da necessidade, uma vez que o Brasil, nas décadas de 1940, 1950 e 1960, carecia de um sistema de pós-graduação e pesquisa nas instituições de ensino superior, tornando necessário recorrer a professores e pesquisadores estrangeiros para formar estudantes brasileiros em nível de pósgraduação e financiar os estudos de pós-graduação no exterior daqueles que viriam a formar as primeiras turmas de professores das universidades brasileiras em sua fase moderna. Mas era filha também de uma intuição muito acertada cujas consequências se fariam sentir por várias décadas: a consciência da importância da exposição do sistema de ciência e tecnologia brasileiro ao ambiente de ciência e tecnologia internacional.

A criação de centros de ensino, de pesquisa e desenvolvimento de projetos aeronáuticos (CTA, ITA e IPD) e de instituições e políticas de formação de recursos humanos para o setor aeronáutico marcaram uma profunda inflexão do setor aeronáutico brasileiro. Até a criação do CTA, do ITA e do IPD, o setor aeronáutico brasileiro era constituído basicamente por pequenas empresas públicas e privadas dedicadas a produzir aviões sob licença ou desenvolver projetos próprios para o nascente mercado de transporte aéreo nacional. O setor carecia das instituições de formação de recursos humanos especializados e de pesquisa e desenvolvimento tecnológico; as políticas para o setor, 
por sua vez, não iam muito além de uma política de financiamento público e da compra, por parte de empresas estatais de transporte aéreo, dos aviões produzidos no Brasil. A II Guerra Mundial, no entanto, tornou evidente a importância estratégica do setor aeronáutico para o Brasil, tanto em suas aplicações militares como em seu papel de instrumento de construção do Estado nacional, uma vez que o avião se mostrava o mais promissor e eficiente meio de transporte a ligar o vastíssimo território brasileiro, esparsa e desigualmente ocupado, levando o Estado a apoiar de modo resoluto o desenvolvimento do setor.

Somente a partir de 1945 é que se pode falar do setor aeronáutico brasileiro como um sistema tecnoprodutivo em construção, isto é, como um setor econômico dotado da estrutura produtiva $e$ de instituições de ciência, tecnologia e educação capazes de produzir o capital científico-tecnológico aplicável aos processos produtivos do setor aeronáutico. Em construção porque somente em 1969 seria fundada a empresa líder do sistema tecnoprodutivo aeronáutico brasileiro: a Empresa Brasileira de Aeronáutica S.A., a Embraer.

A Embraer foi criada com vistas a cumprir uma função muito específica no sistema tecnoprodutivo aeronáutico brasileiro: fabricar, para fins comerciais, os aviões projetados pelas instituições ligadas ao CTA. Consultas iniciais ao empresariado revelaram a pouca disposição destes em criar uma empresa aeronáutica, fosse pela escala de capital econômico e tecnológico requerida, fosse pelos desafios empresariais envolvidos na empreitada - vários autores apontaram os limites econômicos, gerenciais e tecnológicos do empresariado nacional, o que levou em inúmeros casos a que o Estado assumisse a tarefa (cf., entre outros, Cardoso 1963 e Evans 1980). A essa altura o IPD já tinha uma série de projetos promissores em seu portfólio: o avião agrícola EMB-200 Ipanema, o planador Urupema e o Bandeirante, que viria mais tarde a ser o primeiro grande sucesso da Embraer (Miranda 2007). Não havia, no entanto, muito que fazer com todos esses projetos, uma vez que CTA e IPD não tinham os meios - nem eram esses os fins dessas instituições - de dar aplicação produtiva e comercial a eles. A solução de criar uma empresa estatal mostrou-se, portanto, a única possível diante da reticência e mesmo impossibilidade de ver o setor privado encarregar-se por inteiro da empreitada e da necessidade de fazer o projeto de constituição de um sistema tecnoprodutivo aeronáutico brasileiro dar seu mais ousado passo: fabricar aviões tecnologicamente avançados e comercialmente competitivos. 


\section{Embraer: primeiros voos}

Projetar, construir e fazer voar um avião é, das etapas do processo de construção de um sistema tecnoprodutivo aeronáutico, apenas o primeiro desafio. O desafio seguinte, e em certo sentido mais difícil do que o primeiro, é conseguir produzir o avião em série e comercializá-lo em mercados altamente competitivos dominados por empresas tradicionais e mais avançadas tecnoprodutivamente, em geral operando a partir de países dotados de sistemas tecnoprodutivos aeronáuticos altamente desenvolvidos. Disputar espaço nesse mercado a partir de um sistema tecnoprodutivo aeronáutico construído praticamente do zero seria um desafio e tanto; coube à Embraer liderar essa empreitada, no que ela se saiu muito bem.

A Embraer foi criada pelo decreto $\mathrm{N}^{\mathrm{o}} 770$, de 19 de agosto de 1969, assinado pelo general Costa e Silva e subscrita por Antônio Delfim Neto, Márcio de Souza e Mello, Edmundo de Macedo Soares e Hélio Beltrão. O decreto previa condições extremamente favoráveis à Embraer. É razoável supor que só assim a estratégia de constituição de um sistema tecnoprodutivo aeronáutico poderia dar esse passo fundamental. $\mathrm{O}$ decreto $\mathrm{N}^{\mathrm{O}}$ 770 definia nos seguintes termos a forma e a finalidade da Embraer em seu "Capítulo I - Da constituição da Embraer: Art. $1^{\circ}$ Fica a União autorizada a constituir, vinculada ao Ministério da Aeronáutica, na forma deste Decreto-lei, uma sociedade de economia mista que se denominará Embraer- Empresa Brasileira de Aeronáutica S.A.; (...) Art. $2^{\circ}$ A Embraer terá por objeto promover o desenvolvimento da indústria aeronáutica brasileira e atividades correlatas, inclusive projetar e construir aeronaves e respectivas acessórios, componentes e equipamentos e promover ou executar atividades técnicas vinculadas à produção e manutenção do material aeronáutico, de acordo com programas e projetos aprovados pelo Poder Executivo; $\S 1^{\circ} \mathrm{A}$ Embraer recorrerá sempre que possível à execução indireta, mediante contrato desde que exista, na área iniciativa privada capacitada a desenvolver os encargos de execução; $\S 2^{\circ}$ A implantação progressiva da indústria aeronáutica observará critérios de racionalidade econômica, inclusive quanto à necessidade de assegurar escalas mínimas de produção eficientes; $§$ $3^{\circ} \mathrm{O}$ Ministério da Aeronáutica e quaisquer órgãos da administração direta ou indireta federal, darão prioridade à utilização dos produtos e serviços da Embraer" ${ }^{, 5}$. O decreto não deixa dúvidas quanto aos propósitos da criação da Embraer e sua estreita relação

\footnotetext{
${ }^{5}$ Decreto-Lei $\mathrm{N}^{\mathrm{o}} 770$, de 19 de agosto de 1969 , grifos meus.
} 
com a estratégia de catch-up do setor aeronáutico brasileiro: "promover a indústria aeronáutica brasileira" levando-se em conta "critérios de racionalidade econômica (...) assegurar escalas mínimas de produção eficiente" ${ }^{\text {. }}$. E o decreto ia além: conforme estabelecido no "Capítulo IV - Das disposições gerais, Art. 15: A Embraer gozará de isenção de todos os impostos e taxas que incidam ou venham a incidir sobre a importação de matérias-primas, peças complementares, componentes e equipamentos, máquinas e dispositivos, sem similar nacional, destinados à sua produção e serviços", isenção que se estendia "às indústrias nacionais de produção de material aeronáutico, nas importações destinadas à realização de programas aprovados pelo Ministério da Aeronáutica", além de ficar encarregada, segundo o disposto no Art. 17, a contribuir “para a formação de pessoal técnico, necessário à indústria aeronáutica e para a preparação de operários qualificados, podendo organizar cursos, conceder auxílios a estabelecimentos de ensino do País, bolsas de estudo e, ainda, assinar convênios com entidades públicas ou privadas para formação de pessoal técnico-especializado" 7 .

A Embraer teria a forma de empresa de controle estatal de capital misto "financiada em parte pelo governo federal, via Maer [Ministério da Aeronáutica], e em parte pela iniciativa privada, por meio de um programa de capitalização criado em 1970 pelo governo federal que permitia às pessoas jurídicas deduzirem até $1 \%$ do Imposto de Renda mediante a compra de ações da empresa" (Miranda 2007: 41). Entre as principais ações de apoio à criação da Embraer, Miranda (2007) elenca "a concessão de uma área ao lado do CTA para receber as instalações da empresa; compras feitas pelo governo brasileiro no segmento da aviação militar, que somente nos dois primeiros anos de funcionamento da empresa representaram cerda de oito anos de produção; transferência para a Embraer de todo o corpo técnico do Departamento de Aeronaves do CTA (num total de 150 engenheiros e técnicos), além de máquinas e equipamentos do centro de pesquisa; celebração de um acordo para formar recursos humanos para a indústria brasileira de componentes aeronáuticos, abrangendo o $\mathrm{CNPq}$ e a financiadora de Estudos e Projetos (Finep); implementação de um programa de certificação aeronáutica, que visava a melhorar a qualidade da produção interna, de modo a adequá-la aos padrões e normas internacionais" (Miranda 2007: 41-42).

\footnotetext{
${ }^{6}$ Idem, grifos meus.

${ }^{7}$ Idem, grifos meus.
} 
No dia 2 de janeiro de 1970 tomou posse a primeira diretoria da Embraer, presidida pelo Coronel-Aviador Ozires Silva, dando início efetivo a suas operações. No ano seguinte seria criada mais uma instituição para compor o sistema tecnoprodutivo aeronáutico brasileiro, o Instituto de Fomento e Coordenação Industrial (IFI), cuja missão era "Contribuir para a garantia do desempenho, da segurança e da disponibilidade de produtos e sistemas aeroespaciais de interesse do Comando da Aeronáutica, prestando serviços nas áreas de Normalização, Metrologia, Certificação, Propriedade Intelectual, Transferência de Tecnologia e Coordenação Industrial, fomentando assim o complexo científico-tecnológico aeroespacial brasileiro" ${ }^{\text {. }}$.

Foi sobre esse arranjo institucional, a essa altura já bastante completo e complexo, que o sistema tecnoprodutivo aeronáutico brasileiro se desenvolveu. Nele a Embraer buscou o apoio necessário para desempenhar a contento sua missão de projetar, fabricar e vender aviões capazes de competir no mercado aeronáutico mundial com as mais avançadas empresas norte-americanas e europeias.

\section{Empresa aeronáutica: ter ou não ter}

A criação da Embraer foi um passo fundamental da estratégia de construção de um sistema tecnoprodutivo aeronáutico no Brasil, sem o qual muito provavelmente o catchup não teria sucesso. Não seria, aliás, a primeira vez que um projeto de construção de um sistema tecnoprodutivo aeronáutico por meio de uma estratégia de catch-up tropeçaria justo nesse passo: como já vimos, Argentina e Indonésia, em momentos diferentes, não obstante o domínio tecnológico em projeto e construção de aviões adquirido a duras penas, viram suas tentativas de desenvolver sistemas tecnoprodutivos aeronáuticos nacionais fracassarem: na fase comercial de seus planos, no caso da Indonésia, ou por ausência de tal fase, no caso argentino. No caso da Indonésia, um projeto em muitos pontos inovador esbarrou na desconfiança internacional em relação às instituições certificadoras indonésias, consideradas insuficientemente independentes para garantir a segurança e qualidade dos processos de produção dos N-250 indonésios, não obstante o projeto ser uma parceria com a espanhola Casa, que não teve maiores problemas para certificar seus N-250 e vendê-los no mercado europeu, retardando,

\footnotetext{
${ }^{8}$ http://www.ifi.cta.br/institucional_missao.php, acessado em 31/07/2012.
} 
dificultando e até mesmo impedindo a comercialização de aviões de produção indonésia. Deficiências institucionais, no caso, de agência governamental de certificação independente, inviabilizaram a comercialização do N-250. Quanto à Argentina, as políticas que levaram ao domínio tecnológico dos processos de projeto e produção de aviões, garantindo momentaneamente a autonomia tecnológica do país em projeto e construção aeronáutica, não se fizeram acompanhar por preocupações com a fase comercial do desenvolvimento do setor tecnoprodutivo aeronáutico nacional, fissurados que estavam - tanto os governos civis como os militares - no componente de defesa do setor aeronáutico sem jamais buscar a constituição de uma empresa destinada a comercializar os aviões projetados e produzidos na Argentina. Consequentemente, a tecnologia desenvolvida ao longo de décadas não teve aplicação comercial, o que inviabilizou o projeto de construção do setor tecnoprodutivo aeronáutico argentino tão logo as condições políticas e macroeconômicas reverteram, inviabilizando o financiamento exclusivamente estatal do setor.

Afinal, por que é tão importante buscar a viabilidade comercial dos projetos e produtos do setor tecnoprodutivo aeronáutico - aliás, de qualquer setor tecnoprodutivo objeto de políticas estatais? Não me refiro, claro, a tecnologias sensíveis, cuja comercialização, se e quando acontece, vem cheia de regras, de nãos e poréns, de modo a dificultar o máximo possível a transferência de tecnologia e a consequente perda do diferencial competitivo; são casos em que a fronteira tecnológica é espaço proibido fortemente protegido, como ocorre com tecnologias de aplicação exclusivamente militar. As tecnologias aeronáuticas, no entanto, são essencialmente duais, portanto de aplicação comercial e militar. Por isso, e pelo caráter estratégico da tecnologia aeronáutica (entre as quais suas conexões com as tecnologias aeroespaciais), o setor aeronáutico pode contar com a possibilidade de reaver parte dos vultosos investimentos por meio da comercialização de seus produtos civis no mercado - quase sempre a parte menor, digase de passagem, tamanha a escala daqueles investimentos - reduzindo assim em algum grau sua dependência direta (pesquisa e desenvolvimento pré-competitivo, compras públicas, crédito) e indireta (formação de recursos humanos, ciência básica) do Estado.

Nos casos em que o Estado resolve apoiar a construção de um setor tecnoprodutivo por meio de políticas de catch-up, ele não o faz, salvo raras exceções, para prestar homenagem ao fetiche da tecnologia, mas com o objetivo de que aquele setor tecnoprodutivo desenvolva tecnologias próprias, gere efeitos de spillover tecnológico 
para outros setores, qualifique a mão de obra, aumente a competitividade da economia nacional e produza divisas de exportação. É por isso que o Estado apoia e tem participação numa Bombardier, Airbus, Boeing; foi por isso que o Estado apoiou e teve participação na criação e desenvolvimento da Embraer. E nem poderia ser diferente: a empresa é, no capitalismo contemporâneo, a organização que leva ao mercado, na forma de tecnologia, o conhecimento aplicável aos processos produtivos. Para que o conhecimento reverta em desenvolvimento econômico e social, é preciso que ele vá ao mercado. Sob as formas capitalistas contemporâneas de desenvolvimento econômico e social, é a empresa a organização capaz de converter conhecimento em capital.

Nesse ponto, a estratégia de catch-up do setor aeronáutico brasileira foi muito feliz: a criação da Embraer e o constante apoio à empresa, tanto em sua fase majoritariamente estatal quanto em sua fase majoritariamente privada, fizeram com que o projeto de construir um setor tecnoprodutivo aeronáutico brasileiro fosse além da fase heroica e voluntarista e atingisse a fase competitiva, em que o domínio tecnológico é medido pelo resultado da competição no mercado internacional. A Embraer é, até o momento, um sucesso, qualquer que seja o critério. Esse sucesso foi construído em diferentes momentos e sob circunstâncias muito diversas: de sua fundação em 1969 até hoje, ela teve uma longa história em que distintas trajetórias tecnológicas, institucionais, econômicas e comerciais apresentaram, em suas múltiplas e mutantes configurações, seguidos desafios aos quais a Embraer e o Estado brasileiro quase sempre responderam, se não imediatamente, pelo menos a tempo de evitar o pior, adaptando-se aos diferentes contextos econômicos e tecnoprodutivos do Brasil e do mundo.

A criação da Embraer é uma das fases essenciais do projeto brasileiro de construção de um sistema tecnoprodutivo aeronáutico nacional. A empresa foi criada com o objetivo expresso de produzir comercialmente os aviões projetados no IPD, contanto para isso com engenheiros altamente qualificados formados no ITA e em centros de excelência no exterior. Com a criação da Embraer o sistema tecnoprodutivo aeronáutico brasileiro ganhava a peça que faltava: CTA, ITA e IPD construíram no quase quarto de século que transcorreu entre a fundação do CTA em 1945 e a criação da Embraer em 1969 as bases desse sistema: instituições de pesquisa e desenvolvimento tecnológico e uma escola de engenharia capaz de fornecer pessoal apto a desempenhar funções de P\&D aeronáutico. Em relação à formação de engenheiros, atente-se para o fato de que essa tarefa foi não apenas em larga medida internalizada, pelo menos no nível da graduação. Para a 
formação em nível de pós-graduação o Brasil continuaria a contar por algum tempo com o expediente de envio de estudantes ao exterior, o que não foi nem é ruim, pelo contrário, uma vez que permite expor estudantes de pós-graduação a universidades, pesquisadores e pesquisas de ponta capazes de sustentar o desenvolvimento de um sistema de pesquisa e desenvolvimento tecnológico em aeronáutica. A formação de pessoal qualificado em número e qualidade suficiente para atender a demanda de um sistema tecnoprodutivo aeronáutico já a essa altura bastante diversificado, contanto com escolas de engenharia, institutos de pesquisa e desenvolvimento e uma recém-criada empresa aeronáutica, elementos determinantes da capacidade absortiva de um sistema tecnoprodutivo: mão de obra qualificada, instituições de formação de recursos humanos, centros de pesquisa e desenvolvimento e empresas.

As capacidades absortivas do sistema tecnoprodutivo aeronáutico brasileiro em 1969 já estavam avançadas a ponto de permitir a criação da Embraer para a produção de aviões: o jato de treinamento avançado e ataque ao solo EMB 326 Xavante, fabricado sob licença da italiana Aermacchi (com quem a Embraer voltaria a interagir no início da década de 1980 para o desenvolvimento conjunto do avião de ataque ar-superfície AMX), e o turboélice EMB 110 Bandeirante, avião de passageiros regional de uso civil e militar com capacidade para 12 a 21 passageiros desenvolvido no CTA sob liderança do engenheiro aeronáutico francês Max Holste, além do planador EMB 400 Urupema, desenvolvido no ITA, e do avião agrícola EMB-200 Ipanema, outro projeto desenvolvido pelo ITA, este sob encomenda do Ministério da Agricultura. Um portfólio bastante variado - ousado até.

Corre entre os atuais engenheiros da Embraer a seguinte caracterização da empresa comparando o período sob controle estatal com o período após a privatização: a Embraer era, em sua fase estatal, uma empresa de engenheiros, ao passo que após a privatização ela virou uma empresa de gestores, dividindo a história da Embraer em duas fases: a primeira, de 1969 a 1994, com ênfase no desenvolvimento tecnológico e pouca atenção ao lado comercial; a segunda, de 1994 até o presente, marcada pela inversão dos termos, dando-se maior importância ao lado comercial do empreendimento em relação aos aspectos tecnológicos. Há um pouco de verdade nessa caracterização, mas ao exagerar certos traços ela perde detalhes importantes, sobretudo o seguinte, essencial para o argumento dessa tese: se é verdade que o empenho no desenvolvimento tecnológico foi muito forte na fase "engenheira" da Embraer (1969-1994), os projetos 
da empresa também foram, desde o começo, comercialmente orientados, alcançando mesmo grande sucesso comercial, como atestam o avião de treinamento Tucano e o turboélice Bandeirante; por outro lado, o gênio empresarial da fase "gestão" teve sua mais eloquente manifestação na acertada combinação de visão estratégica do setor de aviação regional e pioneirismo na adoção de soluções tecnológicas na sua linha de jatos regionais. Capacidades tecnológicas e de gestão sempre se combinaram, em diferentes proporções, ao longo da história da Embraer, sendo os fatores responsáveis pelas várias décadas de sucesso da empresa.

\section{Trajetórias tecnoprodutivas e aprendizagem no sistema tecnoprodutivo aeronáutico brasileiro}

Nesta seção descrevo a trajetória tecnoprodutiva da Embraer examinando seus principais projetos e seus impactos sobre a estratégia tecnológica e de mercado da empresa para analisar os processos de aprendizagem tecnológica e comercial ao longo de suas quatro décadas de existência. Quarenta anos durante os quais o mercado e o setor tecnoprodutivo aeronáutico mundiais sofreram alterações profundas às quais muitas empresas grandes e tradicionais não sobreviveram; de sua parte, nesse período a Embraer cresceu e consolidou sua liderança no mercado de jatos regionais de até 120 passageiros, figurando hoje, ao lado de Boeing, Airbus e Bombardier, entre as quatro OEMs que integram o duplo duopólio do mercado aeronáutico civil mundial. Feito nada trivial cujo resultado, a cada passo, dependeu da correta interpretação do modo como as dimensões tecnológicas e comerciais interagiam e afetavam a trajetória e a estratégia da Embraer e do setor aeronáutico mundial. O acúmulo de conhecimento proporcionado pelo longo processo de aprendizagem - do qual a Embraer soube extrair preciosas e muitas vezes difíceis lições - permitiu à empresa se adaptar às diferentes configurações tecnoprodutivas e de mercado dos últimos quarenta anos.

Não se perca de vista, no entanto, que no ano em que a Embraer foi fundada o sistema tecnoprodutivo aeronáutico brasileiro já contava quase vinte e cinco anos de conhecimento e tecnologia desenvolvidos, testados e acumulados por meio de suas instituições de $\mathrm{P} \& \mathrm{D}$ e de formação de engenheiros aeronáuticos, da construção de protótipos naquelas instituições e mesmo da interação com as poucas empresas 
aeronáuticas existentes no Brasil, com destaque para a Sociedade Construtora Aeronáutica Neiva. Faltava, é verdade, uma empresa que produzisse com fins comerciais os vários projetos desenvolvidos no CTA: faltava, enfim, submeter a tecnologia criada pelas instituições de ensino, pesquisa e desenvolvimento do setor tecnoprodutivo aeronáutico brasileiro ao teste de mercado. A Embraer cumpriria esse papel apoiada em um quarto de século de acúmulo de conhecimento em tecnologias aeronáuticas. Quanto aos grandes desafios de gestão, produção e comercialização de seus produtos, no entanto, a Embraer não podia recorrer ao repositório de conhecimentos previamente acumulados pela simples razão dele não existir - ainda; nesse particular, ela teria que aprender sozinha e tirar suas próprias lições.

Para dar seus primeiros passos a Embraer contou, além de todo o conhecimento tecnológico acumulado pelo sistema tecnoprodutivo aeronáutico brasileiro em suas instituições e recursos humanos, com um empurrãozinho do Estado na forma de encomendas governamentais, mais especificamente: a produção sob licença do jato de treinamento avançado e ataque ao solo EMB 326 Xavante e o desenvolvimento e produção do turboélice EMB 110 Bandeirante e do avião agrícola EMB-200 Ipanema. A empresa iniciava sua operação, portanto, com um portfólio diversificado e uma carteira de pedidos firmes - dado que governamentais - que lhe permitiriam desenvolver os processos de aprendizagem produtiva, gerencial e comercial que faltavam ao sistema tecnoprodutivo aeronáutico brasileiro.

Esses três aviões marcaram profundamente, cada um a sua maneira, a trajetória tecnoprodutiva posterior da Embraer: o EMB-200 Ipanema, entre outros motivos, pela sua longevidade, tendo entrado em produção em 1972 e sendo fabricado até hoje, ostentando ainda o feito de ser o primeiro avião do mundo produzido em série a utilizar como combustível o etanol. Encomenda do Ministério da Agricultura, esse pequeno avião agrícola de pulverização teria uma participação indireta em outro importante capítulo da história da tecnologia no Brasil, a criação da Embrapa e a consequente expansão da produção agrícola e do agronegócio brasileiro, ocorrida a partir da década de 1970 com o desenvolvimento de cultivares adaptados ao clima e solo brasileiros e da mecanização e uso intensivo de defensivos agrícolas - estas últimas suas discretas, ainda que em vários sentidos ambíguas, contribuições. 
Foram, no entanto, o EMB 326 Xavante e o EMB 110 Bandeirante os dois projetos que marcaram mais profundamente a trajetória tecnoprodutiva da Embraer, projetos cujos ecos ainda ouvimos nos atuais Super Tucano e na família de jatos regionais EMB 170190 e ERJ, projetos que permitiram à Embraer produzir um avião a jato e projetar, produzir e comercializar um avião regional, o que permitiu à empresa entrar em contato com tecnologias críticas para um sistema tecnoprodutivo em pleno processo de catchup. Além da consolidação do domínio tecnológico e produtivo, os projetos do EMB 326 Xavante e o EMB 110 Bandeirante permitiram à Embraer adquirir as competências em gestão e estratégia de mercado no segmento de aviões regionais e proporcionar a primeira incursão da empresa no altamente competitivo mercado de aviação norteamericano, em que o EMB-110 Bandeirante despontou como um dos melhores produtos em fins da década de 1970 e ao longo de toda a década de 1980.

A história do EMB 110 Bandeirante começa ainda antes da criação da Embraer, fundada com o objetivo expresso de desenvolver e produzir esse avião. Como vimos, um pequeno número de empresas e o próprio CTA, em colaboração com suas instituições associadas IPD e ITA, já produziam aviões no Brasil há algum tempo - algumas empresas até mesmo antes da criação do CTA (o Muniz M-7, projeto do major e engenheiro da aviação do Exército Brasileiro Antônio Guedes Muniz, começou a ser fabricado em 1937). Eram, no entanto, aviões de pequeno porte e reduzida autonomia de voo, destinados no mais das vezes a uso militar, em funções como aviões de treinamento ou em tarefas de observação aérea e orientação de artilharia. Os países dotados de sistemas tecnoprodutivos aeronáuticos mais avançados já vinham fazendo aviões de médio e grande porte desde a década de 1930, reconfigurando a indústria aeronáutica militar e civil no mundo todo. Era imperativo, portanto, que o nascente sistema tecnoprodutivo aeronáutico brasileiro desse um salto em direção à produção de aviões maiores e mais complexos, de modo a reduzir a sua distância da fronteira tecnoprodutiva aeronáutica. Afinal, uma estratégia de catch-up tecnoprodutivo consiste justamente nisso: em reduzir, por meio de saltos, a distância que separa um país, setor ou empresa de países, setores ou empresas tecnoprodutivamente mais avançados.

Em 1964, quando o sistema tecnoprodutivo aeronáutico brasileiro articulado em torno do CTA já contava, portanto, perto de uma década de acúmulo de aprendizagem em pesquisa, desenvolvimento e formação de engenheiros, o Ministério da Aeronáutica encomendou ao CTA estudo de viabilidade de produção em série de aviões de 
passageiros de médio porte no Brasil. MAER nem CTA descartaram a possibilidade de produzir aviões de passageiros de médio porte sob licença de empresas aeronáuticas estrangeiras. Aliás, é bom que se diga, esse expediente, longe de ser contrário aos fins de uma estratégia de catch-up tecnoprodutivo, quase sempre é parte importante do desenvolvimento de um setor aeronáutico em vias de fazer o catch-up, tendo sido usado extensamente também no caso brasileiro, contanto que, cedo ou tarde, o sistema tecnoprodutivo avance em direção ao domínio das fases mais nobres e complexas de projetar, produzir, testar e comercializar aviões. Avanço inescapável, aliás, já que em algum momento da trajetória da estratégia de catch-up será preciso dar o salto mortal em direção à fronteira tecnoprodutiva, salto no qual se aposta, no caso do setor aeronáutico, quase sempre tudo: empresa, instituições, políticas públicas, uma vez que falhar, dados os vultosos investimentos e esforços políticos e humanos necessários para levar o setor aeronáutico até o ponto em que ele se encontra mais ou menos pronto para saltar, resulta em fracasso completo.

O sucesso de uma estratégia de catch-up depende de vários fatores, dos quais o momento de dar o salto que o fará se aproximar da fronteira tecnoprodutiva é um dos mais importantes - e mais difíceis. Inescapável, sim, mas nem por isso - ou até por isso - não deve ser dado de afogadilho. Um pouco antes, o salto não será suficiente para reduzir a distância da fronteira tecnoprodutiva: a ausência de um ou mais tipos de instituição (de pesquisa e desenvolvimento, de coordenação dos esforços, de formação de pessoal, de regulação e certificação), a inexistência ou pouca atenção dada ao aspecto comercial na estratégia, a falta de competitividade da empresa responsável por produzir comercialmente os aviões, são razões que podem, combinadas ou por si só, botar tudo a perder e levar ao fracasso da estratégia de catch-up. Tardiamente, o salto resulta sem efeito: o conhecimento em suas diversas formas (laboratórios, tecnologias, recursos humanos, aviões, estratégias comerciais) fica obsoleto, e o que era pra ser salto tecnoprodutivo acaba sendo tropeço. Escolher o momento preciso de dar o salto mais ousado, portanto, é decisivo para o sucesso de uma estratégia de catch-up.

Pois bem, pesados os prós e contras das duas alternativas: de um lado, avanço tecnoprodutivo incremental alcançado por meio da produção sob licença de uma empresa aeronáutica estrangeira de um avião de médio porte; de outro, avanço tecnoprodutivo radical resultante de um projeto nacional desenvolvido pelo CTA e suas instituições associadas e produzido por uma empresa aeronáutica ainda por ser criada; 
optou-se pela segunda, o desenvolvimento e produção de um avião pelo sistema tecnoprodutivo aeronáutico brasileiro. Foi então encomendado ao CTA o projeto do Bandeirante, destinado a suprir a Força Aérea e a aviação civil brasileiras de um avião de passageiros de médio porte e autonomia de voo compatível com a extensão territorial do país.

As vantagens de projetar e produzir um avião de médio porte no Brasil eram muitas, a começar do processo de aprendizagem envolvido na empreitada. E havia muito que aprender; basta pensar nas sucessivas etapas que compõem o ciclo tecnoprodutivo aeronáutico: 1) decisão de projetar e produzir o avião; 2) projeto do avião; 3) prototipagem de componentes e testes em ambiente controlado; 4) prototipagem do avião e testes em ambiente real; 5) desenvolvimento do processo produtivo; 6) produção do avião em escala comercial; 7) certificação do avião para fins comerciais; 8) comercialização do avião; 9) suporte ao cliente. Enfim, um curso completo de aeronáutica avançada.

Ao aprendizado dos aspectos referentes ao ciclo tecnoprodutivo descrito acima devemos acrescentar o aspecto de aprendizagem e construção institucional que ocorreria nessa nova fase da estratégia de catch-up do setor tecnoprodutivo aeronáutico brasileiro. Com efeito, o arranjo institucional do sistema tecnoprodutivo brasileiro construído a partir da criação do CTA em 1946 e completado nas décadas seguintes pela criação do ITA e do IPD necessitaria de uma nova instituição, apta, do ponto de vista organizacional, a projetar, produzir e comercializar os aviões criados pelas instituições do sistema tecnoprodutivo aeronáutico brasileiro. Esta nova instituição, como vimos, era uma empresa, a Embraer. E nem poderia ser diferente, uma vez que a nova fase da estratégia de catch-up exigia a produção comercial de aviões. Sem esse passo, a estratégia brasileira de catch-up tecnoprodutivo aeronáutico teria muito provavelmente o mesmo destino do setor aeronáutico argentino, cujo segundo erro foi não ter desenvolvido o componente comercial do setor (o primeiro foi não criar uma instituição de formação de recursos humanos para o setor aeronáutico). Aprender a ter uma empresa aeronáutica é uma das mais valiosas, e das menos triviais, lições.

Essa nova fase do sistema tecnoprodutivo aeronáutico brasileiro abriria também um novo tema de aprendizagem: a comercialização dos aviões. Já vimos que tecnologia não é tudo: um produto tecnologicamente avançado precisa, para ser considerado uma 
inovação, passar pelo teste do mercado, que consiste basicamente em ser mais competitivo do que seus similares - competitividade que pode decorrer do preço, da escala de produção, da tecnologia empregada, da estratégia comercial, do pioneirismo no mercado etc. Cada um desses fatores irá determinar a competitividade final de um produto. Não devemos, quando falamos de inovação, nos deixar cegar pelo fetiche da tecnologia: pela ideia de que inovação é inovação tecnológica; mas também pela noção que procede, por um processo de distinção, a uma hierarquização das formas de conhecimento: científico, tecnológico, técnico, gerencial, comercial. O peso que cada uma das formas de conhecimento assume varia e depende de um conjunto muito grande de fatores, fazendo com que qualquer tentativa de hierarquização a priori seja não apenas inútil, mas também enganosa: inútil porque raramente chega a conclusões corretas; enganosa porque acaba por indicar caminhos que a experiência histórica e a análise sociológica não recomendariam fosse maior a atenção com as diferentes configurações que cada artefato ou sistema tecnoprodutivo assume.

O aprendizado dos aspectos comerciais da fabricação de aviões só poderia ser adquirido por uma empresa. Nenhuma outra organização seria capaz de aprender a reagir à complexidade do ambiente tecnoprodutivo em que fatores de mercado, tecnológicos, políticos, institucionais e geopolíticos determinam o resultado final do empreendimento tecnoprodutivo, podendo inclusive fadar ao fracasso produtos tecnologicamente avançados que não levam em consideração os demais fatores. $O$ conceito de sistema tecnoprodutivo permite compreender o modo como diferentes dimensões interagem gerando configurações históricas particulares. No caso da estratégia de catch-up do sistema tecnoprodutivo aeronáutico brasileiro, uma série de fatores se combinaram para determinar o sucesso da empreitada: fatores políticos, institucionais, tecnológicos e comerciais. Em relação especificamente à Embraer, seu sucesso dependeu fortemente da trajetória pregressa do sistema tecnoprodutivo aeronáutico brasileiro constituído a partir do pós-guerra e do modo como aqueles fatores se combinaram e foram enfrentados.

Uma das vantagens de se projetar e fabricar no Brasil um avião é poder adaptar o projeto às necessidades e realidades do país, e não apenas no que diz respeito à estrutura tecnoprodutiva existente ou a ser criada durante o processo de catch-up, mas também quanto às especificações técnicas e operacionais do avião. País de dimensões continentais, esparsa e escassamente povoado, possuidor de vastíssima fronteira fazendo divisa com dez países, dotado de péssima infraestrutura de transporte rodoviário, 
ferroviário, hidroviário e aeroportuário, incontáveis núcleos de povoação em lugares remotos atingíveis apenas por meios rudimentares de transporte em viagens perigosas que podiam se estender por vários dias, as características do território e a forma de sua ocupação pediam um meio de transporte aéreo rápido, capaz de vencer grandes distâncias e decolar e pousar em pistas improvisadas levando passageiros e carga a pontos isolados do território nacional. Esse avião teria que ser capaz de operar em condições climáticas adversas (clima tropical e subtropical) e com grande autonomia em relação a centros de manutenção e reparo. Não eram muitos os aviões então existentes aptos a atender a essas exigências; por outro lado, a escassez de aviões com essas características indicava também um nicho bastante especializado e ainda não ocupado do mercado mundial de aviação. Foi visando produzir um avião com esse perfil que o Bandeirante foi projetado, e foi nesse segmento de mercado que a Embraer fez sua primeira e bem-sucedida incursão no mercado mundial de aviação, sobretudo no setor de aviação civil, mas também no militar.

O Bandeirante é um avião bimotor turboélice de porte médio (médio para os anos 1960), com capacidade de transportar doze a vinte e um passageiros, para uso civil e militar, adaptável ao transporte de cargas e com autonomia de voo de 1.900 quilômetros. Desenvolvido no CTA, mais especificamente pelo IPD, seu projeto, que recebeu o número IPD 6504, foi liderado pelo Coronel e engenheiro aeronáutico do ITA Ozires Silva, figura fundamental do sistema tecnoprodutivo aeronáutico brasileiro, tendo presidido a Embraer de sua fundação em 1969 até 1986, personagem cuja influência ainda se fez sentir no processo de privatização da empresa em 1994. O projeto do IPD 6504 contou também com a importante participação do engenheiro aeronáutico francês Max Holste, convidado por Ozires Silva a tomar parte no projeto, contribuindo com sua larga experiência em projeto e produção de aviões. O novo avião deveria essencialmente ser capaz de operar em condições aeroportuárias e climáticas precárias, como as que seriam encontradas na maior parte do território brasileiro e em outros países tropicais e subtropicais de industrialização e urbanização tardia e infraestrutura de transportes precária.

O primeiro protótipo do IPD 6504 - que recebeu a designação EMB-100 Bandeirante, em versão de oito lugares, que não chegou a ser fabricada seriadamente, dando lugar ainda na fase de testes e prototipagem ao EMB-110, versão com capacidade entre doze a vinte e um lugares que veio a ser efetivamente fabricado em série - consumiu, de 
acordo com o Centro Histórico da Embraer, "três anos e quatro meses e 110 mil horas de projeto, tendo sido executados 12 mil desenhos de fabricação; 22 mil horas de cálculo estrutural e aerodinâmico e 282 mil horas de fabricação do avião e de seu ferramental" (Centro Histórico Embraer). O desenvolvimento do projeto do IPD 6504 demonstrou na prática o acerto da estratégia de catch-up aeronáutico brasileiro em se submeter, antes de dar o salto que aproximaria o sistema tecnoprodutivo aeronáutico brasileiro da fronteira tecnoprodutiva do setor, a um longo processo de aprendizagem e acúmulo de conhecimento pelo CTA e instituições associadas - ITA e IPD - e na nascente aglomeração industrial na região de São José dos Campos. A complexidade do desenvolvimento do projeto do IPD 6504 e do arranjo institucional sobre o qual ele se apoiou ficou patente na diversidade de especialistas e instituições que dele tomaram parte: além de 300 engenheiros e técnicos do Departamento de Aeronaves (PAR) do IPD, o projeto contou também com a participação de outras instituições do MAER e empresas como Aerotec (fabricante do T-23 Uirapuru) e Avitec (atual Motortec). O primeiro protótipo do projeto IPD $6504 \mathrm{fez}$ seu voo inaugural em 27 de outubro de 1968.

Pois bem, o avião voava; até aí, nada demais. Difícil mesmo seria produzir em série o avião e, mais difícil ainda, comercializá-lo com sucesso no mercado nacional e internacional. Começava aqui o maior desafio até então para o jovem sistema tecnoprodutivo aeronáutico brasileiro, desafio no qual outros países, antes e depois Argentina, Japão, México, Indonésia -, não tiveram sucesso: desenvolver um setor aeronáutico competitivo e apto a disputar de igual para igual com as OEMs de países mais próximos da fronteira tecnoprodutiva aeronáutica, reduzindo ao máximo possível sua própria distância por meio do salto proporcionado pela estratégia de catch-up.

Talvez a decisão de maiores e mais profundas consequências para a trajetória inicial da Embraer e do projeto do Bandeirante em particular tenha sido a reconfiguração do número de passageiros do projeto inicial do IPD 6504, que passou de oito na versão do EMB-100 para uma configuração que permitia de doze a vinte e um passageiros na versão EMB-110 Bandeirante. A decisão não deve ter sido fácil, uma vez que implicaria realizar modificações importantes no projeto original de oito lugares, aumentando os custos e atrasando um projeto que já contava inclusive com um protótipo fabricado e testado. A decisão, no entanto, se mostrou correta e previdente: os responsáveis pelo projeto compreenderam que o mercado de aviões regionais estava naquele momento 
mudando para um novo padrão de capacidade de passageiros, de dez para vinte ou mais passageiros, em função da expansão do mercado de aviação civil em todo o mundo. Por conta dessa mudança no segmento de mercado em que a Embraer estava entrando, o mercado de aviões regionais de médio porte, a configuração do Bandeirante foi alterada ainda na fase de prototipagem e testes de um máximo de oito lugares para um máximo de vinte e um - aumento de mais de duas vezes e meia na sua capacidade de passageiros, nada desprezível, portanto. $\mathrm{O}$ aumento da capacidade de passageiros de um máximo de oito para uma faixa de doze a vinte e um passageiros garantiu ao EMB-110 Bandeirante maior penetração no mercado de aviação comercial, além de antecipar o aumento do tamanho dos aviões regionais que ocorreria nas décadas de 1970 e 1980, estendendo a sobrevida comercial do projeto, que continuaria a ser competitivo por mais de vinte anos depois de sua entrada em produção.

Essa capacidade de interpretar os sinais do mercado mundial de aviação e desenvolver estratégias tecnoprodutivas e comerciais capazes de colocar a Embraer em um patamar de alta competitividade em relação a seus concorrentes, portanto de posicionar a empresa muito próxima à fronteira tecnoprodutiva do setor aeronáutico e de aviação mundial, foi desde os primórdios da Embraer um de seus mais importantes diferenciais competitivos. A esse fator deve-se atribuir grande parte do sucesso da Embraer ao longo de sua trajetória. Essa forma específica de conhecimento - a habilidade de fazer convergirem inteligência de mercado e capacidades tecnoprodutivas em uma estratégia coerente visando ao aumento da competitividade da empresa - é a principal vantagem competitiva da Embraer ao longo de sua trajetória, estando presente nas mais diversas fases da empresa, desde sua criação até os dias atuais, antes e depois, portanto, de sua privatização.

A habilidade de alinhar a estratégia tecnoprodutiva e comercial da empresa aos movimentos do mercado aeronáutico e de aviação mundial apresenta-se como condição necessária para o sucesso de um sistema tecnoprodutivo intensivo em tecnologia e em especial para uma estratégia de catch-up no setor. Nesse sentido, se por um lado a existência de uma empresa com essa habilidade específica não é garantia de sucesso, por outro, a inexistência no sistema tecnoprodutivo de uma empresa dotada dessa habilidade é quase sempre certeza de insucesso, como demonstra de maneira exemplar o caso do desenvolvimento do setor aeronáutico argentino. 
A produção em série do EMB-110 Bandeirante pela Embraer teve início em 1971, quando, se não todos, pelo menos a maioria dos desafios tecnoprodutivos envolvidos na fabricação seriada do modelo haviam sido satisfatoriamente resolvidos, com o primeiro voo de uma unidade produzida em série sendo realizado em 9 de agosto de 1972. Mas o verdadeiro teste de um avião comercial é, no entanto, comercializá-lo. E nisso o EMB110 Bandeirante se saiu muito bem.

A produção do EMB-110 Bandeirante começaria em instalações bastante modestas, um hangar construído em área cedida pelo CTA em suas imediações, de modo a tirar proveito de economias de aglomeração. O plano inicial previa a produção de dois EMB110 Bandeirante/mês por aproximadamente quinhentos engenheiros e técnicos. As primeiras encomendas do EMB-110 Bandeirante foram feitas pelo MAER, num total de oitenta unidades, aplicando o instrumento de política industrial chamado compras governamentais, que mesmo na atualidade ainda move a indústria aeronáutica mundial e da qual nenhuma das empresas do duplo duopólio de OEMS (Boeing, Airbus, Embraer e Bombardier) quer ou pode abrir mão, como mostram o desenvolvimento pela Embraer do cargueiro militar KC-390 e a disputa entre a Boeing e a Airbus para o fornecimento do novo avião de reabastecimento da Força Aérea dos Estados Unidos, vencido, depois da invalidação de uma primeira licitação favorável à Airbus, pela empresa americana Boeing. Essa encomenda inicial foi fundamental para que a Embraer pudesse se engajar em um processo de aprendizagem tecnoprodutiva, encomenda sem a qual não apenas a Embraer especificamente, mas todo o sistema tecnoprodutivo aeronáutico brasileiro e a própria estratégia de catch-up para o setor aeronáutico nacional poderiam sucumbir entrar em stall é a imagem mais adequada - e se espatifar sem sobreviventes, do mesmo modo como aconteceu com Argentina, Indonésia, Japão.

O projeto do Bandeirante gerou uma série de oportunidades de aprendizagem para a Embraer. A primeira e mais evidente diz respeito ao desenvolvimento e acúmulo de capacidades de produzir seriadamente um avião. A execução de um projeto aeronáutico é uma atividade altamente complexa, tanto pelos desafios relativos ao processo de manufatura quanto às fases de testes e certificação dos aviões, só podendo ser plenamente dominada pela experiência repetida. Os dois maiores desafios no que toca à manufatura do EMB-110 Bandeirante diziam respeito ao escalonamento da produção, isto é, a transição da montagem quase artesanal característica da fase de prototipagem 
para a produção em série do avião; e à integração dos diferentes sistemas que compõem o avião, ambos estreitamente ligados às fases de testes e certificação.

São muitas as diferenças entre construir um protótipo e construir um produto final em série. Evidentemente, o ineditismo da construção de um protótipo apresenta dificuldades muito específicas: a ausência de ferramental específico e de processos de manufatura e controle de qualidade, a necessidade de adaptações subótimas e a descoberta, ao longo da construção do protótipo, de deficiências do projeto original. Daí a necessidade de construir e aprimorar uma série de protótipos (pelo menos dois, podendo chegar a quatro ou cinco) até que se atinja um domínio satisfatório do processo de manufatura e que todas as adaptações e correções tenham sido implementadas. No caso do EMB-110 Bandeirante, foram construídos três protótipos antes do avião passar à fase de produção em série - o primeiro consumiu três anos e quatro meses e um total de 110 mil horas de trabalho para ser completado.

Entre os procedimentos de maior complexidade na montagem de um protótipo está a integração dos múltiplos sistemas que compõem um avião. As dificuldades vão desde coisas aparentemente triviais, como a conversão de diferentes unidades de medida usadas na especificação de componentes para um mesmo sistema métrico até a verificação, na prática, da compatibilidade entre componentes dos mais diversos fabricantes produzidos segundo métodos e especificações técnicas muito diferentes. A ideia, completamente incorreta, aliás, de que a Embraer e demais OEMs executam uma tarefa absolutamente trivial, a de montadoras de aviões, ignora o caráter altamente complexo das atividades de integração de sistemas. De nada adianta combinar, digamos, os melhores equipamentos aviônicos existentes se os parâmetros eletroeletrônicos entre eles são incompatíveis, gerando interferências ou falhas em seu funcionamento. Comparando, há na maior ou menor habilidade de integrar sistemas a mesma diferença que há entre um bom e um péssimo cozinheiro; não se trata apenas de juntar ingredientes - que podem até ser os mesmos -, mas de combiná-los conforme um método que permita um bom resultado final.

As dificuldades envolvidas na fabricação de protótipos, como a inexistência de processos de produção e métodos de controle de qualidade estabelecidos e a alta complexidade da integração de sistemas, são potencializadas na transição da fase de prototipagem para a fase de produção em série. Nesta, as adaptações têm que ser 
reduzidas a um mínimo possível, que por sua vez também precisa ser parametrizado de modo a garantir a qualidade do processo de produção de componentes e a compatibilidade no processo de montagem; ferramental e procedimentos de manufatura precisam ser criados e sistematizados; finalmente, todo o processo de produção precisa atender aos critérios de eficiência e racionalidade econômica, equação em que tempo e custos de produção são as variáveis mais relevantes e a partir das quais todos os demais processos precisam ser otimizados. Processos e tecnologias passam a ser medidos não por suas qualidades independentes, mas pela busca do equilíbrio ótimo entre qualidade - dos processos e tecnologias - e viabilidade econômica desses mesmos processos e tecnologias. O "melhor" componente aviônico, do ponto de vista tecnológico, tem que ser considerado também em relação ao tempo para sua produção e montagem e, sobretudo, seu custo, de todos o fator mais importante na definição da viabilidade comercial e, portanto, da sua competitividade no mercado.

É nesse contexto de produção em escala comercial com vistas à maximização da competitividade que ganha sentido a ideia de que construir e fazer voar um avião é, de todas as tarefas envolvidas no processo de constituição de um sistema tecnoprodutivo aeronáutico, a mais fácil; difícil mesmo é construir e fazer voar esse avião obedecendo a parâmetros mínimos de qualidade e a preços competitivos. O verdadeiro desafio do sistema tecnoprodutivo aeronáutico brasileiro residia em sua viabilização enquanto empreendimento comercial apto a competir segundo os mesmos níveis de excelência das empresas, setores e países mais avançados do ponto de vista tecnoprodutivo aeronáutico.

$\mathrm{Na}$ trajetória que começa no projeto do avião e termina em sua produção seriada para fins comerciais, passando pela construção e teste de protótipos, modificações do projeto, desenvolvimento dos processos de produção em série e construção das versões que serão comercializadas, há ainda um passo sem o qual nenhum avião pode ser operado comercialmente: o processo de certificação pelas autoridades aeronáuticas e de aviação civil. E não se trata, nem de longe, de um procedimento formal. A certificação de um avião é um dos gargalos mais importantes em sua trajetória rumo à comercialização. Para receber certificação para operar em um determinado espaço aéreo nacional e em aeroportos específicos, um avião passa por uma extenuante bateria de testes nos quais deve demonstrar capacidade de operação dentro de parâmetros de 
desempenho e segurança e condições de voo definidos pelas autoridades de aviação para cada modelo de avião.

O processo de certificação de aviões pelas agências responsáveis pela regulação da aviação civil oferece um exemplo bastante eloquente, ainda que pouco conhecido, do entrelaçamento de fatores tecnoprodutivos e político-institucionais. Nesse particular, a questão toma a seguinte forma: o avião pode até ser avançadíssimo tecnologicamente e tão seguro quanto possa ser o ato de entrar num charuto com asas propulsionado por motores de alta potência e sair voando pelos céus; no entanto, se esse avião não for submetido e aprovado nos processos de certificação, o empreendimento é natimorto. As dificuldades iniciais para certificar o N-250, fabricado pela indonésia IPTN, foram o principal fator inviabilizador de um projeto de resto bastante bom do ponto de vista, como demonstrou o sucesso de seu irmão-gêmeo, fabricado pela espanhola CASA. Como já vimos, a demora em certificar o CN-235 fez com que a IPTN perdesse o tempo de lançamento do avião nos mercados norte-americano e europeu; neste último, aliás, o CN-235, versão espanhola do N-250 fabricado pela espanhola CASA e desenvolvido em conjunto com a IPTN, alcançou boas vendas, relegando o N-250 ao então pequeno mercado asiático. Acrescente-se portanto mais este à já longa lista de potenciais obstáculos e impedimentos à viabilidade tecnoprodutiva de um avião: a certificação é condição sem a qual o avião, por melhor que seja, não pode ser comercializado.

Esse, no entanto, não foi um problema para o EMB-110 Bandeirante, já que a certificação doméstica do avião cabia ao CTA, que homologou o EMB-110 Bandeirante em dezembro de 1972. No ano seguinte a Embraer começaria a entregar os primeiros de um total de oitenta EMB-110 Bandeirante encomendados pela Força Aérea Brasileira (FAB) e a primeira unidade vendida para uma empresa de aviação civil, a Transbrasil. A partir daí, o EMB-110 seguiria uma muito bem-sucedida trajetória comercial, com alta aceitação do aparelho pelos mercados interno e externo, e nestes não apenas em países menos avançados tecnologicamente e carentes de boa infraestrutura aeroportuária, mas também no mercado europeu e norte-americano. As primeiras vendas para o mercado externo foram feitas para o Uruguai, num total de quinze aviões: cinco EMB-110 Bandeirante para equipar a Força Aérea Uruguaia e dez EMB-200 Ipanema.

Entre os motivos da boa aceitação do EMB-110 Bandeirante estava seu reduzido custo de operação, em especial o baixo consumo de combustível desse avião regional de 
médio porte propulsionado por turboélice em comparação aviões similares de propulsão a jato. A lucratividade no setor de aviação civil é função do total de passageiros/carga por milha, cujo retorno é determinado em última análise pelos custos do combustível de aviação, uma vez que o preço do combustível é o fator com maior peso na composição dos custos do setor. O baixo custo de operação de um avião, portanto, é um dos principais diferenciais de competitividade de um modelo em relação a seus concorrentes. Essa vantagem foi potencializada pelos dois choques do petróleo, em 1973 e 1979, acrescentando à vantagem inicial do EMB-110 Bandeirante um fator exógeno que continuaria a afetar o setor aeronáutico e de aviação civil por muitos anos. Com efeito, foi apenas na década de 1990 que aviões regionais de médio porte com propulsão a jato tornaram-se competitivos em relação aos similares com propulsão a motores turboélice, dando espaço para a entrada em cena de jatos regionais.

Para aumentar suas vendas nos mercados internacionais, não bastava ao EMB-110 Bandeirante a certificação pelo CTA, uma vez que muitos países exigem que cada modelo de avião seja certificado em suas próprias agências ou em um seleto grupo de agências estrangeiras com procedimentos de certificação aceitos por outros países. $\mathrm{O}$ EMB-110 Bandeirante começou, por isso, a ser submetido a processos de certificação em agências de aviação estrangeiras. As primeiras certificações internacionais do EMB110 Bandeirante foram concedidas pela autoridade francesa de aviação civil, a Direction Générale de L'Aviation Civile (DGAC), em dezembro de 1977, e pela autoridade britânica de aviação civil, a Civil Aviation Authority (CAA).

Faltava, no entanto, abrir as portas do maior mercado de aviação do mundo, os Estados Unidos. A tarefa não seria das mais fáceis, pois incluía alterar regras que vetavam o uso de aviões de pequeno e médio porte na aviação civil regional. Segundo o Centro Histórico Embraer, "a empresa buscou a homologação nos Estados Unidos, junto a Federal Aviation Administration (FAA); no entanto, até o fim da década de 1970, o uso de aviões de pequeno porte em rotas regionais não era permitido nos Estados Unidos. Depois de diversos acordos, em maio de 1978 a FAA diminuiu as exigências para a operação de aviões menores. Com isso, a Embraer necessitava apenas conseguir um comprador para dar início ao processo de homologação, o que ocorreu em 21 de junho de 1978, quando Robert Terry, presidente da Aero Industries, fechou um contrato de compra de três Bandeirantes, que seriam utilizados pela Aero Commuter, subsidiária da 
empresa. Assim, em 18 de agosto de 1978, três dias após a homologação na Inglaterra, o Bandeirante EMB 110P1 foi homologado pela FAA, nos Estados Unidos"9.

As mudanças nas regras que regulavam o mercado norte-americano de aviação regional e a certificação do EMB-110 Bandeirante pela FAA abriram uma nova fase na trajetória do avião, que logo viu suas vendas no mercado norte-americano dispararem. A estratégia de penetração no mercado norte-americano contou também com a criação, em 1979, da subsidiária Embraer Aircraft Corporation, em Fort Lauderdale, estado da Flórida, responsável por reposição de peças, serviços de pós-vendas e treinamento de pilotos de companhias operando o EMB-110 Bandeirante.

A internacionalização das vendas do EMB-110 também foi importante por ter oferecido uma das primeiras oportunidades para a empresa aplicar o que viria a ser um de seus diferenciais competitivos ao longo das décadas passadas e ainda hoje é um dos componentes centrais de sua estratégia tecnoprodutiva e comercial: a estreita interação com os clientes de seus aviões (empresas de aviação regional, no caso do EMB-110 Bandeirante) para identificação conjunta de adaptações e melhorias, bem como de oportunidades tecnológicas e de mercado. Esse processo levou ao desenvolvimento das versões EMB-110 P1 e EMB-110 P2, aquela com capacidade para dezoito passageiros, este um avião de porta larga adaptável ao transporte de passageiros e cargas, igualmente homologados pela FAA.

O EMB-110 Bandeirante foi produzido por trinta anos, de 1971 a 1991. Foram fabricados um total de 498 aviões, divididos quase meio a meio entre o mercado interno e mercados internacionais: 253 vendidos no Brasil e 245 no exterior, dos quais 320 ainda estão operando. Um bom começo para a Embraer no ultracompetitivo mercado aeronáutico mundial.

Os primeiros voos da Embraer no processo de aprendizagem tecnoprodutivo não se resumiram, no entanto, ao EMB-110 Bandeirante. A empresa também recorreu a outras formas de aprender dos engenhos e artes da produção de aviões: além da produção de aviões projetados no âmbito do CTA, casos do já citado EMB-110 Bandeirante e do EMB-200 Ipanema, avião agrícola desenvolvido pelo Departamento de Aeronaves

\footnotetext{
${ }^{9}$ Centro Histórico Embraer, "EMB-110 Bandeirante".
} 
(PAR) do IPD, instituição associada ao CTA e também desenvolvedora do EMB-110 Bandeirante e que a essa altura acumulando uma experiência nada desprezível no desenvolvimento de projetos aeronáuticos, a Embraer também projetou - pela primeira vez do zero - e fabricou em série o planador para voo a vela de competição EMB-400 Urupema e passou a montar e mais tarde a produzir o jato de treinamento militar EMB326 GB Xavante, projeto da italiana Aermacchi. Tudo isso num curtíssimo espaço de tempo: de 1970 a 1973.

A história do EMB-200 Ipanema é resultado da convergência de duas linhas de força do processo mais geral de desenvolvimento tecnoprodutivo levado a cabo nos anos 1960 e 1970 que visavam a criar no Brasil sistemas tecnoprodutivos: o aeronáutico e o agropecuário. Avião de pulverização de defensivos agrícolas, o EMB-200 Ipanema nasceu de um pedido do Ministério da Agricultura ao CTA no ano de 1969, interessado em desenvolver um avião produzido no Brasil capaz de substituir os aviões agrícolas importados dos EUA para uso no Brasil e dar impulso à revolução agropecuária.

Apesar da segurança financeira que um pedido governamental como esse oferecia, o CTA e mais tarde a Embraer, encarregada de aperfeiçoar o projeto inicial do Ipanema, inicialmente desenvolvido pelo Departamento de Aeronaves (PAR) do IPD/CTA, assumiam um projeto voltado para o que era, àquela altura, um setor ainda pouco desenvolvido da economia brasileira, o agropecuário. Foi só a partir dos anos 1970 que o agronegócio brasileiro começou a se desenvolver como setor tecnoprodutivo, isto é, aplicando ciência e tecnologia à atividade produtiva. A mecanização da produção agrícola, o desenvolvimento biotecnológico aplicado à agropecuária e o uso intensivo de defensivos e fertilizantes agrícolas só se disseminariam no setor agrícola brasileiro durante a década de 1970, ganhando seu mais importante impulso da Empresa Brasileira de Pesquisa Agropecuária, a Embrapa, criada em 1973. Portanto, o que hoje parece uma aposta certa com mercado garantido, dados o tamanho e a escala atuais do agronegócio brasileiro, comportava, na época em que o Ministério da Agricultura solicitou ao CTA o desenvolvimento de um avião agrícola brasileiro, certo risco. Risco mais comercial do que tecnológico, uma vez que, àquela altura do desenvolvimento do sistema tecnoprodutivo aeronáutico brasileiro, aviões similares já vinham sendo projetados e produzidos de forma contínua e com algum sucesso, entre os quais o SP-18 Onça, projetado pelo Instituto de Pesquisas Tecnológicas (IPT) do estado de São Paulo. 
Havia, no entanto, algumas oportunidades de aprendizagem tecnoprodutivas importantes que o CTA e a Embraer trataram de aproveitar no desenvolvimento do EMB-200 Ipanema. Em primeiro lugar, projetar, desenvolver protótipos e testá-los; em segundo, passar da prototipagem para a produção seriada; em terceiro, comercializar o avião nos mercados interno e externo. Cada uma dessas etapas oferecia ao jovem sistema tecnoprodutivo brasileiro a chance de testar métodos, aperfeiçoar processos, enfim, expor o CTA, instituições associadas e a Embraer aos desafios de projetar, construir e vender um avião, ainda que enfrentando desafios menores do que os envolvidos no EMB-110 Bandeirante.

Batizado de Ipanema, nome da fazenda que sediava um centro de aviação agrícola do Ministério da Agricultura em Iperó, cidade vizinha a Sorocaba, interior de São Paulo, o projeto do avião agrícola começou a ser desenvolvido pelo Departamento de Aeronaves (PAR) do IPD/CTA com financiamento do Ministério da Agricultura em 1969. Com a criação da Embraer naquele mesmo ano e sua entrada em operação no ano seguinte, o desenvolvimento, produção e comercialização do Ipanema foram transferidos para a empresa nascente, assim como o EMB-110 Bandeirante e o planador EMB-400 Urupema, cujos projetos e desenvolvimento iniciais couberam ao CTA. Na Embraer, o Ipanema recebeu a designação EMB-200 Ipanema, com o qual viria a ser comercializado.

O EMB-200 Ipanema foi o segundo avião fabricado pela Embraer; a honra de inaugurar a linha de produção da empresa coube ao planador EMB-400 Urupema, cabendo ao EMB-326 Xavante e ao EMB-110 Bandeirante o terceiro e quarto lugares na fila, respectivamente - todos eles neste que seria o annus mirabilis da Embraer, 1971. Impressiona também a velocidade com que CTA e Embraer desenvolveram, produziram e comercializaram seus primeiros aviões: o Ipanema foi encomendado e projetado em 1969; o primeiro protótipo voou em 1970; em 1971 veio a primeira encomenda comercial, dez unidades compradas pela empresa Corsário de Aviação S.A., mesmo ano de sua certificação; a primeira entrega de um EMB-200 Ipanema sendo realizada no ano seguinte, 1972.

Com apoio governamental que incluiu a compra de aviões pelo Ministério da Agricultura para serem usados em cursos de aviação agrícola e a inclusão de aviões agrícolas entre os implementos passíveis de serem financiados por linhas de crédito para 
o agronegócio - efeito indireto do acelerado desenvolvimento do agronegócio brasileiro, afinal, os sistemas tecnoprodutivos aeronáutico e agropecuários brasileiros estavam se desenvolvendo ao mesmo tempo, frutos de um processo mais geral de desenvolvimento tecnoprodutivo pelo qual o país passava naquela quadra histórica,$- \mathrm{o}$ EMB-200 Ipanema logo conquistou uma posição importante no segmento de aviões agrícolas. O EMB-200 Ipanema foi também, junto com o EMB-110 Bandeirante, desbravador dos mercados externos, como já vimos: as primeiras vendas externas de aviões pela Embraer foram feitas para o Uruguai, que adquiriu cinco EMB-110 Bandeirante e dez EMB-200 Ipanema que começaram a ser entregues em 1975.

Nos anos seguintes, o EMB-200 Ipanema passaria por modificações incorporadas em diversas versões do avião, fazendo deste, como no caso do EMB-110 Bandeirante, um work in progress em que cada aprimoramento do projeto original gerava uma nova oportunidade de aprendizagem tecnoprodutiva ou comercial para a Embraer em particular e para o sistema tecnoprodutivo aeronáutico brasileiro de modo geral.

Em 1984, a Embraer comprou a empresa Indústria Aeronáutica Neiva S.A., subsidiária de Embraer que assumiria a produção do EMB-200 Ipanema e a produção sob licença de diversos modelos de aviões da americana Piper. O EMB-200 Ipanema seria continuamente aprimorado em sucessivas versões, entre as quais o EMB-202 Ipanema movido a etanol, desenvolvido em 2002 e recebendo certificação em 2004. Único avião fabricado desde a criação da Embraer, já foram entregues mais de 1.200 unidades do Ipanema em suas diferentes versões ao longo de quarenta anos de produção, com um market share no Brasil de $85 \%$ do segmento de aviões agrícolas.

Por modesto que seja do ponto de vista tecnológico, o EMB-200 Ipanema cumpriu um importante papel na evolução tecnoprodutiva e comercial da Embraer e, de lambuja, no desenvolvimento do agronegócio brasileiro. Calhou dos dois processos andarem juntos e se alimentarem mutuamente, com ambas as partes se beneficiando diretamente dos progressos tecnoprodutivos de um e outro setor.

\section{Outro modo de aprendizado pela prática: a produção sob licença}

Até agora reconstruímos a trajetória tecnoprodutiva de dois aviões projetados pelo CTA e instituições associadas, mais especificamente o Departamento de Aeronaves (PAR) do 
IPD; e desenvolvidos, produzidos e comercializados pela Embraer: o EMB-110 Bandeirante e o EMB-200 Ipanema e o EMB-400 Urupema. Já vimos a importância desses aviões na trajetória tecnoprodutiva do CTA e da Embraer, devido sobretudo às oportunidades de aprendizagem geradas ao longo do processo de projetar, produzir em série e comercializar os aviões. Esses aviões permitiram aos atores do sistema tecnoprodutivo aeronáutico brasileiro aprender fazendo, uma das formas mais importantes de aprendizagem quando se trata de desenvolvimento tecnoprodutivo, em função de seus efeitos de desenvolvimento e acúmulo de conhecimentos científicos, tecnológicos, de gestão e comerciais. E entre os modos possíveis de se aprender fazendo, a experiência adquirida com o EMB-110 Bandeirante e o EMB-200 teve a vantagem de ser um processo de ciclo completo, contemplando desde o projeto original até a comercialização, serviços de pós-venda e interação com os clientes para futuros aprimoramentos do projeto original, passando pelas fases de prototipagem, testes, certificação e desenvolvimento de métodos e processos de produção em série. De todos os modos de aprendizagem, este último, aprendizado pela prática de ciclo completo projeto-produção-comercialização, é seguramente o que gera o maior volume de conhecimento total e as maiores oportunidades de aproximar o sistema tecnoprodutivo da fronteira tecnoprodutiva do setor.

Há, no entanto, outros modos de aprender fazendo além do ciclo completo projetoprodução-comercialização que, ainda que menos intensivos em geração e acúmulo de conhecimento - isto é, mesmo gerando um volume de conhecimento menor em comparação ao ciclo completo projeto-produção-comercialização -, podem oferecer oportunidades muito importantes de desenvolvimento tecnoprodutivo. É o caso da produção sob licença de aviões de outras empresas, um dos modos mais disseminados de aprendizagem tecnoprodutiva no setor aeronáutico.

A principal vantagem da aprendizagem por meio da produção sob licença de aviões é permitir à empresa que assume a produção acumular e gerar conhecimento em fases específicas do ciclo completo de produção sem a necessidade de dominar todas as fases, em especial as mais complexas, como projeto, prototipagem e desenvolvimento de métodos e processos produtivos. Os processos de aprendizagem por meio da produção de aviões sob licença geram desenvolvimento e acúmulo incrementais de conhecimento, domínio de tecnologias maduras e experiência com fases menos complexas do ciclo. Colocam, por isso, a empresa que vai produzir aviões sob licença em contato com 
conhecimentos, tecnologias e processos mais avançados que ela não domina, sem que para isso ela precise passar por todas as fases de geração e acúmulo de conhecimentos. Os processos de aprendizagem por meio da produção sob licença permitem a uma empresa ou sistema tecnoprodutivo reduzir a distância da fronteira tecnoprodutiva sem que para isso seja preciso ter domínio completo de todos os conhecimentos que compõem o ciclo completo de projeto-produção-comercialização. Comparada ao processo de aprendizagem proporcionado por aprender fazendo o ciclo completo, essa é uma solução subótima, mas não necessariamente ruim, podendo até ser uma excelente opção se combinada a outras formas de aprendizagem. Quando uma estratégia de catchup está apoiada unicamente no desenvolvimento tecnoprodutivo por meio da produção sob licença, suas chances de sucesso são escassas, pois essa modalidade de geração e acúmulo de conhecimento não é capaz, por si só, de levar a empresa ou sistema tecnoprodutivo às imediações da fronteira tecnoprodutiva. Os conhecimentos gerados e acumulados por meio da aprendizagem por meio da produção sob licença são, forçosamente, incompletos, parciais e quase sempre referidos a tecnologias maduras ou mesmo próximas da condição de obsolescência tecnoprodutiva.

Quando combinada com outras formas de aprendizagem tecnoprodutiva, no entanto, a produção sob licença tem muito a contribuir para o sucesso de uma estratégia de catchup de um sistema tecnoprodutivo. A produção sob licença, quando complementar e secundária a outras modalidades de aprendizagem tecnoprodutiva, permite à empresa ou ao sistema tecnoprodutivo como um todo entrar em contato com tecnologias e processos que ela não domina e com isso preparar, com base nos demais processos de aprendizagem tecnoprodutiva, importantes avanços de suas capacidades tecnoprodutivas. Foi o que a Embraer fez com o EMB 326 Xavante.

A oportunidade de produzir sob licença o jato de treinamento Aermacchi MC 326 abriu dois novos campos de atuação para a Embraer: o primeiro, tecnológico - produção de um avião com propulsão a jato; o segundo, comercial - entrada no mercado de defesa com um avião exclusivamente militar, ao contrário do EMB-110 Bandeirante, de uso dual (civil e militar). Encomendado pela Força Aérea Brasileira, que queria substituir seus jatos T33A em operação, o MC 326 da Aermacchi foi escolhido de olho nas possibilidades de aprendizagem por meio da produção sob licença pela Embraer e posterior nacionalização da produção do avião. Projetado na década de 1950, portanto ainda na infância dos aviões a jato, e operando desde 1962, o MC 326 permitiria à 
Embraer aprender primeiro a montar a partir de kits completos e em seguida a produzir um avião a jato, tecnologia com a qual a empresa até então não havia lidado - lembre-se o leitor que o EMB-Ipanema é um monomotor turboélice, o EMB-110 Bandeirante um bimotor turboélice e o EMB-400 Urupema um singelo planador para competições de voo a vela. A propulsão a jato, portanto, era uma novidade para a Embraer.

Velharia, no entanto, para a indústria aeronáutica mundial. O primeiro avião a jato, o protótipo Heinkel HE 178, testado pela Luftwaffe foi construído em 1939. Foi por pouco que os nazistas não desenvolveram até o ponto de produção seriada caças a jato a tempo de serem usados em larga escala na guerra: o primeiro caça a jato da força aérea alemã, o Messerschmitt Me 262, entrou em linha de produção em 1944. Na verdade, a corrida tecnológica e militar para desenvolver e produzir seriadamente aviões de propulsão a turbojato envolveu, além dos alemães (com os modelos acima citados), italianos (Caproni Campini N.1, que fez seu primeiro voo em 1940), ingleses (Gloster E 28/39, primeiro voo em 1941 - protótipo do famoso Gloster Meteor, primeiro avião a jato a ser produzido em série pelos britânicos, começando a ser produzidos em 1943 e entrando em operação em 1944) e norte-americanos (Bell XP-59A, voo inaugural em 1942). Dos primeiros protótipos e aviões produzidos em série até o início dos anos 1970, a tecnologia de turbojatos havia evoluído muito e foi utilizada tanto em aviões militares como em aviões civis. Para uma empresa como a Embraer, recém-criada e disposta a realizar um catch-up tecnoprodutivo e se aproximar da fronteira tecnoprodutiva do setor aeronáutico daquele momento, aprender a lidar com aviões de propulsão a jato era parte fundamental de sua estratégia e sem a qual a empresa não conseguiria acompanhar de perto os avanços do setor aeronáutico mundial, correndo o risco de se ver presa a tecnologias e processos de desenvolvimento e produção maduros a caminho da obsolescência. O sistema tecnoprodutivo brasileiro, Embraer em particular, escolheu como forma de aprendizagem e domínio dessa tecnologia - o avião de propulsão a jato - a produção sob licença.

O contato com a tecnologia do motor a jato e a tarefa de produzir, ainda que a partir de kits completos ou contribuindo no máximo com modificações pontuais do projeto e integração de sistemas similares, aviões a jato, testar e acompanhar de perto a operação das unidades produzidas pela própria Embraer significava cumprir com uma parte importante dos requisitos demandados para a produção de aviões de modo geral e jatos em particular. Não se tratava, evidentemente, de aprender a fazer motores a jato; a 
Embraer, afinal, é uma OEM, interessada portanto em aprender a integrar sistemas e produzir seriadamente aviões de propulsão a jato.

A noção de sistema tecnoprodutivo não se esgota em suas dimensões tecnológicas, muito pelo contrário: o conceito procura justamente insistir na importância das dimensões institucionais, comerciais e mercadológicas dos processos de desenvolvimento, seja de empresas ou setores específicos, seja de países. No caso do EMB 326 Xavante, as dimensões institucionais, comerciais e mercadológicas proporcionariam aprendizados do mais alto valor para a Embraer e o restante do sistema tecnoprodutivo aeronáutico brasileiro. Se do ponto de vista tecnoprodutivo a produção de aviões sob licença é uma forma limitada e parcial de desenvolvimento e acúmulo de conhecimentos tecnológicos e produtivos, as possibilidades de aprendizagem institucional e mercadológica proporcionadas por essa modalidade de aprendizagem e desenvolvimento tecnológico podem ser enormes.

Do ponto de vista do aprendizado institucional, a produção sob licença do EMB 326 Xavante deu uma lições que a Embraer jamais esqueceria: em primeiro lugar, a experiência de estabelecer relações comerciais com a empresa italiana Aermacchi para transferência de tecnologia preparou o terreno para outras colaborações e cooperações internacionais, por exemplo, o desenvolvimento conjunto com a própria Aermacchi e a Aeritalia (atual Alenia Aeronautica) do jato de ataque AMX, nas décadas de 1970 e 1980. É razoável supor que essa lição tenha sido aplicada nas décadas de 1990 e 2000, quando a Embraer lançou mão de parcerias de risco para o desenvolvimento de seus produtos.

Quanto ao aprendizado mercadológico, o EMB 326 Xavante proporcionou à Embraer sua incursão na produção de aviões exclusivamente militares (o EMB-110 Bandeirante tinha versões militares, mas era basicamente um avião de transporte de passageiros e cargas), ainda que um avião militar de treinamento. Com isso, a Embraer desenvolveu conhecimentos - tecnológicos, institucionais e mercadológicos - que abririam caminho para seus mais importantes e bem-sucedidos projetos, os aviões de treinamento militar Tucano e Super Tucano.

A produção sob licença do MC 326 Aermacchi pela Embraer visava, de imediato, a permitir a substituição pela Força Aérea Brasileira de seus jatos T-33 A na função de avião de treinamento, e num segundo momento a nacionalização da produção. $\mathrm{O}$ avião 
produzido pela Embraer receberia a designação de EMB 326 Xavante. A FAB encomendou inicialmente 112 unidades do modelo para treinamento dos pilotos que operariam os caças supersônicos franceses Mirage III, em processo de aquisição pela FAB naquele momento. O EMB 326 Xavante foi produzido pela Embraer de 1971 a 1981, atingindo um total de cento e oitenta e duas unidades operadas pela FAB (167) e pelas forças aéreas do Paraguai (9) e Togo (6) ${ }^{10}$.

A curva de aprendizagem da Embraer pode ser aferida pelo seguinte fato: o EMB 326 Xavante foi o terceiro avião produzido pela Embraer e o primeiro jato produzido no Brasil. Os ganhos em conhecimentos tecnoprodutivos aeronáuticos foram importantes, pois a produção sob licença proporciona formas específicas, ainda que limitadas, de aprendizagem tecnoprodutiva.

Para produzir sob licença o EMB 326 Xavante, a Embraer precisou enviar engenheiros e técnicos à sede da Aermacchi, na Itália, na cidade de Varese, e recebeu engenheiros e técnicos italianos em suas instalações em São José dos Campos. O intercâmbio de capacitar pessoal da Embraer a produzir o MC 326 Aermacchi/ EMB 326 Xavante proporcionou à empresa e ao sistema tecnoprodutivo aeronáutico brasileiro a oportunidade de engajar-se em um processo de transferência tecnológica bastante intenso e sem o qual o país não conseguiria apresentar pesquisadores, engenheiros e técnicos à tecnologia dos aviões de propulsão a jato. A transferência tecnológica consiste não apenas no acesso aos conhecimentos codificados, seja em manuais, seja em artefatos tecnológicos, mas também aos conhecimentos não codificados frutos de longos processos de aprendizagem prática. O contato com engenheiros e técnicos brasileiros com seus pares italianos permitiu àqueles entrarem em contato com conhecimentos não codificados adquiridos ao longo de muitos anos de experiência prática por parte daqueles, que eram assim transmitidos, o quanto possam ser transmitidos conhecimentos não codificados, para a Embraer. Isso equivaleu a acelerar o processo de aprendizagem da empresa brasileira com um empurrão inicial, e não se deve de modo algum subestimar o papel dessa forma de aprendizagem. $O$ intercâmbio dos conhecimentos sobre técnicas e processos de produção de aviões a jato fez com que a Embraer avançasse em sua curva de aprendizagem sem precisar se submeter a formas mais completas - e complexas - de aprendizagem, por exemplo, a produção de ciclo completo. Transferência tecnológica parcial, mas ainda assim transferência - e quando

\footnotetext{
${ }^{10}$ Centro Histórico Embraer.
} 
se trata de reduzir a distância da fronteira tecnológica por meio de uma estratégia de catch-up, é preciso acelerar o processo e queimar etapas tecnoprodutivas mais maduras e fazer em poucos anos o que outros fizeram em muitos.

A aprendizagem mais relevante e de maiores consequências, no entanto, era aprender a produzir seriadamente aviões a jato. Essa, sem dúvida, a maior contribuição do EMB 326 Xavante ao sistema tecnoprodutivo aeronáutico brasileiro. Produzir sob licença não é um processo irreflexivo, maquinal, que dispensa aprendizados técnicos, científicos, institucionais. É expor todo o sistema tecnoprodutivo - engenheiros e técnicos, instituições de formação de recursos humanos, de pesquisa e desenvolvimento, empresas, instituições públicas do setor aeronáutico - a uma nova tecnologia: o motor a jato, que deve, por isso, vir acompanhada de outras tecnologias - de processo, de gestão, institucionais, políticas -, resultando num amplo processo de aprendizagem tecnoprodutiva. Se por um lado a produção sob licença é uma forma relativamente limitada de desenvolvimento e acúmulo de conhecimento tecnoprodutivo, permitindo apenas uma transferência parcial de tecnologia, quando aliada a uma estratégia que contempla projeto e produção de ciclo completo, pode acelerar muito o processo de absorção e aprendizagem tecnológica.

Dos modos de aprendizagem tecnoprodutiva, a produção sob licença é a menos glamorosa e a mais arriscada; os riscos, no entanto, não lhe são inerentes, genéticos, resultam antes da ausência de modos complementares de aprendizagem tecnoprodutiva. No caso da Embraer, a aprendizagem por meio da produção sob licença foi complementada por outra forma de aprendizagem: a aprendizagem por ciclo completo projeto-produção-comercialização, como no EMB-110 Bandeirante. Tudo isso contaria mais tarde, e muito, quando a Embraer deu o seu mais arrojado passo, que consistiu em desafiar as principais OEMs produtoras de jatos regionais desenvolvendo e produzindo sua própria família de jatos regionais.

Na década de 1970 a Embraer lançaria mão da produção sob licença como forma de aprendizagem tecnoprodutiva e transferência tecnológica em acordo com a empresa aeronáutica americana Piper. O contrato incluía inicialmente quatro modelos: os bimotores EMB 810 Sêneca e EMB 820 Navajo, e os monomotores EMB 721 Sertanejo e EMB 720 Minuano. Por meio de parcerias com a empresa Sociedade Construtora Neiva, a linha Piper da Embraer ainda seria acrescida dos monomotores EMB 710 
Carioca, EMB 711 Corisco e EMB 712 Tupi, e posteriormente da fabricação da versão turboélice do EMB 820 Navajo. Outra empresa aeronáutica brasileira, a Aerotec, seria encarregada da produção de componentes da linha Piper. A produção sob licença não criou benefícios apenas para a Embraer, gerando também spillovers para outras empresas do sistema aeronáutico brasileiro, qualificando o setor e diversificando a produção nacional de aviões. Prova de que, quando complementar a outras formas de aprendizagem tecnoprodutiva - pois apenas com a produção sob licença não é possível realizar o catch-up tecnoprodutivo -, a produção sob licença pode desempenhar um papel importante numa estratégia mais ampla de catch-up.

Uma estratégia bem-sucedida de catch-up não para, no entanto, na construção de um sistema tecnoprodutivo aeronáutico completo com instituições de formação de pessoal, institutos de pesquisa e desenvolvimento e criação de uma empresa comercial, tampouco se esgota no desenvolvimento de projeto e produção de ciclo completo ou nos acréscimos incrementais advindos da produção sob licença. É preciso manter-se nas proximidades da fronteira tecnoprodutiva e sustentar os avanços alcançados. 


\section{Capítulo 4: A competição hoje: a Embraer e o segmento de jatos regionais}

Não demorou muito para que a Embraer elegesse os aviões regionais como seu principal produto: em 1974, pouco tempo depois dos primeiros EMB-110 Bandeirante começarem a ser entregues, a Embraer já partia para o desenvolvimento do seu segundo avião regional, o EMB-120 Brasília, incorporando diversos elementos de seu aprendizado anterior com o EMB-110 Bandeirante e demais aviões desenvolvidos ou produzidos sob licença pela empresa.

O projeto do EMB-120 Brasília foi lançado oficialmente em 1979. Destinado à aviação regional, o EMB-120 Brasília, turboélice de cabine pressurizada com capacidade para até trinta passageiros, incorporou avanços tecnológicos importantes em comparação ao EMB-110 Bandeirante. Segundo o Centro Histórico Embraer, o EMB-120 Brasília "tinha a mesma empenagem em "T" do Xingu e asa de perfil supercrítico. Foi o primeiro avião a usar as recém-criadas turbinas PW115 de $1.500 \mathrm{HP}$, fabricadas pela Pratt \& Whitney, que, em conjunto com as hélices desenvolvidas pela Hamilton Standard, permitiriam ao bimotor chegar à velocidade superior a $500 \mathrm{~km} / \mathrm{h}$. O avião também apresentava algumas comodidades, como ar condicionado durante o voo e baixo nível de ruído e vibração" $"$.

O componente tecnológico do processo de aprendizagem proporcionado pelo EMB-110 Bandeirante e outros projetos da Embraer não foi o único aproveitado no desenvolvimento do projeto do EMB-120 Brasília. A certificação do avião, fase crítica do processo de comercialização de novos modelos, beneficiou-se das campanhas de homologação de aviões pela Embraer anteriores. Neste ponto, a experiência com certificação em agências internacionais mostrou-se muito importante, uma vez que desfez barreiras de entrada ao mercado internacional para o EMB-120 Brasília. Tendo feito seu primeiro voo em julho de 1983 e entrado em produção em 1984, o EMB-120 Brasília obteve certificação nacional homologada pelo CTA em maio de 1985 e certificação internacional pela agência alemã de aviação civil no ano seguinte, 1986.

\footnotetext{
${ }^{11}$ Centro Histórico Embraer.
} 
Além dos avanços tecnológicos e da experiência em campanhas de certificação de seus aviões, o EMB-120 Brasília contou ainda com uma vantagem adicional em relação aos primeiros projetos da Embraer: a maior capacidade de comercialização do avião e conhecimentos mais avançados em inteligência de mercado adquiridos pela empresa com a experiência anterior da venda de aviões para os mercados nacional e internacional. As redes de clientes e os modos de interação já haviam sido desenvolvidos, presume-se que a muito custo, durante o processo de comercialização, serviços de pós-vendas e feedback dos usuários de aviões anteriores da Embraer, especialmente o EMB-110 Bandeirante, e foram aproveitadas para dar suporte ao novo projeto. Nesse meio tempo, a Embraer estabeleceu sua subsidiária europeia, a Embraer Aviation International (EAI), sediada em Paris. A EAI daria suporte não só para as operações comerciais e de apoio técnico na Europa, como também para clientes da África e do Oriente Médio.

O EMB-120 Brasília foi um grande sucesso comercial, sobretudo no mercado internacional, mais precisamente nos mercados norte-americano e europeu. Ao contrário do EMB-110 Bandeirante, inicialmente encomendado pela Força Aérea Brasileira para se viabilizar produtiva e comercialmente e só depois vendido no exterior (a princípio às forças armadas uruguaias, em seguida a uma empresa francesa de aviação comercial), o EMB-120 Brasília estreou direto no mercado internacional. De acordo com o Centro Histórico Embraer, "antes mesmo da primeira entrega, [o EMB-120 Brasília] já era o avião de sua classe mais vendido no mundo. A primeira empresa aérea a receber o Brasília foi a norte-americana Atlantic Southeast Airlines, baseada em Atlanta, no estado da Geórgia, em 1985"12.

Na década de 1990 a Embraer desenvolveu o Plano de Manutenção Programada do EMB-120 Brasília, uma nova metodologia de manutenção que reduziu os custos de operação do modelo, tornando-o ainda mais competitivo; e lançou uma versão adaptada do avião capaz de operar com passageiros e carga. A empresa produziu mais de 350 unidades do EMB-120 Brasília, operadas por cerca de trinta companhias de aviação comercial de vários países, entre as quais a francesa Air Littoral, primeira empresa estrangeira a adquirir um EMB-110 Bandeirante - fato que fala por si só em termos de satisfação do cliente com os aviões da Embraer. O EMB-120 Brasília operado pela Air Littoral, diga-se de passagem, era na década de 1980 o aparelho com melhor

\footnotetext{
${ }^{12}$ Centro Histórico Embraer.
} 
desempenho de toda a frota mundial desse modelo, o que mostra também a importância para uma OEM do acesso ao conhecimento desenvolvido e acumulado pelos clientes que operam seus aviões em condições comerciais, fazendo do feedback do cliente outra forma de aprendizagem tecnoprodutiva para a Embraer.

A segunda incursão da Embraer no mercado de aviões regionais, a bordo do EMB-120 Brasília, beneficiou-se, e muito, de toda a experiência anterior adquirida no desenvolvimento, produção e comercialização do EMB-110 Bandeirante. Com efeito, a partir do EMB-120 Brasília, a Embraer assumiria lugar de destaque no segmento de aviões regionais e assim continuaria pelas décadas seguintes até o ponto em que se encontra atualmente, dividindo com a Bombardier o título de maior fabricante de aviões regionais do mundo. O EMB-120 Brasília representou um passo a mais em direção à proeminência da Embraer como fabricante de aviões regionais.

O passo seguinte, contudo, foi em falso: o EMB/CBA 123 Vector. A rigor, se por um lado o EMB-120 Brasília é herdeiro direto da aprendizagem acumulada pela Embraer no desenvolvimento, produção e comercialização de seu primeiro avião regional, o EMB110 Bandeirante, não é o substituto deste último em termos de projeto e de segmento de mercado. Se havia importantes sobreposições tecnoprodutivas relativas a projeto, prototipagem, testes, manufatura e certificação entre os dois modelos, o aspecto comercial dos dois primeiros aviões regionais de Embraer comportava diferenças importantes em termos de mercado, operação e desempenho. Com maior capacidade de passageiros e melhor desempenho, o EMB-120 Brasília estava apto a operar em distâncias maiores e como meio de transporte complementar a linhas comerciais de aviões de médio e grande porte. O EMB-110 Bandeirante, por sua vez, não obstante suas qualidades técnicas, operacionais e comerciais, ia aos poucos ficando defasado em termos de desempenho em relação a aviões do mesmo tamanho operando em rotas diretas entre cidades menores. A Embraer precisava desenvolver um avião de transporte regional de pequeno porte com desempenho superior aos turboélices da década de 1970, caso do seu EMB-110 Bandeirante. Começaram então os estudos para o desenvolvimento do EMB 123.

Com os estudos de mercado e o pré-projeto do avião já avançados, o desenvolvimento do EMB 123 foi acrescido de um componente geopolítico que se mostraria ao fim prejudicial ao projeto: o estabelecimento de um acordo de cooperação de 
desenvolvimento e produção do EMB 123 com a Argentina. A Fábrica Argentina de Material Aeroespacial (FAMA) formaria a parceria com a Embraer para desenvolver, produzir e comercializar o EMB 123, rebatizado depois da assinatura do acordo de cooperação de CBA 123 Vector (Cooperação Brasil Argentina) ${ }^{13}$. O objetivo declarado do programa era produzir um avião competitivo em mercados internacionais, e não apenas substituir similares em operação nos dois países.

Já vimos que, a essa altura - meados dos anos 1980 -, o sistema tecnoprodutivo aeronáutico argentino já havia passado de seu ponto ótimo e começava a declinar. Sujeito às idas e vindas de governos civis e militares, incapaz de formar recursos humanos em quantidade suficiente para atender à demanda de sua indústria aeronáutica, escassa e sazonalmente financiados pelo governo de turno e sofrendo as consequências de um setor francamente voltado à aviação militar e com pouco interesse pelo lado comercial da indústria aeronáutica, o governo Argentino viu na possibilidade de cooperação não apenas uma oportunidade de se envolver em um processo de aprendizagem e transferência tecnológica com uma empresa que começava claramente a dominar o mercado de aviões regionais - além de estar muito bem posicionada no setor de aviação militar por conta do programa AMX e do desenvolvimento do Tucano -, mas também e talvez até de superar a maior de todas as deficiências do sistema tecnoprodutivo aeronáutico argentino: a pouca experiência em comercialização de aviões e em inteligência de mercado. Com a parceria com o Brasil a Argentina vislumbrava uma chance de desenvolver os conhecimentos que permitiriam ao seu setor aeronáutico realizar a convergência das tendências tecnológicas e de mercado, que a Embraer dominava bem.

O EMB/CBA 123 Vector chegou a voar - dois protótipos foram construídos -, realizando seu primeiro voo em junho de 1990, mas o projeto não vingou e foi encerrado no ano seguinte. Nenhum dos sessenta aviões da encomenda inicial foi produzido, colocando um fim ao acordo de cooperação entre Brasil e Argentina.

Fatores de ordem externa tornaram o projeto inexequível. Pesaram contra a continuidade do projeto do EMB/CBA 123 Vector seus altos custos de produção: o virtuosismo tecnológico do avião não era viável economicamente, isto é, a relação entre

\footnotetext{
${ }^{13}$ Segundo o Centro Histórico Embraer, "inicialmente, o novo avião havia sido apelidado de "Paraná" pelos argentinos, e de "Tapajós", pelos brasileiros, mas, como o principal objetivo era atingir o mercado internacional, deveria ter um nome mais fácil de pronunciar. Por isso, foi realizado concurso internacional que recebeu mais de seis mil sugestões. O nome escolhido foi Vector". Centro Histórico Embraer, Histórico CBA 123 Vector.
} 
qualidade tecnológica e custos de produção não era competitiva em relação aos aviões da categoria do EMB/CBA 123 Vector. O ponto ótimo de um projeto, em termos comerciais, é o ponto em que o custo de produção maximiza a qualidade tecnológica sem perder competitividade no mercado.

O momento pelo qual passavam as economias latinoamericanas também não era dos mais propícios a investimentos de alto risco, como é o caso do setor aeronáutico: nem a FAMA, nem a Embraer, nem mesmo os governos de Brasil e Argentina tinham fôlego financeiro para bancar um projeto repleto de incertezas e desafios tecnoprodutivos e comerciais.

Outra razão para o fracasso do projeto do EMB/CBA 123 Vector diz respeito a uma mudança do mercado internacional de aviação que desta vez a Embraer demorou a perceber: o aumento da demanda por aviões com maior capacidade de passageiros. Construído na plataforma do EMB 120 Brasília, destinado a substituir o EMB-110 Bandeirante no segmento de aviões regionais de pequeno, o EMB/CBA 123 Vector foi projetado em um momento em que a demanda do mercado de aviões regionais estava mudando para aparelhos com maior capacidade de passageiros - uma das razões, aliás, que levou a Embraer anos antes a desenvolver o EMB 120 Brasília, com capacidade para trinta passageiros, atenta à mudança do perfil da aviação comercial mundial em direção a aviões médios. Os fatores que levaram a Embraer a projetar um avião regional com maior capacidade de passageiros continuavam definindo as tendências do mercado aeronáutico. No momento em que estava sendo projetado, não havia mais espaço no mercado, isto é, demanda, por um avião com a capacidade para doze passageiros como o EMB/CBA 123 Vector.

Nem tudo nesse projeto, no entanto, foi prejuízo. Dele ficaram três lições: a primeira, a conscientização por parte da Embraer de que, no futuro próximo, a tendência da aviação regional seria de aumento da capacidade de passageiros dos aviões; a segunda, a percepção de que os aviões regionais teriam, cada vez mais, de ter desempenho superior ao permitido pelos motores turboélices, levando a trajetória tecnológica dos aviões regionais a embicarem em direção ao motor a jato; a terceira, o desenvolvimento pela Embraer durante o projeto do EMB/CBA 123 Vector do conceito tecnoprodutivo de família de produtos, aplicado às famílias ERJ e E-Jets, que marcaria todos os passos posteriores de seus aviões regionais. 


\section{Uma nova estratégia tecnoprodutiva e comercial: as famílias de jatos regionais da Embraer ERJ e E-Jets}

Decidida a manter sua posição no mercado de aviação comercial especializando-se no segmento de aviões regionais, a Embraer se preparou para dar um novo salto evolutivo. Salto, e não passo, pois, como viria a provar o fracasso do projeto do EMB/CBA 123 Vector, as mudanças pelas quais passava o mercado de aviões regionais estavam reconfigurando radicalmente a demanda: aviões com maior capacidade de passageiros e com desempenho bastante superior aos turboélices que até então dominavam o segmento. A combinação da adaptação de uma plataforma de um turboélice de pequena capacidade de passageiros com inovações e melhorias incrementais e a adoção de motores turboélice cujo desempenho se aproximasse de motores a jato não seria suficiente, como ficou demonstrado pelo fracasso do EMB/CBA 123 Vector. Essa solução seria subótima e colocaria no mercado um aparelho que em poucos anos estaria obsoleto, incapaz de competir com aviões com maior capacidade de passageiros e com o desempenho dos motores a jato.

A demanda do mercado internacional de aviação comercial por aviões regionais com maior capacidade de passageiros e desempenho superior aos turboélices em operação problema cuja solução não passava mais pela evolução incremental dos motores turboélices, mas pela adoção de motores a jato - foi captada pela Embraer durante o desenvolvimento do EMB/CBA 123 Vector; a consciência desse novo estado de coisas levou ao encerramento do projeto, não apenas por razões de ordem técnica, mas pelas mudanças da configuração do mercado de aviões regionais nas décadas seguintes.

Uma vez gerada essa interpretação sobre os desenvolvimentos futuros do mercado de aviões regionais - aparelhos com maior capacidade de passageiros e propulsão a jato cumpria agora desenhar uma estratégia tecnoprodutiva e comercial adequada à perspectiva de como seria a nova configuração do mercado. Delinear uma estratégia tecnológica e comercial envolve um alto grau de risco, uma vez que se trata de imaginar desenvolvimentos futuros de um conjunto muito grande de fatores interligados influenciando-se mutuamente: evolução da aviação comercial e do número de passageiros, modelos de logística de transporte aéreo, trajetórias de inúmeras tecnologias que se combinam para dar forma a um avião, regulação do setor, preço do combustível de aviação, estrutura da cadeia de fornecedores, competição com outras 
OEMs, entre outros. Uma aposta errada, no setor aeronáutico, pode colocar tudo a perder, tão vultosos são os investimentos necessários para o desenvolvimento de um avião. Vindo de um projeto que fracassou (EMB/CBA 123 Vector), a Embraer tinha muito pouco espaço para erros.

No papel, a estratégia que a Embraer deveria traçar para manter sua posição no segmento de aviões regionais era bastante simples. Eram dois os critérios definidores da evolução futura do segmento: 1) aviões com maior capacidade de passageiros e 2) com alto desempenho, que naquele momento equivalia a dizer: com propulsão a jato. A empresa deveria, portanto, desenvolver um avião que atendesse a esses dois critérios. Nasceu assim o EMB 145, depois rebatizado de ERJ 145, que mais tarde seria a base da família ERJ, conceito tecnoprodutivo central dos jatos regionais da Embraer desde então.

Alinhado à tendência prevista para o segmento de aviões regionais nas décadas seguintes pela Embraer, o EMB/ERJ 145 foi projetado com capacidade para cinquenta passageiros, propulsão a jato e a exigência de ter custos operacionais compatíveis com os de aviões regionais turboélices. O desenvolvimento do projeto do ERJ $145^{14}$ teve início no ano de 1989 - dois anos, portanto, depois do início do projeto do EMB/CBA 123 Vector. A crise econômica pela qual passava o Brasil naquele momento, no entanto, paralisou o projeto de desenvolvimento do ERJ 145, que só seria retomado em 1991. Os dois anos entre o lançamento oficial do projeto e seu início efetivo deram tempo à Embraer de fazer algumas alterações de projeto importantes para o desempenho operacional do ERJ 145, entre as quais sua adaptação para operar em pistas curtas e o aumento de sua capacidade de pousos e decolagens ${ }^{15}$. Essas alterações expandiram as condições de operação do ERJ 145, aumentando a competitividade do avião frente a outros modelos com limitações relativas a tamanho de pista e capacidade de pouso e decolagem.

As décadas de 1980 e 1990 foram anos de muitas e importantes transformações em todo o setor aeronáutico mundial, e não apenas na trajetória tecnoprodutiva e comercial específica dos aviões regionais. A estrutura do setor mudou radicalmente, sobretudo no que diz respeito à organização, hierarquia e localização geográfica das cadeias de

\footnotetext{
${ }^{14}$ O projeto nasceu com a tradicional designação dos aviões da Embraer - EMB 145; em 1997, no entanto, o avião passou a ser designado pela sigla ERJ 145, ERJ valendo por Embraer Regional Jet. Para facilitar a vida da leitora, Daqui em diante irei me referir ao EMB 145 apenas por sua designação atual, ERJ 145.

${ }^{15}$ Centro Histórico Embraer, Histórico ERJ 145.
} 
fornecedores. A principal mudança foi a adoção de parcerias de compartilhamento de riscos (risk sharing) como modo de distribuir os custos de desenvolvimento de novos produtos ao longo da cadeia, reduzindo os riscos para as OEMs. As OEMs deixaram de ser desenvolvedoras diretas de tecnologia de sistemas e componentes, passando a liderar o desenvolvimento de tecnologias pela demanda junto à cadeia de fornecedores. A Embraer não ficou à margem dessas alterações, adotando ela também a estratégia de compartilhamento de riscos com sua cadeia de fornecedores.

O compartilhamento de risco entre OEMs e fornecedores consiste em um acordo de desenvolvimento de componentes e sistemas liderado pela OEM, isto é, determinado pelas necessidades tecnoprodutivas da OEM, em parceira com seus fornecedores, que assumem parte substantiva dos investimentos e desafios de desenvolvimento tecnológico e inovação sob a seguinte cláusula: a remuneração dos investimentos feitos pelo fornecedor no desenvolvimento de alguma encomenda da OEM só ocorre em caso de sucesso comercial do programa específico no qual o fornecedor está envolvido. Em outras palavras, o retorno do investimento depende do sucesso comercial do avião projetado, desenvolvido, integrado e comercializado pela OEM. A aposta é alta, mas como o retorno é diretamente proporcional ao risco, a cooperação de fornecedores com OEMs capazes de desenvolver projetos de sucesso pode gerar elevados retornos.

Essa forma de arranjo produtivo exige que a OEM desenvolva capacitações de grande complexidade em projeto e gestão da cadeia produtiva para coordenar centenas de fornecedores espalhados por vários países - além das alterações relativas à organização e hierarquia das cadeias produtivas da indústria aeronáutica mundial, o setor também passou por mudanças na localização geográfica de produtores tradicionais. Afora isso, a entrada de novos produtores de países com menos tradição no setor aeronáutico aumentou ainda mais a complexidade da gestão da cadeia de fornecedores. Com efeito, muitas OEMs tradicionais do setor aeronáutico passaram por dificuldades na década de 1990 por conta da incapacidade de coordenar múltiplos atores em torno de um projeto aeronáutico, como a holandesa Fokker (1919-1996), uma das mais importantes fabricantes de aviões regionais até as vésperas de sua falência.

Um dos principais efeitos da reorganização da estrutura produtiva do setor aeronáutico mundial nas décadas de 1980 e 1990 foi a convergência das estratégias tecnoprodutivas das OEMs por meio de suas ligações com os chamados fornecedores nível 1, grandes 
empresas sistemistas e produtores de componentes de alto conteúdo tecnológico que fazem a intermediação entre as OEMs, a montante da cadeia produtiva e, a jusante, as fornecedoras de partes e sistemas de média e baixa complexidade, ou de níveis 2 e 3 . As empresas do nível 1 são integradoras de componentes e sistemas aviônicos, de estrutura e de propulsão, localizando-se logo abaixo das OEMs na cadeia produtiva aeronáutica. Entre os fornecedores da indústria aeronáutica, são as empresas maiores, mais complexas e tecnologicamente mais avançadas e desempenham um papel fundamental ao desenvolverem soluções de grande espectro de aplicação adotadas em maior ou menor grau por várias ou mesmo todas as atuais grandes OEMs que formam o duplo duopólio Boeing-Airbus e Embraer-Bombardier.

Essas conexões indiretas entre OEMs via fornecedores tornou mais clara a divisão entre líderes e seguidores de desenvolvimento tecnológico no setor aeronáutico, e esse ponto é muito importante numa análise de estratégias de catch-up aeronáutico. A forma de organização da atual estrutura da indústria aeronáutica mundial gera spillovers tecnológicos que fluem dos líderes de desenvolvimento tecnológico para os seguidores pela cadeia de fornecedores. Essa estrutura potencializa as externalidades positivas associadas ao desenvolvimento tecnológico de empresas individuais: os desenvolvimentos tecnológicos dos líderes são internalizados por um conjunto maior de fornecedores da cadeia diretamente ligada à OEM, mas também de modo indireto por seus competidores: outras OEMs.

Há um risco, contudo, que toca em especial a Embraer, que diz respeito à acomodação de uma empresa, por vocação ou necessidade, na posição de seguidora de desenvolvimento tecnológico alheio. Se por um lado os incentivos financeiros e tecnológicos para essa acomodação não são desprezíveis - afinal, os custos de desenvolvimento de um componente ou sistema por fornecedores sob demanda de outras OEMs não incidem diretamente sobre a seguidora de desenvolvimento tecnológico, essa estratégia só é positiva no curto prazo; com o passar do tempo ela começa a ter retornos decrescentes até o ponto de inversão da tendência, em que a empresa fica ameaçada de se inviabilizar tecnologicamente e, em consequência, financeira e comercialmente, pois a distância da fronteira tecnológica começará a aumentar. Não basta ser usuário das tecnologias mais avançadas, e mesmo essa tarefa aparentemente trivial - comprar tecnologia desenvolvida pelos líderes de desenvolvimento tecnológico do setor - exige desenvolver conhecimentos 
tecnoprodutivos que qualifiquem a empresa seguidora/usuária de desenvolvimento tecnológico de terceiros a incorporar componentes e sistemas a seus projetos. A correta utilização de uma tecnologia demanda graus mínimos de proficiência nos conhecimentos tecnoprodutivos a ela associados. No caso da indústria aeronáutica, a inexistência de laboratórios avançados e engenheiros e técnicos qualificados impedirá, já no médio prazo, a utilização de tecnologias alheias nos projetos da empresa seguidora. Dilema: tentar inovar e ser líder em desenvolvimento tecnológico, com todos os riscos e incertezas que isso comporta, ou beber dos spillovers gerados pelas empresas líderes?

Por um lado, se a empresa líder de desenvolvimento tecnológico assume os riscos de perseguir a inovação, o fato é que ela, por seu pioneirismo, é a primeira a colher os frutos de seus avanços; vantagens de quem chega antes. Entre essas vantagens, a definição das trajetórias tecnológicas futuras do setor é das mais relevantes.

A competitividade de aviões comerciais é em grande parte função de seu desempenho operacional, do qual a eficiência energética é um dos aspectos mais importantes. Antes do advento das estruturas em materiais compósitos, a competição por melhorias de desempenho dos aviões envolvia, sobretudo, motorização e aerodinâmica. Como são tecnologias maduras e acessíveis por meio de transações de mercado - compra e venda e suas variantes -, o espaço de competição é pequeno. No entanto, uma vez incorporados materiais compósitos na fabricação das estruturas de seus aviões, a empresa passa a contar com dois diferenciais competitivos, um relativo, outro absoluto. O diferencial competitivo relativo diz respeito a motorização e aerodinâmica, das quais todas as empresas possuem capacidades tecnoprodutivas ou compram de um pequeno conjunto de fornecedores - por exemplo, a vantagem competitiva de um avião sobre outro em termos de motorização pode ser anulada pela aquisição de motores iguais; trata-se, afinal, de tecnologia madura, cujos conhecimentos necessários para sua integração a projetos de aviões já dominados pelas OEMs contemporâneas. A questão pode ser solucionada pela aquisição de motores iguais, equivalentes ou superiores. $\mathrm{O}$ diferencial competitivo absoluto diz respeito à nova tecnologia - materiais compósitos , que ainda não é acessível por mecanismos de mercado, já que o domínio dos conhecimentos necessários para sua utilização constitui uma barreira de entrada para as demais empresas, dando à empresa pioneira em seu desenvolvimento e adoção uma vantagem competitiva que não está imediatamente disponível para os demais 
competidores. A empresa que primeiro incorporou materiais compósitos para fabricação de estruturas terá não apenas alterado radicalmente os parâmetros da competição pela introdução de um terceiro componente na equação que define o desempenho operacional de um avião, como também passará a definir as trajetórias tecnológicas futuras, - tanto das tecnologias diretamente implicadas (utilização de materiais compósitos em estruturas de aviões), como de tecnologias indiretamente associadas por exemplo, a possibilidade de adotar, em função do menor peso do avião com estrutura em materiais compósitos, sistemas de taxiamento auxiliares que diminuam ou dispensem o uso das turbinas, reduzindo ainda mais o consumo de combustível e a emissão de poluentes e ruídos, melhorando consequentemente o desempenho operacional da aeronave.

Os conhecimentos tecnoprodutivos necessários para utilização de uma nova tecnologia não estão, no primeiro momento, disponíveis para todas as empresas. A empresa pioneira no desenvolvimento e utilização de uma nova tecnologia - a empresa líder de desenvolvimento tecnológico - terá, desse modo, se posicionado na fronteira tecnoprodutiva do setor e passará a definir, em conjunto com os seus parceiros de desenvolvimento da nova tecnologia, as trajetórias tecnológicas futuras do setor. São esses momentos de entrada em cena de tecnologias disruptivas, que agregam um diferencial de competitividade muito maior do que aquele possível nos moldes da arquitetura tecnoprodutiva anterior, em que empresas, setores e países ficam para trás, tornando-se espectadores - passageiros, para ficar com uma imagem aeronáutica - dos desenvolvimentos futuros.

Um conjunto de fatores, entre os quais dificuldades financeiras da Embraer e do Brasil, mudanças na demanda por aviões regionais, que dali em diante deveriam ter maior capacidade de passageiros e desempenho de aviões a jato, alterações na estrutura das cadeias produtivas da indústria aeronáutica mundial, exigiu que a Embraer alterasse sua estratégia tecnoprodutiva, tanto no que concerne ao novo avião a ser projetado - um jato com maior capacidade de passageiros - quanto a sua relação com a cadeia de fornecedores - parcerias de compartilhamento de risco com fornecedores internacionais. Nesse contexto teve início o desenvolvimento do ERJ 145. A qualidade do projeto garantiu que ele fosse retomado, atraindo importantes fornecedores internacionais dispostos a tomar parte no seu desenvolvimento compartilhando o risco, portanto apostando na viabilidade tecnoprodutiva e comercial do avião - que realmente se 
mostraria um sucesso. Foi o início das parceiras estratégicas entre a Embraer e sua cadeia de fornecedores, que contava com acordos de parcerias de riscos com a espanhola Gamesa, a norte-americana C\&D, a chilena ENAER e a belga Sonaca. A cadeia de fornecedores era composta ainda por sistemistas como a britânica RollsRoyce, as norte-americanas Honeywell, Goodrich, Hamilton Sundstrand, Parker Aerospace, Sierracin e EATON, a suíça Liebherr e a francesa Thales, além de mais de 350 fornecedores menores ao redor do mundo.

Lançado em 1989, mas tendo que aguardar dois anos até seu início efetivo por causa da crise econômica brasileira e da crise financeira que a própria Embraer vinha enfrentando desde fins dos anos 1980, o projeto do ERJ 145 passaria ainda por um segundo e mais delicado período: a privatização da Embraer, em 1994. Muita coisa mudou na empresa, e o ERJ 145 passou a ocupar o centro de sua estratégia, que agora visava não apenas consolidar sua boa posição no segmento de aviões regionais como também disputar a liderança com as empresas líderes do segmento. A qualidade do projeto do ERJ 145 e as parcerias estratégicas eram alguns dos atrativos oferecidos aos eventuais compradores da Embraer em sua privatização.

A década de 1990 foi um período bastante agitado para a Embraer: começou com a combinação de crise financeira da empresa com a crise econômica; passou pelo encerramento de um projeto - CBA 123 - que, caso seguisse adiante e entrasse em produção, chegaria ao mercado em estado avançado de obsolescência; culminou com a privatização da Embraer, adquirida pelos bancos Bozano Simonsen, Wasserstein e Perella (que sairíam da sociedade em 1996) com participação dos fundos de previdência Previ, do Banco do Brasil, e Sistel.

Por outro lado, foi nos anos 1990 que a Embraer desenvolveu o ERJ 145 e a subsequente família de jatos ERJ. Paralelamente, a empresa desenvolveu uma nova geração do avião de treinamento Tucano, o Super Tucano, e uma variante armada desse modelo; e, de lambuja, teve $20 \%$ de suas ações vendidas para um grupo composto pelas empresas francesas do setor aeronáutico francesas Dassault, Thales e Snecma e pela empresa pan-europeia EADS, no que a Embraer chamou de parceria estratégica.

Talvez a principal vantagem tecnoprodutiva e comercial das famílias de jatos ERJ e EJets da Embraer sobre seus concorrentes, em especial em relação à Bombardier, resida no fato de que as plataformas de cada família foram desenvolvidas para atender às 
demandas e necessidades específicas identificadas pela inteligência de mercado e tecnológica da empresa, e não adaptadas a partir de outros projetos. A importância reside no fato de que nos casos em que uma plataforma é desenvolvida a partir do zero, tanto o projeto do avião quanto o processo tecnoprodutivo e comercial são otimizados para aquelas demandas e necessidades.

A família E-Jets foi desenvolvida para atender ao segmento de aviões situado entre os jatos regionais, com capacidade máxima de passageiros na casa dos setenta, e os narrow-bodies, com capacidade máxima de passageiros na faixa de cento e cinquenta a duzentos. A expansão do mercado de aviação comercial gerou oportunidades para o desenvolvimento de jatos regionais capazes de atender a rotas de média a alta densidade, para as quais os aviões com capacidade máxima de até cinquenta passageiros, caso dos jatos da família ERJ Embraer e dos Bombardier CRJ100/200 (Canadair Regional Jet), com capacidade máxima de até cinquenta passageiros, se mostravam pequenos, e os narrow-bodies, por exemplo, o Boeing 737 (capacidade de 85 a 205 passageiros em seus nove modelos) e a família de jatos Airbus 320 (cuja capacidade de passageiros vai de 132 a 220 passageiros em seus quatro modelos), grandes demais.

Bombardier e Embraer identificaram uma oportunidade de negócios importante no segmento de jatos com capacidade na faixa de setenta a 150 passageiros. Jatos desse tamanho poderiam suprir a demanda crescente de passageiros em voos regionais de curta e média distância com densidade de passageiros média a alta que conectassem com maior eficiência os aeroportos servidos por narrow-bodies e wide-bodies. As estratégias tecnoprodutivas de cada uma das empresas, no entanto, foram diferentes, e explicam o maior sucesso da Embraer.

A estratégia tecnoprodutiva da Bombardier para entrar no segmento de jatos regionais com capacidade de passageiros na faixa dos 70 a 150 passageiros consistiu em alongar seu jato regional menor, o CRJ200 Bombardier, com capacidade para até cinquenta passageiros, de modo a aumentar sua capacidade de passageiros. Nasceram assim, com base na plataforma do CRJ200, os jatos regionais CRJ700, CRJ900 e CRJ1000, com capacidade entre setenta e cem passageiros nos diferentes modelos. Cada um desses jatos compete diretamente com modelos da Embraer. 
A estratégia tecnoprodutiva da Embraer foi diferente daquela adotada pela Bombardier. Mais ousada, mais difícil, mais arriscada, mas ao fim mais acertada, sendo até o momento a estratégia vencedora: em vez de alongar a plataforma da família de jatos ERJ, a Embraer decidiu desenvolver uma nova família de jatos. Os E-Jets, ao contrário dos CRJ700, CRJ900 e CRJ1000, foram desenvolvidos a partir do zero: otimizados, portanto, para os requisitos operacionais e tecnoprodutivos de jatos com maior capacidade de passageiros. Os jatos da Bombardier, por sua vez, ao serem alongados para comportar um número maior de passageiros, acabam por sair do ponto ótimo do projeto, com todas as desvantagens que isso acarreta.

Lançada em 1999, a família de jatos E-Jets Embraer seria composta por quatro jatos com capacidade entre 78 e 115 passageiros: EMBRAER 170, EMBRAER 175, EMBRAER 190 e EMBRAER 195. A nova família de jatos da Embraer foi um lance bastante arrojado da empresa não só pelos desafios envolvidos no desenvolvimento tecnoprodutivo de aviões de porte maior do que até então a empresa havia feito, como também por representar um passo a mais em direção ao segmento imediatamente superior de jatos comerciais, os narrow-bodies, domínio do duopólio de primeira ordem Boeing-Airbus. Sem constituir ameaça imediata, o fato é que o lançamento da família de jatos E-Jets, bem como os CRJ700, CRJ900 e CRJ1000 e posteriormente os CSeries Bombardier (em dois modelos, o CS100, com capacidade para 110 passageiros, e o CS300, com capacidade para 130 passageiros), mostrava que o duopólio de segunda ordem Embraer-Bombardier poderia eventualmente se aproximar do segmento de narrow-bodies, como, aliás, tem sido o caso do CSeries Bombardier, golpe que Airbus e Boeing já acusaram por meio de uma estratégia comercial bastante agressiva voltada a impedir o sucesso dos CSeries que pode, sob certas condições (rotas menos densas), competir diretamente com os Boeing 737 e os Airbus 320.

A família de jatos E-Jets repetiu, em escala ampliada, os desafios da família ERJ, bem como muitas de suas estratégias. As dificuldades tecnoprodutivas eram maiores. No entanto, a Embraer contava agora com a experiência da gestão da cadeia produtiva e dos acordos de compartilhamento de risco adquirida no desenvolvimento, produção e comercialização proporcionada pela família de jatos ERJ, aprendizagem que se mostraria fundamental para o sucesso dos E-Jets. 
A família de jatos E-Jets da Embraer foi desenvolvida para ocupar o segmento de mercado de aviões regionais de 70 a 120 passageiros, disputando a liderança do segmento com sua concorrente direta e parceira de duopólio Bombardier. Passada mais de uma década desde o lançamento do primeiro avião da família, o programa dos E-Jets foi bem sucedido, contribuindo enormemente para consolidar a posição da Embraer no segmento de jatos comerciais de pequeno e médio porte, nichos de mercado que ela ocupa com as famílias ERJ e E-Jets, respectivamente.

Os processos de aprendizagem pelos quais a Embraer passou ao longo desses pouco mais de vinte anos de produção de jatos regionais de pequeno e médio porte permitiram à empresa desenvolver e acumular os conhecimentos tecnoprodutivos não apenas de desenvolvimento e produção de aviões a jato, mas também os conhecimentos relativos à gestão da cadeia mundial de fornecedores e à inteligência de mercado, que se tornaram talvez os maiores diferenciais competitivos da Embraer nessa sua nova fase, de par com as qualidades tecnológicas e as vantagens e baixos custos operacionais dos aviões das famílias ERJ e E-Jets.

A aprendizagem acumulada ao projetar, produzir e comercializar aviões cada vez maiores, começando pelo EMB-100, modificado para ser tornar o EMB-110 Bandeirante, até o EMBRAER 190, passando pelo EMB-120 Brasília, o CBA 123 e as famílias ERJ e E-Jets, permite à Embraer hoje desenvolver um avião como o bimotor turbofan de transporte militar KC-390 e preparar até mesmo voos mais altos em direção a segmentos de aviões comerciais de maior capacidade de passageiros, o que aproximaria o portfólio de aviões da empresa do segmento de narrow-bodies, hoje dominado pelo duopólio Boeing-Airbus e no qual a Bombardier, principal concorrente da Embraer, começa a avançar com seus CSeries.

Há, contudo, muitos desafios que a Embraer precisará enfrentar para manter sua posição no mercado de jatos regionais. O principal desafio diz respeito à posição de seguidora de desenvolvimento tecnológico alheio em que a Embraer quase sempre baseou sua estratégia. A inexistência de fornecedores de primeiro e segundo níveis no Brasil e a incapacidade de a empresa ser no mais das vezes líder de desenvolvimento tecnológico, em função de sua pequena escala de produção (se comparada às escalas alcançadas por Boeing e Airbus, estas sim líderes de desenvolvimento tecnológico) fazem com que a Embraer esteja sempre um passo atrás. Ainda que seguindo de perto as empresas 
líderes, o fato é que haverá sempre uma distância entre a Embraer e suas concorrentes Bombardier, Boeing e Airbus em termos de desenvolvimento tecnológico. A Embraer estará, portanto, perto da fronteira tecnoprodutiva do setor, mas nunca na fronteira propriamente dita.

Ao longo da próxima década a Embraer passará a competir não apenas com a Bombardier no segmento de jatos regionais, mas terá que se ver, e muito em breve, com a concorrência de jatos regionais da Rússia, do Japão e da China. Se competir com a Bombardier já não é fácil, a situação agora tende a se tornar ainda mais complicada. Nos próximos capítulos, examinarei as estratégias de catch-up e aprendizagem tecnoprodutiva no setor aeronáutico de Japão, China e Rússia no segmento de jatos regionais. 


\section{Capítulo 5: O perigo vem do leste: Japão, catch-up tecnoprodutivo aeronáutico}

Neste capítulo discutirei as duas tentativas de catch-up do setor aeronáutico do Japão, na década de 1960 e nos anos 2000. Analisarei as diferentes estratégias de aprendizagem tecnoprodutiva empregadas pelo Japão e os principais desafios que essas diferentes estratégias acarretam para o catch-up do setor aeronáutico japonês.

\section{Estratégias de aprendizagem tecnoprodutiva e catch-up no setor aeronáutico japonês: um fracasso, uma reorientação e uma nova tentativa}

A análise das estratégias de catch-up no setor aeronáutico japonês oferece um exemplo bastante eloquente de caso de um país que, apesar de ser tecnoprodutivamente avançado em vários setores industriais, não foi capaz de realizar o catch-up tecnoprodutivo em um setor específico, o aeronáutico. O caso japonês é ilustrativo da importância relativa do avanço tecnológico e científico, condição necessária, porém não suficiente para garantir o catch-up tecnoprodutivo, e da centralidade do aspecto tecnoprodutivo e comercial em uma estratégia de catch-up, esta sim condição suficiente para determinar o maior ou menor sucesso de uma estratégia de catch-up. O caso japonês prova que uma avançada base industrial, científica e tecnológica, por si só, não bastam para garantir o sucesso de uma estratégia de catch-up; o segredo está em fazer convergirem trajetórias tecnológicas e condições institucionais e de mercado de modo a desenvolver um produto competitivo tecnológica e comercialmente.

A história do setor aeronáutico japonês mostra também a importância de conhecimentos e instituições específicas ao setor no qual se pretende realizar o catch-up tecnoprodutivo. Se a existência de uma estrutura industrial e de um sistema científico e tecnológico avançado tem efeitos positivos sobre o desenvolvimento de um país, essa circunstância não garante que qualquer desenvolvimento tecnoprodutivo seja bemsucedido. Veremos, portanto, que, apesar de todo o avanço tecnológico e industrial do Japão nos diferentes momentos após a Segunda Guerra Mundial em que o país implementou estratégias de catch-up aeronáutico, o país jamais teve sucesso pleno no 
segmento de aviação comercial, isto é, não conseguiu, até o momento, constituir uma OEM competitiva. A terceira tentativa de catch-up está atualmente em curso.

A história do setor aeronáutico japonês pode ser dividida em três fases, correspondentes a diferentes formas de aprendizagem tecnoprodutiva. A primeira fase corresponde ao período que vai de meados da década de 1950 à primeira metade da década de 1970, fase em que a estratégia de catch-up do setor aeronáutico japonês teve por objetivo constituir uma OEM capaz de projetar, produzir e comercializar um projeto de avião turboélice regional, o YS-11, meta que seria alcançada com recurso aos processos de aprendizagem baseados na produção sob licença e no desenvolvimento de ciclo completo do YS-11, que acabaria não alcançando sucesso comercial. A segunda fase vai de meados da década de 1970 até o início da década de 1990, período em que a estratégia japonesa de catch-up abandonou temporariamente a meta de constituir uma OEM e acrescentou à aprendizagem tecnoprodutiva baseada na produção sob licença a estratégia de desenvolvimento de fornecedores de segundo e terceiro nível para as grandes OEMs norte-americanas, evoluindo, de inícios dos anos 1990 até meados dos anos 2000, para um período marcado pela diversificação das OEMs para as quais as empresas japonesas forneciam por meio de acordos de parcerias de compartilhamento de riscos - atualmente, fornecedores aeronáuticos japoneses têm acordos de desenvolvimento com todas as quatro OEMs que formam o duplo duopólio BoeingAirbus e Embraer-Bombardier. A terceira fase, atualmente em curso, marca a retomada da estratégia de desenvolver uma OEM com base no acúmulo de conhecimento ocorrido nas fases e com os modos de aprendizagem tecnoprodutiva anteriores, mais uma vez mirando o segmento de aviões - desta vez a jato - regionais (Kimura 2006, Niosi e Zhegu 2010).

O Japão tem uma longa história no setor aeronáutico que antecede a Segunda Guerra Mundial. O mítico caça Mitsubishi A6M Zero fez seu primeiro voo em abril de 1939, sendo produzido até o final do conflito, em 1945. Superior em desempenho a qualquer outro caça em operação no teatro do Pacífico até a introdução, em 1943, do Grumman F6F Hellcat, o Mitsubishi A6M Zero atesta o alto nível de desenvolvimento alcançado pelo setor aeronáutico militar japonês já na década de 1930 .

$\mathrm{Na}$ história do setor aeronáutico japonês, no entanto, houve um ponto de suspensão e ruptura de suas atividades no imediato pós-Segunda Guerra Mundial: de 1945 a 1952, o 
Japão, sob ocupação americana, ficou proibido de fabricar aviões de qualquer espécie, civis e militares, sendo obrigado a desativar completamente sua indústria aeronáutica, não tendo produzido um avião sequer nesse período (Niosi e Zhegu 2010). A suspensão das atividades do sistema tecnoprodutivo aeronáutico japonês, em si mesmo um problema de grandes proporções, uma vez que impediu a transmissão de conhecimentos entre gerações, impossibilitou a formação de novos técnicos, engenheiros e gestores e forçou a migração de pessoal qualificado para outros setores econômicos, foi amplificada pela ruptura da arquitetura aeronáutico-mecânica dos aviões ocorrida justamente na década de 1940: o desenvolvimento dos aviões de propulsão a jato e sua produção em escala comercial para aplicações militares e civis. Para o sistema tecnoprodutivo aeronáutico japonês, esses sete anos foram críticos: a indústria aeronáutica do Japão, por assim dizer, foi dormir nas vizinhanças da fronteira tecnoprodutiva aeronáutica e acordou longe da fronteira, em posição de obsolescência tecnoprodutiva. O estrago, portanto, foi grande. Não apenas os japoneses desaprenderam grande parte dos conhecimentos relativos ao desenvolvimento e fabricação de aviões com a desmobilização de pessoal e fechamento de empresas, como também aquilo que sabiam sobre o assunto ficou velho. Ou seja, os conhecimentos que levaram o Japão a produzir um caça como o Mitsubishi Zero já não serviam para muita coisa num mundo em que o avião a jato começava a alçar voo.

Outra circunstância atrasaria ainda mais o sistema tecnoprodutivo aeronáutico japonês: grande parte dos conhecimentos desenvolvidos e acumulados antes da guerra era voltada para a produção de aviões militares, com pouca atenção a aviões comerciais - a aviação comercial, aliás, estava ainda em seus primeiros voos na década de 1930, portanto nem poderia ser muito diferente. Os aviões militares, e os equipamentos militares de modo geral, têm a seguinte característica: considerações de desempenho e qualidade são muito mais relevantes do que os custos de produção. $\mathrm{O}$ desenvolvimento de aviões militares é feito com os olhos primeiro nos aspectos relativos ao desempenho do produto, cabendo às considerações econômicas um papel secundário. Portanto, se o setor aeronáutico japonês se encontrava, às vésperas da Segunda Guerra Mundial, nas vizinhanças da fronteira da tecnologia aeronáutica militar, o mesmo não pode ser dito sobre sua posição em relação à fronteira tecnoprodutiva, em que considerações comerciais são absolutamente centrais. Os conhecimentos acumulados para a produção de aviões militares antes da Segunda Guerra, além de serem específicos da arquitetura 
de aviões com propulsão a motores radiais de hélice e não da nova arquitetura que ia surgindo, em que os aviões passavam a contar com propulsão de motores turboélice e a jato, eram de pouca utilidade para os desafios de produção de aviões civis para fins comerciais.

Antes da Segunda Guerra Mundial, o sistema tecnoprodutivo aeronáutico japonês recorreu amiúde à engenharia reversa como estratégia de aprendizagem tecnoprodutiva. No pós-guerra, o desenvolvimento tecnoprodutivo e a maior regulação dos direitos de propriedade intelectual fizeram da engenharia reversa uma estratégia pouco adequada para o setor aeronáutico. A partir de 1952, quando teve fim o período de proibição da produção de aviões pelo Japão imposto pelos norte-americanos, o sistema tecnoprodutivo aeronáutico japonês passaria a fazer uso de outras estratégias de aprendizagem, em especial a produção sob licença e o desenvolvimento e produção de ciclo completo de um avião regional, o YS-11, de modo a realizar o catch-up no setor aeronáutico.

Apesar do hiato no processo de desenvolvimento do sistema tecnoprodutivo aeronáutico japonês causado pela suspensão das atividades aeronáuticas no imediato pós-guerra, os mesmos quatro grandes grupos industriais que dominavam o setor aeronáutico do país e grande parte da economia japonesa antes da II Guerra Mundial continuaram, findo o período de proibição de produção de aviões no Japão, a ser as empresas líderes do setor: Mitsubishi Heavy Industries, Kawasaki Heavy Industries, Fuji Heavy Industries, fabricantes de estruturas de avião, e Ishikawajima-Harima Heavy Industries, fabricante de motores (Niosi e Zhegu 2010). Quando em 1957 o governo japonês resolveu empreender esforços para diversificar as formas de aprendizagem tecnoprodutiva com o desenvolvimento e produção de ciclo completo do YS-11, com o objetivo de levar o país além dos limites da aprendizagem tecnoprodutiva por meio da produção sob licença, ele o fez apoiando-se nesses quatro grandes grupos industriais.

A aprendizagem tecnoprodutiva no setor aeronáutico japonês foi retomada, na primeira metade dos anos 1950, com atividades de MRO (maintenance, repair and overhaul). Se por rum lado o MRO (no caso do setor aeronáutico) ou seus equivalentes em outros setores podem ser uma importante forma de dar início à aprendizagem tecnoprodutiva e acumular conhecimento básico, uma vez que permitem um primeiro contato com as tecnologias e produtos do setor, seu efeito é extremamente limitado em relação ao total 
de conhecimento que precisa ser acumulado e desenvolvido para que uma estratégia de catch-up que vise dominar projeto e produção de ciclo completo tenha sucesso. Manutenção e reparo podem, quando muito, ser um passo em direção a formas mais complexas de aprendizagem e transferência de. O governo japonês logo se deu conta de que para realizar o catch-up no setor aeronáutico seria necessário adotar uma estratégia mais ousada. O Japão então optou por uma forma mais complexa de aprendizagem tecnoprodutiva: a produção sob licença de aviões militares.

De 1952 até o fim da década as empresas japonesas fabricaram sob licença dois modelos militares projetados por empresas americanas: o caça F-86 Sabre, da North American Aviation, e o avião de treinamento T-33, da Lockheed. A produção de aviões militares norte-americanos pelo Japão tinha por objetivo prover alguma forma de capacitação e reequipamento militar ao Japão - sob a tutela cerrada, evidentemente, dos EUA. Com isso, esperava-se que o Japão não sairia da esfera de influência geopolítica, tecnológica e econômica dos EUA, transformando o antigo inimigo em aliado. A aprendizagem por meio da produção sob licença, no entanto, é limitada por vários fatores, a começar pelo fato de que na imensa maioria dos casos as tecnologias licenciadas são relativamente obsoletas. Além disso, a produção sob licença priva o sistema tecnoprodutivo de desenvolver conhecimentos de projeto, prototipagem e testes, fundamentais para dominar projeto e produção de ciclo completo de aviões. A transferência de conhecimento que se dá por meio da produção sob licença, portanto, é bastante limitada e dificilmente permite ao receptor do conhecimento desenvolver as habilidades necessárias para realizar plenamente o catch-up tecnoprodutivo. Era necessário, portanto, complementar a aprendizagem tecnoprodutiva por meio da produção sob licença com outras formas de aprendizagem. O governo japonês escolheu a mais ousada e arriscada forma de aprendizagem com vistas a realizar o catch-up: o desenvolvimento e produção de ciclo completo de um avião regional.

A primeira tentativa de implementar uma estratégia de catch-up no setor aeronáutico japonês no pós-guerra foi capitaneada pelo MITI, tendo início pouco depois do fim da proibição de produzir aviões imposta ao Japão ao fim da Segunda Guerra. A partir de 1956, tanto MITI quanto empresas privadas do setor aeronáutico produzindo aviões militares sob licença começaram a pressionar o governo japonês por uma mudança na estratégia de catch-up, conscientes de que a produção sob licença limitava suas ambições: "dependence on licensed production of military aircraft handicapped the 
industry not only by preventing designers from gaining experience, but also by becoming too dependent on politically sensitive military demand" (Kimura 2006).

Muitos fatores influenciaram a decisão do Japão de empreender uma estratégia de catchup com vistas a dominar projeto e produção de ciclo completo e constituir uma OEM nacional: Kuo (2009) aponta a importância da ideologia industrialista no governo japonês, em especial no MITI (da sigla em inglês para Ministry of International Trade and Industry), guiado fortemente pela ideia de intervenção governamental por meio de políticas industriais para correção de falhas de mercado; Friedman e Samuels (1993) associam o projeto de desenvolvimento de uma OEM japonesa ao tecnonacionalismo característico da estratégia de desenvolvimento japonês no pós-guerra, ideologia que buscava, por meio do desenvolvimento tecnológico nacional, compensar o sentimento de derrota e humilhação que assombraria por tanto tempo a sociedade japonesa.

Em termos de trajetória de aprendizagem tecnoprodutiva, o desenvolvimento e produção de ciclo completo e posterior comercialização de um avião civil de transporte de passageiros foi a terceira forma de aprendizagem tecnoprodutiva adotada pelo Japão no pós-guerra, em sequência às atividades de MRO e à produção sob licença. A estratégia de catch-up do setor aeronáutico japonês entrava em sua fase mais ousada e complexa e se aproximava de sua prova final: conseguindo desenvolver, produzir e comercializar com sucesso seu avião, a estratégia teria alcançado o objetivo de aproximar o sistema tecnoprodutivo aeronáutico japonês da fronteira tecnoprodutiva aeronáutica.

Líder da empreitada, o MITI criou uma estrutura institucional, empresarial, produtiva e financeira altamente complexa para desenvolver o YS-11, avião regional com motor turboélice e capacidade para até sessenta e quatro passageiros, fazendo do YS-11 um dos maiores aviões regionais da época. Esse arranjo deu com toda espécie de dificuldades e obstáculos relativos à coordenação de atores, alinhamento de objetivos e expectativas e accountability dos envolvidos, sendo o principal fator a contribuir para o fracasso do YS-11 e dessa primeira estratégia de catch-up do setor aeronáutico japonês.

Fiel à lógica mais geral que orientou o desenvolvimento tecnoprodutivo japonês em outros setores industriais, o MITI desenvolveu um arranjo institucional em que grandes grupos industriais privados eram liderados por agências estatais criadas especialmente para executar políticas de desenvolvimento setoriais. Em 1957, a Associação da 
Indústria Aeronáutica japonesa criou, com apoio do MITI, a Associação de Pesquisa e Desenvolvimento de Transporte Comercial (Yusoki Sekkei Kenkyu Kyokai, abreviado para Yuken), dando início ao desenvolvimento do YS-11. O Yuken era um consórcio de empresas e agências governamentais que ficaria responsável pelas atividades de pesquisa e comercial do YS-11, bem como do desenvolvimento do projeto técnico do avião. As empresas participantes do consórcio colaboravam no planejamento e no desenvolvimento de estruturas e componentes básicos sob coordenação do Yuken. No ano seguinte, 1958, a Dieta Nacional do Japão aprovou a Lei de Promoção da Indústria Aeronáutica, garantindo recursos no orçamento nacional para o projeto do YS-11.

Em 1959, o Yuken se tornou uma empresa de política nacional (empresas estatais responsáveis pelo desenvolvimento e execução de políticas estratégicas), a Nihon Airplane Manufacturing Company (Nihon Kokuki Seizo Kabushiki Kaisha), ou NAMCO. A NAMCO tinha 50\% de participação do governo e 50\% de participação de empresas privadas, entre as quais as empresas parceiras de produção, que incluíam os grandes conglomerados industriais japoneses Mitsubishi Heavy Industries (MHI), com 25,5\%, Kawasaky Heavy Industries (KHI), com 13\% e Fuji Heavy Industries (FHI), com 6,5\% (Kimura 2006, Kanatsu 2006, Kuo 2009), além de dezenas de empresas menores, muitas das quais pouco ou nada ligadas ao setor aeronáutico. Valendo-se de suas atribuições como empresa de política nacional, a NAMCO garantia o retorno financeiro dos investimentos dos parceiros privados, o que fazia parte, por sua vez, da política industrial do MITI, que dava prioridade ao desenvolvimento e difusão de tecnologias sobre questões relativas a custos e eficiência.

A NAMCO ficou responsável pelas atividades de testes e comercialização, cabendo às parceiras produtoras, em número de seis, a pesquisa, desenvolvimento e produção de estruturas e componentes específicos com a seguinte divisão de trabalho: à Mitsubishi Heavy Industries (MHI), cabia a fuselagem dianteira e a integração final do avião; à Kawasaky Heavy Industries (KHI), a seção principal das asas; à Fuji Heavy Industries (FHI), a empenagem; à Shin Meiwa, a fuselagem traseira; à Showa, elementos estruturais; e à JAMCO, ailerons e flaps. A Rolls-Royce forneceria os motores (Kimura 2006).

Como estratégia de catch-up tecnoprodutivo, o desenvolvimento do YS-11 teve resultados modestos, aquém de seus objetivos iniciais. E isso por vários motivos, 
ligados, sobretudo, às deficiências da estrutura institucional, empresarial, produtiva e financeira montada pelo MITI.

Os problemas começavam pela estrutura de coordenação governamental do empreendimento. Apesar da liderança do consórcio estar sob responsabilidade do MITI, outros dois ministérios também tinham influência sobre as decisões que afetavam a estratégia de catch-up do setor aeronáutico: o Ministério dos Transportes e a Agência Japonesa de Defesa. Segundo Kanatsu (2006), a tentativa de catch-up do setor aeronáutico japonês foi negativamente afetada por batalhas interministeriais, uma vez que os papéis não estavam muito bem definidos e havia grande sobreposição de atribuições e responsabilidades no desenvolvimento do projeto. Para o MITI, tratava-se de realizar um catch-up tecnoprodutivo no setor aeronáutico japonês aplicando as ferramentas de desenvolvimento industrial usadas no fomento a outros setores; para o Ministério dos Transportes, de definir o papel do transporte aéreo na política nacional de transportes; para a Agência Japonesa de Defesa, importava por um lado não desviar recursos econômicos e humanos da produção sob licença de aviões militares que garantissem, sob as regras impostas pela potência ocupante, capacidade militar de defesa e, por outro, garantir o desenvolvimento futuro de capacidade de desenvolvimento e produção autônoma de aviões militares (Kanatsu 2006).

O problema com o arranjo institucional, empresarial, produtivo e financeiro da primeira estratégia de catch-up japonesa não parava por aí: a estrutura de consórcio entre empresas criou diversas dificuldades para o empreendimento. Em primeiro lugar, as empresas não participaram propriamente por livre e espontânea vontade, mas foram convidadas - com as devidas pressões em pontos sensíveis aplicadas pelo MITI - a participar do projeto. O MITI fez valer toda sua autoridade sobre os grandes conglomerados japoneses para garantir a participação dessas empresas no desenvolvimento, produção e comercialização do YS-11. No entanto, se o MITI garantiu a participação formal das empresas, ele não pode forçá-las a se envolverem completamente no projeto. Como empresa atribuía pouca importância ao resultado final do projeto, já que o governo garantiria os retornos financeiros do projeto independentemente de seu sucesso, o empenho de cada uma ficou muito aquém do necessário (Kanatsu 2006). 
Em segundo lugar, esse arranjo era muito frágil em termos dos incentivos oferecidos aos diferentes atores envolvidos. Para o governo de modo geral e o MITI e a empresa de política pública NAMCO em particular, o objetivo do projeto consistia em fazer avançar o desenvolvimento tecnológico e produtivo do setor aeronáutico japonês; a questão da competitividade final do produto, portanto de sua viabilidade comercial, foi relegada a segundo plano. As grandes empresas envolvidas no consórcio, por sua vez, tinham poucas razões para se empenharem em um projeto cujo resultado final dependia em grande medida do empenho - incerto - das outras empresas envolvidas no projeto. Além disso, indefinições relativas às formas de apropriação e distribuição dos resultados do esforço em comum reduziam ainda mais os incentivos de desenvolvimento tecnoprodutivo e comercial. Essas circunstâncias causaram sucessivos e sempre maiores adiamentos do cronograma e aumentos do orçamento, o que pouca importava a cada empresa individualmente, já que o MITI estava no empreendimento com uma postura do tipo realizar o catch-up a qualquer custo, garantindo às empresas envolvidas o retorno dos investimentos independentemente dos resultados comerciais do projeto. A estrutura institucional, empresarial, produtiva e financeira montada pelo MITI criou incentivos para um desempenho subótimo dos atores envolvidos.

Além disso, a rota de desenvolvimento industrial traçada para a estratégia de catch-up, que previa o desenvolvimento e produção de quase todas as estruturas e componentes por empresas japonesas, mostrou-se irrealista, dado o estágio tecnoprodutivo das empresas da cadeia de fornecedores do setor aeronáutico japonês, incapazes de acompanhar os avanços tecnoprodutivos das grandes empresas industriais envolvidas no projeto. De acordo com Kimura (2006): “the Japanese main manufacturers intended to cover all activities throughout the value chain by coordinating and consolidating the individual competences. (...) Extending the domain of activities all throughout the value chain was unrealistic for the Japanese manufacturers in regard to their current competences and learning potentials. Actually, the firms were fully aware of that the required level of dynamic strategic fit for catching up was infeasible due to enormous risks and significant opportunity costs associated with investing in aircraft production and sales" (Kimura 2006: 125).

Apesar das dificuldades causadas pelo arranjo institucional, empresarial, produtivo e financeiro criado pelo MITI na primeira tentativa de catch-up no setor aeronáutico japonês, em 1962, bem ou mal, o YS-11 foi lançado. Os resultados do projeto do YS- 
11, no entanto, foram ambíguos. Do ponto de vista tecnológico, é possível falar até mesmo em sucesso relativo do projeto, uma vez que o desenvolvimento de ciclo completo do YS-11 permitiu ao sistema tecnoprodutivo aeronáutico japonês consolidar o conhecimento acumulado pelas formas anteriores de aprendizagem tecnoprodutiva MRO e produção de aviões militares sob licença, além dos conhecimentos desenvolvidos antes da Segunda Guerra.

Do ponto de vista comercial, no entanto, não há dúvidas de que o projeto do YS-11 foi um fracasso: foram produzidos apenas 182 unidades do YS-11 de 1962 a 1974, quase todas operando no Japão devido às dificuldades de comercialização do avião, devidas à pouca tradição e experiência no mercado de aviação comercial e sobretudo à escassa experiência no aspecto comercial do setor aeronáutico. O projeto finalmente foi abandonado em 1974, com perdas financeiras vultosas - devidamente assumidas pelo MITI.

Kuo (2009), mesmo concordando com a natureza ambígua dos resultados do projeto do YS-11 (separando avanços tecnoprodutivos, de um lado, e desempenho comercial aquém do esperado, do outro) e atribuindo ao arranjo institucional, empresarial, produtivo e financeiro e em particular à política de garantia de retornos às empresas por parte do MITI a responsabilidade pelo fracasso, em termos, do projeto, reconhece que, naquela altura de desenvolvimento do setor aeronáutico japonês, a estratégia de criar incentivos artificiais de mercado para realizar o catch-up era muito provavelmente a única disponível, por mais arriscada que fosse: "public measures (functioning as artificial market incentives) such as this problematic return guaranty were indispensable and important elements of Japanese industrial policy in promoting aircraft industry under its weak military market arrangements. Without these artificial market incentives, Japanese manufacturers might simply turn their heads away from aircraft industry since there was not sufficient market demand, just concentrate on other large market and low-risk works" (Kuo 2009: 285).

Kimura (2006), por sua vez, apesar de reconhecer os avanços relativos aos conhecimentos tecnoprodutivo acumulados ao longo do projeto do YS-11, chama a atenção para um importante fator limitante do catch-up tecnoprodutivo aeronáutico japonês: a tentativa de realizar o desenvolvimento tecnoprodutivo nacional em grau máximo e garantir a independência tecnológica do Japão no setor aeronáutico, que 
tomou forma na tentativa de constituir uma cadeia de fornecedores composta quase inteiramente de empresas japonesas (exceto no caso dos aviônicos e motores, comprados de empresas estrangeiras), restringiu o acesso do sistema tecnoprodutivo aeronáutico japonês a novos fluxos de conhecimentos, constituindo o que Kimura (2006) definiu como um sistema fechado de conhecimento: "Although knowledge diffusion was significant within the system, the absolute amount of new knowledge inflowing into the system was little. The sources for new technological and process knowledge was mainly limited to publication, reverse engineering and experiences gained from the production of military aircraft. In-house $R \& D$ and technological support from the research organizations, such as the National Aircraft Laboratory, were not enough to build an up-to-date commercial aircraft" (Kimur 2006: 126). Ou seja, por mais conhecimento que o sistema tecnoprodutivo aeronáutico japonês houvesse acumulado e desenvolvido àquela altura, esse sistema fechado de conhecimento não era avançado o bastante - ou, em outras palavras, a distância da fronteira tecnológica ainda era grande demais - para permitir um desenvolvimento puramente autóctone do setor no Japão.

Tudo pesado, o fato é que a primeira estratégia de catch-up do setor aeronáutico japonês empreendida por meio do projeto de desenvolvimento e produção do YS-11 não deu o resultado esperado, ficando aquém de seu objetivo maior de aproximar o setor da fronteira tecnoprodutiva aeronáutica da época. Apesar de acertos e avanços importantes, sobretudo do ponto de vista tecnoprodutivo, mas também em termos de aprendizagem institucional - ainda que uma lição do que não se deve fazer, o que tem sem dúvida algum mérito e utilidade -, o catch-up não se realizou.

Será que o Japão pecou por excesso de ousadia ao querer criar uma OEM para disputar mercado no segmento da aviação comercial regional? Ora, já naquele momento a estrutura industrial, tecnológica e científica do Japão era mais avançada do que a do Brasil, e nem por isso o catch-up brasileiro deixou de ter sucesso. Não faltou vontade a nenhum dos países, sobretudo a suas elites tecnopolíticas, para por em ação uma estratégia de catch-up tecnoprodutivo, donde não se poder atribuir o fracasso de um e o sucesso de outro ao empenho com que o sistema político e econômico se atirou à tarefa. As razões para o fracasso da primeira tentativa de catch-up aeronáutico no Japão, como vimos, foram outras: de ordem institucional, empresarial, produtiva e financeira e, por que não, ideológica, na forma do tecnonacionalismo que animava a burocracia do MITI. 
Talvez tenha, isso sim, sobrado vontade: realizar o objetivo de independência tecnoprodutiva quase total se mostrou inviável. Era necessário, portanto, de modo a não botar a perder integralmente os esforços de catch-up tecnoprodutivo empreendidos nas décadas de 1950 e 1960 pelo governo e empresas japonesas, mudar de estratégia.

É lugar comum entre historiadores interpretar a história do Japão como um movimento pendular entre dois extremos: períodos de ensimesmamento total, nos quais a insularidade japonesa deixa de ser apenas uma descrição geográfica e passa a ser também um fenômeno cultural e econômico, a alternarem-se com fases de grande abertura ao mundo exterior; fases de xenofobia crônica seguidas de tempos de uma plasticidade zen. Foi assim dos séculos XVII a meados do século XIX, quando o país se manteve num isolamento em que tudo e todo estrangeiro eram, por definição, perigosos; até a Restauração Meiji em 1968, período em que o Japão se abriu decididamente ao mundo exterior e empreendeu seu impressionante catch-up tecnoprodutivo industrial e a modernização, à moda "ocidental", de sua sociedade.

Não surpreende, portanto, que à tentativa de conquistar a independência tecnoprodutiva no setor aeronáutico por meio do desenvolvimento autóctone não apenas de um avião comercial mas de toda a cadeia produtiva aeronáutica tenha se seguido um período de grande abertura ao sistema tecnoprodutivo aeronáutico mundial: foi a fase da inserção de empresas japonesas - aquelas mesmas que haviam desenvolvido e acumulado conhecimentos tecnoprodutivos no setor aeronáutico ao longo da primeira tentativa de catch-up aeronáutico japonês, o projeto YS-11 - nas cadeias globais de fornecedores, período que se estende, grosso modo, de meados da década de 1970 até começos dos anos 2000 .

\section{Uma nova estratégia: aprendizagem tecnoprodutiva por meio da participação como fornecedores em cadeias globais de valor}

Refeito do fracasso de sua primeira tentativa de realizar o catch-up de seu sistema tecnoprodutivo aeronáutico, em princípios da década de 1980 o Japão começou a reformular sua estratégia: em vez de mirar logo na constituição de uma OEM e no desenvolvimento e produção independente de um avião comercial, como fora o caso do YS-11, a nova estratégia optou por uma aproximação gradual e indireta do objetivo: 
inserção de empresas japonesas nas cadeias globais de fornecedores para grandes OEMs estrangeiras. O desenvolvimento de ciclo completo de um avião comercial ficava, por ora, suspenso.

Em 1986, sob coordenação do mítico MITI, o governo japonês colocou em prática uma nova estratégia de desenvolvimento do setor aeronáutico do Japão, que consistia em desenvolver o setor nacional pela intensa colaboração internacional e inserção de empresas fornecedoras japonesas em posições estratégicas da cadeia global - o contrário, portanto, da estratégia anterior, que visava desenvolver todos os elos da cadeia produtiva aeronáutica japonesa de modo autônomo e com domínio científico, tecnológico e gerencial completo. O setor aeronáutico japonês nos anos seguintes aprofundaria seus laços com OEMs e fornecedores internacionais por meio de contratos de outsorcing e acordos de transferência tecnológica, baseando-se na experiência anterior de Fuji, Kawasaki e Mitsubishi, que vinham atuando como fornecedoras de terceiro nível para a Boeing e a McDonnell Douglas havia mais de duas décadas. Os contratos de fornecimento de componentes e subsistemas e de transferência de tecnologia envolveram empresas como a Boeing, a McDonnell Douglas, a General Dynamics e a Lockheed Martin. Como fornecedoras, as empresas japonesas adquiriram domínio tecnológico de vários componentes e subsistemas e mesmo a liderança em alguns materiais e técnicas construtivas, como a produção em material compósito.

Mais do que um recuo em relação à tentativa anterior, a inserção de empresas japonesas em cadeias globais de fornecedores representou uma alteração da estratégia de aprendizagem tecnoprodutiva. Não se tratava mais da aprendizagem por atividades de MRO, nem por produção sob licença de aviões militares, nem de desenvolvimento de ciclo completo de um avião comercial: a estratégia agora de aprendizagem consistia em qualificar um pequeno grupo de empresas para se tornarem fornecedoras de terceiro e segundo nível para as grandes OEMs estrangeiras. À medida que a aprendizagem e a transferência de tecnologia ganhassem massa crítica, a estratégia se voltaria para a qualificação e inserção de empresas japonesas nas cadeias globais de como fornecedores de primeiro nível - o mais nobre, do ponto de vista da engenharia e tecnologia envolvidas, uma vez que as fornecedoras de primeiro nível atuam na interface entre OEMs e fornecedoras, cabendo a elas grande parte das atividades de pesquisa e desenvolvimento e integração de subsistemas. 
O objetivo da estratégia de catch-up do setor aeronáutico japonês também mudou. Segundo Kimura: "MITI and the industry began the strategic shift from redefining the meaning of success. They put more emphasis on the aircraft industry's technological characteristics-such as technological intensity, high value added, and extensive linkages to other "knowledge-based industries"-rather than on its business opportunities. They regarded the aircraft industry as the quintessential strategic industry, a resource for raising the technological level of the entire economy (Samuels, 1994, p. 245). The criteria for success in the industry thus changed from 'catching up rapidly as an independent competitor in the market' towards 'upgrading product and process competences gradually" (Kimura 2006: 127). Essa nova estratégia tinha uma vantagem adicional: se bem sucedida, ela levaria o sistema tecnoprodutivo aeronáutico japonês até uma distância segura da fronteira tecnoprodutiva a partir de onde o Japão poderia intentar uma nova arrancada em direção à constituição de uma OEM capaz de desenvolver, produzir e comercializar aviões comerciais - como de fato o Japão tem atualmente tentado.

A estratégia de inserção de empresas japonesas na cadeia global de fornecedores de OEMs estrangeiras beneficiou-se enormemente da mudança pela qual o setor aeronáutico mundial passou a partir de fins da década de 1970 e que em grande medida vigora até os dias de hoje: a desverticalização da estrutura produtiva das grandes empresas aeronáuticas e a formação de cadeias globais de fornecedores. Levados pelo aumento da concorrência e dos custos do transporte aéreo ocorridos na década de 1970 e pelos efeitos da prolongada crise econômica da década de 1980, as OEMs estabelecidas passaram a recorrer às parcerias de compartilhamento de riscos com empresas fornecedoras, reduzindo e diversificando os riscos tecnológicos, financeiros $\mathrm{e}$ comerciais envolvidos no desenvolvimento e produção de aviões civis. O Japão buscaria tirar proveito dessa situação para qualificar seu setor aeronáutico.

Kuo (2009) elenca quatro razões para a adoção uma estratégia com vistas não ao desenvolvimento e produção de um avião por meio da constituição de uma OEM, mas pela inserção de empresas japonesas nas cadeias globais de produção da indústria aeronáutica: "First, with international joint projects, Japan's aircraft industry could acquire advanced aircraft technology from their foreign partners without huge expenses on indigenous $R \& D$. Second, it could compensate for Japan's insignificant domestic commercial aircraft market. Third, Japanese manufacturers could benefit from foreign 
military technology in collaborative projects to alleviate the structural problems embedded in the weak military market structure. Finally, the international joint projects could create sufficient market demand, increase reputation, and establish marketing and service network for Japan's aircraft industry" (Kimura 2209: 286-287).

Vimos que a primeira tentativa de realizar o catch-up do setor aeronáutico japonês esbarrou, entre outros, em problemas de institucionais, entre os quais a falta de coordenação e de incentivos para orientar as ações das empresas japonesas. Atento a esse ponto, em 1973 o MITI criou uma instituição cuja tarefa principal era representar e coordenar a participação dos atores do sistema tecnoprodutivo aeronáutico japonês junto à Boeing: a Civil Transport Development Corporation (CTDC), que substituiu a NAMCO nas atividades de coordenação do desenvolvimento do setor aeronáutico japonês.

A primeira OEM a estabelecer acordos de parceira para desenvolvimento conjunto de projetos com compartilhamento de riscos com empresas japonesas foi a americana Boeing. O MITI chegou a analisar propostas de outras OEMs, entre elas as americanas McDonnell Douglas e Lockheed e a holandesa Fokker, mas acabou optando, em 1978, pela parceria com a Boeing para o desenvolvimento do que mais tarde seria o programa B767. Pesou a favor da Boeing sua seu histórico de relações com empresas fornecedoras japonesas, que vinham desenvolvendo e produzindo componentes para os programas B747, B737 e B757 desde fins dos anos 1960 (Kimura 2006).

O primeiro grande projeto de colaboração capitaneado pela CTDC foi o programa do Boeing 767. Nessa mesma época (fins da década de 1970), um projeto de desenvolvimento de um avião regional com capacidade entre cem e cento e cinquenta passageiros, o projeto YX, estava em gestação na CTDC, que propôs à Boeing que os esforços fossem combinados em um projeto de colaboração internacional, o projeto YX/7X7 (Kuo 2009: 288). O 7X7 se tornaria o B767, jato wide-body com capacidade para duzentos e trinta passageiros. O acordo de colaboração no desenvolvimento e produção com compartilhamento de riscos entre os parceiros japoneses e a Boeing sob coordenação da CTDC garantiu a participação das empresas japonesas em 15\% do programa YX/7X7, basicamente para o desenvolvimento e produção de estruturas. Três empresas foram subcontratadas pela CTDC para o projeto YX/7X7: a Fuji Heavy Industries (FHI), a Kawasaki Heavy Industries (KHI) e a Mitsubishi Heavy Industries 
(MHI). O projeto de colaboração internacional teve fim em 1982, ano em que o Boeing 767 entrou em produção (Kuo 2009).

O programa YX/7X7 marcou uma inflexão na estratégia de catch-up do sistema tecnoprodutivo aeronáutico japonês: apesar da participação do governo nas fases iniciais de desenvolvimento do projeto por meio da CTDC, seu papel se restringiu ao financiamento e coordenação das atividades de pesquisa e desenvolvimento. A divisão do trabalho atribuía ao governo os custos de $P \& D$ e as empresas se responsabilizavam pelos riscos comerciais do empreendimento. Quando o Boeing 767 foi certificado, em 1982, a CTDC se retirou do projeto, cessando a participação direta do governo. A partir desse momento, a empresa privada Commercial Airplane Corporation assumiu a produção e comercialização das estruturas e componentes anteriormente desenvolvidos.

Kuo (2009) avalia que essa primeira experiência de colaboração internacional com compartilhamento de riscos entre os parceiros japoneses e uma OEM estrangeira, não obstante ter redundado em ganhos para os dois lados, mostrou-se limitada em relação às pretensões de aprendizagem tecnoprodutiva nutridas àquela altura pelo sistema aeronáutico japonês ainda: "Boeing could significantly lower the overall $R \& D$ and production costs with cheaper and high quality Japanese made components to increase its international competitiveness. In addition, it also established reliable partnership and collaboration experience with major Japanese producers while gained access to Japanese market. To Japan, the ICP project offered the best opportunity to access cutting edge aircraft technology and gain actual production experience. However, it was not able to obtain access to the upstream conceptualization and design as well as downstream marketing activities under Boeing's control growth strategy". (Kuo 2009: 290-291). Se a nova estratégia de colaboração com OEM estrangeiras criava condições para acelerar a aprendizagem tecnoprodutiva do setor aeronáutico japonês, essa forma de aprendizagem ainda não era capaz de qualificar o sistema tecnoprodutivo japonês para as atividades de mais alta complexidade envolvidas no desenvolvimento de ciclo completo.

Em 1982 a Civil Transport Development Corporation (CTDC) deu lugar à Japan Aircraft Development Company (JADC), responsável por coordenar a participação do sistema tecnoprodutivo aeronáutico japonês no programa do Boeing 777 , exercendo basicamente as mesmas funções desempenhadas antes pela CTDC: a empresa pública 
coordenava o consórcio e se encarregava das atividades de pesquisa e desenvolvimento, cabendo ao setor privado as atividades de produção e comercialização dos resultados.

Em 1986 a Lei de Promoção da Indústria Aeronáutica de 1958 foi revisada para incorporar em sua letra o espírito da nova estratégia de catch-up do sistema tecnoprodutivo aeronáutico japonês: o Artigo 1, que definia como objetivo da lei "a promoção do desenvolvimento doméstico de aviões e motores de aviões e consequentemente reduzir o déficit comercial", passou a definir como meta "a promoção do desenvolvimento internacional conjunto de aviões e motores de aviões e consequentemente facilitar a colaboração internacional no setor" (Kimura 2006: 128). A mudança da Lei de Promoção da Indústria Aeronáutica se fez acompanhar pela criação de mais uma instituição de suporte ao sistema tecnoprodutivo aeronáutico japonês, o International Aircraft Development Fund (IADF), responsável por direcionar os empréstimos a taxas de juros subsidiadas do Banco de Desenvolvimento japonês para iniciativas de colaboração internacional e parcerias de compartilhamento de riscos (Kimura 2006).

É importante notar que a mudança da estratégia de catch-up do sistema tecnoprodutivo aeronáutico japonês não se deu de forma abrupta nem por completa ruptura com o passado. Não se tratou de interrupção, mas de mudança de ênfase, na medida em que os planos de desenvolvimento de ciclo completo de um avião japonês e constituição de uma OEM não foram de todo abandonados, apenas adiados, sem que jamais desaparecessem dos objetivos do MITI. Ele apenas perdeu a centralidade que tinha na primeira tentativa de catch-up, mas continuaria presente.

Em 1984, a JADC, sob orientação do MITI, deu início ao projeto de desenvolvimento de um avião wide-body com capacidade para cento e cinquenta passageiros. Dessa vez, no entanto, a estratégia de aprendizagem tecnoprodutiva era bem diferente: não se tratava mais do desenvolvimento de ciclo completo de um avião e de quase toda sua cadeia produtiva de forma autônoma e inteiramente independente; a nova tentativa mirava as possibilidades de colaboração com a Boeing para realizar a aprendizagem tecnoprodutiva referente ao desenvolvimento de ciclo completo de aviões e seu empuxo para expandir e adensar a cadeia de fornecedores japoneses para o setor aeronáutico.

Em 1986, a JADC assinou com a Boeing um contrato de desenvolvimento colaborativo do projeto YXX/7J7, futuro Boeing 777. Em 1990, o sistema tecnoprodutivo 
aeronáutico japonês, JADC à frente, fechou contratos que garantiam o fornecimento de um total de aproximadamente $25 \%$ dos componentes e estruturas do Boeing 777 . Até aquele momento, o plano japonês ia dando certo: estavam pegando carona no desenvolvimento colaborativo para produzirem seu próprio avião.

Tudo mudou, no entanto, quando a Boeing, tendo recebido suas primeiras encomendas do novo avião, decidiu encerrar o desenvolvimento colaborativo para se concentrar somente no desenvolvimento de seu próprio avião, o Boeing 777. Pudera: o YXX seria um irmão gêmeo do Boeing 777, competindo diretamente não apenas por clientes, mas também por fornecedores - um quarto dos quais eram japoneses sob a liderança da JADC e do MITI.

Sem nada que pudesse fazer para mudar esse estado de coisas, só restou ao MITI declarar-se satisfeito com a aprendizagem tecnoprodutiva acumulada enquanto durou $\mathrm{O}$ projeto colaborativo do YXX/7J7(de 1986 a 1994) e abandonar o projeto YXX. A partir de então, a JADC passou a se concentrar no desenvolvimento do projeto YSX, jato regional inicialmente projetado com capacidade para cento e dez passageiros. O projeto YSX vinha sendo desenvolvido paralelamente ao projeto YXX, com muito menor dedicação e intensidade, contudo.

O destino do projeto YSX, no entanto, não foi muito mais feliz do que o do YXX, pelo menos no curto prazo: em 1998, frente às dificuldades tecnoprodutivas associadas ao desenvolvimento do YSX, o MITI reduziu brutalmente os investimentos no projeto, passando a se concentrar quase exclusivamente no apoio ao desenvolvimento de fornecedores de componentes, estruturas e sistemas aeronáuticos. Além do corte de orçamento do projeto YSX, o avião também sofreu seu próprio corte, com a capacidade de passageiros passando para oitenta passageiros.

A nova configuração do YSX, no entanto, ia ao encontro do plano da Mistsubishi de desenvolver um jato regional com igual capacidade, o Mitsubishi Regional Jet (MRJ). Se é verdade que a nova estratégia deslocou a ênfase do desenvolvimento e produção de ciclo completo de forma autônoma e independente de um avião japonês para a qualificação da cadeia de fornecedores como modo de fazer o catch-up do sistema tecnoprodutivo aeronáutico do Japão, também é verdade que o objetivo final de criar uma OEM capaz de desenvolver, produzir e comercializar aviões comerciais nunca saiu inteiramente dos planos do Japão. 
Do ponto de vista da participação do governo, as políticas de desenvolvimento da cadeia de fornecedores do setor aeronáutico pela colaboração com OEMs estrangeiras, e nas fases iniciais quase exclusivamente com a Boeing, houve uma importante alteração: o MITI deixou de oferecer contratos com retorno garantido, passando a adotar como instrumento de financiamento empréstimos pontuais, deixando o retorno econômico na dependência do sucesso final dos projetos, isto é, de sua viabilização comercial. Além de criar incentivos para as empresas envolvidas, essa forma de financiamento aumentou as barreiras de entrada do setor, uma vez que apenas empresas com capacidade de desenvolvimento tecnoprodutivo se arriscavam a tomar parte nos acordos de desenvolvimento colaborativo, gerando, portanto, mecanismos de seleção das empresas postulantes a projetos aeronáuticos. Do ponto de vista da eficiência da política, esse novo instrumento de financiamento melhorou a qualidade do gasto e o resultado final da política.

Em relação à cadeia de fornecedores, dá prova do acerto da nova estratégia de catch-up aeronáutico a qualificação da cadeia de empresas fornecedoras japonesas. Em começos dos anos 1980, as empresas aeronáuticas japonesas eram quase todas fornecedoras de terceiro e segundo nível, produzindo e às vezes desenvolvendo componentes e estruturas de baixa e média complexidade e intensidade tecnológica. Em fins da década de 1980, algumas empresas da cadeia de fornecedores aeronáuticos japonesas já haviam se qualificado como fornecedoras de primeiro nível, portanto capazes de produzir e desenvolver componentes, sistemas e estruturas de maior complexidade e intensidade tecnológica. A estratégia, portanto, vinha dando certo.

Além da qualificação tecnoprodutiva, os acordos de colaboração com OEM estrangeiras permitiram ao sistema tecnoprodutivo aeronáutico japonês envolver-se na fase de comercialização dos aviões. Foi o caso do desenvolvimento colaborativo entre JADC e Boeing no projeto YXX/B7J7 (futuramente o Boeing 777), em que empresas japonesas participaram do da comercialização do novo avião, permitindo ao sistema tecnoprodutivo aeronáutico japonês engajar-se em um processo de aprendizagem de conhecimentos de que até então não dispunha e que haviam sido críticos no fracasso da estratégia anterior de catch-up aeronáutico. O desenvolvimento e acúmulo de conhecimentos relativos à comercialização e pós-venda foram especialmente valiosos, uma vez que só podiam ser acessados por uma OEM com a experiência e o marketshare da Boeing. Repetindo a estratégia da colaboração no desenvolvimento do Boeing 
767, a JADC também envolveu a Mitsubishi, a Kawasaky e a Fuji no projeto YXX/B7J7, além de outras empresas menores (Kuo 2009).

Segundo Kuo (2009), também no projeto do YXX/B7J7, Boeing e JDAC - e o sistema tecnoprodutivo aeronáutico japonês - obtiveram benefícios mútuos. De parte da Boeing, o desenvolvimento colaborativo por meio de parcerias internacionais permitiu economias de escala que tornaram tanto o Boeing 767 quanto o Boeing 777 altamente competitivos. Além disso, na condição de líder de desenvolvimento tecnoprodutivo dos projetos, ela pode manter em níveis aceitáveis a transferência de tecnologia de modo a não solapar sua própria posição no mercado global de aviação. Quanto ao sistema tecnoprodutivo aeronáutico japonês, "the successful experience from Boeing's B767 and B777 projects have further enhanced Japanese manufacturers' technological level and capabilities, and at the same time provided them with needed experience, reputation, and access to further collaborate with more major international manufacturers and system integrators such as Airbus" (Kuo 2009: 293). Kimura (2006) também identifica benefícios mútuos da colaboração entre o sistema tecnoprodutivo aeronáutico japonês e a Boeing, em especial a transformação de "Japanese manufacturers as competitive suppliers for Boeing's international collaboration projects. For the Japanese aircraft industry, the Boeing-Japan collaboration has delivered technology and know-how, a significant stream of long-term business, relatively low-risk access to the global commercial aircraft market, and government support in developing their design and manufacturing competences" (Kimura 2009: 131). Kimura acrescenta ainda que a estratégia de desenvolvimento colaborativo internacional fez com que o sistema tecnoprodutivo aeronáutico japonês deixasse de ser um sistema fechado de conhecimento, uma vez que os projetos com a Boeing apresentaram inúmeras oportunidades de aprendizagem e transferência de conhecimento, aproximando-o do ponto de massa crítica em que é possível avançar mais ousadamente em direção à fronteira tecnoprodutiva aeronáutica mundial (Kimura 2009).

Ao longo da segunda metade da década de 1990 e por toda a década de 2000, o sistema tecnoprodutivo aeronáutico japonês acelerou ainda mais o desenvolvimento de sua cadeia de fornecedores do setor aeronáutico e suas colaborações internacionais. A diversificação das OEMs com quem o setor aeronáutico japonês entrava em projetos de colaboração internacional foi o principal meio de avançar no catch-up do setor e superar as limitações de colaborar exclusivamente com a Boeing. Segundo Kimura (2006): 
"collaboration with Boeing has limitations for the further development of the industry. One limitation is that a new development project does not occur very often in the commercial aircraft industry (...) Another limitation is that Boeing prevents the Japanese manufacturers from producing the important components, such as the cockpit and main wing, and from engaging in crucial operational spheres, such as sales activity" (Kimura 2006: 132). Em face disso, o sistema tecnoprodutivo aeronáutico japonês aumentou o seu espectro de colaborações com grandes OEMs a partir de meados da década de 1990, com projetos conjuntos entre Mitsubishi e Bombardier, Kawasaki com Embraer e Fuji com Raytheon. Até mesmo a reticência em estabelecer acordos de colaboração com a Airbus por receio de melindrar a Boeing, concorrente direta da OEM europeia, foi vencida, com empresas aeronáuticas japonesas fornecendo estruturas e sistemas para o A380 e A350. E nem poderia ser diferente: do modo como está estruturada a cadeia global de valor da indústria aeronáutica contemporânea, para que um fornecedor atinja as economias de escala e o domínio tecnoprodutivo que o habilitam a fornecer para as grandes OEMs, é preciso quase sempre fornecer para duas ou mais OEMs para obter escala e estabelecer relações de desenvolvimento e transferência de tecnologia que garantam a competitividade do fornecedor.

É por isso, aliás, que uma política de desenvolvimento do setor aeronáutico brasileiro centrada exclusivamente na Embraer estaria fadada ao fracasso. Mesmo tomando a Embraer como empresa-líder na qual apoiar o desenvolvimento da cadeia de fornecedores do setor aeronáutico brasileiro, a Embraer, por si só, não é capaz de gerar demanda suficiente para que um fornecedor obtenha as economias da escala que a tornariam competitivas globalmente; para tanto, é preciso fornecer para duas ou mais OEMs. Há ainda o segundo componente, o desenvolvimento conjunto e transferência de tecnologia, e o fato de a Embraer ser uma empresa seguidora de desenvolvimentos tecnológicos alheios dificultaria ainda mais o desenvolvimento da cadeia de fornecedores brasileiros apoiado exclusivamente nela.

Uma segunda mudança importante na estratégia de inserção do sistema tecnoprodutivo aeronáutico japonês ocorrida a partir da segunda metade da década de 1990 foi o abandono gradativo das colaborações internacionais por meio de consórcios liderados por agências governamentais, dando lugar a colaborações diretas entre fornecedores japoneses e OEMs estrangeiras. Nesse novo arranjo, o papel do MITI e da JADC se viu sensivelmente reduzido. Nas palavras de Kimura (2006), “having accumulated product- 
related competences and having developed a reputation as competent sub-system suppliers, they have learned to stand on their own feet" (Kimura 2006: 132).

A estratégia de catch-up do sistema tecnoprodutivo aeronáutico japonês por meio da inserção de empresas em cadeias globais de fornecedores deve grande parte de seu sucesso às mudanças pelas quais passou o setor aeronáutico global nas décadas de 1980 e 1990, em especial a disseminação das parcerias de compartilhamento de riscos entre OEMs e fornecedores. Outro fator que contribuiu para o sucesso da estratégia de catchup foi a aprendizagem institucional pela qual passou o sistema tecnoprodutivo aeronáutico japonês desde sua primeira tentativa de catch-up, que visava desenvolver e produzir um avião japonês e criar não apenas uma OEM mas também toda a cadeia de fornecedores de modo autônomo e independente em relação ao resto do setor aeronáutico global. O objetivo da estratégia mudou, passando a buscar a inserção de empresas japonesas nas cadeias globais de valor, colocando em segundo plano, mas sem nunca abandonar a meta, de desenvolver e produzir um avião japonês e uma OEM japonesa.

A principal razão do sucesso da estratégia empreendida ao longo das décadas de 1990 e 1980, no entanto, se deveu às formas de aprendizagem tecnoprodutiva adotadas pelo sistema tecnoprodutivo aeronáutico japonês que, sem abrir mão de formas já vigentes, como a produção sob licença de aviões militares, incorporou formas de aprendizagem tecnoprodutiva que aumentavam o desenvolvimento e acúmulo de conhecimentos por parte do setor aeronáutico japonês promovendo a transferência tecnológica de empresas estrangeiras para empresas japonesas. A aprendizagem tecnoprodutiva por meio de parcerias internacionais de compartilhamento de riscos foi capaz de qualificar a cadeia de fornecedores japoneses, que de fornecedores de segundo e terceiro nível passou também a contar com fornecedores de primeiro nível, reduzindo assim a distância do sistema tecnoprodutivo aeronáutico japonês da fronteira tecnoprodutiva aeronáutica contemporânea. A ponto de, a partir de meados da década de 2000, a Mitsubishi ter dado início ao desenvolvimento de um jato regional com capacidade entre setenta a noventa passageiros, ideia que vinha sendo gestada desde fins da década de 1990 com o nome de projeto YSX. 


\section{O MRJ e a cartada final - por ora - do catch-up aeronáutico japonês}

Projeto nunca inteiramente abandonado, o desenvolvimento e produção de um avião por uma OEM japonesa foi retomado com força em 2003, quando o governo japonês, sob coordenação da JADC - subordinada ao METI (Ministry of Economy, Trade and Industry), ex-MITI - lançou, em conjunto com empresas japonesas com forte atuação no setor aeronáutico, o programa "R\&D of Environment-Friendly, High-Performance Small Aircraft". O programa apoiava-se nos estudos e projetos do YSX, sucessor menor do YXX/B7X7, cujo desenvolvimento inicial foi feito em colaboração com a Boeing (o YXX/B7X7 foi projetado com capacidade entre 100 e 150 passageiros, ao passo que o YSX teria capacidade na faixa de 70 a 90 passageiros).

Foi com base nas competências adquiridas como fornecedoras de empresas líderes internacionais que a Mitsubishi decidiu projetar e produzir seu próprio jato regional, o Mitsubishi Regional Jet (MRJ), de setenta a noventa lugares, com grandes seções de sua estrutura construídas em materiais compósitos. O MRJ concorrerá diretamente com a família ERJ da Embraer e a família o Bombardier CRJ700 e começará a produção em 2012.

O sistema tecnoprodutivo aeronáutico do Japão passa neste momento por uma transição de um setor largamente baseado em fornecedores para uma situação em que uma das maiores e mais tradicionais empresas japonesas do setor aeronáutico tenta se reposicionar como OEM em um segmento em que Bombardier e Embraer já estão consolidadas e em que Japão, China e Rússia estão atualmente momento implementando estratégias para concorrer nessa mesma faixa de jatos regionais na faixa de setenta a cento e dez lugares. A competição no setor será muito intensa nos próximos anos e contará com muitas empresas colocando produtos e modelos de negócios em disputa. Tudo indica que o setor não aguenta um número tão grande de concorrentes no mesmo segmento, o que significa que nem todas as empresas sairão vencedoras. Daqui a dez ou vinte anos será possível contar a história de como a estratégia $x$ do país $y$ para o seu setor aeronáutico deu certo ou errado e por que. A inserção das empresas aeronáuticas japonesas nas cadeias de valor de grandes OEMs e fornecedoras de componentes e subsistemas e seu domínio tecnológico em materiais compósitos (uma das principais inovações tecnológicas destinadas a reduzir o peso dos aviões, 
diminuindo consequentemente o consumo de combustível e aumentando sua eficiência, é uma das mais fortes tendências de mercado para as próximas décadas) colocam o setor aeronáutico japonês em posição bastante vantajosa. Além disso, o mercado asiático oferece as perspectivas mais promissoras de crescimento da demanda por jatos regionais, conferindo uma vantagem adicional ao Japão - não fosse o fato de que os outros três desafiantes do duopólio Bombardier/Embraer vêm eles também da Ásia: Rússia e China, colocando as empresas desses países em concorrência direta por um mesmo mercado regional.

O desenvolvimento de um jato regional japonês com capacidade entre setenta e noventa passageiros contou inicialmente com projetos competidores da Fuji Heavy Industries (FHI) e da Mitsubishi Heavy Industries (MHI), com coordenação e colaboração nos estágios iniciais da JADC, em 2003. No mesmo ano, a Mitsubishi deu início a estudos de viabilidade tecnoprodutiva e comercial de um jato regional com capacidade entre trinta e cinquenta passageiros, mas em 2005 o projeto foi alterado para um avião com capacidade entre setenta e noventa passageiros, em função da maior demanda de mercado identificada pela Mitsubishi para jatos regionais desse tamanho. No mesmo ano a Mitsubishi tornou público seu projeto de desenvolvimento e produção de um jato regional, levando à definição do projeto da MHI como vencedor, recebendo o nome de MRJ - Mitsubishi Regional Jet. O MRJ será o primeiro jato regional a fazer uso extenso de materiais compósitos em estruturas como asas e empenagem, no que a Mitsubishi estará se valendo da proficiência tecnoprodutiva em desenvolvimento e fabricação de estruturas em materiais compósitos, adquirida ao longo de décadas de colaboração com OEM internacionais, em especial a Boeing.

O governo japonês, por meio da JADC, que não só coordenava os esforços de desenvolvimento articulando os atores do sistema tecnoprodutivo aeronáutico japonês e de fornecedores internacionais, mas também colaborava nas fases de pesquisa e desenvolvimento e no financiamento do projeto, anunciou em 2007 um aporte significativo de recursos para o MRJ, cobrindo aproximadamente um terço dos custos de desenvolvimento inicial do avião. Entre as empresas japonesas envolvidas no projeto figuram a Fuji, com participação direta em pesquisa e desenvolvimento do MRJ, e a Toyota, maior acionista da Fuji e uma das maiores investidoras privadas do projeto MRJ. Mitsui Corporation, Sumitomo Corporation e o Banco de Desenvolvimento do Japão são outros atores japoneses com participações importantes no desenvolvimento e 
produção do MRJ. Entre os fornecedores internacionais de componentes e sistemas encontramos Pratt \& Whitney (turbinas), Parker Aerospace (sistemas hidráulicos), Hamilton Sundstrand (sistemas auxiliares), Rockwell Collins (aviônicos e computadores de bordo) e Nabtesco (controladores de voo).

$\mathrm{O}$ processo de desenvolvimento e produção do MRJ até o momento indica que o sistema tecnoprodutivo aeronáutico japonês aprendeu, e muito, com as experiências passadas. E não foi apenas em termos estritamente tecnológicos e produtivos que se deu o aprendizado, patente no desenvolvimento da cadeia de fornecedores de terceiro, segundo e primeiro nível e na sua bem-sucedida inserção nas cadeias globais de valor, fornecendo primeiro para a Boeing e depois para Bombardier, Embraer e Airbus, e no projeto de desenvolvimento de ciclo completo de um jato regional, mas também nos aspectos que se mostraram os mais críticos na primeira tentativa de desenvolver, produzir e comercializar um avião japonês: as dificuldades do arranjo industrial desenhado para o projeto do YS-11 - múltiplos atores com participações e desinteresse pelos resultados do projeto mais ou menos desiguais - e a inexperiência comercial das empresas japonesas em venda e pós-venda de aviões.

Quanto ao primeiro aspecto acima, a solução consistiu em concentrar riscos e retornos em uma única grande empresa, a Mitsubishi Heavy Industries, cabendo a outros atores do sistema tecnoprodutivo aeronáutico japonês o papel de desenvolvedores e fornecedores do MRJ. Esse arranjo cria os incentivos necessários para que a Mitsubishi e suas fornecedoras empenhem-se ao máximo no desenvolvimento, produção e comercialização de um produto competitivo.

Em relação ao segundo aspecto, o lado comercial do projeto, a Mitsubishi criou uma subsidiária, a Mitsubishi Aircraft Corporation, responsável por desenvolver as atividades de inteligência de mercado, vendas e pós-vendas, bem como o processo de certificação do MRJ. A criação da Mitsubishi Aircraft aumenta sensivelmente as chances de sucesso do MRJ, já que, na condição de empresa diretamente interessada nos resultados comerciais do projeto MRJ, ela tem os incentivos para buscar a melhor estratégia comercial e transmitir isso aos demais stakeholders do empreendimento.

Outro passo importante em direção à viabilização comercial do MRJ foi dado com a série de encomendas firmes e opções de compra que a Mitsubishi Aircraft recebeu das empresas de transporte aéreo japonesas All Nippon Airways ( ANA) e Japan Airlines 
(JAL). A Mitsubishi Aircraft espera que as encomendas iniciais da ANA e da JAL estimulem outras empresas aéreas, a começar por empresas asiáticas - o que não será tão fácil, uma vez que a China e a Rússia estão desenvolvendo jatos regionais que competirão diretamente com o avião da Mitsubishi -, a encomendar unidades do MRJ, com isso viabilizando sua produção, estímulo tanto mais necessário porque os pedidos firmes e as opções de compra feitos pela ANA e pela JAL não atingiram as 100 unidades que a Mitsubishi Aircraft definiu como quantidade mínima de pedidos para dar início à produção comercial do MRJ. A Mitsubishi Aircraft espera vender 1.000 unidades do MRJ ao longo das próximas duas décadas.

O resultado final da estratégia de catch-up do sistema tecnoprodutivo aeronáutico japonês, no entanto, ainda está para ser apurado. O voo inaugural do MRJ, previsto inicialmente para 2011, só deve ocorrer, tudo dando certo, em 2013; e essa é a parte mais simples da questão; as dificuldades de monta referem-se ao processo de produção, cuja dimensão crítica, a integração de sistemas, é ainda pouco desenvolvida no sistema aeronáutico japonês, em especial no caso do segmento comercial, em que a experiência anterior, o YS-11, se deu há mais de meio século; e à comercialização do avião. Projetar e fazer voar aviões é uma coisa; produzir em escala comercial e vender, outra bem diferente. 


\section{Capítulo 6: Um negócio da China? Meu mercado por sua tecnologia: off-sets como estratégia de aprendizagem tecnoprodutiva}

A China será capaz de passar pelo vale da morte dos processos de desenvolvimento tecnoprodutivo, a saber, a transição de uma economia de baixa e média tecnologia com vantagens competitivas advindas de ganhos de escala e baixos salários e preços para uma que deriva parte substancial de sua competitividade da inovação e da intensidade de conhecimento aplicado aos processos produtivos? Afinal, segundo os modelos de catch-up econômico e tecnológico (Abramovitz 1986; Cohen e Levinthal 1990; Mathews 2008), quanto mais um país se aproxima da fronteira tecnoprodutiva, maiores são os custos e dificuldades para continuar avançando. Esse é o desafio enfrentado pela China neste ponto de seu processo de desenvolvimento econômico. A análise da estratégia de catch-up do setor aeronáutico chinês oferece pistas interessantes sobre as políticas chinesas em indústrias intensivas em tecnologia e pode ajudar a compreender melhor as perspectivas do desenvolvimento do país nos próximos anos.

Há paralelos evidentes entre as trajetórias de desenvolvimento econômico da China e outros países, em especial asiáticos. Pensemos, por exemplo, na trajetória dos setores automotivo e eletroeletrônico de Japão, Coreia do Sul e China, que começaram por processos de aprendizagem por atração de empresas estrangeiras e/ou produção sob licença e/ou engenharia reversa e/ou formação da cadeia de fornecedores e passaram à formação de empresas nacionais que derivam sua competitividade de salários e preços baixos utilizando tecnologias maduras e aprendendo por meio de desenvolvimento e produção de ciclo completo, tirando proveito do acesso privilegiado ao mercado doméstico e a mercados externos menos sofisticados nos quais considerações relativas a preços suplantam fatores como inovação e conteúdo tecnológicos. Nessa fase, os produtos dessas empresas gozam de baixo prestígio, como foi o caso das primeiras incursões do Japão na produção de eletroeletrônicos na década de 1970 e da chegada de automóveis japoneses ao mercado norte-americano em finais da década de 1970 e começo da década de 1980 e da entrada de empresas coreanas no Brasil, tanto no caso de automóveis como de eletroeletrônicos. Por fim, tudo dando certo, chega o momento em que essas empresas acumularam conhecimento suficiente para se aproximarem competitivamente da fronteira tecnoprodutivo de seu setor, passando da posição de seguidoras a líderes em inovação. A essa altura, o prestígio tecnoprodutivo de algumas 
poucas empresas nacionais passa a ser associado ao conjunto das empresas do país, refletindo o avanço mais amplo do desenvolvimento tecnoprodutivo de inúmeros setores nacionais. Também o Japão, entre as décadas de 1960 e 1980, depois a Coreia do Sul, nos anos 1980 e 1990, e mais recentemente a China desenvolveram seus setores automotivo e eletroeletrônico saindo de uma posição de atraso e até inexistência de atividades no setor para aproximarem-se rapidamente da fronteira tecnoprodutiva do setor, colocando várias de suas empresas entre as mais competitivas globalmente.

Esse modelo de trajetória de desenvolvimento tecnoprodutivo, no entanto, varia segundo o setor, em especial em relação às diferenças de intensidade de conhecimento entre setores. Se os setores automotivo e eletroeletrônico são casos clássicos de sucessos de empresas em diversos países, o setor aeronáutico oferece uma perspectiva oposta, com muitas e variadas tentativas malsucedidas de catch-up, cabendo ao Brasil o solitário posto de único caso de sucesso pleno até o momento. A China pretende desenvolver uma OEM capaz de desenvolver, produzir e comercializar um jato regional muito brevemente, e conta com uma série de vantagens já conhecidas dos observadores do desenvolvimento tecnoprodutivo chinês recente: competitividade em salários e preços, gigantesco mercado doméstico e, por que não, vontade e determinação de sua elite tecnopolítica em buscar o desenvolvimento tecnoprodutivo do país. Já vimos, no entanto, que no caso do setor aeronáutico, esses fatores não bastam: instituições e políticas de ciência, tecnologia e inovação (CTI), recursos humanos, empresas e estratégias de aprendizagem tecnoprodutivas desempenham um papel fundamental no resultado final das tentativas de catch-up aeronáutico.

Este capítulo examina os desafios específicos de desenvolvimento tecnoprodutivo do setor aeronáutico chinês. Na primeira seção traço um breve histórico do setor aeronáutico chinês, identificando as estratégias de aprendizagem tecnoprodutiva adotadas em suas diferentes fases, bem como os arranjos institucionais e as políticas do setor; em seguida, examino o papel atual do setor aeronáutico na política industrial no atual Plano Quinquenal, no qual, apesar de não ser enquadrado como uma das indústrias ou setores pilares, ou seja, não figurar entre os setores industriais aos quais se atribui prioridade máxima, é ainda assim considerado um setor estratégico, objeto de inúmeras ações de construção institucional e desenvolvimento tecnoprodutivo; por último, descrevo a trajetória tecnoprodutiva do Comac ARJ21, jato regional atualmente em desenvolvimento na China e que deverá competir diretamente com aparelhos da 
Embraer e Bombardier, bem como com os projetos em gestação no Japão (MRJ) e na Rússia (Sukhoi Superjet 100), se estes vieram a vingar, e do COMAC C919, narrowbody que competirá diretamente com os similares da Boeing e da Airbus.

\section{Economia, ciência, tecnologia e inovação na China}

O maior obstáculo ao pleno desenvolvimento do setor tecnoprodutivo aeronáutico chinês - entendido como o desenvolvimento, produção e comercialização bem sucedidos de um avião capaz de competir com os produtos das empresas do duplo duopólio da aviação civil mundial (Boeing, Airbus, Embraer e Bombardier) - é a pouca experiência acumulada pela China no setor aeronáutico em geral e no setor de aviões civis em particular, no qual conta com pouco mais de duas décadas de esforços relevantes em direção ao catch-up tecnoprodutivo, uma vez que antes dos anos 1990 o setor aeronáutico chinês dedicava-se basicamente a produzir, sob licença, projetos originais soviéticos ou norte-americanos com vistas a suprir o mercado interno de aviões, devotando pouca atenção à aprendizagem, desenvolvimento e acúmulo tecnoprodutivo no setor aeronáutico e à dimensão comercial do negócio. A transição do sistema tecnoprodutivo aeronáutico chinês da aprendizagem de tecnologias e conhecimentos maduros para a redução da distância em relação à fronteira tecnoprodutiva aeronáutica mundial é, no momento, o maior desafio para seu catch-up. As diferentes formas de aprendizagem tecnoprodutiva, bem como as vantagens e limites inerentes a cada uma, serão os determinantes fundamentais do sucesso ou fracasso do catch-up chinês. Vejamos, portanto, como as estratégias de aprendizagem tecnoprodutiva no setor aeronáutico evoluíram na China.

Para compreendermos o desenvolvimento tecnoprodutivo chinês das últimas três décadas, é necessário ter em mente os dois pontos de inflexão da política econômica, industrial e comercial da China: 1978, ano em que o país começa suas primeiras reformas econômicas, e o período de abertura dos anos 1990. Concomitantemente, devemos analisar o processo paralelo de reforma das políticas de CTI, iniciado em 1985 e cuja forma atual corresponde ao estipulado no Décimo e no Décimo Primeiro Planos Quinquenais, referentes aos períodos de 2001-2005 e 2006-2010, respectivamente. Vistos lado a lado, o processo mais geral de transformação econômica da China e as 
modificações pelas quais passou seu sistema de CTI indicam que o desenvolvimento econômico e social chinês mais recente tem posto grande ênfase em aumentar a intensidade de conhecimento da economia chinesa.

As reformas econômicas iniciadas por Deng Xiaoping em 1978 introduziram mecanismos de livre mercado em diversas áreas da economia chinesa, sendo levadas a cabo em duas fases: na primeira, a partir de 1978 e durante toda a década de 1980, a China abriu sua economia para investimentos externos e permitiu a criação de empresas privadas, entre outras medidas. Na segunda fase, que vai de fins da década de 1980 estendendo-se por todo o decênio seguinte, as reformas econômicas foram aprofundadas: diversas empresas estatais em setores não estratégicos foram parcial ou totalmente privatizadas, o controle de preços foi reduzido e o sistema regulatório tornou-se menos restritivo. Nessa fase a economia chinesa aumentou seu grau de abertura: mais empresas estrangeiras passaram a atuar direta ou indiretamente em território chinês - sempre, obrigatoriamente, por meio de joint ventures com empresas chinesas. Empresas chinesas, por sua vez, passaram por um forte processo de internacionalização de suas operações, pela criação de subsidiárias ou pela aquisição de empresas estrangeiras.

A participação do Estado chinês na economia, no entanto, continuou significativa, tanto de modo indireto, por exemplo, no apoio financeiro ao processo de internacionalização de empresas chinesas, como também por meio das muitas empresas estatais em setores estratégicos. As empresas estatais chinesas desempenham, aliás, um papel bastante especial no desenvolvimento econômico da China: por meio delas o Estado implementa suas principais políticas industriais, tecnológicas e de comércio exterior.

As reformas econômicas chinesas não visavam apenas introduzir mecanismos de livre mercado na economia chinesa, mas também mudar profundamente a estrutura da economia chinesa e sua forma de inserção na economia mundial, tarefa ainda em curso. Para atingir esse objetivo, a China precisará alterar significativamente os fatores que determinam a alocação de recursos entre os setores de sua economia e que determinam, em última instância, os fundamentos da competitividade - ou da sua falta - da economia chinesa. A China precisará reduzir o peso de fatores como baixos salários e capital abundante e aumentar o peso de fatores como intensidade tecnológica e proximidade das fronteiras tecnoprodutivas contemporâneas na equação que determina sua 
competitividade. Se não tiver sucesso em alterar a estrutura de sua economia nesse sentido, sucumbirá à chamada armadilha da renda média, ponto do desenvolvimento econômico em que os retornos do aumento dos fatores trabalho e capital começam a ser decrescentes, só podendo ser superado por meio do aumento da produtividade e intensidade tecnológica. Nesse ponto, as políticas de CTI desempenham papel importante.

O processo de reforma do sistema de CTI da China teve início em meados da década de 1980 e correu paralelamente ao processo mais geral de reforma econômica. Xiwei e Xiangdong (2007) dividem o processo de reformas do sistema de CTI chinês em três fases: de 1985 a 1992, sob o lema "construindo a nação por meio da ciência e da educação"; de 1992 a 1999, período dedicado à reforma do sistema de ensino superior e dos institutos de pesquisa e sua articulação com o sistema tecnoprodutivo; e de 1999 até os dias atuais, nos quais se aprofundou a reforma do sistema de ensino superior e foi retomado o lema "construindo a nação por meio da ciência e da educação" (Xiwei e Xiangdong 2007).

Xiwei e Xiangdong (2007) caracterizam o sistema chinês de CTI no período anterior às reformas dos anos 1980 como altamente centralizado em termos institucionais e excessivamente concentrado na produção de conhecimento e tecnologia nas áreas de defesa e indústrias pesadas, modelo em larga medida inspirado no sistema soviético de CTI. O principal efeito das reformas efetuadas a partir de 1985 foi diversificar as áreas de produção científica e tecnológica e descentralizar o sistema chinês de CTI, conferindo maior flexibilidade e velocidade de resposta a incentivos de origens diversas daqueles definidos pelas estruturas de planejamento central características do Estado chinês.

A reforma do sistema chinês de CTI teve como marco inicial a "Resolução do Comitê Central do Partido Comunista da China sobre a reforma do sistema de ciência e tecnologia", de 1985, e se deu sob o lema "construindo a nação por meio da ciência e da educação". Seu objetivo central foi aumentar a interação de universidades e centros de pesquisa com empresas. Entre ações empreendidas e objetivos alcançados, Xiwei e Xiangdong (2007) elencam: a redução do orçamento de universidades e centros de pesquisa como modo de estimular a busca por fundos por meio da interação com o sistema produtivo; a reforma do sistema regulatório de patentes e propriedade 
intelectual para facilitar a colaboração de universidades e centros de pesquisa com empresas; a criação da primeira zona de desenvolvimento de alta tecnologia em Pequim, em 1988; e o lançamento do Programa Tocha, dedicado à promoção de outras zonas de desenvolvimento de alta tecnologia (Xiwei e Xiangdong 2007: 319).

A fase seguinte de reforma do sistema chinês de CTI, que começou em 1992, ocorreu pari passu com a segunda fase de macroreformas desencadeada por Deng Xiaoping. A "Lei da República Popular da China para o Progresso da Ciência e da Tecnologia" e o "Programa de Escalada" são seus marcos iniciais e visavam a apoiar a pesquisa em ciência básica e aumentar a autonomia das universidades e centros de pesquisa na definição de suas agendas de pesquisa. Nessa fase, a mudança mais importante foi a aprovação pelo Conselho de Estado, ainda no ano de 1991, de um documento elaborado pelas Comissões de Educação e de Ciência que regulamentava a existência de empresas criadas e afiliadas a universidades e centros de pesquisa, aumentando consideravelmente a interação entre as instituições do sistema de CTI e o setor produtivo chinês e oferecendo incentivos para a criação de empresas por professores, alunos e pesquisadores daquelas instituições. Tratava-se não apenas de apoiar a interação de universidades e centros de pesquisa com empresas por meio de cooperação no desenvolvimento de produtos e processos e na prestação de serviços técnicos, mas de permitir e incentivar a criação, por aquelas instituições, de empresas de alta tecnologia. Entre outras medidas destinadas a estimular a criação de empresas de alta tecnologia nascidas de universidades e centros de pesquisa, o governo chinês permitiu que professores e pesquisadores daquelas instituições assumissem cargos de dedicação em tempo parcial ou total às empresas ou fundassem seus próprios empreendimentos sem ter que abrir mão de suas posições como professores ou pesquisadores de universidades e centros de pesquisa públicos. De acordo com Xiwei e Xiangdong (2007), em 2000 nove anos, portanto, após a regulamentação das empresas afiliadas a universidades/centros de pesquisa, a China já contava com 2.097 empresas de alta tecnologia originadas e vinculadas a instituições do sistema de CTI chinês (Xiwei e Xiangdong 2007: 319).

A terceira fase do processo de reformas do sistema chinês de CTI vai de 1999 aos dias de hoje; o lema de 1985, "construindo a nação por meio da ciência e da educação", foi retomado, dessa vez como acompanhamento do objetivo de fortalecer o sistema nacional de CTI e acelerar a comercialização de ciência e tecnologia na forma de 
inovações. Segundo Xiwei e Xiangdong 2007, uma das mudanças mais relevantes foi a transformação de centros públicos de pesquisa em empresas de alta tecnologia ou empresas prestadoras de serviços de alta tecnologia (Xiwei e Xiangdong 2007: 319). A partir de 2000, as reformas do sistema chinês de CTI passaram a dedicar atenção especial aos parques científicos. Em 2001, o governo chinês passou a realizar avaliações da produtividade e competitividade das empresas afiliadas a universidades e centros de pesquisa, concedendo autonomia às empresas promissoras.

Foi mero acaso que as reformas do sistema chinês de CTI tenham ocorrido paralelamente e de modo a complementar as reformas econômicas da China nas últimas três décadas? Ou essa coincidência é fruto da consciência do atraso tecnoprodutivo chinês em relação aos países de economias mais avançadas? Fico com a última hipótese. Seja como for, o fato é que a concomitância das reformas econômicas e do seu sistema de CTI preparou a China para enfrentar o problema fundamental de toda tentativa de desenvolvimento econômico: adquirir o conhecimento necessário para aproximar a economia nacional e suas empresas da fronteira tecnoprodutiva do momento. A China, no entanto, ainda se encontra a meio caminho de sua trajetória de desenvolvimento econômico e social, longe, portanto, da fronteira tecnoprodutiva da maioria dos setores econômicos, e assim deverá continuar por algum tempo. Contudo, já se aproxima da fronteira tecnoprodutiva de alguns setores, como eletrônica, e microeletrônica e energias alternativas, e se empenha em avançar em outros: é o caso do setor aeronáutico civil. A China terá sucesso em sua transição rumo a uma economia intensiva em conhecimento e capaz de competir diretamente com as empresas líderes dos países mais avançados economicamente? O exame da estratégia de catch-up do setor aeronáutico chinês oferecerá algumas pistas sobre o que esperar do desenvolvimento econômico e social da China.

\section{O setor aeronáutico chinês: instituições, políticas e empresas}

De todas as vantagens comparativas da China, seu enorme mercado atual e gigantesco mercado potencial nas próximas décadas é uma das mais valiosas. Menina dos olhos tanto do capital estrangeiro como do capital estatal e privado chinês, o acesso ao seu mercado interno é a moeda de troca em todas as tratativas chinesas quando o assunto é 
abertura, integração e internacionalização econômica. Até aí, nada de mais: negociar o acesso ao mercado interno é das práticas mais antigas e bem estabelecidas em economia internacional. A China, no entanto, tem utilizado o controle ao acesso a seu mercado interno de forma altamente estratégica e com vistas não apenas a garantir empregos domésticos e divisas oriundos de exportações, mas também a transferência de tecnologia de empresas estrangeiras para empresas chinesas.

Essa, em suma, é a cláusula central da estratégia chinesa de catch-up do setor aeronáutico: troca-se o acesso ao mercado interno pelo acesso à tecnologia de empresas estrangeiras do setor aeronáutico, que mal podem esperar o momento de tirar seu quinhão do mercado chinês de aviação comercial. De olho nesse mercado não só vasto como também muito pouco explorado, as OEMs do duplo duopólio, assim como muitas das mais importantes empresas fornecedoras de primeiro e segundo nível, têm estabelecido acordos de joint venture nos moldes chineses: participação majoritária de chineses, acordos de off-set concedidos às joint ventures ou empresas sob controle exclusivamente chinês e, sobretudo, transferência de tecnologia para empresas chinesas pelas mais diversas formas de aprendizagem tecnoprodutiva por aprendizado pela prática, entre as quais engenharia reversa, treinamento técnico, produção sob licença, qualificação de fornecedores, criação de centros de pesquisa e desenvolvimento na China, entre outros.

A decisão de transferir tecnologia em troca de acesso ao mercado interno chinês envolve riscos para as empresas transferidoras, a começar pelo fato de que assume-se o risco de criar potenciais competidores no médio ou longo prazo, exigindo por parte das empresas estrangeiras extrema atenção aos acordos de propriedade intelectual e uma correta avaliação de quão sensíveis são as tecnologias e conhecimentos repassados.

Os riscos, no entanto, não se restringem a problemas relativos a transferência tecnológica e propriedade intelectual, afetando também os próprios contratos comerciais nos quais se baseiam os acordos de joint ventures e transferência de tecnologia: as promessas de aquisição de aviões por empresas aéreas estatais chinesas. Nesse particular, o caso da Harbin Embraer Aircraft Industry (HEAI), subsidiária chinesa da Embraer, é bastante eloquente. Os pedidos firmes e opções adicionais de compra de aviões da empresa brasileira, que seriam montados na China pela Harbin Embraer, acabaram não se realizando. O que parecia ser um negócio da China acabou sendo um 
negócio na China, o que é completamente diferente. Há mais coisas em uma preposição do que sonha nossa sociologia e do que poderia imaginar a Embraer quando, de modo pioneiro, estabeleceu a joint venture com a Harbin. E no caso da Embraer os termos da joint venture ainda foram bons, com o lado brasileiro detendo $51 \%$ de participação no empreendimento.

Em linhas gerais, portanto, a estratégia de catch-up do setor aeronáutico chinês consiste no franqueamento do acesso a seu mercado interno, por meio de promessas de compra por empresas aéreas estatais chinesas de aviões montados na China ou que utilizam componentes fabricados na China, em troca da tecnologia das empresas estrangeiras, tanto de OEMs como de fornecedoras de primeiro e segundo nível. Até aí, o acordo parece bom. Acontece que a China quer mais: quer ela própria desenvolver, produzir e comercializar seus próprios aviões comerciais - o que ela já está fazendo.

Comparando as estratégias chinesa e japonesa (a atual, não a malfadada tentativa dos anos 1950-1960) de catch-up do setor aeronáutico, uma diferença fica evidente: ao passo que os japoneses desenvolveram pacientemente sua cadeia de fornecedores, com a qualificação gradual de suas empresas como fornecedoras de terceiro e segundo nível para empresas de segundo e primeiro nível, até se arriscarem a desenvolver, produzir e comercializar seus próprios aviões comerciais, os chineses adotaram uma estratégia muito mais ousada que dispensa a qualificação avançada de empresas fornecedoras chinesas, lançando-se em menor tempo à tentativa de desenvolver, produzir e comercializar seus próprios aviões comerciais. Para ter sucesso na empreitada, a China conta com a experiência adquirida anteriormente com a produção sob licença ou por meio de engenharia reversa de aviões militares soviéticos e aviões comerciais norteamericanos.

O processo de aprendizagem tecnoprodutiva no setor aeronáutico chinês teve início logo após a vitória dos revolucionários de Mao Tsé Tung, em 1949. Em abril de 1951, o governo chinês publicou a "Resolução para Construção da Indústria Aeronáutica". A essa altura, a China já contava com fábricas de aviões em Xi'an, Shanghai, Shenyang e Chengdu, que serviriam de base para a futura construção do setor aeronáutico chinês. Em termos de suas capacidades tecnoprodutivas, o setor evoluiu aos poucos de atividades de MRO para produção sob licença e desenvolvimento conjunto, até o 
estágio atual, em que a China procura dominar o ciclo completo de desenvolvimento e produção de aviões militares e civis.

O desenvolvimento do setor tecnoprodutivo aeronáutico chinês apoiou-se fortemente na transferência de tecnologia e desenvolvimento conjunto de aviões militares com a União Soviética. O primeiro projeto conjunto foi para desenvolvimento do caça interceptador MIG-21 e de sua versão chinesa, o Chengdu Jian-7. A ruptura de relações entre a União Soviética e a China em 1960, no entanto, interrompeu o projeto do lado chinês, por sua vez levado adiante e completado pelos soviéticos. Em 1962, em meio às primeiras e malsucedidas tentativas de reaproximação (que só se efetivaria em 1989), os chineses receberam alguns MIG-21 soviéticos e partes incompletas do projeto do avião. A empresa estatal chinesa Fábrica de Aviões Shenyang foi encarregada de completar a documentação do projeto por meio de engenharia reversa, que recebeu a designação de Chengdu Jian-7. Vicissitudes da história chinesa, no entanto, entre elas a Revolução Cultural, atrasaram o pleno desenvolvimento das capacidades tecnoprodutivas necessárias para produzir em escala o Chengdu Jian-7: a versão chinesa só alcançaria a versão soviética, em termos de projeto, produção seriada e desempenho operacional na década de 1980.

Foi na década de 1980 e também lançando mão de acordos de produção sob licença e de engenharia reversa que a China produziu seus primeiros aviões comerciais: o Y-10, avião baseado no Boeing 707 (desenvolvido por meio de engenharia reversa a partir do B707) e produzido pelas Indústrias do Ministério da Aeronáutica (Shanghai Aircraft Manufacturing Company); e o Xi'an Y-7, avião regional turboélice com capacidade para 52 passageiros produzido pela Xi'an Aircraft Corporation (XAC) com base no Antonov An-24 soviético (Goldstein 2005: 7). O Xi'an Y-7 serviria de base para o desenvolvimento do Xi' an MA60, turboélice com capacidade para 56 a 60 passageiros (essencialmente uma versão alongada do Xi'an Y-7 200A), produzido conjuntamente pela XAC e pela China Aviation Industry Corporation I (AVIC I).

O tempo de desenvolvimento dos projetos foi bastante longo, ainda mais se levarmos em conta tratarem-se de aviões produzidos sob licença e posteriormente aprimorados por meio de engenharia reversa. O projeto do Xi'an Y-7 teve início em 1966, o voo inaugural do primeiro Xi'an Y-7 montado na China ocorreu em 1970 e a produção das versões chinesas só se iniciariam em 1977; mesmo assim, o Xi'an Y-7 só começou a ser 
entregue em 1984. O projeto dificilmente pode ser considerado um sucesso. $\mathrm{Na}$ avaliação de Nolan e Zhang, "the Y-7 turboprop was able to win only a limited number of domestic orders. In the year 2000, just 64 of the $Y-7 s$ were in service in thirteen domestic airlines. (...) Export orders were negligible. By the late 1990s, a total of only 130 Y-7s had been produced, and new orders had dried up completely. To compound matters, in the year 2000, a Y-7 exploded in mid-air. Following the conclusion of the crash investigation, all Y-7s were taken out of service in June 2001" (Nolan e Zhang 2002: 45).

O destino do Y-10 não foi melhor. Projeto em quase tudo inferior ao Boeing 707, avião com o qual deveria competir diretamente no mercado chinês e países vizinhos, o Y-10 não conseguiu assegurar o número mínimo de encomendas necessárias para viabilizar sua entrada em produção. Numa demonstração dos riscos de se contar com promessas de encomendas como estímulo ao desenvolvimento e produção de um avião, as companhias aéreas estatais chinesas se recusaram a comprar o Y-10, já que, entre outras características negativas, ele era mais pesado, apresentava maior consumo de combustível e tinha menor autonomia de voo do que o Boeing 707. Com a competitividade da aviação comercial sendo em larga medida função dos custos operacionais, em especial do consumo de combustível dos aviões que ela opera, o Y-10 estava definitivamente fora do páreo. Isso para não falar das limitações tecnoprodutivas do Y-10: Nolan e Zhang contam que "the test models were, reportedly, only able to fly for around half an hour at a time. Only two of the Y-10s were built. The plane never entered commercial production, and the Y-10 programme was halted in 1985" (Nolan e Zhang 2002: 45). Segundo Goldstein (2005), tanto o Xi' an Y-7 quanto o Xi'an Y-10 "proved to be major commercial failures and safety concerns further compounded matters." (Goldstein 2005: 7-8). Triste fim.

A história dos projetos Y-7 e Y-10 dá a medida de quão arriscado pode ser trocar tecnologia, ou mesmo montar aviões localmente, em troca de acesso ao mercado chinês e contando com encomendas de empresas estatais chinesas. Se nem no caso de projetos de interesse nacional como o Xi'an Y-7 e o Xi'an Y-10 o governo chinês conseguiu garantir a compra por companhias aéreas estatais de quantidades significativas - no caso do Y-7 - ou do mínimo necessário para entrada em produção do modelo - caso do Y-10 -, o que dizer de acordos com companhias estrangeiras? Vimos que a Embraer passou por essa experiência recentemente: a promessa de encomendas de aviões da Embraer 
que seriam montados na fábrica da Harbin Embraer, na China, ficaram muito aquém do volume inicialmente acordado.

A China também recorreu à aprendizagem tecnoprodutiva por meio da produção sob licença. Em 1985, a Shanghai Aviation Industry Cooperation estabeleceu acordo com a McDonnell Douglas para montagem na China de kits do MD-82/MD-83. A primeira unidade foi entregue em 1986, tendo sido fabricados um total de 35 unidades até 1994, 5 das quais foram exportadas para os EUA. A princípio um contrato de "montagem sob licença”, a cooperação da Shanghai Aviation Industry Cooperation com a McDonnell Douglas logo evoluiu para um acordo de off-set para produção na China de componentes e estruturas do MD-82, MD-83 e do MD-90. Com a aquisição da McDonnell Douglas pela Boeing em 1997, a Shanghai Aviation Industry Cooperation passou a fornecer também para a Boeing, um dos passos mais importantes para o desenvolvimento tecnoprodutivo aeronáutico chinês.

Essas tentativas de produção e comercialização de aviões civis e as experiências iniciais em desenvolvimento parcial de componentes e integração de sistemas tiveram, obviamente, seu mérito, à medida que expuseram o setor tecnoprodutivo aeronáutico chinês a um processo de aprendizagem tecnoprodutiva e de comercialização de aviões civis. Ser exposto, no entanto, não quer dizer obter sucesso. A verdade é que a aprendizagem tecnoprodutiva do setor aeronáutico chinês avançou muito pouco entre as décadas de 1960 e 1990, de modo que, na década de 1990, o setor aeronáutico chinês dispunha de razoável experiência na produção de aviões militares, graças sobretudo à cooperação com a antiga União Soviética, mas escassa capacidade de desenvolvimento, produção e comercialização de aviões civis.

A comercialização, que envolve desde inteligência de mercado até serviços de pósvendas, passando por questões igualmente relevantes como consolidação de marca e interação com clientes, é em geral a parte mais delicada e difícil de uma estratégia de catch-up do setor aeronáutico civil de qualquer país, pois envolve conhecimentos intangíveis que dificilmente podem ser transferidos, seja por venda, seja por engenharia reversa. Os conhecimentos necessários para a produção de aviões e as diversas formas de capital não econômico sobre a qual a comercialização bem-sucedida se apoia - como o capital simbólico associado à marca, ou o capital social presente na capacidade de gerir cadeias globais de valor - têm uma curva de aprendizagem bastante longa, só 
podendo ser desenvolvidos por meio de aprendizado pela prática e interações constantes por extensos períodos com fornecedores e clientes. No que diz respeito ao aspecto comercial e às diferentes formas de capital que o compõem, saltos ou acelerações súbitas do processo de aprendizagem são muito pouco comuns, até mesmo raros. O domínio dos conhecimentos e tecnologias necessários para o desenvolvimento e produção de aviões, condição suficiente para a produção de aviões militares, não basta para construir um setor tecnoprodutivo aeronáutico civil. Nesse caso, tecnologia é apenas parte do problema; é necessário ter sucesso na comercialização daqueles conhecimentos e tecnologias incorporados aos aviões civis. Vender é que são elas.

\section{A atual estratégia chinesa de catch-up aeronáutico}

Esse cenário, contudo, começou a mudar ainda na década de 1990, quando o governo chinês deu início a uma série de reformas do setor tecnoprodutivo aeronáutico civil que preparariam o caminho para a tentativa de executar uma estratégia de catch-up a partir de meados da década de 2000. O setor tecnoprodutivo aeronáutico chinês passou por uma profunda reformulação que consistiu não apenas numa ampla reestruturação industrial e organizacional das empresas do setor como também em alterações da estratégia de desenvolvimento tecnoprodutivo, que passou desde então a ser uma estratégia de catch-up estrito senso.

Duas mudanças importantes ocorreram na década de 1990 no setor tecnoprodutivo aeronáutico da China. Em 1993, o $8^{\circ}$ Congresso Nacional do Povo colocou todas as empresas e institutos de pesquisa do setor aeronáutico chinês sob controle da Aviation Industry Corporation of China (AVIC) "with the aim of creating an ultra-large industrial group, combining military and civil aviation and capable of competing globally" (Goldstein 2005: 8). A AVIC seria responsável por implementar a estratégia de catch-up aeronáutico chinês, conhecida como Plano de Decolagem em Três Passos. O primeiro passo consistiu em estabelecer acordos de off-set com grandes OEMs para adquirir os conhecimentos e tecnologias necessários para futuramente desenvolver e produzir seus próprios aviões, uma estratégia clássica de aprendizagem tecnoprodutiva no setor aeronáutico. 
Foram firmados acordos de off-set com a Boeing para produção de empenagem, estabilizadores horizontais e fuselagem traseira e com a McDonnell Douglas para produção da seção do nariz e de estabilizadores horizontais para os MD-80 e MD-90. Boeing e McDonnell Douglas investiram na qualificação de técnicos e na modernização das fábricas que produziriam os componentes previstos no acordo de off-set para que eles atendessem às certificações da agência americana de aviação (FAA) e pudessem, consequentemente, ser utilizados em aviões produzidos pelas duas companhias.

Entre 1985 e 1994, a Shanghai Aviation Industrial Corporation vinha montando na China os jatos MD-82 e MD-83. Com base nessa experiência, a McDonnell Douglas viu uma oportunidade de aprofundar a cooperação com o governo chinês sob o Plano de Decolagem em Três Passos, propondo-se a produzir e a montar, por meio de subsidiárias da AVIC, 75\% de aviões do modelo MD-90 (com exceção dos motores e dos aviônicos). O acordo de off-set previa a compra, pela agência chinesa de aviação civil e linhas aéreas a ela subordinadas, de aviões da McDonnell Douglas produzidos na China em troca da transferência de tecnologia. O acordo de off-set era complementado pela produção sob licença de aviões da McDonnell Douglas, potencializando portanto as oportunidades de aprendizagem tecnoprodutiva, que dependem largamente de alcançar de efeitos cumulativos e multiplicativos pela combinação de diferentes formas de aprendizagem.

A agência chinesa de aviação civil, no entanto, não contava com a resistência das linhas aéreas chinesas (estatais e a ela subordinadas) em seguir suas orientações de compra dos aviões produzidos e montados na China, o que pôs a perder o acordo com a McDonnell Douglas em particular e a primeira fase do Plano de Decolagem em Três Passos. As dificuldades financeiras da McDonnell Douglas, que culminariam com sua venda para a Boeing, em 1997, representaram uma dificuldade adicional à execução do acordo e ao sucesso da estratégia de aprendizagem tecnoprodutiva. Em 1998, quando o acordo com a McDonnell Douglas foi encerrado, só haviam sido entregues três MD-90 com conteúdo de componentes localmente produzidos na ordem de 50\% a 60\% (Goldstein 2005: 9). Comparado às dezenas de encomendas inicialmente prometidas e à meta de $75 \%$ de conteúdo local, o primeiro passo do Plano de Decolagem em Três Passos não levou o setor tecnoprodutivo aeronáutico chinês muito longe nem o aproximou significativamente da fronteira tecnoprodutiva aeronáutica. 
O segundo passo do Plano de Decolagem em Três Passos procuraria aproveitar as possibilidades de cooperação com a Airbus para o desenvolvimento de um jato regional com capacidade para cem passageiros, o Air Express 100 (AE-100). Se o primeiro passo do plano consistia em adquirir capacitações e conhecimentos básicos na montagem de aviões e produção de peças, o segundo passo visava a envolver o setor tecnoprodutivo aeronáutico chinês em um processo de aprendizagem de desenvolvimento de projeto mais especificamente, de aquisição de conhecimentos e tecnologias necessários para projetar um avião de médio porte, o AE-100, em colaboração com uma grande OEM, a Airbus. O projeto de desenvolvimento do AE-100, no entanto, acabou sendo encerrado prematuramente, entre outros motivos, por conta da insistência da China em assumir as atividades de integração de sistemas, tarefa para a qual as empresas chinesas estavam claramente despreparadas, dada sua pouca experiência no assunto. Etapa crítica do processo de aprendizagem tecnoprodutiva, a integração de sistemas aeronáuticos exige grande domínio e experiência no assunto. Além disso, a transferência de conhecimentos e tecnologias em integração de sistemas daria à China capacitação em uma etapa fundamental do desenvolvimento e produção de aviões. É esse tipo de conhecimento e de tecnologia que as empresas e países que dominam o setor se negam a compartilhar e transferir. É por isso que toda estratégia de catch-up no setor aeronáutico irá se deparar em algum momento de sua trajetória com a necessidade de desenvolver por conta própria os conhecimentos e tecnologias críticos que darão autonomia tecnoprodutiva e, consequentemente, capacidade de entrar no mercado e competir com outras empresas.

Também por isso o Plano de Decolagem em Três Passos previa como terceiro e último passo o desenvolvimento e produção de ciclo completo de um avião de 180 lugares. Esse passo completaria o périplo do catch-up tecnoprodutivo, que consiste basicamente em empreender uma sequência de experiências de aprendizagem e atingir autonomia em cada uma das capacidades, da aquisição de conhecimentos e tecnologias básicas do processo tecnoprodutivo ao domínio do ciclo de desenvolvimento completo de aviões, passando pela etapa intermediária de desenvolvimento colaborativo. Sem esse passo, no entanto, nada feito: nada de catch-up tecnoprodutivo.

O Plano de Decolagem em Três Passos, contudo, falhou fragorosamente em cada um de seus passos. Falhou em produzir e montar em escala comercial aviões produzidos sob licença da McDonnell Douglas; falhou em adquirir competências básicas de desenvolvimento de projeto e integração de sistemas de um avião de médio porte; 
falhou, por fim, e naturalmente, dados os resultados frustrantes dos passos anteriores, no desenvolvimento de ciclo completo de um avião de grande porte. Fracasso total? Nem tanto; apesar do fracasso em cada uma das etapas que preparavam os passos seguintes por meio da acumulação e desenvolvimento de conhecimentos e tecnologias de emprego nas fases posteriores, houve também ganhos, ainda que pequenos, uma vez que as experiências de aprendizagem tecnoprodutiva em que o setor aeronáutico chinês se envolveu apresentaram oportunidades de domínio de conhecimentos e tecnologias relevantes e que mais tarde seriam utilizadas - estão sendo no momento empregadas numa segunda tentativa de catch-up do setor. Um fracasso global, mas nem por isso desprovido de sucessos locais.

O catch-up no setor aeronáutico no segmento comercial, no entanto - e tenho insistido nesse ponto - só é completo se os aspectos tecnoprodutivos são confirmados pela competitividade do produto final em relação aos seus concorrentes; se o produto final é comercialmente viável; se vende ou encalha. A prova do catch-up é vendê-lo, e quanto a esse ponto, a China não chegou nem perto na sua primeira tentativa de catch-up - a bem da verdade, não havia o que vender.

Ao final do Plano de Decolagem em Três Passos, primeira tentativa de catch-up tecnoprodutivo do setor aeronáutico chinês, ficou claro para o governo chinês e para a AVIC que seriam necessárias alterações profundas no setor tecnoprodutivo aeronáutico para que uma nova estratégia de catch-up desse certo. A primeira medida foi separar a AVIC, criada em 1993 para dar suporte ao Plano de Decolagem em Três Passos, em duas empresas, de modo a tentar aumentar a eficiência, produtividade e competitividade do setor aeronáutico chinês por meio da especialização e divisão clara de tarefas entre atores. Em 1999 a AVIC foi dividida em duas empresas: AVIC I e AVIC II.

A reforma industrial e organizacional do setor aeronáutico chinês não começou, no entanto, com a criação da AVIC em 1993 ou na sua subsequente divisão em AVIC I e AVIC II em 1999. A história das empresas aeronáuticas estatais chinesas começou em 1951, durante a Guerra da Coreia, com a criação da empresa industrial estatal Comissão de Administração da Indústria Aeronáutica. Ao longo de sua história, essa empresa assumiu diversas configurações industriais e organizacionais, sempre subordinada ao Ministério da Aeronáutica da China. Longe de ser uma empresa especializada e dedicada exclusivamente ao setor aeronáutico, a empresa industrial do Ministério da 
Aeronáutica da China atuava, por meio de suas subsidiárias e empresas irmãs, nos mais variados ramos industriais, produzindo aviões e componentes aeronáuticos, mas não só: máquinas de lavar roupa, geladeiras, ventiladores, bicicletas e automóveis eram alguns dos bens produzidos por essa empresa que chegou a ter 500.000 empregados. Em 1997, pouco antes, portanto, da reestruturação e divisão da AVIC em AVIC I e AVIC II, as vendas de produtos aeronáuticos atingiam apenas $23 \%$ do total de vendas da empresa (US\$ 650 milhões em valores da época).

Da abertura econômica chinesa até o presente a empresa industrial do Ministério da Aeronáutica da China passou por várias reformas: em 1982, a empresa, que então se chamava Departamento de Mecânica Industrial $\mathrm{N}^{\mathrm{O}} 3$, passou a se chamar Indústria do Ministério da Aeronáutica. Em 1988, em função de alterações na estrutura ministerial chinesa que concentraram a responsabilidade pelas atividades do setor aeronáutico e aeroespacial em um único ministério, a empresa passou a se chamar Indústria do Ministério da Aeronáutica e Aeroespacial. No ano de 1993, a empresa seria renomeada para China Aviation Industry Corporation (AVIC). Nessa época, preocupações com a eficiência, produtividade e competitividade da empresa começaram a ganhar relevo, ainda que de forma tímida. Finalmente, em 1999, a AVIC foi dividida em duas empresas, AVIC I e AVIC II, consolidando-se como as mais importantes empresas aeronáuticas da China, responsáveis indiretamente pelo desenvolvimento do ARJ21 e do C919, projetos para os quais foi criada uma empresa especialmente dedicada ao desenvolvimento desses dois projetos, a Commercial Aircraft Corporation of China (COMAC).

A trajetória da AVIC e de suas empresas associadas é bastante ilustrativa da mudança de rumos do setor aeronáutico chinês nas últimas três décadas - da abertura econômica de fins dos anos 1970, intensificada na década de 1990 por reformas econômicas que aproximaram a economia chinesa de economias de mercado, até os dias atuais: a transição de um setor tecnoprodutivo aeronáutico militar para um modelo em que a aviação civil passa a ser central para o desenvolvimento tecnoprodutivo e para a estratégia de catch-up. Segundo Nolan e Zhang (2002), mais do que papel de destaque, o segmento civil do setor tecnoprodutivo aeronáutico chinês passou a ser responsável por liderar o caminho do desenvolvimento do setor aeronáutico como um todo, incluindo o segmento militar- nas palavras de Nolan e Zhang, caracterizando as 
mudanças do setor na China: "the policy of 'military to civilian conversion' and the strategy of 'civilian supports military"' (Nolan e Zhang, 2002: 42).

A transição do setor militar para o civil levou, nas décadas de 1980 e 1990, o conglomerado industrial AVIC a passar por um processo de desespecialização setorial: em 1979, apenas 7,5\% das vendas da empresa Indústria do Ministério da Aeronáutica provinham de produtos não aeronáuticos; já em 1997, quase $80 \%$ das vendas da AVIC eram de produtos não aeronáuticos - dos quais automóveis, autopeças e motocicletas representavam 62\% das vendas de produtos não aeronáuticos naquele ano (Nolan e Zhang 2002: 42). Essa desespecialização se deu sob uma estrutura de conglomerado formado por 116 empresas com grande autonomia em relação à AVIC, inclusive para tomar decisões de investimentos, diversificação de suas atividades e áreas de atuação e criação de novas subsidiárias.

Em 1999, o governo chinês decidiu reestruturar a AVIC, reorientando suas atividades para o setor aeronáutico. Foram criadas duas empresas sob controle estatal, a AVIC I e a AVIC II, dedicadas a diferentes segmentos: a AVIC I ficou responsável pelo desenvolvimento e produção de aviões de grande e médio porte; a AVIC II por aviões de pequeno porte e helicópteros. O objetivo da reestruturação da AVIC foi concentrar a atuação das novas empresas em seu core business, livrando-a dos efeitos de dispersão de recursos e divergência de objetivos e estratégias que afetavam a eficiência, produtividade e competitividade do conglomerado. As novas empresas concentrariam esforços e recursos no setor aeronáutico e se dedicariam a projetos de desenvolvimento tecnoprodutivo convergentes com a estratégia mais ampla de catch-up tecnoprodutivo no setor aeronáutico chinês. AVIC I e AVIC II deveriam simultaneamente "competir e cooperar", segundo Zhu Yuli, presidente da AVIC (Financial Times, 2 de fevereiro de 1999, apud Nolan e Zhang 2002: 46).

Coordenar uma relação ao mesmo tempo de cooperação e competição mostrou-se tarefa impossível, e em 2008 AVIC I e AVIC II foram refundidas em uma única empresa, a Aviation Industry Corporation of China. A divisão da AVIC não resolveu problemas antigos (gigantismo do conglomerado, falta de alinhamento das empresas, dispersão de recursos) e criou novos: duocefalismo, ambiguidade na atribuição de responsabilidades e tarefas e competição acirrada por recursos escassos. Na avaliação de Nolan e Zhang: "instead of one huge diversified conglomerate with no capability to compete with the 
multinationals, the 'reform' of AVIC in 1999 created two smaller, and even less internationally competitive conglomerates. The reform could have separated the vast civilian from the aerospace business, but was unable to do so because this would have provoked such opposition from the subordinate entities who stood to lose many of their most profitable activities" (Nolan e Zhang 2002: 46). O objetivo da refusão da AVIC em 2008 foi corrigir os problemas herdados da estrutura anterior e os criados com a divisão das empresas.

A AVIC atual é a empresa responsável por liderar o desenvolvimento do setor tecnoprodutivo aeronáutico chinês. Conta com aproximadamente 550 mil empregados divididos em 11 unidades de negócios do setor aeronáutico e quase duzentas subsidiárias: Changhe Aircraft Industries Group (CHAIG), Chengdu Aircraft Industry Corporation (CAC), Guizhou Aviation Industry Group (GAIC), Harbin Aircraft Industry Group (HAIG), Hongdu Aviation Industry Group (HAIG), Nanchang Aircraft Manufacturing Company (NAMC), Shaanxi Aircraft Corporation (SAC), Shanghai Aviation Industry Group (SAIC), Shenyang Aircraft Corporation (SAC), Xian Aircraft Company (XAC) e Commercial Aircraft Corporation of China (COMAC). As empresas do conglomerado AVIC operam nos segmentos de defesa, aviões de transporte, logística, motores de aviões, helicópteros, testes de voo, aviônicos e pesquisa e desenvolvimento aeronáutico. Além de empresas e subsidiárias, a AVIC também lidera 33 instituições de CTI do setor aeronáutico chinês e seis universidades.

A AVIC, por meio de suas empresas associadas e suas subsidiárias, produz os turboélices regionais Xian MA-60, MA-600 e MA-700, os aviões de transporte Shaanxi Y-8 e Harbin Y-12, o helicóptero militar Harbin Z-9, os caças Chengdu J-10, Xian JH7/FBC-1, Chengdu FC-1/JF-17 (desenvolvido em conjunto com o Paquistão) e Guizhou JL-9. A AVIC também participa de programas internacionais como fornecedora de componentes para o caça de treinamento Karakorum-8 (outro programa de desenvolvimento conjunto com o Paquistão), o Embraer ERJ-145 e o helicóptero Eurocopter EC120.

Para o desenvolvimento do jato regional ARJ21 (capacidade de 175 passageiros) e o narrow-body C919 (com capacidade entre 150 e 190 passageiros), a AVIC criou em 2008 a Commercial Aircraft Corporation of China, ou COMAC, com sede em Xangai. A COMAC deverá ser a empresa responsável pela produção e comercialização do 
ARJ21 e do C919. Além desses dois projetos, a COMAC também desenvolve dois aviões wide-body, o C929 (para 290 passageiros) e o C939 (para 390 passageiros). Estes dois projetos, no entanto, ainda estão nos estágios iniciais de desenvolvimento tecnoprodutivo e de inteligência de mercado, e talvez jamais saiam do papel. A COMAC tem acordos de cooperação com a Bombardier para o desenvolvimento do ARJ21 e do C919, do lado chinês, e CRJ-Series, CSeries e Q-Series, do lado canadense.

A estratégia de catch-up do setor tecnoprodutivo aeronáutico chinês também tem procurado acesso a novos mercado e tecnologias pela aquisição de empresas estrangeiras - estratégia eficaz adotada em outros setores industriais chineses. No final de 2009, a Xi'an Aircraft Industry Group, da AVIC, comprou a Austria Future Advanced Composites Corporation (FACC), fabricante austríaca de materiais compósitos, tecnologia que deverá ser empregada em larga escala em produtos aeronáuticos nas próximas décadas. A FACC é fornecedora da Airbus (programa A380) e da Boeing (787). Sua aquisição posiciona a AVIC e a Xi'an Aircraft Industry Group na cadeia de fornecedores da Boeing e da Airbus e potencialmente na cadeia de fornecedores da Embraer e da Bombardier.

\section{Tentando levantar voo novamente: a estratégia atual de catch-up do setor tecnoprodutivo aeronáutico chinês}

O desenvolvimento do setor tecnoprodutivo aeronáutico chinês é claramente um caso de estratégia nacional de catch-up: já em 1951 o governo chinês publicou a Resolução para Construção da Indústria Aeronáutica, com vistas a fazer desenvolver seu setor tecnoprodutivo aeronáutico; em 1993, foi a vez do governo chinês colocar em prática o Plano de Decolagem em Três Passos. Os resultados de ambas as tentativas ficaram muito aquém do esperado. A proverbial paciência chinesa, contudo, parece também dar as caras quando o assunto é catch-up aeronáutico: o $11^{\circ}$ e o $12^{\circ}$ Planos Quinquenais para o Desenvolvimento Econômico e Social da República Popular da China definiram o desenvolvimento do setor aeronáutico nacional como uma de suas mais altas prioridades.

Os Planos Quinquenais para o Desenvolvimento Econômico e Social da República Popular da China são o principal instrumento político de planejamento do governo 
chinês. O $1^{\circ}$ Plano para o Desenvolvimento Econômico e Social foi implementado entre os anos de 1953 e 1957, logo após o chamado período de transição, que se seguiu à vitória dos revolucionários comunistas chineses em 1949 sob a liderança do camarada Mao Tsé Tung. Com exceção dos anos de 1963 e 1965, a China sempre contou com Planos Quinquenais para planejar o desenvolvimento econômico e social do país. São eles os: $2^{\circ}$ Plano Quinquenal (1958-1962), $3^{\circ}$ Plano Quinquenal (1966-1970), $4^{\circ}$ Plano Quinquenal (1971-1975), 5 Plano Quinquenal (1976-1980), 6 Plano Quinquenal (1981-1985), 7º Plano Quinquenal (1986-1990), 8 Plano Quinquenal (1991-1995), $9^{\circ}$ Plano Quinquenal (1996-2000), 10 Plano Quinquenal (2001-2005), $11^{\circ}$ Plano Quinquenal (2006-2010) e o atual 12 Plano Quinquenal (2011-2015).

Os Planos Quinquenais chineses mais recentes introduziram uma diferenciação entre, de um lado, indústrias ou setores pilares, áreas de máxima prioridade estreitamente vinculadas ao desenvolvimento econômico e social da China e com implicações geopolíticas diretas (energia e indústrias de base, por exemplo), e de outro, indústrias ou setores estratégicos, aqueles para os quais o avanço tecnoprodutivo é considerado importante, mas relativamente menos prioritário do que as indústrias ou setores pilares. O setor aeronáutico tem sido considerado uma indústria estratégica nos últimos três planos quinquenais $\left(10^{\circ}, 11^{\circ}\right.$ e $12^{\circ}$ Planos Quinquenais de Desenvolvimento Econômico e Social).

A estratégia de catch-up no setor tecnoprodutivo aeronáutico chinês figurou com destaque nos planos de desenvolvimento econômico e tecnológico chineses pela primeira vez no $10^{\circ}$ Plano Quinquenal (2001-2005) e continuou a ser um setor prioritário no $11^{\circ}$ Plano Quinquenal (2006-2010) e no $12^{\circ}$ Plano Quinquenal (20112015).

O $10^{\circ}$ Plano Quinquenal (2001-2005) tinha objetivo principal para o catch-up tecnoprodutivo do setor aeronáutico chinês o desenvolvimento do projeto do jato regional ARJ21, iniciado em 2002, com previsão para fazer seu voo inaugural em 2002 e entrar em produção em 2005. O desenvolvimento do ARJ21 ficou a cargo do consórcio ACAC, à época subordinado à AVIC I Commercial Aircraft Company. O voo inaugural teve que esperar até 2008. No momento, o avião ainda está na fase de testes e certificação. 
O $11^{\circ}$ Plano Quinquenal para o Desenvolvimento Econômico e Social vigorou entre os anos de 2006 a 2010 e colocava o desenvolvimento do setor tecnoprodutivo aeronáutico chinês entre as tarefas prioritárias para aquele quinquênio. O $11^{\circ}$ Plano Quinquenal estabelecia como metas o desenvolvimento e produção de um jato regional e um avião civil de grande porte com configuração de narrow-body aptos a receberem certificação da FAA - e, consequentemente, a disputarem espaço no mercado de aviação global, não somente chinês; e a atração de OEMs e fornecedoras estrangeiras para operaram na China e interagirem com a cadeia produtiva aeronáutica chinesa de modo a qualificá-la, adensá-la e inseri-la em cadeias globais de valor do setor aeronáutico.

No Plano Quinquenal atualmente em vigor, o $12^{\circ}$ Plano Quinquenal para o Desenvolvimento Econômico e Social (2011-2015), o apoio ao setor tecnoprodutivo aeronáutico é um dos setores estratégicos, sendo por isso objeto de políticas voltadas à “inovação e desenvolvimento de novas indústrias estratégicas" assim definidas: "Construct industrialization platforms for homemade trunk and feeder airplanes, general-purpose airplanes and helicopters, and a spatial infrastructure framework composed of navigation, remote sensing and communication satellites, and develop intelligent control systems, high-class numerically controlled machines, high-speed trains and urban rail traffic equipment, etc" $\left(12^{\circ}\right.$ Plano Quinquenal para o Desenvolvimento Econômico e Social). O $12^{\circ}$ Plano Quinquenal reitera o apoio ao desenvolvimento do setor aeronáutico civil em relação ao militar e o aprofundamento da inserção internacional do setor aeronáutico chinês por meio da atração de empresas aeronáuticas estrangeiras para operarem na China e cooperarem com empresas chinesas para atingir os objetivos de desenvolvimento do setor aeronáutico doméstico.

\section{COMAC ARJ21 e COMAC C919}

A China escolheu um caminho ousado em sua estratégia de catch-up no setor aeronáutico: está apostando em dois projetos em que competirá diretamente com Embraer e Bombardier no segmento de jatos regionais e com Boeing e Airbus no segmento de narrow-bodies. Duas apostas nos dão um universo de três resultados possíveis: sucesso nos dois projetos; sucesso em apenas um dos projetos; e fracasso em ambos os projetos. Em face do histórico de desenvolvimento dos projetos até o 
momento e da estrutura do setor e mercado aeronáuticos globais nos dias atuais, quais as perspectivas de sucesso para a estratégia de catch-up da China?

O ARJ21 é o principal projeto de desenvolvimento tecnoprodutivo aeronáutico do $10^{\circ}$ Plano Quinquenal de Desenvolvimento Econômico e Social, que vigoraria entre 2001 e 2005, e continua a ser prioritário no $11^{\circ}$ e $12^{\circ}$ Planos Quinquenais. O projeto do ARJ21 teve início no ano de 2000, quando a Comissão de Ciência, Tecnologia e Indústria de Defesa Nacional (COSTIND) reconheceu que o setor tecnoprodutivo aeronáutico chinês não tinha condições de fabricar aviões de grande porte capazes de competir com os modelos da Boeing e da Airbus (Goldstein 2005), conforme ficou claro na tentativa de montar e em seguida produzir aviões da McDonnell Douglas e no fracassso do desenvolvimento de ciclo completo de um avião civil de grande porte pela China, terceira etapa do Plano de Decolagem em Três passos. O governo chinês mudou então seus planos, resolvendo dar um passo atrás: dedicar-se ao desenvolvimento de ciclo completo de um jato regional de médio porte, o ARJ21 (sigla em inglês para Asian Regional Jet of the $21^{\text {st }}$ Century). Para o desenvolvimento do ARJ21 foi criada a ACAC (AVIC I Commercial Aircraft Company), empresa controlada por duas subsidiárias da AVIC II, a XAC (Xanghai Aircraft Corporation) e o Xanghai Aircraft Design Institute. A ACAC ficaria responsável pelo desenvolvimento, prototipagem, testes, produção, certificação e comercialização do ARJ21 (Goldstein 2005). O consórcio ACAC é formado pelas subsidiárias da AVIC Chengdu Aircraft Industry Group (responsável pela construção do nariz do ARJ21), Xi'an Aircraft Company (asas e fuselagem), Shenyang Aircraft Corporation (empenagem) e Shanghai Aircraft Company (montagem e integração de sistemas). O ARJ21 empregará, por meio de acordos de compartilhamento de riscos, componentes da General Electric (motores CF34-10A, usados também nos jatos regionais da Embraer e da Bombardier), Honeywell (sistemas de controle), Rockwell Collins (aviônicos), Hamilton Sundstrand (sistemas elétricos a unidades auxiliares de força), Eaton (painel de controle), Dassault Systèmes (softwares de projeto), Parker Hannifin (sistemas primários de controle de voo) e Liebherr Aerospace (trens de pouso), além de partes e componentes de fornecedores chineses e estrangeiros de segundo e terceiro nível na cadeia aeronáutica. O Instituto de Design Antonov deu suporte a fases críticas do projeto do ARJ21, em especial no projeto das asas e da fuselagem (Goldstein 2005). 
O ARJ21 Xiangfeng (Fênix Crescente) é um jato regional com capacidade para 72 a 105 passageiros, dependendo da versão. O ARJ21 foi desenvolvido a partir do MD-90 (por sua vez uma variação do DC-9), que foi montado e produzido sob licença nas décadas de 1980 e 1990, sem grande sucesso. O ARJ21 será oferecido em quatro variantes: o ARJ21-700, primeiro modelo e plataforma de desenvolvimento das demais variantes, jato regional com capacidade entre 70 a 95 passageiros; o ARJ21-900, versão estendida do ARJ21-700 com capacidade para 95 a 105 passageiros; o ARJ21F, com configuração de cargueiro; e o ARJ21B, jato executivo de grande porte com capacidade para até 20 passageiros.

O desenvolvimento do ARJ21 começou em março de 2002. Previa inicialmente voo inaugural em 2005 e entrada em produção em 2007. O cronograma teve inúmeros atrasos, comuns no desenvolvimento de ciclo completo de aviões até para empresas do porte da Boeing ou da Airbus, ainda mais para entrantes tardias empreendendo a primeira tentativa de projetar e produzir um jato regional de médio porte. O primeiro voo só seria realizado em novembro de 2008, após uma sequência de adiamentos devido a atrasos nas fases de integração de sistemas e testes. Em meados de 2011, o ARJ21 ainda estava em fase de testes dos quatro protótipos construídos até então.

Ainda durante o desenvolvimento do ARJ21, o consórcio ACAC foi reestruturado e passou a se chamar COMAC (Commercial Aircraft Corporation of China). A COMAC assumiu a responsabilidade de terminar o projeto do ARJ21, inclusive a fase de prototipagem, testes em ambiente controlado e ambiente real, certificação na CAAC (Civil Administration Aviation of China) e na FAA (Federal Administration Authority) - passo fundamental para dar ao ARJ21 acesso a mercados fora da Ásia -, produção, comercialização e pós-vendas. CAAC e FAA negociam desde 2003 o protocolo de homologação para certificação de tipo do ARJ21-700, mas os sucessivos atrasos no projeto e falhas graves em testes realizados na China (entre eles a quebra de uma asa durante testes estáticos de carga máxima em voo com peso de prova inferior ao peso máximo do projeto original) têm impedido o avanço das negociações. A COMAC reajustou o cronograma de entrada em produção e promete obter certificação de tipo da CAAC e da FAA ainda em 2013 e entregar o primeiro ARJ21-700 no final de 2013 para a companhia aérea chinesa Chengdu Airlines. 
O desenvolvimento do ARJ21 passa atualmente por fase crítica: apesar de contar com algumas dezenas de pedidos opcionais de compra, os pedidos firmes ainda são poucos e têm sido revistos pelas companhias aéreas em função dos sucessivos atrasos nos prazos de entrega. O governo chinês tem muito pouco poder sobre as decisões de compra de companhias aéreas chinesas, tanto privadas como estatais, e não seria a primeira vez que um projeto de avião chinês não consegue contar com compras de empresas nacionais para viabilizar a entrada em produção de um projeto estratégico para o setor tecnoprodutivo aeronáutico chinês e para o governo da China de modo geral, que atribui alta prioridade ao desenvolvimento de ciclo completo de aviões. Acresce que, na atual conjuntura do mercado aeronáutico global, o mercado doméstico chinês, por maior e mais promissor que seja, não tem escala suficiente para, por conta própria e competindo com Embraer e Bombardier, viabilizar a entrada em escala de produção comercial de um avião nacional. Para se viabilizar na atual estrutura do mercado global de OEMs e fornecedores aeronáuticos, novos entrantes não poderão contar apenas com encomendas domésticas, mas terão que conquistar espaço nos mercados internacionais para atingir as escalas de produção que viabilizam os custos de desenvolvimento do projeto tanto da nova OEM quanto de seus fornecedores, aos quais ela se associa por meio de parceiras de compartilhamento de riscos.

O mesmo vale para o COMAC C919 e sua competição direta com Boeing e Airbus - o mercado chinês, no fundo, é mais apetitoso visto de fora do que visto de dentro: as OEMs e os fornecedores estrangeiros de primeiro e segundo nível estão, por força de sua situação como empresas estabelecidas, em muito melhor posição para lucrarem com o fabuloso mercado de aviação da China do que as próprias empresas chinesas. Além do mais, a China dessa vez está fazendo uma dupla aposta em sua estratégia de catch-up aeronáutico: no segmento de jatos regionais, com o ARJ21, e no segmento de narrowbodies, com o C919. Resta saber se a aposta dupla diversificou riscos ou dispersou recursos. Ainda é cedo para dar a resposta definitiva, mas o exame do C919 pode nos ajudar a elaborar uma resposta provisória a essa questão.

O COMAC C919 é a aposta chinesa para entrar no segmento de aviões de passageiros de grande porte, atualmente dominado pela Boeing e pela Airbus. O programa de desenvolvimento do C919 foi previsto no $11^{\circ}$ Plano Quinquenal de Desenvolvimento (2006-2010) e é parte fundamental da estratégia chinesa de catch-up tecnoprodutivo aeronáutico. O C919 será um narrow-body com capacidade para 168 a 190 passageiros. 
Ele começou a ser projetado em 2008 e a data inicial de entrada em produção inicialmente era 2015, depois adiada para 2016, com as primeiras entregas previstas para 2020. O projeto está, portanto, em suas fases iniciais.

O C919 será produzido pela COMAC em Xangai, na mesma fábrica do ARJ21. COMAC e governo chinês pretendem usar o desenvolvimento e produção do C919 para atrair fornecedores estrangeiros de primeiro nível para a China, de modo a adensarem e desenvolverem tecnoprodutivamente o setor aeronáutico doméstico, qualificando fornecedores chineses de segundo e terceiro nível da cadeia e com esperanças de criar um fornecedor de primeiro nível chinês. Em relação ao ARJ21, o C919 terá um índice de nacionalização de suas partes e componentes mais elevado (nacionalização no sentido de produção na China e também, em algum grau, por empresas chinesas). $\mathrm{O}$ governo chinês espera conseguir convencer os fornecedores estrangeiros a formarem joint ventures com empresas chinesas, estratégia típica do desenvolvimento chinês nas últimas décadas, em que o acesso por parte de empresas estrangeiras ao mercado chinês se dá por meio do estabelecimento de acordos de joint venture e transferência de tecnologia.

O C919 usará motores da CFM International, joint venture da norte-americana General Electric com a Snecma, divisão da francesa Safran, sistema de geração e distribuição de força da Hamilton Sundstrand, que estabelecerá uma joint venture com a AVIC para desenvolvimento e produção dos sistemas e componentes, sistemas auxiliares de força da Honeywell International, sistemas de controle de ar da Liebherr Aerospace, sistemas hidráulicos da Parker Hannifin, controles fly-by-wire, sistemas hidráulicos, de controle de combustível e sistemas inerciais da Parker Aerospace e sistemas de iluminação da Goodrich. A princípio, todos os fornecedores deverão estabelecer joint ventures com empresas chinesas para tomarem parte no programa do C919.

A COMAC ainda não definiu quais versões do C919 serão desenvolvidas, mas tudo indica que as variantes seguirão padrão similar do ARJ21: uma versão curta, uma estendida, um cargueiro e um avião adaptável a diferentes funções especializadas. A COMAC buscará certificação de tipo para o C919 na CAAC e na FAA, de modo a viabilizar sua comercialização para outros mercados além dos asiáticos. Já vimos, no entanto, que quando o assunto é certificação de tipo concedido pela Federal Aviation Authority, querer não é poder. 


\section{Apostas arriscadas: diversificar riscos ou dispersas recursos?}

A China está decidida a ter sucesso em sua estratégia de catch-up do setor tecnoprodutivo aeronáutico nacional. Resta saber se o plano vingará. Qualquer país disposto a entrar no segmento de aviões civis de médio e grande porte precisará competir com Embraer e Bombardier, no primeiro caso, e Boeing e Airbus, no segundo. Não há como escapar disso. A China, não contente em enfrentar um dos duopólios, resolveu partir para cima de ambos, tudo de uma vez.

A estratégia de catch-up adotada pela China tende a enfraquecer os dois projetos, uma vez que leva à dispersão de recursos financeiros e humanos que são, dada a distância em que a China atualmente se encontra da fronteira tecnoprodutiva aeronáutica mundial, escassos. Nesse contexto, a probabilidade de que os dois projetos deem certo é menor do que a probabilidade de que ambos fracassem.

A China enfrentará muitas dificuldades ao longo da implementação de sua estratégia de catch-up, em especial no que diz respeito à entrada no mercado internacional de aviões civis. Os mercados chinês e asiático, no entanto, podem dar ao setor aeronáutico chinês o tempo necessário para reduzir a distância da fronteira tecnoprodutiva e tentar, numa próxima investida, desenvolver projetos capazes de competir com Boeing e Airbus ou Embraer e Bombardier no mercado global. Não fosse por um pequeno detalhe: a China vai competir, se seus projetos decolarem, diretamente com Japão e Rússia por esse mesmo mercado. Se a China não tomar cuidado, ela não será derrotada por Boeing ou Airbus, nem por Embraer ou Bombardier, mas pelos novos entrantes asiáticos. 


\section{Capítulo 7: Rússia e a (difícil) volta por cima do setor aeronáutico civil}

A queda de um Sukhoi Superjet 100 durante um voo de promoção do novo jato regional russo na Indonésia - o primeiro avião de passageiros desenvolvido por uma empresa russa desde o fim da União Soviética -, além da péssima publicidade que atraiu para o avião e sua fabricante, a mitológica Sukhoi, levou os analistas a se perguntarem se os mesmos problemas que até hoje impediram a Rússia de obter êxito no mercado internacional de aviação civil, a saber, a fama (ainda que injusta) de produzir aviões pouco seguros, também assombrariam a tentativa de renascimento do setor tecnoprodutivo aeronáutico civil russo. Os resultados das investigações sobre as reais causas do acidente, se falha do piloto ou falha do aparelho - ainda não são conhecidas, e a julgar pelos interesses envolvidos, talvez nunca venham a ser inteiramente revelados. Seja como for, a verdade é que, por ora, o estrago está feito; resta saber quanto dele poderá ser revertido no médio e longo prazo.

O Superjet 100 da Sukhoi, jato regional com capacidade para setenta e oito a noventa e oito passageiros, não é a única aposta da atual estratégia de catch-up tecnoprodutivo aeronáutico russo: a Rússia, como a China, também está fazendo uma aposta dupla em sua tentativa de reduzir sua distância da fronteira tecnoprodutiva aeronáutica contemporânea e desafiar o duplo duopólio de Boeing e Airbus, Embraer e Bombardier. Por meio da Irkut, empresa irmã da Sukhoi - ambas controladas pela United Aviation Corporation, empresa criada pelo presidente Vladimir Putin em 2006 para liderar o desenvolvimento, produção e comercialização de aviões civis pela Rússia -, os russos estão tentando emplacar, além do jato regional da Sukhoi, um narrow-body com capacidade na faixa de cento e cinquenta passageiros, o Irkut MS-21.

A aposta é ousada: o Superjet 100 concorrerá com os aviões da Embraer e da Bombardier; o MS-21, com os aviões da Boeing e da Airbus. Como se não bastasse, vêm por aí o MRJ japonês e o ARJ21 chinês, ambos também tentando entrar no segmento de jatos regionais atualmente dominado por Embraer e Bombardier, e o C919, este para brigar no segmento de jatos com capacidade na faixa de cento e cinquenta passageiros. Do jeito que a coisa vai, não haverá espaço para todos os que já estão no mercado e mais os que estão tentando entrar. 
A estratégia da Rússia para o desenvolvimento de seu setor aeronáutico envolve aproveitar competências de projeto aeronáutico existentes, mobilizar fornecedores locais e aproveitar as cadeias globais de valor nas quais suas empresas aeronáuticas estão inseridas para desenvolver seus próprios jatos regionais. Como sempre, ao fim e ao cabo o sucesso de uma estratégia de catch-up no setor de aviação civil será medido pelo sucesso comercial mais do que pelo virtuosismo tecnológico e produtivo do avião, e nisto reside o maior desafio para o catch-up aeronáutico russo.

Neste capítulo, examinarei a estratégia atual de catch-up tecnoprodutivo aeronáutico russo e os dois projetos nos quais a estratégia de catch-up se baseia: o Sukhoi Superjet 100 e o Irkut MS-21. Farei um breve histórico do setor tecnoprodutivo aeronáutico russo para depois apresentar a estrutura contemporânea do setor aeronáutico russo e discutir as ações e políticas mais recentes e o desenvolvimento dos dois aviões com os quais a Rússia pretende conquistar espaço no mercado internacional de aviação civil. $\mathrm{O}$ capítulo fecha com uma discussão sobre as perspectivas do catch-up russo e suas implicações para a competição pelos mercados global, no caso de a estratégia russa ser inteiramente exitosa, ou asiático, se for o caso de um êxito parcial em termos de competitividade por mercados. A possibilidade de se restringir ao mercado russo e de seus satélites geopolíticos não pode ser descartada - mas deverá ser considerada indicador de fracasso da estratégia de catch-up tecnoprodutiva aeronáutica russa.

\section{Rússia: idas e vindas do setor aeronáutico e o catch-up contemporâneo}

A União Soviética e depois a Rússia têm um dos mais tradicionais setores aeronáuticos do mundo, sua história estendendo-se das primeiras décadas do século $\mathrm{XX}$ até o presente. No período soviético, o sistema tecnoprodutivo era composto por institutos de projetos encarregados de projetar e testar os protótipos por eles desenvolvidos, entre os quais os renomados institutos de projetos experimentais Antonov, Ilyushin, Sukhoi, Tupolev e Yakovlev; e fábricas dedicadas à produção em escala industrial dos projetos desenvolvidos pelos institutos, como as empresas Irkut, Smolensk e Sokol (Niosi e Zhegu 2010). O setor era composto também por agências de certificação de aviões, organismos de promoção de exportações e instituições de formação de recursos 
humanos, fazendo do sistema tecnoprodutivo soviético um dos mais completos e avançados de sua época.

De modo geral, o sistema tecnoprodutivo aeronáutico soviético diferia em muitos aspectos dos sistemas tecnoprodutivos aeronáuticos de outros países. O sistema soviético era, por um lado, altamente centralizado e planejado; por outro, contava com uma profusão de atores organizados segundo lógicas e objetivos bastante independentes entre si: institutos de pesquisa dedicados ao desenvolvimento de tecnologias específicas; fábricas que assumiam a produção dos projetos daqueles institutos; e cadeia de fornecedores altamente especializada no que diz respeito aos modelos para os quais desenvolvia e produzia componentes e sistemas, com pouca relação com o restante do sistema tecnoprodutivo aeronáutico soviético. Digamos assim: uma cabeça comandando e várias pernas e braços que às vezes obedeciam, às vezes ignoravam, às vezes simplesmente não conseguiam se coordenar entre si.

A União Soviética projetou, produziu e comercializou alguns dos mais famosos aviões militares da época, entre os quais os caças, bombardeiros, cargueiros e aviões civis do instituto de projetos experimentais Mikoyan-Gurevitch, mais conhecido pela abreviatura MiG aposta nas designações de seus aviões; do instituto de projetos experimentais Tupolev, projetista do Tupolev ANT-20 Maxim Gorky, que com seus oito motores foi o maior avião da década de 1930 - marcado para sempre pela queda de uma unidade do ANT-20 Maxim Gorky em um voo de demonstração sobre Moscou, matando quarenta e cinco pessoas; e do instituto de projetos experimentais Antonov, instituto de projetos ucraniano produtor do Antonov Na-225, maior avião do mundo na atualidade. Esse, aliás, o traço fundamental do setor aeronáutico soviético e pós-soviético: esse espécime muito peculiar de instituição do seu setor aeronáutico, o instituto de projetos experimentais, ou Opytnoe Konstructorskoe Byuro. Oficialmente, designados por números; acontecia, no entanto, e com certa frequência até, de um OKB alcançar tamanha fama pela qualidade técnica e capacidade de liderança de seus projetistaschefes que eles passavam a ser conhecidos pelo nome dos projetistas-chefes em suas fases áureas: Artem Ivanovich Mikoyan e Mikhail Iosifovich Gurevich, do OKB-155, ou OKB-MiG, Pavel Osipovich Sukhoi, do OKB-51, ou OKB-Sukhoi, Oleg Konstantinovich Antonov, do OKB-153, ou OKB-Antonov, Andrei Nikolayevich Tupolev, do OKB-156, ou simplesmente OKB-Tupolev. 
Os Opytnoe Konstructorskoe Byuro, ou apenas OKB, os institutos de projetos experimentais, eram instituições dedicadas a projeto, prototipagem e teste de tecnologias avançadas, em geral de aplicação militar. Os OKBs não eram responsáveis pela produção dos equipamentos que desenvolviam, contando apenas com estrutura laboratorial e manufatureira para as fases de desenvolvimento de projeto e construção de protótipos para testes. Caso aprovados, os projetos entravam em produção seriada em fábricas com capacidade de produção em larga escala.

Várias empresas do setor tecnoprodutivo aeronáutico russo contemporâneo descendem diretamente de OKBs do princípio da era soviética, ou seja, datando das décadas de 1920 e 1930. Os OKBs MiG e Sukhoi foram fundados em 1939, o OKN Antonov em 1946 e o OKB Tupolev nos rescaldos da Revolução Russa, no longínquo 1922.

A Segunda Guerra Mundial exigiu do setor tecnoprodutivo aeronáutico soviético o desenvolvimento acelerado de conhecimentos em projeto e produção em larga larguíssima seria mais exato - escala. Estar na fronteira tecnoprodutiva aeronáutica, ou seja, alcançar a independência tecnoprodutiva, era questão de vida ou morte para quem se defendia dos alemães de Hitler, e a União Soviética dedicou enormes esforços humanos e econômicos para fazer frente ao sistema tecnoprodutivo aeronáutico alemão, na época dos mais, se não o mais, avançado do mundo, chegando ao final da guerra a projetar e produzir alguns dos primeiros aviões à jato. A experiência de projetar e produzir aviões cujos parâmetros de competitividade eram estabelecidos não por transações de mercado, mas pela letalidade dos aparelhos em combates aéreos e missões de bombardeio contra forças inimigas que dispunham do estado da arte em aviação militar, ofereceu um tipo de incentivo extraeconômico - um incentivo civilizacional e existencial que ao longo da história tem se mostrado uma das mais seguras fontes de inventividade e superação humanas: a guerra - extremamente forte, exigindo máximo empenho por parte da URSS no desenvolvimento de seu sistema tecnoprodutivo aeronáutico nas décadas de 1930 e 1940. A subsequente Guerra Fria continuou, ainda que dessa vez sem recorrer a embates bélicos diretos, a oferecer incentivos para o desenvolvimento do setor aeronáutico soviético. A União Soviética soube aproveitar essas circunstâncias geopolíticas para aprender o máximo possível, o que lhe permitiu constituir um dos mais avançados setores tecnoprodutivos aeronáuticos do mundo e que ainda hoje lhe permite projetar e produzir aviões como os caças Sukhoi T-50 e SU-35. 
Nem só no segmento aeronáutico militar a União Soviética mostrou seu avanço tecnoprodutivo: aviões civis soviéticos também foram produzidos e vendidos aos milhares por todo o bloco soviético e entre países não alinhados, muitos dos quais continuam em operação até hoje - é verdade que com níveis de segurança em voo cada vez mais baixos. Desde fins da Segunda Guerra Mundial a União Soviética tem investido no desenvolvimento do segmento civil de modo a suprir infraestrutura de transporte para vencer as enormes distâncias da União Soviética - por sinal, uma das motivações por trás do desenvolvimento do sistema tecnoprodutivo aeronáutico brasileiro.

$\mathrm{Na}$ fase inicial do desenvolvimento do sistema tecnoprodutivo aeronáutico soviético, a estratégia de aprendizagem recorreu amplamente à engenharia reversa, tendo baseado muitos de seus modelos em aviões norte-americanos ou britânicos, países que dominavam o setor aeronáutico naquela época. Combinada à aprendizagem acumulada no desenvolvimento e produção de aviões militares - processo cujas características centrais eram a necessidade de desenvolver, aprimorar e escalonar a produção dos aviões em curto espaço de tempo -, a União Soviética reuniu as condições para levar seu sistema tecnoprodutivo aeronáutico até a fronteira tecnoprodutiva da época: instituições de formação de recursos humanos altamente qualificados especializados no setor aeronáutico; institutos de pesquisa e desenvolvimento aeronáutico; indústrias com competências em manufatura de aviões em escala industrial; amplos mercados nacional e internacional; e políticas de apoio governamental ao setor aeronáutico. A União Soviética contou com essas vantagens competitivas enquanto existiu; após seu fim, elas regrediram significativamente ou deixaram de existir.

A regressão econômica e social que se seguiu ao fim do sistema soviético afetou as mais variadas dimensões da existência da Rússia e das ex-repúblicas soviéticas. Não foi diferente com o sistema tecnoprodutivo aeronáutico da ex-União Soviética, cuja herança, além do mais, se dispersou nas várias novas repúblicas: durante a década de 1990, o setor aeronáutico deixou de ser prioritário para o governo russo, que parou de apoiar o setor por meio de políticas públicas.

A divisão da União Soviética em repúblicas mais ou menos ligadas à Rússia por meio da Comunidade de Estados Independentes ou completamente independentes acarretou a perda de importantes instituições de desenvolvimento e fábricas de produção de aviões 
para a Rússia. A diminuição de sua capacidade de influência sobre os estados bálticos (Letônia, Lituânia e Estônia) redundou na perda de importantes instituições de ensaios e testes aeronáuticos. O caso da Ucrânia talvez tenha sido ainda pior (para os russos, evidentemente, não para os ucranianos): ao se separar da Rússia, a Ucrânia ficou com a mítica Antonov, localizada na nova e independente república.

Em meio à incapacidade do Estado russo de dar qualquer apoio ao setor aeronáutico, seguiu-se um movimento de privatizações e liberalização do setor de aviação comercial russo. Várias companhias aéreas foram criadas, assumindo rotas antes operadas pela Aeroflot. Todavia, ao contrário da Aeroflot, que manteve em operação os aviões da era soviética- aviões de péssima fama no que diz respeito a níveis de segurança e manutenção dos aparelhos a esta altura em sua maioria velhos -, as dezenas de novas companhias aéreas privadas que foram criadas na Rússia após o processo de privatização e liberalização do setor aeronáutico russo passaram a comprar novos aviões modernos produzidos por empresas de outros países. O setor aeronáutico russo, em especial o segmento civil, perdeu uma das condições que lhe davam vantagens competitivas no desenvolvimento e produção de aviões: e existência de mercado cativo garantindo uma demanda constante por seus produtos. $\mathrm{O}$ segmento aeronáutico civil russo viu-se reduzido às funções de MRO (maintenance, repair and overhaul). $\mathrm{O}$ segmento aeronáutico militar, por sua vez, deixou de contar com as aquisições de países do bloco soviético, tendo que passar a disputar o fornecimento de aviões e helicópteros militares em um novo ambiente geopolítico no qual norte-americanos, franceses, russos e até mesmo suecos disputam grandes contratos de venda de equipamentos militares. Comparado ao segmento civil, no entanto, o segmento aeronáutico militar foi afetado em menor grau, mantendo-se até hoje na fronteira tecnoprodutiva em aviação militar, como é o caso dos caças de quarta geração da família Sukhoi SU-27 (composta ainda por SU-30, SU-33, SU-34 e SU-35), ainda hoje exportados para diversos países e considerados aviões da maior qualidade.

Muitas das instituições do sistema tecnoprodutivo aeronáutico soviético, no entanto, sobreviveram, mal e por pouco, à queda da União Soviética, e continuam em operação nos dias atuais. Essas instituições foram transformadas em empresas privadas com grande participação de capital estatal competindo globalmente pelo mercado de aviões civis e militares. 
O fato é que nos anos que se seguiram ao fim do sistema soviético a produção de aviões comerciais pela Rússia praticamente parou. Segundo Graaf (2008), de 1996 a 2005 a Rússia fabricou apenas $1 \%$ de todos os aviões civis produzidos no mundo, entregando no período de 1996 a 2004 entre seis e nove aviões por ano, dez em 2005. Em 2008, apenas um terço da capacidade produtiva da indústria aeronáutica russa estava em uso (Graaf 2008).

\section{O setor aeronáutico russo hoje: estrutura e empresas}

Meio século de acúmulo de conhecimentos, tecnologias e competências manufatureiras e produtivas representa, não resta dúvida, capital dos mais valiosos. Sabendo disso, em 2005 a Rússia, sob a presidência de Vladimir Putin, determinou a formação de uma Comissão Governamental para a Integração de Empresas Produtoras de Aviões da Federação Russa, liderada pelo ministro da Indústria e Energia, Viktor Khristenko. A Comissão ficou encarregada de apresentar um plano capaz de revitalizar o setor aeronáutico russo a partir das instituições e competências herdadas do período soviético.

A proposta delineada pela Comissão Governamental recomendou a criação de uma companhia estatal de capital aberto que reunisse sob seu controle as mais importantes empresas estatais e algumas empresas privadas do setor aeronáutico russo, tanto OEMs como fornecedores de primeiro nível. O novo conglomerado aeronáutico, criado em novembro de 2006, recebeu o nome de United Aircraft Corporation (UAC). A criação da UAC foi a resposta da Rússia à seguinte questão relativa ao seu setor aeronáutico e de transporte aéreo: o país deveria continuar a trajetória tecnoprodutiva dependente que se instalou no período pós-regime soviético, isto é, contando para a modernização de seu setor aeronáutico com a compra de aviões das quatro grandes OEMs atuais (Boeing, Airbus, Embraer e Bombardier) e com a atração de empresas aeronáuticas estrangeiras para produzirem na Rússia ou formarem joint ventures com empresas russas; ou o país deveria se apoiar no sistema tecnoprodutivo legado pelo período soviético para se engajar em uma estratégia de catch-up tecnoprodutivo com fins de readquirir independência tecnoprodutiva no setor aeronáutico? A constituição da UAC significou um sim à adoção de uma estratégia de catch-up do setor aeronáutico. 
Para compreender a decisão do governo russo é preciso ter em mente não apenas o amplo, se bem que levemente obsoleto, estoque de conhecimentos e tecnologias no setor aeronáutico acumulado ao longo de meio século sob o sistema soviético e herdado em grande parte pelos russos, como também as perspectivas de crescimento do mercado de aviação na Rússia e em países da Comunidade de Estados Independentes e outros vizinhos sob a esfera de influência da Rússia - perspectiva de crescimento amplificada pela acentuada regressão do setor após o fim do sistema soviético, resultando em um mercado potencial muito superior ao mercado atual - e a necessidade de diversificar o ainda poderoso segmento de aviação militar russo. Disponibilidade de conhecimento tecnoprodutivo e demanda de mercado ofereceram razões poderosas para a Rússia colocar em prática sua atual estratégia de catch-up aeronáutico.

A estratégia de catch-up russa vislumbra, como toda estratégia de catch-up que se preze, conquistar espaço no mercado global de aviação civil, portanto, desenvolver e produzir aviões capazes de competir nas proximidades da fronteira tecnoprodutiva contemporânea do setor aeronáutico e tornar-se um player global do setor. Para isso, no entanto, a UAC precisará enfrentar as quatro OEMs que atualmente dominam o mercado global, Boeing, Airbus, Embraer e Bombardier, e as tentativas de Japão e China de entrarem no mercado.

O plano de consolidação e revitalização do setor aeronáutico russo elaborado pela Comissão Governamental para a Integração de Empresas Produtoras de Aviões da Federação Russa previa que a UAC se organizasse nos moldes de um conglomerado verticalizado composto por empresas do segmento civil e militar, OEMs e fornecedores de primeiro nível. A UAC integraria sete das maiores empresas fabricantes de aviões e cinco institutos de projetos experimentais remanescentes do sistema soviético. A UAC foi formada pelas seguintes empresas estatais e institutos de projetos experimentais, que cederam cada qual diferentes participações acionárias para a capitalização do conglomerado: Sukhoi Aviation Holding Corporation (cedendo 100\% de suas ações para a UAC), Aviaexport Foreign Trade Corporation (cedendo 15\%), Ilyushin Finance Corporation (cedendo 38\%), Ilyushin Interstate Aviation Company (cedendo 86\%), Nizhny Novgorod Aviation Plant - Sokol (cedendo 38\%), Novosibirsk Aviation Production Association - C. P. Chkalov (cedendo 25,5\%), Tupolev (cedendo 90,8\%), Komsomolsk-on Amur Aircraft Production Association - Yuri Gagarin (cedendo 25,5\%) e Financial Leasing Company (cedendo 58\%) (UAC 2008). Além dessas 
empresas e institutos de projetos experimentais, a empresa privada NPK Irkut também foi incorporada ao conglomerado mediante a cessão de $38,2 \%$ de suas ações para a UAC. Como a Sukhoi é detentora de $11,89 \%$ das ações da Irkut, a UAC obteve maioria de ações na Irkut, passando a ser sua controladora com um total de 80,9\% de suas ações. (UAC 2008). A UAC também planeja incorporar o instituto de projetos experimentais RSK MiG, empresa estatal russa produtora de aviões militares.

Inicialmente cogitou-se a incorporação da empresa ucraniana Antonov ASTC, cuja linha de produtos complementaria o portfólio da UAC. Um memorando de entendimento foi assinado em 2007 prevendo cooperação em projeto, produção e marketing entre a UAC e a Antonov. As tratativas entre os governos russo e ucraniano, no entanto, não avançaram muito até o momento, descartando por ora a possibilidade de incorporação da ucraniana Antonov à russa UAC.

O plano de consolidação e revitalização do sistema tecnoprodutivo aeronáutico russo determina que apenas a UAC e empresas controladas pelo conglomerado terão acesso a apoios e investimentos governamentais russos, o que deixa de fora muitos fornecedores de primeiro nível do setor aeronáutico russo. Ainda assim, a UAC trabalha em estreita cooperação com alguns desses fornecedores, como é o caso da NPO Saturn, fornecedora de motores para a Sukhoi Civil Aircraft e para aviões civis e militares da Tupolev. A Saturn, por sua vez, estabeleceu uma joint venture com a francesa Snecma, a Superpower, para fornecer à Sukhoi e Tupolev, ambas controladas pela UAC. A exclusão de apoios e financiamentos governamentais para empresas que não façam parte da UAC não as impede de trabalhar em conjunto com a UAC e portanto, pressupõe-se, de receber apoios e financiamentos governamentais indiretos via UAC. A UAC está organizada em quatro unidades de negócios: Aviação Militar, Aviação de Transporte e Especializada, Aviação Civil e Partes e Componentes.

\section{Duas apostas russas: Sukhoi Superjet 100 e Irkut MS-21}

A Rússia, do mesmo modo que a China, também aposta, como objetivo inicial de sua estratégia de catch-up, no desenvolvimento de um avião regional, o Sukhoi Superjet 100, que irá competir diretamente com aviões da Embraer e da Bombardier (com a 
possibilidade de enfrentar também Mitsubishi, com seu MRJ, e COMAC, com o ARJ21, no segmento de jatos regionais, o que daria à Ásia três OEMs disputando espaço em um mesmo segmento) e de um narrow-body, o Irkut MS-21, que competirá com aviões da Boeing e da Airbus (e quem sabe com a COMAC também, se o C919 vingar), respectivamente.

O SuperJet 100 é um jato regional com configurações para setenta e oito a noventa e oito passageiros, dependendo da variante, produzido pela Sukhoi Civil Aircraft, subsidiária da UAC, em cooperação com Boeing, Goodrich, Iliushyn (empresa do conglomerado UAC) e a Superpower (joint venture da russa Saturn com a francesa Snecma). Esta última estabeleceu um acordo de compartilhamento de riscos com a Sukhoi Civil Aircraft para o desenvolvimento de motores para o Superjet 100. O desenvolvimento do Superjet 100 teve início em 2000, portanto seis anos antes da criação da UAC, formada em grande parte para assumir o desenvolvimento de projetos aeronáuticos russos promissores. O Superjet $100 \mathrm{fez}$ seu primeiro voo em 2008 e realizou seu primeiro voo comercial em 2011. O programa Superjet 100 conta com aportes vultosos do Ministério da indústria e da Energia da Rússia, sendo considerado um projeto de altíssima prioridade.

Estão sendo produzidas duas variantes do Sukhoi Superjet 100: o Superjet 100-75, ou SSJ 100-75, para setenta e cinco passageiros, e o Superjet 100-95 (SSJ 100-95), para noventa e cinco passageiros. Uma variante menor, o SSJ 100-60, para sessenta passageiros, teve seu desenvolvimento postergado. Estão previstas versões estendidas do Superjet 100, o SSJ 100-110 e o SSJ 100-130, para cento e dez e cento e trinta passageiros, respectivamente, além de variantes de jatos executivos e cargueiros.

A Boeing colaborou estreitamente com a Sukhoi nas fases iniciais de desenvolvimento do Superjet 100, tendo assinado contrato de cooperação em 2002 para apoiar a empresa russa em projeto, certificação, produção, marketing e pós-vendas. O apoio da Boeing foi fundamental para o desenvolvimento inicial do Superjet 100, transferindo conhecimentos em áreas nas quais a experiência da Sukhoi em particular e do sistema tecnoprodutivo russo em geral estavam, para dizer o mínimo, defasada em relação à fronteira tecnoprodutiva contemporânea.

Uma das maiores fragilidades do sistema tecnoprodutivo aeronáutico russo talvez seja a pouca experiência nas fases de comercialização de aviões, tanto em vendas no mercado 
internacional quanto nos serviços de pós-vendas, centrais na estratégia de qualquer OEM que queira competir globalmente. Para enfrentar a falta de experiência na comercialização de aviões, a Sukhoi estabeleceu uma joint venture com a empresa italiana Alenia Aermacchi, subsidiária da Finmecanicca, que se encarregará de vendas e pós-vendas do Superjet 100 sob a joint venture Superjet International.

O Superjet 100 recebeu certificação de tipo da agência responsável pela aviação civil da Comunidade de Estados Independentes, a Interstate Aviation Committee (IAC), em fevereiro de 2011. Em fevereiro de 2012 o Superjet 100 obteve certificação de tipo da agência europeia de aviação civil, a European Aviation Safety Agency (EASA), o que representa uma importante vitória nos planos de competir internacionalmente (para além de sua esfera mais imediata de influência geopolítica) com Embraer e Bombardier no segmento de jatos regionais.

O Sukhoi Superjet 100 está longe, no entanto, de vingar. Além dos atrasos no processo de desenvolvimento, prototipagem, testes, certificação e entrada em produção, o modelo tem tido baixa eficiência de operação e está longe de ser um sucesso de vendas. De novembro de 2005, quando começaram suas encomendas, a junho de 2012, foram assinadas 246 intenções de compra e 104 opções. Até o momento, no entanto, apenas 11 aparelhos foram entregues. O voo de demonstração na Indonésia, que terminou de modo trágico, visava justamente ampliar a exposição do Superjet 100 e conquistar novos compradores que viabilizassem o aumento da produção do modelo.

A aposta da UAC para o mercado de aviões narrow-body é o Irkut MS-21 (Magistralny Samolyot 21 veka, ou Avião de Passageiros do Século 21), avião com capacidade entre cento e cinquenta e duzentos e doze passageiros, projetado e fabricado pela Irkut em conjunto com outras empresas russas, como Ilyushin, Tupolev e Yakovlev (projeto) e Aviastar (produção), (Niosi e Zhegu 2010). A Sukhoi Civil Aircraft está encarregada do desenvolvimento e produção das asas em materiais compostos. Hamilton Sundstrand e Rockwell, esta última em joint venture com a russa Avionika, deverão fornecer sistemas e aviônicos para o MS-21, e a Goodrich, em parceria com a russa Aviapribor, fornecerá os sistemas de controle. O MS-21 contará com motores Pratt \& Whitney desenvolvidos em joint venture com a russa Aviadvigatel. A Pratt \& Whitney deverá fornecer o motor PW1000G, que irá equipar, além do MS-21, os Bombardier CSeries, o Mitsubishi Regional Jet (MRJ0) e como opção de motorização do A320neo (new engine option). 
O projeto do MS-21 prevê o desenvolvimento de um avião de última geração, incorporando plenamente avanços da fronteira tecnoprodutiva contemporânea, com inovações como uso extensivo de materiais compostos e metais especiais. O MS-21 deverá competir com os atuais narrow-body da Boeing e da Airbus, as famílias B737 e A320, bem como com a nova geração de narrow-body atualmente em desenvolvimento por essas duas empresas. A princípio, o MS-21 terá três variantes básicas: o MS-21 200ER, para cento e cinquenta a cento e sessenta e dois passageiros, o MS-21 300ER, com capacidade para cento e oitenta e um a cento e noventa e oito passageiros, e o MS21 400ER, para duzentos e doze a duzentos e trinta passageiros.

As entregas do MS-21, inicialmente previstas para 2016, deverão ser adiadas por um ou dois anos no mínimo. O andamento do programa do MS-21, contudo, seguramente será influenciado, para o bem e para o mal, pelos desdobramentos do programa do Superjet 100, no momento lutando para sobreviver a um imediato pós-lançamento bem pouco promissor.

\section{Perspectivas do catch-up russo: vencer no mundo ou vencer na Ásia, perder no mundo ou perder na Ásia}

O destino do Sukhoi Superjet 100 e do Irkut MS-21, ambos projetos de empresas do conglomerado United Aircraft Corporation, e do sistema tecnoprodutivo aeronáutico russo como um todo, julgará o resultado alcançado pela atual estratégia de catch-up aeronáutico empreendida pela Rússia. O fracasso, como sempre, é uma possibilidade bastante concreta, assim como o fracasso parcial, definido como ficar restrito aos mercados regionais da Ásia - se bem que a expansão do mercado regional asiático promete redefinir o significado de mercado regional.

Competir com as quatro grandes OEMs com dois produtos que competem diretamente nos segmentos de aviões regionais (dominado por Embraer e Bombardier) e de aviões narrow-body (em que Boeing e Airbus mandam) envolve grandes riscos, ainda mais se levarmos em conta que no segmento de aviões regionais o Japão está tentando entrar com seu Mitsubishi MRJ e que a China está implementando uma estratégia muito similar à russa, desenvolvendo tanto um avião regional como um narrow-body, COMAC ARJ21 e C919, respectivamente. Ou seja, o número de competidores tende a 
aumentar de quatro para sete somados os segmentos de aviões regionais e narrow-body - isso para não falar no segmento de jatos executivos, que assiste atualmente à chegada do HondaJet. A UAC tem planos de desenvolver e produzir também um avião cargueiro militar, o cargueiro de múltiplo emprego Ilyushin Il-214, que competiria no segmento atualmente ocupado pelo Lockheed C-130 Hércules - justamente o segmento do Embraer KC-390 atualmente em desenvolvimento.

A experiência histórica mostra que estratégias de catch-up no setor aeronáutico podem fracassar por serem excessivamente tímidas ou ousadas demais. Rússia - e China tenderão a fracassar pelo segundo motivo. 


\section{Capítulo 8: Análise comparativa da configuração das estratégias de catch-up de Brasil, Argentina, Indonésia, Japão, Rússia e China}

Este capítulo estabelece uma comparação sistemática das estratégias de catch-up tecnoprodutivo aeronáutico de Brasil, Argentina, Indonésia, Japão, Rússia e China. Aplico um modelo de análise comparativa qualitativa (QCA) para comparar os casos e definir as dimensões mais relevantes para a análise de estratégias nacionais de catch-up. Começo apresentando a metodologia de QCA e a operacionalização do modelo analítico e passo então à análise comparativa sistemática entre casos. O capítulo fecha com uma discussão sobre as estratégias de catch-up aeronáutico dos países analisados.

\section{Análise qualitativa comparada - QCA}

A metodologia de análise qualitativa comparada (qualitative comparative analysis QCA) é parte de uma família de métodos conhecidos como métodos comparativos configuracionais (configurational comparative methodology, CCM). Essa família de métodos tem por objetivo realizar uma análise comparada sistemática entre casos modelados qualitativamente. Além de permitir a comparação sistemática de casos complexos, uma das principais vantagens dos métodos comparativos configuracionais é o fato de eles apresentarem resultados bastante robustos em comparações de poucos casos (estudos com $N$ pequeno).

Em linhas gerais, os métodos comparativos configuracionais transformam casos em configurações: "a configuration is a specific combination of factors (or stimuli, causal variables, ingredients, determinants... - we call these 'conditions"' in CCM terminology) which produce a given outcome of interest" (Rihoux e Ragin 2008: 10).

Para operacionalização do método comparativo configuracional, será empregada a técnica de análise qualitativa comparada (QCA) em sua variante para modelagem de conjuntos discretos, também referido por crisp set $Q C A$ ou simplesmente csQCA (a técnica de QCA também pode ser implementada para conjuntos contínuos ou difusos multi-value $Q C A$, ou mvQCA, e fuzzy-set $Q C A$, ou fsQCA, respectivamente - e também em modelagens do tipo most similar, different outcome/most different, same outcome, 
ou MSDO/MDSO, conforme Rihoux e Ragin 2008:11). O objetivo das técnicas de QCA é identificar condições de ocorrência de resultados, por exemplo, quais as condições para a ocorrência de resultados bem sucedidos de estratégias nacionais de catch-up no setor aeronáutico: "the various techniques of QCA precisely identify and narrow down such 'conditions of occurrence” (Rihoux e Ragin 2008: 20).

Além de permitir análises comparadas de poucos casos ( $N$ pequeno), as técnicas de QCA analisam os casos de comparação "in the attempt to include both important typical cases, and the more paradoxical or contrary ones. QCA indeed tends to give explanations without dismissing 'exceptions' ou 'outliers'. These noncoforming cases, on the contrary, often shed a special light on the understanding of specific processes" (Rihoux e Ragin 2008: 24). Esse aspecto confere uma grande vantagem ao QCA, pois permite a comparação sistemática de casos bastante diferentes em termos de condições de ocorrência, tempo e espaço dos eventos e resultados. Nesta pesquisa, esse aspecto viabiliza a comparação entre casos que, afora o fato de terem empreendido estratégias de catch-up no setor aeronáutico, têm de resto muito pouco em comum.

A metodologia de QCA emprega uma definição muito específica de causalidade: a causação conjuntural múltipla. A noção significa essencialmente que "different constelletions of factors may lead to the same result" (Rihoux e Ragin 2008: 24). Ainda segundo Rihoux e Ragin: “different causal 'paths' (...) may lead to the same outcome (...). The term 'multiple' refers to the number of paths, while the term 'conjunctural' conveys the notion that each path consists of a combination of conditions. Thus multiple conjunctural causation contains the notion of equifinality, which simply means that different paths can lead to the same outcome (...). Since it views causality as contextand conjuncture-specific, QCA rejects any form of permanent causality (...). Bottom line, by using QCA, the researcher is urged not to specify a single causal model that best fits the data, as one usually does with statistical techniques, but instead to determine the number and character of the different causal models that exist among comparable cases." (2008: 25).

$\mathrm{Na}$ análise qualitativa comparada, os casos (unidades de análise) são modelados segundo duas classes de variáveis: variáveis-condição e variáveis-resultado. Um caso é composto pela combinação de variáveis-condição e variáveis resultado: a série de condições ou características com as quais o problema é modelado e a resultante 
daquelas condições. As combinações de condições em um caso constituem uma configuração. Nesta pesquisa, variáveis-condição são: a existência de instituições de formação de mão de obra especializada e altamente qualificada para atuar no sistema tecnoprodutivo aeronáutico e instituições de pesquisa e desenvolvimento especializadas no setor aeronáutico, a adoção de uma ou mais políticas de aprendizagem tecnoprodutiva (produção sob licença, internacionalização endógena ou exógena) e a constituição de uma OEM orientada comercialmente. Quanto às variáveis resultados, elas são duas: fracasso ou sucesso da estratégia de catch-up, sucesso entendido como a capacidade de dominar o desenvolvimento de ciclo completo e produzir e comercializar aviões segundo os conhecimentos e tecnologias na fronteira tecnológica e capazes de competir com outros aviões na fronteira tecnoprodutiva contemporânea.

A técnica de QCA será, portanto, empregada para explicar os resultados das estratégias de catch-up de Argentina, Brasil, Indonésia, Japão, China e Rússia de acordo com as configurações de variáveis-condição, que são justamente as características mais relevantes segundo o modelo explicativo das estratégias de catch-up no setor aeronáutico desenvolvido nesta tese. A seção seguinte descreve a operacionalização do modelo pela técnica de análise qualitativa comparada de conjuntos discretos (csQCA).

\section{Dados histórico-qualitativos}

As técnicas de QCA empregam dados qualitativos de alta complexidade em suas análises. Comumente, os dados utilizados em análises de QCA envolvem técnicas de coleta de dados qualitativos ou interpretações históricas a partir de fontes primárias ou secundárias.

Os dados usados para a análise de QCA que se segue são dados qualitativos sobre processos históricos multidimensionais (tecnológicos, institucionais e empresariais). Foram coletados, sistematizados e empregados na elaboração de um modelo analítico capaz de explicar as condições que levam ao sucesso ou ao fracasso as várias estratégias de catch-up tecnoprodutivo aeronáutico discutidas nesta tese. Os dados provêm de literatura sobre desenvolvimento e catch-up de sistemas tecnoprodutivos aeronáuticos e de documentos oficiais de empresas e governos, além de relatórios de consultorias e 
empresas do setor aeronáutico. As informações utilizadas para construção do modelo analítico foram obtidas em especial, mas não apenas, de Narula 2003, Criscuolo e Narula 2002, McGuire 2011, Goldstein 2005 e 2005, Nolan e Zhang 2002 e 2003, Vertesey e Szirmay 2010, Niosi e Zhegu 2008, Niosi e Zhegu 2010, Bédier et al 2008, Kanatsu 2006, Kimura e 2006 Kuo 2009, entre outras referências.

Os dados foram confirmados pela técnica de triangulação de fontes, em que se busca obter de fontes diversas a confirmação e reconfirmação de dados até um ponto de alta redundância e saturação de informações.

Complementarmente, vários dados foram verificados e confirmados com especialistas do setor aeronáutico, muitos dos quais engenheiros e gestores com mais de duas décadas de experiência no setor, quase todos funcionários da Embraer. Essas entrevistas e conversas geraram dados referentes à trajetória da Embraer e à situação atual da OEM brasileira em relação a seus competidores estrangeiros, em especial Bombardier, Mitsubishi, Comac e Sukhoi.

Esses procedimentos metodológicos garantiram a qualidade das informações aqui utilizadas.

\section{Operacionalização do modelo analítico de estratégias de catch-up no setor aeronáutico e análise comparativa sistemática entre casos}

O modelo desenvolvido ao longo desta tese e que será operacionalizado neste capítulo por meio da técnica de análise qualitativa comparada de conjuntos discretos (csQCA) é composto por três elementos: 1) casos, ou seja, as unidades de análise: estratégias nacionais de catch-up aeronáutico; 2) variáveis-condição, isto é, os termos explicativos do modelo ou, se quisermos, as características ou variáveis que explicam o resultado; e 3) variável-resultado, sucesso ou fracasso da estratégia de catch-up no setor aeronáutico. Como se trata de uma análise qualitativa comparada modelada na forma de conjuntos discretos, a codificação das variáveis-condição e variável-resultado assume os valores 0 ou 1, indicando binariamente a presença (1) ou ausência (0) da condição de interesse e a presença (1) ou ausência (0) de resultado sucesso na estratégia de catch-up. 
Não se deve, no entanto, confundir o procedimento de codificação das variáveiscondição com as condições históricas efetivamente encontradas em cada caso estudado. A codificação define de modo discreto, presença (1) ou ausência (0), um problema que historicamente se apresenta de modo contínuo ou difuso: como graus de presença ou graus de ausência de condições e resultados. A codificação 1 não indica presença integral de uma condição, assim como a codificação 0 não indica ausência total de uma condição. Por exemplo, a condição "instituições de formação de recursos humanos" não pretende descrever a presença ou ausência completa dessas instituições, mas sim diferenciar, de um lado, os casos de Argentina e Indonésia, que formavam recursos humanos especializados em aeronáutica em quantidade insuficiente para sustentar o desenvolvimento dos respectivos sistemas tecnoprodutivos aeronáuticos e, do outro, o caso do Brasil, que contou com uma instituição capaz de formar recursos humanos especializados em aeronáutica em quantidade e qualidade bastante o suficiente para sustentar o desenvolvimento de seu sistema tecnoprodutivo aeronáutico.

Em outras palavras, no que segue, as definições de presença ou ausência de uma determinada condição devem ser interpretadas não em seu sentido estrito, como variáveis discretas binárias indicando a existência ou inexistência de uma condição, mas como variáveis contínuas ou difusas em que 1 indica a presença em grau qualitativamente diferente de uma condição codificada como 0. A ausência de uma condição, em alguns casos, pode indicar a inexistência completa da condição; no mais das vezes, no entanto, indicará presença irrelevante.

O modelo analítico desenvolvido nesta tese pretende compreender quais as condições de ocorrência de resultados de sucesso ou fracasso das estratégias de catch-up do setor aeronáutico. A análise procederá em duas etapas: a primeira, histórica; a segunda, prospectiva. Por meio da exploração de casos de estratégias de catch-up cujo resultado já conhecemos (a saber, sucesso da estratégia do Brasil e fracasso das estratégias de Argentina, Indonésia e da primeira tentativa de catch-up do Japão), criar um modelo que ajude a prognosticar os prováveis resultados das estratégias atualmente em execução (segunda tentativa do Japão, China e Rússia). A Figura 1 apresenta o modelo de comparação entre casos, condições e resultados das estratégias de catch-up do setor aeronáutico. 
Figura 1: Estrutura do modelo analítico dos casos de catch-up aeronáutico encerrados e atuais
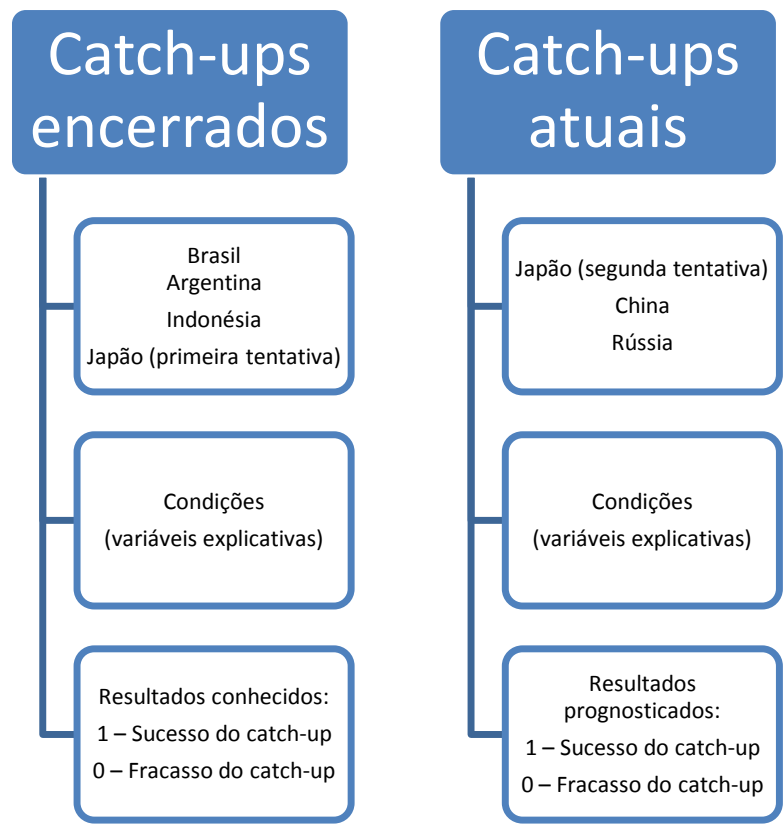

Serão comparadas, portanto, as estratégias de catch-up para as quais já sabemos os resultados (Brasil, Argentina, Indonésia e a primeira tentativa do Japão) com tentativas de catch-up ora em curso (segunda tentativa do Japão, China e Rússia). O caso do catchup do sistema tecnoprodutivo aeronáutico brasileiro é tomado como paradigmático e deverá, por isso, oferecer o modelo (isto é, a configuração de condições) que descreve os casos de sucesso (o resultado de ocorrência); Argentina, Indonésia e Japão (em sua primeira tentativa), oferecerão o modelo (isto é, a configuração de condições) que descreve os casos de fracasso (resultado da ocorrência); Japão (segunda tentativa), China e Rússia serão objeto da análise na atualidade.

Por meio da comparação do modelo que descreve as condições de ocorrência de sucesso ou fracasso no primeiro grupo com as condições presentes atualmente no segundo grupo, formularei um prognóstico do resultado das estratégias de catch-up em curso. $\mathrm{O}$ modelo histórico derivado dos casos de Brasil, Argentina, Indonésia e da primeira tentativa do Japão será usado para compreender e prognosticar os desenvolvimentos presentes e futuros de estratégias de catch-up de China, Rússia e a segunda tentativa do Japão. Pela comparação dos modelos dos dois períodos será possível identificar as 
configurações de condições de ocorrência que aumentam a probabilidade de sucesso ou fracasso de uma estratégia de catch-up.

As dimensões do modelo explicativo sobre condições de fracasso ou sucesso de estratégias nacionais de catch-up tecnoprodutivo aeronáutico são a base da análise qualitativa comparada. O modelo explicativo é composto por seis variáveis-condição: 1) aprendizagem tecnoprodutiva por produção sob licença; 2) aprendizagem tecnoprodutiva por internacionalização endógena (atração de empresas estrangeiras para produzirem no país); 3) aprendizagem tecnoprodutiva por internacionalização exógena (inserção de empresas nacionais em cadeias globais de valor); 4) instituições de formação de recursos humanos (técnicos, tecnológicos e científicos) especializados no setor aeronáutico; 5) instituições de pesquisa e desenvolvimento dedicadas ao setor aeronáutico; e 6) OEM comercialmente orientada. Essas dimensões assumem valores 0 e 1, indicando ausência ou presença da variável-condição. Assim, por exemplo, o valor 1 para a variável "instituições de pesquisa e desenvolvimento dedicadas ao setor aeronáutico" significa que o país em questão possuía instituições desse tipo, ao passo que o valor 0 indicaria ausência dessas instituições naquele país (segundo as definições de presença e ausência acima). Igualmente, valores 1 para a variável "aprendizagem tecnoprodutiva por produção sob licença" indicam que o país lançou mão, em sua estratégia de catch-up, dessa forma de aprendizagem (produção sob licença), e valores 0 indicam que tal modo de aprendizagem não foi empregado.

As dimensões explicativas do modelo podem ser divididas em dimensões de estratégia de aprendizagem tecnoprodutiva: 1) aprendizagem tecnoprodutiva por produção sob licença; 2) aprendizagem tecnoprodutiva por internacionalização endógena (atração de empresas estrangeiras para produzirem no país); 3) aprendizagem tecnoprodutiva por internacionalização exógena (inserção de empresas nacionais em cadeias globais de valor); fatores institucionais: 4) instituições de formação de recursos humanos (técnicos, tecnológicos e científicos) especializados no setor aeronáutico; 5) instituições de pesquisa e desenvolvimento dedicadas ao setor aeronáutico; e fator empresarial: 6) OEM comercialmente orientada. As Tabelas 1 e 2 apresentam os valores para cada um dos modelos, do período 1 e do período 2. 
Tabela 1: Modelo período 1 de estratégias de catch-up aeronáutico

\begin{tabular}{|c|c|c|c|c|c|c|c|}
\hline \multirow{3}{*}{$\begin{array}{c}\text { Casos } \\
\text { País } \\
\end{array}$} & \multicolumn{6}{|c|}{ Condições } & \multirow{3}{*}{$\begin{array}{c}\text { Resultado } \\
\begin{array}{c}\text { Sucesso do } \\
\text { catch-up }\end{array} \\
\text { Resultado } \\
\end{array}$} \\
\hline & \multicolumn{3}{|c|}{\begin{tabular}{|c|}
$\begin{array}{c}\text { Dimensão aprendizagem } \\
\text { tecnoprodutiva }\end{array}$ \\
\end{tabular}} & \multicolumn{2}{|c|}{$\begin{array}{c}\text { Dimensão } \\
\text { institucional }\end{array}$} & \multirow{2}{*}{$\begin{array}{c}\begin{array}{c}\text { Dimensão } \\
\text { empresarial }\end{array} \\
\text { OEMCom } \\
\end{array}$} & \\
\hline & $\begin{array}{c}\text { ProdLi } \\
\text { c }\end{array}$ & $\begin{array}{c}\text { EndoIn } \\
t\end{array}$ & ExoInt & RHInst & P\&DInst & & \\
\hline Brasil & 1 & 0 & 0 & 1 & 1 & 1 & 1 \\
\hline Argentina & 1 & 0 & 0 & 0 & 0 & 0 & 0 \\
\hline Indonésia & 0 & 0 & 1 & 0 & 1 & 1 & 0 \\
\hline Japão 1 & 1 & 0 & 0 & 1 & 1 & 0 & 0 \\
\hline
\end{tabular}

Legenda: ProdLic: produção sob licença; EndoInt: Internacionalização endógena; ExoInt: Internacionalização exógena; RHInst: Instituições de RH; P\&DInst: Instituições de P\&D; OEMCom: OEM comercialmente orientada.

Tabela 2: Modelo período 2 de estratégias de catch-up aeronáutico

\begin{tabular}{|c|c|c|c|c|c|c|c|}
\hline Casos & \multicolumn{6}{|c|}{ Condições } & $\begin{array}{c}\text { Resultad } \\
\text { o } \\
\end{array}$ \\
\hline País & \multicolumn{3}{|c|}{$\begin{array}{c}\text { Dimensão aprendizagem } \\
\text { tecnoprodutiva }\end{array}$} & \multicolumn{2}{|c|}{$\begin{array}{c}\text { Dimensão } \\
\text { institucional }\end{array}$} & \multirow{2}{*}{$\begin{array}{c}\begin{array}{c}\text { Dimensão } \\
\text { empresarial }\end{array} \\
\text { OEMCom } \\
\end{array}$} & $\begin{array}{l}\text { Sucesso } \\
\text { do catch- } \\
\text { up }\end{array}$ \\
\hline & ProdLic & $\begin{array}{c}\text { EndoIn } \\
\mathbf{t}\end{array}$ & ExoInt & $\begin{array}{c}\text { RHIns } \\
\mathbf{t} \\
\end{array}$ & $\begin{array}{c}\text { P\&DIns } \\
t\end{array}$ & & $\begin{array}{c}\text { Resultad } \\
\text { o } \\
\end{array}$ \\
\hline Japão 2 & 0 & 0 & 1 & 1 & 1 & 1 & 1 \\
\hline China & 1 & 1 & 0 & 1 & 1 & 1 & 0 \\
\hline Rússia & 0 & 0 & 0 & 1 & 1 & 1 & 0 \\
\hline
\end{tabular}

Legenda: ProdLic: produção sob licença; EndoInt: Internacionalização endógena; ExoInt: Internacionalização exógena; RHInst: Instituições de RH; P\&DInst: Instituições de P\&D; OEMCom: OEM comercialmente orientada.

O passo final da análise consiste em atribuir valores à variável-resultado do modelo do período 2 de estratégias de catch-up: sucesso (1) ou fracasso (0). Neste ponto, é preciso ter em mente o seguinte: as estratégias de catch-up do período 2 são, por assim dizer, um trabalho em andamento. Por isso, ainda que seja desejável, e mesmo necessário, em vista do esforço de compreensão das estratégias de catch-up aqui empreendido, avaliar, com base no presente estado, o sucesso ou fracasso das estratégias de catch-up do 
período 2 (segunda tentativa do Japão, China e Rússia), essa avaliação é menos defiinitiva do que aquela feita para o período 1, cuja distância no tempo permite maior segurança na em relação à atribuição de sucesso ou fracasso das tentativas de catch-up aeronáutico. Por outro lado, a atribuição de sucesso à segunda tentativa de catch-up aeronáutico do Japão e fracasso às estratégias de China e Rússia é, em si, prognóstico dos desenvolvimentos futuros das estratégias de catch-up aeronáutico desses países.

Enfim, não obstante as dificuldades de avaliar no calor da hora acontecimentos em andamento e cujos resultados finais ainda são em certa medida desconhecidos, a partir dos dados disponíveis até o momento, tudo sugere que devemos tratar, para fins analíticos, a segunda tentativa de catch-up tecnoprodutivo aeronáutico do Japão como caso de sucesso, e as tentativas de China e Rússia como casos de fracasso - até o momento, bem entendido.

\section{Resultados da análise de Análise Qualitativa Comparada - QCA}

Começo pela análise dos resultados do QCA para os casos do primeiro período estudado: Brasil, Argentina, Indonésia e a primeira tentativa do Japão, que tiveram lugar entre as décadas de 1950 e 1980. Examinemos os resultados da explicação do fracasso e da explicação do sucesso das estratégias de catch-up desses países. Em outras palavras, analisaremos as configurações - ou seja, as combinações de condições - que explicam o sucesso e o fracasso das estratégias de catch-up.

$\mathrm{Na}$ explicação do sucesso da estratégia de catch-up do Brasil, a configuração que permitiu tal resultado (sucesso do catch-up) é composta pelas seguintes condições:

Brasil (condições presentes $=1$ e ausentes $=0$ ): presença de produção sob licença (1) + ausência de internacionalização endógena (0) + presença de instituições de formação de recursos humanos (1) + presença de instituições de pesquisa e desenvolvimento (1) + presença de OEM comercialmente orientada (1) => sucesso da estratégia de catch-up 
Brasil (apenas condições presentes $=1$ ): presença de produção sob licença + presença de instituições de formação de recursos humanos + presença de instituições de pesquisa e desenvolvimento + presença de OEM comercialmente orientada $=>$ sucesso da estratégia de catch-up

A configuração de condições que levou ao sucesso da estratégia de catch-up do Brasil no primeiro período combinou a aprendizagem por produção sob licença, que permitiu ao sistema tecnoprodutivo brasileiro entrar em contato e acumular os conhecimentos que permitiriam mais tarde a transição para a aprendizagem por desenvolvimento de ciclo completo; a existência de instituições de formação de recursos humanos e de pesquisa e desenvolvimento especializadas em aeronáutica; e a existência de uma OEM comercialmente orientada. Essas, em suma, são as condições que explicam o sucesso da estratégia de catch-up do Brasil: o processo de aprendizagem tecnoprodutiva cumulativo e gradual, a consistência do arranjo institucional do sistema e a competitividade dos produtos e em especial da OEM responsável por sua produção e comercialização. Essa configuração oferece o paradigma do sucesso das estratégias de catch-up de sistemas tecnoprodutivos aeronáuticos. A explicação do sucesso, porém, é apenas metade, e não necessariamente a parte mais interessante, do problema; entender as condições que levaram ao fracasso de outras estratégias de catch-up é igualmente importante.

A configuração de condições que explicam o fracasso das estratégias de catch-up de Argentina, Indonésia e da primeira tentativa de catch-up do Japão ensinam tanto quanto o exame das condições que explicam o sucesso do Brasil. Na explicação do fracasso da estratégia de catch-up desses países, diferentes razões contribuíram para o fracasso em cada um dos casos.

Em relação à Argentina, as deficiências institucionais e a ausência de uma OEM comercialmente orientadas são as condições que explicam o fracasso de sua estratégia de catch-up:

Argentina (condições presentes $=1$ e ausentes $=0$ ): presença de produção sob licença (1) + ausência de internacionalização exógena (0) + ausência de instituição de formação de recursos humanos $(0)+$ ausência de instituições de 
pesquisa e desenvolvimento (0) + ausência de OEM comercialmente orientada (0) $=>$ fracasso da estratégia de catch-up

Argentina (apenas condições presentes $=1$ ): presença de produção sob licença (1) =>fracasso da estratégia de catch-up

A adoção de uma estratégia de aprendizagem tecnoprodutiva por produção sob licença e a consequente transição para a aprendizagem por desenvolvimento de ciclo completo não foram suficientes, face às deficiências institucionais relativas à ausência de instituições de formação de recursos humanos e de pesquisa e desenvolvimento especializadas em aeronáutica, para levar a bom termo a estratégia de catch-up do sistema tecnoprodutivo aeronáutico argentino. A isso se deve acrescentar a inexistência, na Argentina, de uma OEM comercialmente orientada, e teremos a configuração que explica o fracasso do catch-up aeronáutico naquele país. Por outro lado, note-se que, não obstante uma estratégia bem sucedida de aprendizagem tecnológica estrito senso, em que à produção sob licença seguiu-se um exitoso, do ponto de vista técnico, processo de aprendizagem por desenvolvimento de ciclo completo, que resultou em bons aviões, tecnologicamente falando, o sistema tecnoprodutivo aeronáutico argentino não pode sustentar seus avanços por total falta de condições institucionais, isto é, pela incapacidade de formar recursos humanos especializados com a qualidade e na quantidade necessárias e pela inexistência de centros avançados de pesquisa e desenvolvimento aeronáuticos. Por fim, mas não menos importante, a incapacidade ou falta de vontade de criar uma OEM comercialmente orientada, optando em seu lugar por garantir a demanda por aviões nacionais unicamente por compras militares ou estatais, criaram as condições que levaram ao fracasso da estratégia de catch-up tecnoprodutivo aeronáutico argentino.

A Indonésia, por sua vez, deveu o fracasso de sua estratégia de catch-up tecnoprodutivo a uma combinação de fatores ligados às dimensões tecnoprodutiva e institucional:

Indonésia (condições presentes $=1$ e ausentes $=0$ ): ausência de produção sob licença (0) + presença de internacionalização exógena (1) + ausência de instituições de formação de recursos humanos $(0)+$ presença de instituições de 
pesquisa e desenvolvimento (1) + presença de OEM comercialmente orientada (1) =>fracasso da estratégia de catch-up

Indonésia (apenas condições presentes $=1$ ): presença de internacionalização exógena (1) + presença de instituições de pesquisa e desenvolvimento (1) + presença de OEM comercialmente orientada (1) =>fracasso da estratégia de catch-up

No caso da configuração que explica o fracasso da estratégia de catch-up da Indonésia, tudo indica que ele se deu devido à velocidade excessiva com que ocorreu o processo de catch-up, impedindo o acúmulo e amadurecimento de conhecimentos e instituições do sistema tecnoprodutivo aeronáutico da Indonésia. É possível que uma estratégia de aprendizagem tecnoprodutiva cumulativa e gradual alcançasse resultados melhores, permitindo ao sistema tecnoprodutivo indonésio acumular $\mathrm{e}$ amadurecer os conhecimentos necessários para empreender a fase final do catch-up.

Quanto à dimensão da aprendizagem tecnoprodutiva, a inexperiência com manufatura de aviões, causada em grande parte pela ausência, em sua estratégia de aprendizagem tecnoprodutiva, de uma fase de produção sob licença - importante para expor o sistema tecnoprodutivo aos conhecimentos básicos em produção seriada que podem permitir, em fase posterior, a transição para o desenvolvimento de ciclo completo -, optando, em vez disso, por se lançar diretamente ao desenvolvimento e produção de ciclo completo, cobrou seu preço mais adiante: quando do desenvolvimento e produção de um avião em colaboração com uma OEM estrangeira, a falta de experiência em manufatura aeronáutica causou inúmeros atrasos no projeto e dificultou sobremaneira a certificação da versão indonésia do avião desenvolvido em colaboração com a OEM espanhola.

Em relação à dimensão institucional, a ausência de instituições de formação de recursos humanos na quantidade e em qualidade suficientes para sustentar o sistema tecnoprodutivo aeronáutico da Indonésia não pode ser compensada pela atração de engenheiros aeronáuticos indonésios e de outras nacionalidades com sólida formação e vasta experiência no setor aeronáutico. A oferta em quantidade e qualidade adequadas de mão de obra especializada no setor aeronáutico é uma condição necessária, ainda que 
não suficiente, para o sucesso de uma estratégia de catch-up tecnoprodutivo - aliás, em qualquer que seja a área intensiva em conhecimento.

Quanto à primeira tentativa de catch-up tecnoprodutivo aeronáutico japonês, a principal condição que explica seu fracasso foi a inexistência de uma OEM comercialmente orientada, malgrado a aprendizagem tecnoprodutiva acumulada no período anterior à Segunda Guerra (fase na qual o Japão figurou em posição de destaque por seu virtuosismo tecnoprodutivo) e, no período imediatamente posterior, a produção sob licença e o desenvolvimento de ciclo completo e a existência de instituições de formação de recursos humanos e de pesquisa e desenvolvimento especializadas em aeronáutica.

Japão 1 (condições presentes $=1$ e ausentes $=0$ ): presença de produção sob licença (1) + ausência de internacionalização exógena (0) + presença de instituições de formação de recursos humanos (1) + presença de instituições de pesquisa e desenvolvimento (1) ausência de OEM comercialmente orientada (0) => fracasso da estratégia de catch-up

Em sua primeira tentativa de catch-up tecnoprodutivo aeronáutico, o Japão passou muito perto do sucesso; este escapou-lhe nos momentos finais do processo: na incapacidade de constituir uma OEM comercialmente orientada, isto é, dotada de competências e incentivos para buscar o sucesso comercial de seu avião.

A análise das configurações que explicam o fracasso e o sucesso das estratégias de catch-up tecnoprodutivo aeronáutico no primeiro período mostram que nenhuma condição, isoladamente, é suficiente para garantir o sucesso do catch-up. É apenas a combinação de uma série de condições necessárias em determinada configuração que explica o sucesso do catch-up dos sistemas tecnoprodutivos aeronáuticos. Por outro lado, a ausência de uma OEM comercialmente orientada parece ser, pelo menos no primeiro período das estratégias de catch-up tecnoprodutivo aeronáutico, condição suficiente para explicar o fracasso de uma estratégia de catch-up, mesmo que todas as outras condições estejam presentes, como mostra de forma inequívoca a primeira tentativa de catch-up do Japão. 
Veremos, no exame das configurações do segundo período e na comparação das configurações do primeiro e do segundo período, que essa situação se mantém constante: nenhuma condição, sozinha, é suficiente para explicar (ou garantir) o sucesso de uma estratégia de catch-up. Por outro lado, a ausência de uma condição-chave pode, em certos casos, explicar o fracasso de uma estratégia de catch-up.

Passemos agora à análise dos resultados da QCA para os casos do segundo período estudado: Japão, China e Rússia nos anos 2000. Novamente, examinaremos os resultados da explicação do fracasso e da explicação do sucesso. Analisaremos as configurações - ou seja, as combinações de condições - que explicam o sucesso e o fracasso das estratégias de catch-up.

Trata-se de uma análise da situação atual do catch-up de Japão, China e Rússia. Os processos de catch-up desses países já se encontram muito próximos de uma definição. Ainda que não se possa atribuir com absoluta segurança qual deles obteve sucesso e qual fracassou, a análise das condições atualmente presentes permite, com segurança razoável e em nível aceitável, analisar os resultados obtidos até o momento. Nesse sentido, é possível atribuir sucesso (até o momento) à estratégia de catch-up do Japão e fracasso às estratégias de China e Rússia. Dentro de alguns anos, será possível retomar essa análise a partir de uma avaliação cuja exatidão se beneficie do distanciamento histórico e quiçá de uma avaliação consensual. Por ora, fiquemos com a avaliação possível de ser feita com os dados de que dispomos agora, sempre qualificando a avaliação do sucesso e do fracasso com a seguinte ressalva: sucesso e fracasso até $o$ momento.

A configuração que explica o sucesso (até o momento) da segunda tentativa do Japão de empreender uma estratégia de catch-up de seu sistema tecnoprodutivo aeronáutico é composta pelas seguintes condições:

Japão 2 (condições presentes $=1$ e ausentes $=0$ ): ausência de produção sob licença $(0)$ + ausência de internacionalização endógena $(0)$ + presença de internacionalização exógena (1) + presença de instituições de formação de recursos humanos (1) + presença de instituições de pesquisa e desenvolvimento 
$(1)+$ presença de OEM comercialmente orientada (1) $\Rightarrow>$ sucesso da estratégia de catch-up

Japão 2 (apenas condições presentes $=1$ ): presença de internacionalização exógena (1) + presença de instituições de formação de recursos humanos (1) + presença de instituições de pesquisa e desenvolvimento (1) + presença de OEM comercialmente orientada (1) => sucesso da estratégia de catch-up

A configuração que explica o sucesso (até o momento) da segunda tentativa de catch-up do Japão explicita as características específicas da atual estratégia de catch-up japonês. Do ponto de vista institucional, o Japão conta com instituições de formação de recursos humanos e de pesquisa e desenvolvimento especializadas em aeronáutica e altamente qualificadas. Em relação à dimensão empresarial, desta feita, em contraste com a primeira tentativa de catch-up aeronáutico do Japão, há apenas uma empresa diretamente envolvida (e portanto diretamente interessada) no sucesso da empreitada, ao passo que na primeira tentativa a estrutura de consórcio da OEM criada naquela ocasião causou a dispersão de recursos e a descoordenação entre os atores empresariais e governamentais; além disso, trata-se de uma empresa que detém competências em pesquisa e desenvolvimento, inovação, produção industrial e inteligência de mercado, características que faltaram ao consórcio que deveria desenvolver, produzir e comercializar os resultados da primeira tentativa de catch-up.

Nos pontos acima elencados, a configuração da atual estratégia de catch-up aeronáutico do Japão segue pari passu aquela identificada como determinante do sucesso da estratégia de catch-up do Brasil. No entanto, ela se distingue desta, bem como da primeira tentativa de catch-up japonesa, em dois pontos importantes.

Em primeiro lugar, a configuração da segunda tentativa de catch-up do Japão tem uma característica distintiva em relação à configuração do catch-up brasileiro e da primeira tentativa do Japão de realizar o catch-up: o desenvolvimento da cadeia de fornecedores aeronáuticos de segundo e primeiro nível como passo inicial para só então lançar-se no empreendimento de tentar constituir uma OEM, conforme indicado pela presença de internacionalização exógena, isto é, de inserção de empresas fornecedoras aeronáuticas 
japonesas em cadeias globais de valor como forma de aprendizagem tecnoprodutiva. Nesse ponto, a atual estratégia de catch-up do Japão é bastante diferente das demais estratégias de catch-up aqui analisadas, na medida em que ela se baseia no desenvolvimento da cadeia de fornecedores como estratégia de aprendizagem tecnoprodutiva, deixando para um segundo momento a aprendizagem por desenvolvimento de ciclo completo, característica do processo de constituição de OEMs.

Por outro lado, a atual estratégia de catch-up do Japão, por estar baseada no desenvolvimento da cadeia de fornecedores de segundo e primeiro nível por meio de sua inserção nas cadeias globais de valor do setor aeronáutico, não utilizou a produção sob licença como estratégia de aprendizagem tecnoprodutiva. Mais do que especificidade ou idiossincrasia, a ausência da aprendizagem tecnoprodutiva por meio da produção sob licença na atual estratégia de catch-up tecnoprodutivo aeronáutico japonês é um dos seus pontos vulneráveis. Se é verdade que a aprendizagem tecnoprodutiva é um processo cumulativo e que as competências em produção manufatureira são determinantes para o sucesso final de uma estratégia de catch-up, é bem possível que a ausência, em grau elevado, de aprendizagem tecnoprodutiva por meio da produção sob licença seja um dos fatores limitantes dos esforços de catch-up tecnoprodutivo aeronáutico japonês. Será interessante voltar a este ponto mais à frente e analisar se uma estratégia de catch-up tecnoprodutivo aeronáutico pode abrir mão da aprendizagem por meio da produção sob licença, valendo-se em seu lugar da aprendizagem tecnoprodutiva indireta (no que diz respeito ao projeto e produção de aviões) decorrente do desenvolvimento de fornecedores de segundo e primeiro nível e de sua inserção em cadeias globais de valor. A análise de outras estratégias de catch-up tem mostrado que a aprendizagem cumulativa e direta das competências centrais necessárias para o desenvolvimento e produção de determinado artefato tecnoprodutivo são determinantes no sucesso da empreitada, ao passo que a aprendizagem de competências indiretas tem efeito muito limitado no desenvolvimento tecnoprodutivo de tecnologias e setores específicos.

Examinemos agora os casos que, até o momento, tudo indica tratar-se de tentativas malogradas de realizar o catch-up tecnoprodutivo aeronáutico, China e Rússia. A configuração da China apresenta as seguintes condições: 
China (condições presentes $=1$ e ausentes $=0$ ): presença de produção sob licença (1) + presença de internacionalização endógena (1) + ausência de internacionalização exógena $(0)$ + presença de instituições de formação de recursos humanos $(1)+$ presença de instituições de pesquisa e desenvolvimento $(1)+$ presença de OEM comercialmente orientada (1) $\Rightarrow>$ fracasso da estratégia de catch-up

China (apenas condições presentes $=1)$ : presença de produção sob licença $(1)+$ presença de internacionalização endógena (1) + presença de instituições de formação de recursos humanos (1) + presença de instituições de pesquisa e desenvolvimento (1) + presença de OEM comercialmente orientada (1) => fracasso da estratégia de catch-up

A configuração da estratégia de catch-up aeronáutico da China caracteriza-se por replicar uma peculiaridade do modelo de desenvolvimento econômico chinês: a atração de empresas estrangeiras para produzir, em associação com empresas chinesas, no país, de modo a garantir um alto grau de transferência tecnológica para as empresas nacionais. Essa característica é captada pela presença da condição internacionalização endógena.

O ponto mais vulnerável da estratégia de catch-up tecnoprodutivo aeronáutico chinês é a sua OEM. Se por um lado ela é claramente comercialmente orientada, por ora ainda é difícil avaliar se ela conseguirá vencer as principais dificuldades que determinam o sucesso ou fracasso de OEMs e consequentemente da estratégia de catch-up aeronáutico. Por um lado, o poder de compra do governo chinês, a ser exercido, teoricamente, por meio de empresas estatais chinesas de aviação comercial, já se mostrou em outras ocasiões pouco ou nada eficaz. A estratégia de garantir um número mínimo de pedidos que permitam a entrada em produção dos projetos de aviões nacionais irá inevitavelmente se deparar com as necessidades de eficiência das empresas de aviação comercial e sobretudo com a concorrência de empresas capazes de oferecer produtos mais competitivos do que os produtos chineses. Por outro lado, a pouca 
experiência da OEM chinesa em inteligência de mercado e pós-vendas poderá limitar o sucesso dos aviões chineses aos mercados chinês ou asiático, mercados muito promissores e com grande potencial de crescimento nas próximas duas décadas, mas que não conseguem, sozinhos, gerar demanda em escala suficiente para justificar e manter viva uma OEM iniciante e que terá que disputar venda a venda com Boeing, Airbus, Embraer e Bombardier e muito possivelmente com a Mitsubishi.

Acresce que, no setor aeronáutico, a estratégia de desenvolvimento tecnoprodutivo gradual em direção a produtos de maior qualidade, como fizeram Japão e Coreia do Sul e como faz a própria China nos setores de eletroeletrônicos e automóveis, por exemplo, não é possível. Em razão das altas exigências de segurança, confiabilidade e qualidade dos produtos aeronáuticos, as empresas entrantes não poderão começar com produtos de baixa qualidade e evoluir para produtos de maior qualidade.

Não obstante essas ressalvas relativas às limitações e dificuldades que serão enfrentadas pela OEM chinesa em busca de sua viabilização comercial, o fato é que a China reúne grande parte das condições que compõem uma configuração de sucesso de catch-up. Está difícil, mas não impossível, o sucesso do catch-up aeronáutico chinês.

Quanto à configuração do catch-up tecnoprodutivo aeronáutico russo, ele se caracteriza pelas seguintes condições:

Rússia (condições presentes $=1$ e ausentes $=0$ ): ausência de produção sob licença $(0)$ + ausência de internacionalização endógena (0) + ausência de internacionalização exógena $(0)$ + presença de instituições de formação de recursos humanos $(1)+$ presença de instituições de pesquisa e desenvolvimento $(1)+$ presença de OEM comercialmente orientada (1) $\Rightarrow$ fracasso da estratégia de catch-up

Rússia (apenas condições presentes $=1$ ): presença de instituições de formação de recursos humanos (1) + presença de instituições de pesquisa e desenvolvimento (1) + presença de OEM comercialmente orientada (1) => fracasso da estratégia de catch-up 
O caso da estratégia de catch-up da Rússia deve ser interpretado com cuidado, em especial no que diz respeito às estratégias de aprendizagem tecnoprodutiva. Por um lado, o sistema tecnoprodutivo russo não domina os processos e tecnologias específicos da produção de jatos regionais da nova nem mesmo da atual geração; nem por isso o sistema tecnoprodutivo aeronáutico russo pode ser considerado um iniciante em desenvolvimento e produção de aviões, muito pelo contrário: basta pensarmos na longa história do sistema tecnoprodutivo aeronáutico soviético. Por esse motivo, a ausência de aprendizagem tecnoprodutiva por produção sob licença deve ser entendida no contexto de um sistema tecnoprodutivo com larga e extensa experiência em projeto e produção seriada de produtos aeronáuticos, alguns deles ainda hoje verdadeiras maravilhas tecnoprodutivas.

Quanto à ausência de aprendizagem por meio de internacionalização endógena e exógena, essas sim são condições que podem ter peso decisivo no fracasso da estratégia de catch-up tecnoprodutivo aeronáutico russo. O setor aeronáutico mundial desde sempre e ainda mais depois do processo de internacionalização ocorrido a partir dos anos 1980 depende de cadeias globais de valor e conhecimento, de tal modo que, talvez à exceção dos Estados Unidos, nenhum outro país é detentor da totalidade de conhecimentos e competências tecnoprodutivas necessários para construir e fazer voar um avião. As cadeias globais de valor do setor aeronáutico desempenham, por essa razão, papel central na disseminação e transferência de conhecimentos nas formas de produtos, tecnologias e acordos de compartilhamento de riscos, aspectos que têm caracterizado o setor aeronáutico global nos últimos trinta anos.

A Rússia, no entanto, mantém-se, por inúmeras razões, equidistante das cadeias globais de valor do setor aeronáutico global: pela sua antiga autossuficiência tecnológica herdada da era soviética, mas também pela regressão tecnoprodutiva que assolou a Rússia no imediato fim da URSS, cujos ecos se fazem ouvir até hoje, ainda que cada vez mais distantes. Isso colocou a Rússia em uma posição que, do ponto de vista de seu desenvolvimento tecnológico presente e futuro, é bastante delicada: seus sistemas tecnoprodutivos são hoje sistemas fechados e autorreferenciados, sem vasos de comunicação com sistemas externos de conhecimento. Essa situação de endogamia tecnológica pode ser mortal para as pretensões russas de realizar o catch-up 
tecnoprodutivo aeronáutico e constituir uma OEM capaz de competir de igual para igual com OEMs imersas em cadeias globais de valor e conhecimentos.

Por outro lado, a qualidade das instituições de formação de recursos humanos e de pesquisa e desenvolvimento russas especializadas em aeronáutica são fatores que favorecem o catch-up tecnoprodutivo aeronáutico da Rússia. A existência de OEMs comercialmente orientadas na Rússia, por sua vez, deverá esbarrar em dificuldades parecidas com aquelas que a China enfrentará, em especial as referentes aos conhecimentos relativos a inteligência de mercado e pós-vendas.

Assim como no caso da China, o sucesso do catch-up tecnoprodutivo aeronáutico russo está difícil, mas não impossível. O mais provável é que as duas estratégias resultem em OEMs restritas aos respectivos mercados nacionais e disputem entre si, o que não é bom, o mercado asiático.

Os resultados desta tese também indicam seu potencial de desenvolvimento futuro em trabalhos que aprofundem a análise de cada uma das dimensões que compõem o modelo analítico. Algumas possibilidades já se fazem evidentes: por um lado, seria interessante acrescentar ao modelo analítico uma dimensão contextual referente à transição tecnológica. Estratégias de catch-up que ocorrem em períodos de estabilidade tecnológica têm maior chance de serem bem-sucedidas do que catch-ups em meio a períodos de transição tecnológica. A dimensão transição tecnológica explicaria tanto o fracasso da primeira tentativa de catch-up aeronáutico do Japão, que se deu em meio ao advento dos motores a jato, quanto a maior chance de sucesso de sua atual estratégia de catch-up em comparação a China e Rússia, uma vez que o Japão domina tecnologias de fabricação de aviões com elevado emprego de materiais compósitos, posição a que chegou pelo desenvolvimento de sua cadeia de fornecedores. Isso dá uma vantagem substancial ao Japão em relação à China e Rússia, que correm o risco de colocar no mercado produtos com horizontes de obsolescência curtos em comparação aos produtos de seus concorrentes.

Além disso, em futuros trabalhos seria interessante especificar as dimensões do atual modelo analítico em subdimensões. Deste modo, a dimensão OEM comercialmente orientada, por exemplo, poderia especificar as subdimensões que definem com maior precisão a dinâmica empresarial de empresas aeronáuticas, como a existência de 
departamentos de $\mathrm{P} \& \mathrm{D}$, o número de engenheiros, a evolução das vendas e a intensidade tecnológica.

\section{Discussão: condições de ocorrência de sucesso das estratégias de catch-up ontem e hoje}

As estratégias de catch-up do sistema tecnoprodutivo aeronáutico de Brasil, Argentina, Indonésia, Japão, China e Rússia são frequentemente interpretadas como catch-up em relação à fronteira tecnológica estrito senso. $\mathrm{O}$ modelo de catch-up desenvolvido nessa tese critica a utilização, como ponto de referência único do catch-up, da noção de fronteira tecnológica, propondo a noção ampliada de fronteira tecnoprodutiva, que acrescenta à noção de fronteira tecnológica as dimensões institucionais e empresariais.

Restringir a noção de catch-up à sua dimensão tecnológica equivale a desprezar dimensões fundamentais da explicação dos fatores responsáveis pelo sucesso ou fracasso de estratégias de catch-up. A noção ampliada de catch-up tecnoprodutivo, em comparação com a noção restrita de catch-up tecnológico, desloca o peso explicativo dos termos ciência e tecnologia para os termos produção, inovação, empresa e mercado. A noção ampliada de catch-up tecnoprodutivo tem o seguinte corolário: a mais avançada tecnologia não resulta necessariamente no mais competitivo produto. Nem poderia ser diferente: entre o domínio tecnológico e sua transformação em força produtiva vai um longo caminho passando por dimensões institucionais e empresariais. É o que mostra a análise das estratégias de catch-up de Brasil, Argentina, Indonésia, Japão, China e Rússia: o sucesso e o fracasso são determinados pela combinação de condições - configurações - referentes às dimensões estratégia de aprendizagem tecnoprodutiva, instituições de formação de pessoal e pesquisa e desenvolvimento e empresas comercialmente orientadas. Nesse sentido, fatores tecnológicos, neste modelo de catch-up tecnoprodutivo representados pela dimensão de aprendizagem tecnoprodutiva, são apenas parte da equação, junto com instituições e competitividade empresarial.

Pelo lado das estratégias de aprendizagem tecnoprodutiva, os casos estudados apontam para a importância de combinar à aprendizagem por desenvolvimento de ciclo completo, objetivo final de uma estratégia de catch-up tecnoprodutivo, outras 
modalidades de aprendizagem anteriores ao desenvolvimento de ciclo completo e passando por fases básicas do processo de aprendizagem e acúmulo de conhecimentos, como a produção sob licença ou as formas de internacionalização do sistema tecnoprodutivo aeronáutico (endógena ou exógena). Com efeito, os países que quiseram voar alto demais e colocaram como objetivo primeiro o domínio do desenvolvimento de ciclo completo fracassaram em sua tentativa de catch-up, como foi o caso da Indonésia e do Japão em sua primeira tentativa de catch-up. Aparentemente, não é viável tecnoprodutivamente saltar etapas do processo de aprendizagem; as lições puladas aprendidas cobram mais tarde seu preço, inviabilizando o aprendizado por desenvolvimento de ciclo completo pela ausência de competências produtivas que poderiam ser aprendidas por meio da produção sob licença, ou com uma estratégia de qualificação de fornecedores nacionais por meio da inserção dessas empresas em cadeias globais de valor, ou mesmo pelos efeitos de qualificação de recursos humanos e spillovers gerados com a atração de empresas estrangeiras para produzir no país.

Quanto à dimensão institucional das estratégias de catch-up tecnoprodutivo aeronáutico, a análise mostrou que a ausência de instituições de formação de recursos humanos tem grande peso na explicação do fracasso de algumas estratégias de catch-up, entre outras razões, porque a demanda por pessoal especializado em um sistema tecnoprodutivo aeronáutico próximo da fronteira tecnoprodutiva é de tal ordem que ela não pode ser atingida apenas pela importação de cérebros. A Argentina deve em grande medida o fracasso de sua estratégia de catch-up aeronáutico à quase inexistência no país de instituições de formação de engenheiros aeronáuticos, tendo baseado sua estratégia de recursos humanos na atração de especialistas estrangeiros. O Brasil, em contraste, oferece o mais relevante exemplo da importância de se ter instituições capazes de formar recursos humanos em qualidade e quantidade suficientes para atender a demanda do sistema tecnoprodutivo aeronáutico nacional. O mesmo vale para instituições de pesquisa e desenvolvimento aeronáutico, e também nesse ponto os casos de Argentina e Brasil oferecem exemplos contrastantes: ao passo que o Brasil construiu instituições de pesquisa e desenvolvimento aeronáutico, a Argentina também carecia de instituições especializadas em pesquisa e desenvolvimento aeronáutico, recorrendo em vez disso à adaptação de projetos desenvolvidos no exterior.

O componente empresarial, enfim, mostrou-se determinante em todas as estratégias de catch-up até o momento. Se um sistema tecnoprodutivo aeronáutico não dispuser de 
uma organização dedicada fundamentalmente a perseguir a viabilização econômica do empreendimento de desenvolvimento e produção de aviões, se não contar com uma organização exposta à competição de seus concorrentes e que transmita ao sistema tecnoprodutivo os incentivos para aperfeiçoar-se constantemente de modo a não se distanciar excessivamente da fronteira tecnoprodutiva do momento, então a estratégia de catch-up, além de cara demais - já que ela terá que ser bancada integralmente pelo Estado, uma vez que não recorre aos mecanismos de mercado para extrair parcela significativa de seus ganhos -, vai se desgarrar dos mecanismos que estimulam um sistema tecnoprodutiva a manter-se atualizado e a desenvolver e acumular as competências tecnológicas, institucionais e empresariais necessárias para que ele se mantenha competitivo globalmente. A ausência de empresa comercialmente orientada foi uma das razões para o fracasso da estratégia de catch-up da Argentina e da primeira tentativa do Japão. Por sua vez, a presença de uma OEM comercialmente orientada é uma das razões mais fortes para o sucesso da estratégia brasileira, devido em grande medida ao acerto na criação da Embraer na década de 1960 e depois em sua privatização na década de 1990. A pouca experiência de OEMs russas e chinesas em produção e comercialização de aviões, por sua vez, é o ponto mais vulnerável de suas estratégias de catch-up tecnoprodutivo e o motivo mesmo de considerarmos o catch-up tecnoprodutivo aeronáutico da China e da Rússia como fracassos - até o momento.

A tabela abaixo (Tabela 3) resume o modelo analítico sobre as condições relevantes para o sucesso e fracasso das estratégias de catch-up. São apresentados valores para as dimensões do modelo (aprendizagem tecnoprodutiva, instituições de RH e P\&D e OEM comercialmente orientada) que levam em consideração os valores de cada condição. Os valores atribuídos pretendem mostrar o peso de cada dimensão nos casos estudados: irrelevante (0), parcialmente relevante $(0,5)$ e altamente relevante (1). 
Tabela 3: Scores de dimensões e casos de catch-up tecnoprodutivo aeronáutico

\begin{tabular}{|l|c|c|c|c|}
\hline & \multicolumn{3}{|c|}{ Dimensões do modelo } & \\
\hline & $\begin{array}{c}\text { Aprendizagem } \\
\text { tecnoprodutiva }\end{array}$ & $\begin{array}{c}\text { Instituições de RH } \\
\text { e P\&D }\end{array}$ & $\begin{array}{c}\text { OEM comercialmente } \\
\text { orientada }\end{array}$ & $\begin{array}{l}\text { Score de } \\
\text { países }\end{array}$ \\
\hline Brasil & 1 & 1 & 1 & $\mathbf{3}$ \\
\hline Argentina & 0,5 & 0 & 0 & $\mathbf{0 , 5}$ \\
\hline Indonésia & 0 & 0,5 & 0,5 & $\mathbf{1}$ \\
\hline Japão 1 & 0 & 1 & 0 & $\mathbf{1}$ \\
\hline Japão 2 & 0,5 & 1 & 1 & $\mathbf{2 , 5}$ \\
\hline China & 1 & 1 & 0,5 & $\mathbf{2 , 5}$ \\
\hline Rússia & 0,5 & 1 & 0,5 & $\mathbf{2}$ \\
\hline $\begin{array}{l}\text { Score de } \\
\text { dimensões }\end{array}$ & $\mathbf{3 , 5}$ & $\mathbf{5 , 5}$ & $\mathbf{3 , 5}$ & - \\
\hline
\end{tabular}

A Tabela 3 apresenta duas informações especialmente relevantes: os scores das dimensões e os scores dos países ou casos. Em relação aos scores das dimensões, podemos notar a maior predominância da dimensão instituições de RH e P\&D (score $5,5)$ em relação às dimensões aprendizagem tecnoprodutiva e OEM comercialmente orientada (ambas com scores de 3,5). A menor prevalência das dimensões aprendizagem tecnoprodutiva e OEM comercialmente orientada deve ser interpretada como indicador da elevada importância relativa dessas duas dimensões. Com exceção da Argentina e da Indonésia, ambos casos ocorridos no período 1 das estratégias de catch-up tecnoprodutivo aeronáutico, todos os outros países que empreenderam ou estão empreendendo estratégias de catch-up dispõem de instituições de formação de recursos humanos e de pesquisa e desenvolvimento especializadas em aeronáutica. A dimensão institucional, portanto, ao mesmo tempo em que é condição necessária, isto é, condição sem a qual o catch-up aeronáutico não tem como dar certo, oferece também o piso a partir do qual se dá a competição contemporânea entre esses sistemas tecnoprodutivos. De fato, dada a importância atual da ciência, tecnologia e inovação no desenvolvimento econômico e social, enfim, do conhecimento como fator determinante da riqueza das nações, é quase impossível que uma estratégia de catch-up nos dias de hoje prescinda de um arranjo institucional capaz de formar pessoas e realizar pesquisa e desenvolvimento.

Ao mesmo tempo, a interpretação dos scores das dimensões indica que os maiores desafios de uma estratégia de catch-up tecnoprodutivo aeronáutico dizem respeito à aprendizagem tecnoprodutiva e à dimensão OEM comercialmente orientada. A aprendizagem tecnoprodutiva apresenta desafios bastante peculiares: ela envolve não 
apenas a disposição de um determinado sistema tecnoprodutivo nacional de se lançar em um processo de aprendizagem, mas também a capacidade de estabelecer acordos para produção sob licença, internacionalizar empresas nacionais (internacionalização exógena) e atrair empresas estrangeiras para produzir no país (internacionalização exógena). O mesmo vale para a dimensão empresarial, a presença de OEM comercialmente orientada. Além de dispor da capacidade política e econômica para mobilizar os recursos necessários para a constituição de uma OEM internacionalmente competitiva, a OEM precisa, efetivamente, ser competitiva, o que significa disputar espaço com outras OEMs já estabelecidas. A dimensão institucional, por mais desafiadora que seja, depende de uma decisão autônoma: nasce, essencialmente, de decisões internas de governos nacionais. Não é o que acontece com as outras duas dimensões, que dependem em alto grau de relações de comércio exterior, geopolítica e em especial da competição nos mercados globais. O sucesso ou fracasso das estratégias de catch-up é definido, portanto, por fatores internos e externos. Em comparação ao período 1 (décadas de 1950 e 1960, quando o Brasil realizou seu catch-up aeronáutico), as condições atuais, ou do período 2 (década de 1990 e anos 2000), são muito mais complexas em termos dos fatores externos que nela incidem, em função do caráter altamente internacionalizado das economias contemporâneas e da importância dos fluxos de conhecimento internacionais na forma de pessoas e produtos.

Quanto ao score dos países ou casos, eles indicam, além do aspecto paradigmático do catch-up tecnoprodutivo aeronáutico brasileiro e dos evidentes fracassos dos casos da Argentina e da Indonésia, os aspectos promissores dos catch-ups atuais de Japão e China, ainda que o catch-up japonês tenha vantagens adicionais em relação ao chinês que esses scores não captam, e a menor chance da Rússia de ter sucesso em seu catchup aeronáutico.

Os scores e análises da Tabela 3 também apontam para a robustez do modelo de QCA anteriormente empregado e a complementaridade entre as duas estratégias de análise e apresentação dos dados. Esse fato indica que o modelo analítico das estratégias de catch-up tecnoprodutivo aeronáutico é consistente.

Nunca é demais insistir num último ponto, a assimetria causal das configurações de sucesso e de fracasso: por um lado, nenhuma condição, sozinha, é suficiente para o sucesso; é preciso haver a combinação de várias condições necessárias para que uma 
estratégia de catch-up resulte em sucesso. Por outro lado, a ausência de uma OEM comercialmente orientada é condição suficiente para resultar em fracasso do catch-up aeronáutico. Para obter sucesso, uma estratégia de catch-up tecnoprodutivo aeronáutico precisa dispor da combinação de diferentes condições, sem que a presença de todas as condições que levam ao sucesso seja garantia de sucesso. As razões do fracasso também são várias; a diferença é que basta a ausência de uma condição para botar tudo a perder: a inexistência de uma OEM capaz de transformar em ganhos econômicos todo o conhecimento desenvolvido e acumulado pelo sistema tecnoprodutivo. 


\section{Conclusão}

Afinal, é possível que um país, munido de uma estratégia de catch-up e partindo de um determinado nível prévio de acúmulo de conhecimentos aplicáveis à produção capitalista, reduza aceleradamente a distância que o separa da fronteira tecnoprodutiva de certo segmento ou setor?

Sim.

É fácil?

Não.

Vimos ao longo desta tese que o resultado de uma estratégia de catch-up tecnoprodutivo depende da combinação de uma série de condições mais ou menos conducentes ao sucesso da empreitada. Propus um modelo analítico das estratégias de catch-up tecnoprodutivo no setor aeronáutico composto por três dimensões explicativas: dimensão aprendizagem tecnoprodutiva, dimensão institucional e dimensão empresarial, desdobradas em seis condições. Defini a primeira dimensão por três condições: aprendizagem tecnoprodutiva por produção sob licença, por internacionalização endógena e por internacionalização exógena; a segunda, por duas: instituições de formação de recursos humanos e instituições de pesquisa e desenvolvimento; a terceira, por uma: empresa comercialmente orientada. Demonstrei que nenhuma condição, isoladamente, é suficiente para o sucesso de uma estratégia de catch-up, importando, isso sim, para o bom termo do empreendimento, o modo como se combinam diferentes condições em configurações específicas que aumentam as chances de sucesso do catchup. Por outro lado, concluí que, em se tratando do fracasso de uma estratégia de catchup, a ausência da dimensão empresarial, definida como a existência de uma empresa comercialmente orientada (e capaz de executar a contento essa orientação), é condição suficiente para o malogro do catch-up.

O caso brasileiro permanece até hoje como paradigma de catch-up tecnoprodutivo aeronáutico, referência não apenas na literatura especializada como também junto aos políticos e gestores públicos empenhados em acelerar o desenvolvimento dos respectivos setores aeronáuticos nacionais. Com efeito, o sucesso do catch-up aeronáutico brasileiro é caso único de 1945 para cá. 
Mais variado é o rol de casos de fracasso de catch-up tecnoprodutivo aeronáutico nesse período: Argentina, a primeira tentativa do Japão e Indonésia, para citar apenas os países que tentaram promover o desenvolvimento dos seus setores aeronáuticos até o ponto de constituição de OEMs nacionais, objeto desta tese. No presente, Japão, China e Rússia empreendem tentativas de catch-up tecnoprodutivo aeronáutico com vistas à formação de OEMs nacionais que competirão, em caso de sucesso de suas estratégias, diretamente com as OEMs que formam o atual duplo duopólio do setor: Airbus, Boeing, Embraer e Bombardier. Dentre estes últimos casos, o exame das estratégias de catch-up e das trajetórias de desenvolvimento tecnoprodutivo aeronáutico leva a crer que as maiores probabilidades de sucesso estão com o Japão, com China e Rússia com menores chances. Esse prognóstico deriva diretamente do modelo analítico das estratégias de catch-up tecnoprodutivo aeronáutico desenvolvido ao longo deste estudo.

Aprendemos lições muito relevantes com o estudo de estratégias de catch-up tecnoprodutivo aeronáutico. Tomamos consciência do aspecto multidimensional do desenvolvimento tecnoprodutivo, de modo algum restrito aos aspectos tecnológicos estrito senso. Com efeito, o estudo das tentativas de catch-up aeronáutico mostra que o domínio tecnológico pode ser atingido por diversos caminhos, como a produção sob licença e internacionalização endógena e exógena, mas seu desdobramento virtuoso depende fortemente da existência de um arranjo institucional capaz de sustentar, por instituições de formação de recursos humanos e de pesquisa e desenvolvimento especializadas em aeronáutica, níveis sempre crescentes de acúmulo, desenvolvimento e aplicação de conhecimentos.

No entanto, nem o domínio tecnológico adquirido por processos de aprendizagem tecnoprodutiva nem a existência de um arranjo institucional apto a produzir pessoal, pesquisa e desenvolvimento são suficientes para o sucesso de uma estratégia de catchup tecnoprodutivo aeronáutico. A existência de uma empresa comercialmente orientada, isto é, que persegue obsessivamente a viabilização comercial de seus produtos, procurando sempre o equilíbrio entre qualidade da tecnologia empregada e custos de desenvolvimento e produção, de modo que a conta apurada resulte sempre positiva, ou seja, em lucro, é condição necessária para seu sucesso. Sem esse passo final, a mais avançada tecnologia e as melhores intenções sucumbirão inevitavelmente. 
Essas são as conclusões derivadas diretamente do modelo analítico das estratégias de catch-up tecnoprodutivo aeronáutico desenvolvido nesta tese e aplicado ao exame dos casos que são objeto deste estudo. As lições que podemos tirar das diversas tentativas de catch-up aeronáutico, no entanto, não se esgotam nas dimensões que compõem o modelo analítico. O sucesso do catch-up brasileiro e o fracasso do primeiro catch-up japonês, por serem em certo sentido casos extremos e opostos de trajetórias de desenvolvimento industrial e tecnológico, oferecem ideias valiosas para pesquisas futuras. Tome-se, por exemplo, a diferença em termos de nível de desenvolvimento científico, tecnológico, industrial, institucional e de educação de Brasil e Japão, com evidente vantagem do Japão nesses quesitos, e o sucesso de um e o fracasso do outro em suas tentativas de catch-up afigurar-se-ão como resultados contraintuitivos ou mesmo paradoxais. De fato, dadas as condições de que cada país partia, tudo levaria a crer que os resultados seriam inversos: sucesso do Japão e fracasso do Brasil.

Por outro lado, e complementarmente, o sucesso do Brasil - e o fracasso do Japão poderiam indicar trajetórias futuras de desenvolvimento econômico, se não ruins para o Japão, ao menos auspiciosas para o Brasil. Penso sobretudo nas expectativas de spillover de conhecimentos e tecnologias que o desenvolvimento de um setor avançado e intensivo em conhecimento poderia ter sobre o restante do tecido tecnoprodutivo nacional e nos seus resultados aquém do esperado. Esses aspectos complementares do problema do desenvolvimento econômico: as evidências históricas de que a menor distância agregada, isto é, da economia como um todo, da fronteira tecnoprodutiva não garante o sucesso de uma tentativa de catch-up e, por outro lado, de que a maior distância agregada da fronteira tecnoprodutiva não implica que um país está fadado ao atraso tecnoprodutivo - em poucas palavras, que o catch-up tecnoprodutivo é possível, mas não é fácil - dão prova de que os efeitos mais amplos que nós, todos nós, esperamos que resultem de um processo de catch-up em determinado setor são na verdade muito mais localizados e restritos, gerando muito menos externalidades positivas do que gostaríamos. A promessa embutida na estratégia de catch-up tecnoprodutivo aeronáutico brasileiro, de contaminar outros setores da economia brasileira dando impulso a um ciclo virtuoso de desenvolvimento nacional, mostrou-se, ao fim e ao cabo, um tanto exagerada.

Tudo isso, no entanto, não deve nos levar à conclusão, completamente errada, de que estratégias de catch-up tecnoprodutivo não são benéficas para um país, muito pelo 
contrário. O sentimento que nos toma sessenta e oito anos depois de dados os primeiros passos na estratégia de catch-up tecnoprodutivo aeronáutico, de que poderíamos, deveríamos, precisávamos ter ido mais longe, pode ser atribuído em grande parte a características de nosso catch-up aeronáutico. Com efeito, se por um lado cabe creditar ao foco no desenvolvimento de uma OEM competitiva internacionalmente muito próxima da fronteira tecnoprodutiva mundial do setor aeronáutica o sucesso de nosso catch-up, é inegável que a pouca, quase nenhuma atenção dada ao desenvolvimento da cadeia produtiva aeronáutica nacional foi responsável por limitar os efeitos positivos que poderiam advir da constituição de um sistema tecnoprodutivo aeronáutico nacional dotado de uma OEM como a Embraer. O Brasil optou por concentrar sua estratégia de catch-up aeronáutico no desenvolvimento de uma OEM em função do que me parece ser a total inviabilidade, e mesmo temeridade, de tentar trilhar dois caminhos paralelos cujas linhas, por paralelas, convergem apenas no ponto de fuga de um horizonte imaginário: desenvolvimento de OEM de par com desenvolvimento da cadeia de fornecedores.

O desenvolvimento de uma OEM e da cadeia de fornecedores mostrou-se inviável não apenas em paralelo como também em sequência. Contrariamente ao que poderíamos supor, a sustentação da competitividade de uma OEM é tarefa constante e da qual nunca nos desprenderemos; assim é o setor aeronáutico. Por isso, os recursos para desenvolvimento do setor aeronáutico nacional, por definição escassos, ainda mais em países em desenvolvimento, como é o caso do Brasil, são quase todos direcionados para sustentar a competitividade da OEM, sobrando muito pouco para o desenvolvimento da cadeia de fornecedores aeronáuticos. Melhor assim, diga-se de passagem: antes uma OEM na mão do que uma cadeia de fornecedores e uma OEM voando. São as difíceis decisões que um país como o Brasil precisa tomar.

Tudo indica que o apoio à competitividade da Embraer continuará a ser o foco maior das políticas de desenvolvimento e inovação no Brasil pelos próximos cinco ou dez anos. Nem poderia ser diferente: o setor aeronáutico mundial está passando neste exato momento por uma fase de transição tecnológica profunda, com o advento de aviões mais eficientes e com menor impacto ambiental em uma nova geração de aviões que mudará significativamente os parâmetros da competição no mercado aeronáutico civil. A cesta de novas tecnologias destinadas a atingir esses objetivos inclui a utilização de materiais compósitos na fuselagem e asa de aviões, o desenvolvimento de motores mais 
eficientes, com menor emissão de gases poluentes e ruídos e capazes de operar com combustíveis renováveis, o emprego de sistemas elétricos no lugar de sistemas hidráulicos, tecnologias de otimização de voo por meio de aviônicos e sistemas de controle de voo avançados, trens de pouso autopropulsores, entre outros. As estratégias de desenvolvimento tecnológico atualmente implementadas na Europa, nos EUA e no Canadá, centradas em programas de plataformas demonstradoras tecnológicas - casos dos programas Clean Sky (Europa), Next Generation Air Transportation System (EUA) e Future Major Platforms e Aéro Montreal (Canadá) - estão centradas no desenvolvimento e integração desse conjunto de tecnologias. De sua parte, o Brasil precisará concentrar suas ações de sustentação e aumento da competitividade do setor aeronáutico nacional em esforços para não se distanciar demais da fronteira tecnoprodutiva aeronáutica mundial, sob risco de ver sua competitividade atual se perder em questão de anos. Transições tecnológicas colocam desafios grandes para empresas estabelecidas, e o Brasil precisará desenvolver instrumentos de apoio à inovação e ao desenvolvimento tecnológico e científico de seu setor aeronáutico, mais especificamente da Embraer, capazes de manter o país nas vizinhanças da fronteira tecnoprodutiva aeronáutica, evitando assim o que pode ser um processo irreversível de perda de competitividade da Embraer. Por ora, portanto, continuaremos a ser um país dotado de uma grande OEM, mas desprovidos de uma cadeia de fornecedores aeronáuticos, situação que não observamos entre nossos competidores estabelecidos (Canadá, Europa e EUA). Quanto aos desafiantes, o Japão é o que se encontra mais próximo de possuir uma cadeia de fornecedores relevante, uma das razões para aumentar as possibilidades de sucesso de sua estratégia de catch-up em comparação com China e Rússia, ainda que tal característica não seja garantia de sucesso.

Há, contudo, e quanto a isso não é possível ter dúvidas, benefícios evidentes em executar estratégias de catch-up tecnoprodutivo. São empreendimentos desse tipo que melhoram, ainda que marginalmente, as perspectivas de desenvolvimento de um país. $\mathrm{O}$ desafio que precisamos enfrentar, a partir de uma análise sistemática das experiências anteriores de catch-up tecnoprodutivo, é aumentar significativamente seus efeitos de spillover, suas externalidades positivas, seu potencial de desencadear um ciclo virtuoso de desenvolvimento.

O estudo de experiências anteriores de catch-up tecnoprodutivo aeronáutico guarda certas e inevitáveis idiossincrasias: a trajetória particular do setor e de suas tecnologias e 
formas de produção, o papel geopolítico e a conexão com tecnologias militares, as características de seus mercados e usuários e os tipos de instituições que lhe dão suporte. É possível, contudo, abstrair as especificidades das estratégias de catch-up tecnoprodutivo aeronáutico e procurar, tomando as precauções necessárias, generalizar as conclusões resultantes do estudo do catch-up aeronáutico para tentar formular recomendações transversais sobre estratégias de catch-up tecnoprodutivo em outros setores do Brasil e também de outros países emergentes.

Um modelo mais amplo de estratégias de catch-up tecnoprodutivo deve partir de uma concepção sistêmica do problema, levando em consideração as múltiplas dimensões interconectadas que aumentam a probabilidade de sucesso de uma estratégia de catchup. Isso implica desenvolver processos de aprendizagem tecnoprodutiva, construir instituições de sustentação e ampliação dos esforços de aprendizagem tecnoprodutiva e estruturar uma empresa capaz de produzir e comercializar os produtos gerados pelo sistema tecnoprodutivo. Contar apenas com a produção sob licença ou montagem em território nacional, com a importação de cérebros e pesquisa e desenvolvimento produzidos alhures ou com o estabelecimento no país de empresas estrangeiras que utilizarão o país como plataforma de exportação, sem empreender um processo de aprendizagem tecnoprodutiva que resulte em domínio dos conhecimentos para desenvolvimento e produção de ciclo completo, com a formação de recursos humanos e produção nacional de pesquisa e desenvolvimento e com a criação de empresas nacionais capazes de lançarem-se à competição em mercados globais é receita talvez não para o fracasso total, mas certamente para resultados aquém dos necessários.

Além disso, é preciso garantir que uma estratégia de catch-up tecnoprodutivo construa canais de comunicação de mão dupla com o exterior, sendo capaz tanto de absorver conhecimento externo como de posicionar-se internacionalmente como centro produtor de conhecimento - conhecimento na forma de ciência, tecnologia, produtos e processos. Salvo raríssimas exceções, como os EUA e a protofederação europeia - que ninguém sabe quanto tempo ainda resistirá - nenhum país consegue, atualmente, manter-se na fronteira tecnoprodutiva de todas as tecnologias e indústrias relevantes. Desenvolver capacidades de participação no circuito mundial de produção e consumo de conhecimento é central para o sucesso de qualquer estratégia contemporânea de catchup tecnoprodutivo. 
Mais importante ainda, para que o objetivo final das estratégias de catch-up tecnoprodutivo seja plenamente alcançado, a saber, o desenvolvimento econômico e social que aumente o bem-estar dos indivíduos e lhes permita realizar integralmente a liberdade no sentido que lhe confere Amartya Sem (2010), construir as instituições políticas democráticas que garantirão no mais alto grau possível a disseminação dos resultados alcançados pelo desenvolvimento tecnoprodutivo atingido por meio de estratégias de catch-up, revertendo em desenvolvimento econômico e social coletivo políticas que tendem, na ausência de mecanismos de distribuição social de benefícios privados, a concentrar renda, conhecimento e poder.

O atual modelo de desenvolvimento brasileiro tem não apenas espaço para incorporar em seu arsenal de instrumentos as estratégias de catch-up, com também necessidade. Afinal, as estratégias de catch-up são um modo de construir nosso futuro, criando no presente as bases do que seremos daqui a dez, vinte, trinta ou quarenta anos. O que somos hoje é resultado de decisões tomadas há muito tempo. É o caso não somente da Embraer, como também da Vale, da Petrobrás, da Embrapa, traços distintivos de nossa fisionomia econômica atual que começaram a tomar forma em meados do século passado. É desse ponto que partimos; resta definir aonde queremos chegar. 


\section{Bibliografia}

ACEMOGlu, D., AGHiON, P., and ZILIBOTTI, F. (2002) "Distance to Frontier, Selection, and Economic Growth", NBER Working Paper Series. Massachusetts: National Bureau of Economic Research.

ACEMOGLU, D., AGHiON, P., e ZILIBOTTI, F. (2006) "Distance to Frontier, Selection, and Economic Growth", in: Journal of the European Economic Association, March 4 (1):37-74.

ARBIX, G. (2007) Inovar ou inovar: A indústria brasileira entre o passado e o futuro. São Paulo: Editora Papagaio.

ARBIX, G., DE NEGRI, J.A., MIRRA, E. (2009) "Por uma política de inovação tecnológica”, O Estado de São Paulo (07/10/2009).

ARBIX, G., MARTIN, S. (2010) "Beyond Developmentalism and Market Fundamentalism in Brazil: Inclusionary State Activism without Statism", unpublished article.

AVELLAR, A. P. (2009) "Impacto das políticas de fomento à inovação no Brasil sobre o gasto em atividades inovativas em atividades de P\&D das empresas", in: Estudos Econômicos, São Paulo, v. 39, n. 3: 629-649.

BÉDIER, C., VANCAUWENBERGHE, M. e VAN SINTERN, W. (2008) "The growing role of emerging markets in aerospace”, in: The Mckinsey Quarterly, April.

BERNARDES, R. (2003) "Passive innovation system and local learning: a case study of Embraer in Brazil", in: Globelics: Conferência Internacional sobre Sistemas de Inovação e Estratégias de Desenvolvimento para o Terceiro Milênio, novembro.

BOEING (2011) Boeing Current Market Outlook 2011-2030.

CARDOSO, F. H. (1962) Empresário industrial e desenvolvimento econômico no Brasil. São Paulo: Difel.

CARVALHO, F., GOLDSTEIN, A. (2008) “The 'making of' national giants: technology and governments shaping the international expansion of oil companies from Brazil and China”, UNU-MERIT, Working Paper, 2008-021. 
CASEIRO, L. (2010). A Construção de Multinacionais Brasileiras - Uma inflexão na estratégia de desenvolvimento? Unpublished paper.

CHAIMOVICH, H. (2000) "Brasil, ciência, tecnologia: alguns dilemas e desafios", in: Estudos Avançados 14 (40): 134-143. Instituto de Estudos Avançados, USP. São Paulo.

CLIFF, R., OHLANDT, C. J. R., YANG, D. (2011) "Ready for Takeoff: China's Advancing Aerospace Industry”, in: RAND Corporation - National Security Division.

COHEN, W. M. e LEVINTHAL, D. A. (1990) "Absorptive Capacity: A New Perspective on Learning and Innovation”, in: Administrative Science Quarterly, Vol. 35, No. 1, Special Issue: Technology, Organizations, and Innovation. (March), pp. 128152.

CRISCUOLO, P. e NARULA, R. (2002) “A Novel Approach to National Technological Accumulation and Absorptive Capacity: Aggregating Cohen And Levinthal", in: DRUID Summer Conference on "Industrial Dynamics of the New and Old Economy who is embracing whom?" Copenhagen/Elsinore 6-8 June 2002.

DE GRAAF, A. (2008) "Civil Aviation in Russia", in: An overview on behalf of Air TN, London, 13/14 March 2008.

EMBRAER (2010) Embraer China Market Outlook 2011-2030. Embraer China.

ESTEVES, L. E. e PORCILLE, G. (2010) "Um modelo dinâmico incorporando o hiato tecnológico e a capacidade absortiva", in: Artigo apresentado ao XIII Encontro Regional de Economia - ANPEC Sul 2010, 11 a 13 de agosto de 2010.

EVANS, P. (1980) A Tríplice Aliança: as multinacionais, as estatais e o capital nacional no desenvolvimento dependente brasileiro. Rio de Janeiro: Zahar Editores.

FAGERBERG, J., VERSPAGEN, B. (2009) "Innovation studies - The emerging structure of a new scientific field", in: Research Policy 38: 218-233.

FREEMAN, C., SOETE, L. (2008) A economia da inovação industrial. Campinas: Editora da Unicamp.

FRIEDMAN, D. B. e SAMUELS, R. J. (1993) "How to Succeed without Really Flying: The Japanese Aircraft Industry and Japan's Technology Ideology", in: Regionalism and 
Rivalry: Japan and the United States in Pacific Asia. National Bureau of Economic Research.

GODIN, B. (2006) "The linear model of innovation: the historical construction of an analytical framework", in: Science, Technology, \& Human Values, 31, n. 6: 639-667.

GOLDSTEIN, A. (2002) "Embraer: From national champion to global player", in: Cepal Review No. 77 (August).

GOLDSTEIN, A. (2005) "The Political Economy of Industrial Policy in China: The Case of Aircraft Manufacturing", in: William Davidson Institute Working Paper Number 779 July 2005.

GUIMARÃES, R. (2004) "Bases para uma política nacional de ciência, tecnologia e inovação em saúde”, in: Ciência \& Saúde Coletiva, 9 (2): 375-387.

KANATSU, T. (2006) "Choice of National Strategy and Industrial Organization Comparing Airframe Production Between Brazil and Japan”, in: International Journal of Asia Pacific Studies, Vol. 2 (November).

KIMURA, S. (2006) "Co-evolution of Firm Strategies and Institutional Setting in Firmbased Late Industrialization - The Case of the Japanese Commercial Aircraft Industry”, in: Evolutionary and Institutional Economic Review. 3(1): 109-135 (2006)

KING, D. R. e Nowack, M. L. (2003) "The impact of government policy on technology transfer: an aircraft industry case study", in: Journal of Engineering and Technological Management 20 (2003) 303-318.

KOGUT, B. and ZANDER, U. (1992). "Knowledge of the Firm, Combinative Capabilities, and the Replication of Technology.” Organization Science 3, 383-397.

KUO, Y. (2009) "Market Failure Mentality in Japanese Industrial Policy: Case Studies of Robotics and Aircraft Industries". Dissertation Presented to the Faculty of the University of Southern California Graduate School (Political Science).

LIU, F., SIMON, D. F., SUN, Y. e CAO, C. (2011) “China's Innovation Policies: Evolution, Institutional Structure, and Trajectory”, in: Research Policy 2011. 
MALERBA, F. (2002) "Sectoral systems of innovation and production", in: Research Policy 31 .

MATHEWS, J. A. (2002) "Competitive Advantages of the Latecomer Firm: A Resource-Based Account of Industrial Catch-Up Strategies", in: Asia Pacific Journal of Management, 19, 467-488.

MATHEWS, J. A. (2006) "Catch-up Strategies and the Latecomer Effect in Industrial Development”, in: New Political Economy, Vol. 11, No. 3, September.

MATHEWS, J. A. (2009) "China, India and Brazil: Tiger technologies, dragon multinationals and the building of national systems of economic learning", in: Asian Business \& Management, Vol. 8, 1, 5-32.

MIRANDA, Z. (2007) O voo da Embraer. São Paulo: Editora Papagaio.

MCGUIRE, S. (2011) "The Changing Landscape of the Aircraft Industry", in: International Economics July 2011 IE WIT BP 2011/02, Chatham House.

MOWERY, D., ROSENBERG, N. (2005) Trajetórias da inovação: a mudança tecnológica nos Estados Unidos da América no século XX. Campinas: Editora da Unicamp.

NARULA, R. (2003) "Understanding Absorptive Capacities in an "Innovation Systems" Context: Consequences for Economic and Employment Growth", in: DRUID Working Paper No. 04-02.

NELSON, R., WINTER, S.G. (1982/2005) Uma teoria evolucionária da mudança econômica. Campinas: Editora da Unicamp.

NELSON, R. (2008) "What enables rapid economic progress: What are the needed institutions?", in: Research Policy 37.

NIOSI, J. e ZHEGU, M. (2008) "Innovation System Lifecycle in the Aircraft Sector", in: Entrepreneurship and Innovation - Organizations, Institutions, Systems and Regions Copenhagen, Denmark, June 17 - 20, 2008. 
NIOSI, J. e ZHEGU, M. (2010) "Multinational Corporations, Value Chains and Knowledge Spillovers in the Global Aircraft Industry", in: International Journal of Institutions and Economics, Vol. 2, No. 2, October 2010, pp. 109-141.

NOLAN. P. e ZHANG, J. (2002) "The Challenge of Globalization for Large Chinese Firms", in: UNCTAD Discussion Papers No. 162 (July).

NOLAN. P. e ZHANG, J. (2003) "Globalization Challenge for Large Firms from Developing Countries: China's Oil and Aerospace Industries", in: European Management Journal, Vol. 21, No. 3, pp. 285-299.

PÉREZ, C. (2000). "Cambio de paradigma y rol de la tecnología em el desarollo". Charla en el Foro de apertura del ciclo "La ciencia y la tecnología en la construcción del futuro del país" organizado por el MCT, Caracas.

RIHOUX, B. e RAGIN, C. C. (2008) Configurational Comparative Methods: Qualitative Comparative Analysis (QCA) and Related Techniques. Sage Publications.

RODRIK (2001) "Development Strategies for the Next Century", in: World Bank, Annual World Bank Conference on Development Economics 2000.

ROGERS, M. (2004) "Absorptive capability and economic growth: how do countries catch-up?", in: Cambridge Journal of Economics, 28, 577-596.

ROMER, P. (1986) "Increasing Returns and Long Run Growth", in: Journal of Political Economy, v. 94, n. 5.

ROMER, P. (1990) "Endogenous technological change", in: The Journal of Political Economy, v. 98, n. 5: S71-S102.

ROMER, P. (1994) "The origins of endogenous growth", in; The Journal of Economic Perspectives, v. 8, n. 1: 3-22.

ROMER, P. (2005) “The Arc of Science”, unpublished paper.

ROSENBERG, N. (2006) Por dentro da caixa-preta: Tecnologia e economia. Campinas: Editora da Unicamp.

SHIMIZU, T. (2009) "R\&D Activities for Aeronautics S\&T in Japan, the United States and Europe", in: Quarterly Review, No. 33/October. 
SILVA, A. C. da (2000) "Descentralização em política de ciência e tecnologia", in: Estudos Avançados 14 (39): 61-73. Instituto de Estudos Avançados, USP. São Paulo.

SMITH, R. H. (1945) Conferência do Prof. Richard H. Smith - Brasil, futura potência aérea (Conferência realizada em 26 set 45, no Auditório do Ministério da Educação RJ, a convite do Instituto Brasileiro de Aeronáutica, disponível em: http://www.cta.br/richard.php).

SOETE, L., VERSPAGEN, B., WEEL, B. (2009) "Systems of innovation”, in: MERIT, Working Paper Series: 2009-062.

STOKES, D. E. (2008) O quadrante de Pasteur: A ciência básica e a inovação tecnológica. Campinas: Editora da Unicamp.

TOLEDO, D. G. C. de (2010) "Consensus Building and Policy Design: The 4th National Conference on Science, Technology, and Innovation in Brazil - A Roadmap, 2010-2020", texto apresentado no Smart G Colloquium: Science, Technology and Innovations Systems in Africa and Brazil, Helsinque, Finlândia, agosto de 2010.

VERTESEY, D. e SZIRMAY, A. (2010) “Interrupted Innovation: Innovation system dynamics in latecomer aerospace industries". Paper presented at the Globelics 2010 Conference.

VILLASCHI, A. (2005) “Anos 90: uma década perdida para o sistema brasileiro de inovação?”, in: São Paulo em Perspectiva, v. 19, n. 2: 3-20.

XIWEI, Z. e XIANGDONG, Y. (2007) "Science and technology policy reform and its impact on China's national innovation system", in: Technology in Society 29 (2007) $317-325$.

YIN, R. K (2003) Case Study Research: Design and Methods. Applied Social Research Methods Series, Vol. 5. Sage Publications.

ZHURAVLEV, V. (2011) "Russian approach to aircraft design and aeronautical education”. EWADE 2011. 